D E L L A U N I V E R S I T À D I B O L O G N A CCCVI

\author{
SONIA ABIS
}

\title{
CAPACE DI INTENDERE, INCAPACE DI VOLERE
}

Malinconia, monomania e diritto penale in Italia nel XIX secolo 


\section{CAPACE DI INTENDERE, INCAPACE DI VOLERE}

Malinconia, monomania e diritto penale in Italia nel XIX secolo 
Bononia University Press

Via Ugo Foscolo 7, 40123 Bologna

tel. (+39) 051232882

fax (+39) 051221019

www.buponline.com

e-mail: info@buponline.com

Quest'opera è pubblicata sotto licenza Creative Commons BY-NC-SA 4.0

ISSN 2283-916X

ISBN 978-88-6923-660-0

ISBN online: 978-88-6923-661-7

DOI $10.30682 / \mathrm{sg} 306$

Impaginazione: Sara Celia

Prima edizione: novembre 2020 
Per la presente monografia la Giunta di Dipartimento ha nominato la seguente Commissione di lettura:

Nicoletta Sarti (Alma Mater Studiorum - Università di Bologna), per il Settore Scientifico Disciplinare IUS/19 Storia del Diritto Medievale e Moderno Ugo Bruschi (Alma Mater Studiorum - Università di Bologna), per il Settore Scientifico Disciplinare IUS/19 Storia del Diritto Medievale e Moderno Ivano Pontoriero (Alma Mater Studiorum - Università di Bologna), per il Settore Scientifico Disciplinare IUS/18 Diritto Romano e Diritti dell'Antichità 

«Bench'io sembianza esterna del cor non stimi testimon verace, ché 'n parte troppo cupa e troppo interna il pensier de' mortali occulto giace».

Torquato Tasso, La Gerusalemme liberata, canto V, 41

Ai miei cari 

Note INTRODUTTIVE

Non ti rimembra di quelle parole con le quali la tua Etica pertratta le tre disposizion che 'l ciel non vole, incontenenza, malizia e la matta bestialitade?

Dante Alighieri, Divina Commedia, Inferno, canto XI, 82

Questo adiettivo, matta, pose qui l'autore più in servigio della rima, che per bisogno che n'avesse la bestialità, perciocché bestialità e mattezza si posson dire essere una medesima cosa. Giovanni Boccaccio, Il comento sopra la Commedia

I versi di Dante, qui seguiti dal commento del Boccaccio ${ }^{1}$, furono e sono oggetto di un dibattito plurisecolare, che investe frontalmente alcuni problemi della mia ricerca.

All'interno dell'intricato ginepraio che vede intrecciarsi il concetto di bestialità con il concetto di follia si ritrovano le più antiche suggestioni che evoca la matta bestialitade di cui parla Dante nella

1 Giovanni Boccaccio, Il Comento sopra la Commedia di Dante Alighieri con le annotazioni di Anton Maria Salvini, VI, Firenze, 1724, p. 170. Si veda anche B. Lombardi, La divina Commedia di Dante Alighieri, I, Inferno, Roma, 1820, p. 152. 
narrazione del suo viaggio ultramondano, in particolare nel canto XI dell'Inferno ${ }^{2}$ :

Non ti rimembra di quelle parole con le quai la tua Etica pertratta le tre disposizion che 'l ciel non vole, incontenenza, malizia e la matta bestialitade? e come incontenenza men Dio offende e men biasimo accatta?

Se tu riguardi ben questa sentenza, e rechiti a la mente chi son quelli che sù di fuor sostegnon penitenza, tu vedrai ben perché da questi felli sien dipartiti, e perché men crucciata la divina vendetta li martelli.

Ai primi versi proemiali seguono le notizie di Virgilio sulle suddivisioni del Basso Inferno. L'andamento diegetico cede il passo ad un andamento maggiormente tecnico e schematistico. Dante procede qui ad una variazione di stile modellata secondo le cadenze per divisioni e suddivisioni proprie delle scritture giuridiche e della letteratura teologica scolastica ${ }^{3}$. Virgilio fa riferimento al passo dell' $E$ tica Nicomachea di Aristotele noto a Dante nella traduzione latina ${ }^{4}$, in cui il filosofo greco accenna alle «tre disposizion che 'l ciel non vole», ovvero la malitia, l'incontenenza e la matta bestialitade, «circa mores fugiendorum tres sunt species, malitia, incontinentia et bestialitas $»^{5}$.

2 A proposito del canto XI dell'Inferno, nella letteratura spesso si è parlato di 'intermezzo' nella narrazione del viaggio ultramondano, di 'digressione' dottrinale, di una vacanza della grande poesia dantesca utile a presentare e discutere l'ordinamento delle pene infernali. Cfr. B. NARDI, Il canto XI dell'Inferno, in Letture Dantesche. Inferno, Firenze, 1966, p. 193; G.G. MeErsseman, Il canto XI dell'Inferno, in Nuove letture dantesche, Firenze, 1968, II, p. 1; C. Delcorno, Dare ordine al male (Inferno XI), in L'Alighieri, Ravenna, 1997, p. 181.

3 Per una lettura particolarmente attenta alle ragioni sottese alle variazioni di stile si vedano C. CALENDA, Lettura di Inferno, XI, in Filologia e critica, XX, 1995, pp. 217-241.

4 Aristoteles latinus, Ethica Nicomachea translatio Roberti Grosseteste Lincolniensis sive 'Liber Ethicorum', XXVI, 1-3, f. tertius, VII, ed. R.A. GAUTHIER, Leiden-Bruxelles, 1972, pp. 141-370.

5 Ivi, [45a15], p. 272. 
Un punto cruciale dell'esegesi dantesca riguarda proprio il senso da dare al concetto di matta bestialitade ed eventualmente risiede nell'individuazione del luogo infernale dove questa colpa andrebbe espiata. La nozione di bestialità era emersa nella trattazione aristotelica in una esemplificazione multiforme ed impressionante. Aristotele ricordava: il caso di una donna che dilaniava donne gravide per divorarne il feto; le pratiche cannibaliche messe in atto dalle popolazioni che abitavano il Ponto, regione storica dell'attuale Turchia; le crudeltà gratuite di Falaride ${ }^{6}$, tiranno di Akragas, attuale Agrigento, che governò la città fra il 570 e il 555 a. C. e che fu definito dagli antichi il più crudele di tutti i tiranni. Per tutti questi diversi casi vale un principio etico comune, ossia quello per cui in presenza di una malvagità gratuita e senza causa non può non ipotizzarsi una forma di follia. Chi compie azioni aberranti per motivi futili o in completa assenza di motivazione non può non considerarsi privo del raziocinio e della capacità di elezione. Così scriveva Aristotele:

Propter quod et bestias, neque temperatas, neque intemperatas dicimus [...] Non enim habet [bestia] electionem, neque ratiocinationem. Sed discessit a natura quemadmodum insanientes hominum. Minus autem bestialitas malitia, terribilius autem. Non enim corruptum est optimum quemadmodum in homine, sed corruptum est et non habet [...] Innocentior enim pravitas semper quae non habentis principium. Intellectus autem principium ${ }^{7}$.

Sul concetto di matta bestialitade medievale l'interpretazione autoritativa per eccellenza fu quella di Tommaso d'Aquino, nella sua ampia esposizione in dieci libri dell'Etica aristotelica a Nicomaco. All'inizio del liber septimus si legge: «quod eorum quae sunt circa mores fugienda, tres species sunt: scilicet malitia, et incontinen-

6 Ivi, [48b20-48b25], p. 280: «Dico autem bestiales, puta eam hominem quam dicunt pregnantes rescindentem pueros devorare, vel qualibus gaudere aiunt quosdam silvestrium circa Pontum, hos quidem crudis, hos autem hominum carnibus, hos autem pueros comodare ad invicem in convivium, vel circa Phalarin dictum».

Ivi, [49b30-50a5], pp. 283-284. 
tia, et bestialitas» ${ }^{8}$. Nei testi aristotelici e tomistici la bestialitade viene accostata alla incontinentia e alla malitia. Sembra però che nella bestialitade l'intemperanza e la malizia raggiungano un grado tale da comportare totale assenza o ottundimento della ragione e tale da rendere l'uomo amens simile alla bestia. La bestialitade è 'matta', in quanto contrariamente alla malizia denota sì un atteggiamento malvagio ma che travalica i limiti della natura umana e che sfugge al suo principio regolatore, vale a dire l'intelletto'.

Ma al di là delle suggestioni evocate dalla letteratura dantesca. L'indagine qui mostrata trae il suo spunto contingente da una riflessione intorno al dibattito che imperversa nella dottrina giuridica, nei primissimi anni dell'Ottocento, nell'accostare il crimine commesso per follia morale/malinconia all'omicidio commesso senza una causa e che vede gli interpreti dividersi fra chi, rifiutando le tesi della scienza medico-legale, ne individua il nesso eziologico nella immoralità e chi, al contrario accogliendole, sostiene la tesi della follia morale.

Le riflessioni discordanti dei giuristi possono rappresentare un idoneo punto di partenza per insinuarsi con cautela in questo complesso alveo, fra le pieghe di quei ragionamenti dove è possibile individuare, in un certo qual modo, gli elementi essenziali che rappresentano i momenti fondativi di una nuova teoria della colpevolezza.

8 Tommaso D'Aouino, In decem libros Ethicorum Aristotelis ad Nicomachum expositio, VII, lectio I, Commentarium S. Thomae, n. 1293, Torino, 1964, p. 351.

9 Aristoteles latinus, Ethica Nicomachea, cit., [49a5-49a10], p. 281: «Omnis enim superabundans malitia et insipientia et timididas et intemperantia et crudelitas, hae quidem bestiales, hae autem aegritudinales sunt [...] Et insipientium, hi quidem ex natura irrationales, et solum sensu viventes, bestiales, quemadmodum quaedam genera longe barbarorum»; Tommaso D'Aouino, In decem libros Ethicorum Aristotelis, cit., n. 1296, p. 352: «Alio modo potest corrumpi contemperantia humanarum affectionum, ita quod progrediatur ultra limites humanae vitae in similitudinem affectionum alicuius bestiae, puta leonis aut porci. Et hoc est quod vocatur bestialitas»; Ivi, n. 1299: «Sicut ergo affectiones sensitivae partis aliquando in homine corrumpuntur usque ad similitudinem bestiarum, et haec vocatur bestialitas supra humanam malitiam et incontinentiam»; Ivi, n. 1303, p. 353: «Et ponit tres modos secundum quos aliqui fiunt bestiales [...] primus [...] apud barbaros qui rationalibus legibus non utuntur, propter malam consuetudinem aliqui incidunt in malitiam bestialem. Secundo contingit aliquibus propter aegritudines [...] ex quibus in amentiam incidunt. Tertio propter magnum augmentum malitiae, ex qua contingit quod quosdam superexcellenter diffamamus dicentes eos bestiales». 
D'altronde, è nel laboratorio dei sapientes iuris che avviene il processo di giuripoiesi, e le peculiarità del fenomeno criminoso oggetto di indagine prendono collocazione e forma scientifica, elaborando risposte ai problemi che affannano la prassi giurisprudenziale, in ispecie legati all'elemento soggettivo ${ }^{10}$. Gli snodi che si presentano agli occhi degli interpreti riflettono la natura stessa della colpevolezza, quale «vero universale nel diritto penale» che porta in sé ineluttabilmente «implicazioni filosofiche, morali, antropologiche e sociopsicologiche, per cui dovrebbe sorprendere fino a un certo punto che persistano incertezze al momento di precisarne in sede giuridica la portata e i confini ${ }^{11}$. Analizzare la 'tradizione' di tale teoria significa nuotare in un oceano senza confini e senza approdi.

Già i giuristi di antico regime, nell'affrontare i problemi legati all'imputabilità dei folli, per la necessità di distinguere differenti casistiche di furor si incrociarono con talune peculiari categorie nosologiche e filosofiche di antica tradizione. In particolare, alcuni di loro affrontarono il complesso problema del crimine commesso in una condizione di follia parziale. Essa era intesa come una follia circoscritta ad uno specifico ambito relazionale: il prototipo ne era la melancholia e il furor melancholicus. Tali lessemi si ritrovano attestati non solo nel bagaglio concettuale dei criminalisti del tardo diritto comune ma talvolta anche nella prassi processuale.

Tuttavia l'oggetto di questa ricerca non è l'analisi capillare delle radici e del vario atteggiarsi di questa fattispecie criminale. L'ideaguida è, invece, quella di cogliere l'omicidio senza causa nel momento del suo 'passaggio' e della sua trasfigurazione - appunto fra Settecento e Ottocento - sotto le lenti incrociate di giuristi e scienziati della psiche, nel contesto di una riscrittura del suo significato e della sua prevenzione e repressione. All'inizio dell'Ottocento, con lo sviluppo delle teorie psichiatriche sulla follia parziale - e in essa rientra

10 Sulle concezioni in materia di dolo nella dottrina giuridica del tardo Settecento si veda da ultimo M. CAVINA, Il dolo latente nell'animo. L'elemento soggettivo nell'opera di Filippo Maria Renazzi, in M.R. Di Simone, C. Frova, P. Alvazzi del Frate (a cura di), Filippo Maria Renazzi: Università e cultura a Roma tra Settecento e Ottocento, Bologna, 2019, pp. 227-239.

11 F. Palazzo, Il diritto penale tra universalismo e particolarismo, Lezioni Magistrali, 38, Napoli, 2011, p. 44. 
l'interesse per l'omicidio senza causa -esso diviene oggetto di analisi non soltanto di giuristi bensì di giuristi, medici e medici-legali. Da tale incontro di saperi il problema di qualificarne l'elemento soggettivo diviene molto più articolato.

In relazione al tema delle patologie parziali della mente (malinconia, monomania, mania sistemica, pazzia morale), il reato sprovvisto di una causa finisce in un universo pluri-dimensionale in cui avviene l'incontro fra consolidati assetti normativi e irrompenti innovazioni scientifiche. Fra il 'moderno' dell'ultimo diritto comune e il 'contemporaneo' ottocentesco l'omicidio senza causa può essere colto come esempio e pietra del paragone del tortuoso incontro fra le ragioni della scienza del diritto e le ragioni della scienza tout court.

In apertura è forse utile un primo cenno di ordine semantico. La varia dialettica degli appellativi e delle loro sfumature accompagna tutta la storia dell'omicidio senza causa. Senza causa un omicidio può essere definito - e lo è stato - per le considerazioni più diverse, perché commesso con la più profonda malizia, o con la più fredda crudeltà, o con la più brutale indifferenza. Le parole del diritto cercarono aggettivi. In particolare, nella normazione penale dello Stato Pontificio l'omicidio compiuto in assenza di motivazioni fu aggettivato come bestiale a voler rimarcare la propinquità di tali criminali al regno delle 'fiere' piuttosto che al regno degli uomini.

L'atrocità dell'omicidio senza movente non risiede però - o quantomeno non soltanto - nelle modalità di esecuzione, bensì nella sua irragionevolezza, cioè nell'assenza di una ragione in grado di rendere manifesta la eziologia del crimine, moralmente prima ancora che giuridicamente. Il motivo è imprevedibile e incomprensibile, è - entro certi limiti - futile. Esso risiede, al di fuori del razionale, nell'azione 'cervellotica' dell'omicida. Che poi col termine di cervellotico si debba intendere l'impulso ad uccidere sotto il profilo morale e quindi come malvagità, ovvero che lo si debba intendere sotto il profilo psicopatologico è la ragione della concezione binaria del fenomeno che ha attraversato secoli perdurando nella storia delle idee come uno dei grandi problemi che ci si è proposti di affrontare nella nostra indagine. In questa prospettiva, che presenta una miriade di sfaccettature di carattere sostanziale (dall'individuazione della vo- 
lontarietà del fatto di reato e del relativo modus probandi) l'omicidio commesso per deviazione dalla morale e quindi sprovvisto di un movente esterno, si prospetta come figura opposta a quella della responsabilità piena e volontaria su cui i giuristi formulano le ragioni della responsabilità penale per dolo. I giuristi affrontano un'opera di edificazione penale lavorando su fattispecie in parte oscure che ancora non trovano una loro univoca veste penale.

Il dibattito si arricchisce in modo decisivo nell'Ottocento, al crocevia fra diritto e medicina legale. Nei primissimi scorci del XIX secolo, infatti, sulla scia delle teorizzazioni della psichiatria francese concernenti la follia parziale, l'omicidio senza causa trova collocazione nella nuova categoria patologica della monomania omici$\mathrm{da}$, che costituisce sostanzialmente una metamorfosi della più antica malinconia. La scienza giuridica ottocentesca si apre alle 'monomanie'.

Altro essenziale filo conduttore dell'indagine concerne la sua ricaduta giuridica in termini di pena. Giuristi e legislatori si dimostrano incerti e divisi fra due soluzioni sanzionatorie antitetiche:

1. Considerare l'omicidio senza causa come prodotto connesso ad una follia parziale che esclude l'imputabilità e dunque comporta l'internamento curativo in un manicomio criminale.

2. Considerare l'omicidio senza causa come prodotto di uno sfrenato ed immorale desiderio di uccidere, indice di una tale pericolosità sociale da richiedere un adeguato aggravamento punitivo rispetto all'omicidio comune.

Gli autori di omicidi 'bestiali' erano/sono criminali in senso pieno, maestri nell'arte di nascondere un animo perverso e una tracotante perfidia sotto le più imperturbabili sembianze e sotto le più pacifiche apparenze? Oppure erano/sono criminali la cui libertà morale appare deviata da problematiche di natura psichica? Si tratta di quesiti mai sopiti e mai compiutamente risolti, che si cercherà di affrontare in relazione ai dibattiti fra Settecento e Ottocento in Italia, senza alcuna presunzione teorica e, soprattutto, con quel tremore ac timore multo che dovrebbe esservi in ogni proposito di ricerca. 

CAPITOLO I

MALINCONIA CRIMINALE

I. Follia morale: un itinerario medico-legale (secc. XVII-XIX)

1. La melancholia fra le tipologie giuridiche del furor

La tradizione di ius commune, anteriormente al XVI secolo, dimostrò un sostanziale disinteresse per le classificazioni della malattia mentale. Infatti, le diverse denominazioni con cui veniva identificato il folle sin dal diritto romano - furiosus, demens, mentecaptus, insanus, melancholicus, fatuus, lunaticus - rappresentavano dei meri sinonimi verbali quanto al trattamento giuridico ${ }^{1}$. Poche le eccezioni. Già Ulpiano, sulla scia di Cicerone come emerge nelle Tusculanae disputationes, considerava la fattispecie del furor delle XII Tavole una forma più grave di infermità mentale, rispetto all'insania o dementia delineandone quindi un embrione di classificazione ${ }^{2}$.

Questo fenomeno è particolarmente evidente rispetto alla infermità parziale di mente, problematica che soltanto in piena età

1 Cfr. E. NARDI, Squilibrio e deficienza mentale in diritto romano, Milano, 1983, p. 22; M. BOARI, Qui venit contra iura. Il furiosus nella criminalistica dei secoli XV e XVI, Milano, 1992, p. 294.

2 Cfr. F. Sток, Modelli e tradizione antica nella psicopatologia di Zacchia, in A. Pastore, G. Rossi (a cura di), Paolo Zacchia. Alle origini della medicina legale 1584-1659, Milano, 2008, p. 75. 
moderna troverà progressivamente il suo fulcro nel concetto medico-legale di melancholia. La follia parziale risulta pressocché assente nelle varie classificazioni di furor ad opera dei giuristi bassomedievali. All'interno del quadro delle classificazioni del furor delineato da Baldo degli Ubaldi (1319-1327?-1400) nei suoi Consilia risulta assente uno specifico riferimento ad una follia circoscritta ${ }^{3}$ mentre, in piena età moderna, Prospero Farinacci suddividerà in diverse specie l'universo polimorfo della follia, pur non evidenziando alcuna differenza sul piano giuridico fra il furiosus, il phreneticus, l'insanus, il demens e il mentecaptus ${ }^{4}$. Tutte le forme di malattia mentale producevano gli stessi effetti giuridici sul piano della pena, ovvero potevano essere invocate al fine di mitigarla o escluderla. Tali categorie si ritrovano anche in giuristi minori come nelle Additiones di Claudio Bertazzoli (?-1588) sempre in rapporto di sinonimia giuridica ${ }^{5}$.

3 Baldo degli Ubaldi, Consiliorum sive responsorum, III, Venetiis, 1580, [cons. 347, n. 2]: «[...] dicuntur furiosi largo modo, sive furor sit apparens et existens, sive existens, sed non apparens: quod appellatur conspectus inumbratae quietis, sive amentia, sive dementia».

4 Prospero Farinacci, Variarum quaestionum, et communium opinionum criminalium, V, Venetiis, 1614, [pars I, n. 228]: «Furoris, seu insaniae, licet plures sint species, [...] adverte tamen quod quoad effectum, videtur idem, cum una pro altera in iure accipiatur, et insimul confundentur»; ProsPero FARINACCI, Praxis et theoricae criminalis, Lugduni, 1635, [pars. III, q. 94, n. 2] p. 158: «Propositam regulam procedere non solum in furioso, sed etiam in phrenetico, insano, demente, seu mentecapto. Quomodocumque enim quis tempore delicti sit extra mentem, excusatur».

5 Claudio Bertazzoli, Additiones a Bartolomeo Bertazzoli, Decisivarum consultationum sive responsorum iuris in criminalibus et poenalibus controversiis emissorum [...] libri, Francofurti, 1602, [ad cons. 228, litt. b]: «Insaniae varia ac prope infinita sunt genera, quae et ipsa in hac specie excogitata vocabula superare videntur: sunt enim aliqui, qui neque furiosi sunt, neque amentes, non fatui, non insani, non dementes, non stulti, non leves non insipientes, non fanatici, non maniaci, non phrenetici. Itaque cum varietatem et multiplicitatem insaniae hominum mentibus accomodatam animadvertissent Iurisconsulti, unum stultorum genus constituere decreverunt, idque furiosorum tum ad actus legitimos omnino incapax, et ineptum, tum a poenis delictorum exemptum atque exclusum». 
2. «Furiosus satis suo furore punitur»

Nel Quattrocento il giurista toscano Angelo Gambiglioni (14001465), noto come l'Aretino, enunciava un principio di diritto che si poneva alla base della spinosa questione del furor nella criminalistica. Sul dibattito dottrinale incentrato sul se il folle autore di un reato dovesse essere punito, egli ebbe a dire che «furiosus satis suo furore punitur» ${ }^{6}$. Con tale brocardo si intendeva mettere in luce che la ragione sottesa alla mitigazione o esclusione della pena prima ancora che concernere la imputabilità connessa alla volontà di delinquere, appariva legata al concetto stesso di punizione, alla sua funzione nel diritto e ai suoi effetti sulla persona del criminale.

In questa prospettiva la follia costituirebbe già in sé una punizione a cui il legislatore non dovrebbe aggiungerne altre. Le parole dell'Aretino evocano l'immagine di un individuo, che nel suo stato di alienazione occupa una posizione meta-giuridica a cui le regole giuridiche con clemenza devono adeguarsi. Sotto il profilo del trattamento giuridico, il criminale malinconico era equiparato al criminale affetto da altre forme di malattia mentale e pertanto nei suoi confronti trovavano applicazione gli stessi principi giuridici che alla follia riservavano un trattamento di favore. Lo riferisce nella sua Practica criminalis anche Giulio Claro ${ }^{7}$ (1525-1575) nel riportare la decisione del Senato di Milano, che il 9 luglio 1543 assolse tal Filippo Nicola il quale uccise il proprio figlio unico. In tale processo l'argomentazione a fondamento della sentenza di assoluzione del parricida fu che «furiosus satis suo furore punitur»e che «ignorat furiosus quicquid facit» ${ }^{8}$.

6 Angelo Gambiglioni, Tractatus de maleficiis, Venetiis, 1578, [n. 7] p. 104. In generale sul pensiero del giurista Angelo Gambiglioni da Arezzo si veda G. ZoRDAN, Il diritto e la procedura criminale nel Tractatus de maleficiis di Angelo Gambiglioni, Padova, 1976.

7 Sul giurista Giulio Claro quale membro influente del Senato milanese di vedano G.P. Massetto, La prassi giuridica lombarda nell'opera di Gliulio Claro (1525-1575), in Confluence des droits savants et des pratiques juridiques, [Actes du colloque de Montpellier (12-14 décembre 1977)], Milano, 1979, pp. 491-546, ora in ID., Saggi di storia del diritto penale lombardo: sec. XVI-XVIII, Milano, 1994, pp. 11-59; ID., Un magistrato e una città nella Lombardia spagnola. Giulio Claro pretore a Cremona, Milano, 1985, pp. 175-331.

8 Giulio Claro, Liber Quintus sive Practica Criminalis in Idem Opera omnia, II, Venetiis, 1640, [q. LX, n. 7] p. 502. 
Con le stesse motivazioni fu assolta perché affetta da melanconia Iacobina Ferraria la quale aveva ucciso la sua vittima con tre bastonate. Accertata la presenza di atrabile in eccesso nel suo corpo ${ }^{9}$, precedentemente era stata più volte ricoverata quale 'mentecapta' nell'ospedale di S. Vincenzo e dopo l'assoluzione fu di nuovo trasferita nello stesso ospedale il 24 febbraio $1554^{10}$. Lo stesso caso processuale si ritrova menzionato anche nelle pagine di Prospero Farinacci $(1544-1618)^{11}$, il quale precisava che le regole valide per il furioso sono estendibili alla malattia melanconica. In questa prospettiva, se l'autore del crimine fosse melanconico, frenetico, insano, demente, mentecatto si dovrebbe procedere allo stesso modo che nel caso del furioso e ad ogni modo chiunque al tempo del delitto fosse «extra mentem» andrebbe scusato ${ }^{12}$. La formula «extra mentem» includerebbe qualsiasi forma di follia: con o senza delirio, totale o parziale, permanente o transitoria.

Nella cultura giuridica pre-seicentesca ricorreva talvolta un uso del termine mentecaptus con il quale si intendeva - genericamente e senza conseguenze sulla disciplina giuridica - una infermità parziale rispetto a quella totale del furiosus ${ }^{13}$.

9 Nelle pagine del Claro si fa un chiaro richiamo alla teoria umorale della malattia mentale. In particolare rispetto alla malattia melancolica, la causa della condizione psicopatologica viene individuata in un eccesso di sostanza atrabiliare nell'organismo. Sulla storia antica della malinconia, che trova origine nella medicina galenica e ippocratica, fondamentali i contributi di J. STARobinsKi, Storia del trattamento della malinconia dalle origini al 1900, [trad. it.], Milano, 1990; M. RIVA, Saturno e le Grazie: i malinconici e ipocondriaci nella letteratura italiana del Settecento, Palermo, 1992; R. Klibansky, E. Panofsky, F. Saxl, Saturno e la melanconia: studi su storia della filosofia naturale, medicina, religione e arte, [trad. it.], Torino, 2002.

10 Ibidem.

11 Sull'autore si veda N. Del Re, Prospero Farinacci: giureconsulto romano (1544-1618), Roma, 1999; A. Mazzacane, Farinacci, Prospero, in Dizionario biografico dei giuristi italiani (XII-XX secolo), I, Bologna, 2013, pp. 822-825.

12 Prospero Farinacci, Praxis et theoricae criminalis, [pars tertia], Lugduni, 1635, [q. XCIV] p. 158: «propositam regulam procedere non solum in furioso, sed etiam in phrenetico, insano, demente seu mente capto. Quomodocunque enim quis tempore delicti sit extra mentem, excusatur».

13 Su tale punto avremo modo di fermarci in seguito. 
3. La melancholia come mania circoscritta e il furor come mania generalizzata

Nei primissimi scorci del Seicento il crimine commesso in stato di melancholia ${ }^{14}$ si inserisce in un fitto dibattito scientifico che, per le sue specificità e ricadute, interessa in primo luogo il laboratorio del medico legale, all'interno del quale si compone il delicato equilibrio fra ricognizione clinica e valutazione giuridica. Al di là di ogni partizione disciplinare, la scienza medica coinvolge, più o meno consapevolmente, la scienzia iuris in un lungo processo di risoluzione di problemi dottrinari che non è mosso da esigenze definitorie di natura sostanziale, quanto piuttosto da urgenze di natura processuale e probatoria ${ }^{15}$, che razionalizzano teorie fondamentali per il penale sostanziale. La concezione antica della melanconia affondava le sue radici, come rivelano le pagine del medico polacco Daniel Sennert ${ }^{16}$ (1572-1637), nell'immagine plasmata sul calco ereditato dall'antica medicina greca di Areteo di Cappadocia (II sec. d.C. ${ }^{17}$ che, nella tassonomia delle malattie della mente in croniche e acute, avvicinava la melancholia alla mania inserendola nella comune categoria delle infermità croniche. Fra i medici antichi ${ }^{18}$ anche Celio Aurelia-

14 Per un confronto su un caso di omicidio commesso da un malinconico in cui la malinconia veniva invocata come malattia della mente ed elevata a causa di mitigazione della pena si veda M. CalabritTo, A case of melancholic Humors and Dilucida Intervalla, in Intellectual History Review, 3, 2018, pp. 139-154; Per un confronto sulla storia medica della melancholia si veda anche ID., Curing Melancholia in Sixteenth-Century Medical Consilia between Theory and Practice, in Journal of History of Medicine, 3, 2012, pp. 627-664.

15 Sul sistema delle prove legali in epoca moderna si veda G. CHIOdi, Nel labirinto delle prove legali: la testimonianza del complice nel processo penale d'età moderna, in Rivista internazionale di Diritto Comune, 24, 2013, pp. 113-179; Sul diritto delle prove si vedano anche le preziose ricerche e le riflessioni circoscritte all'epoca medievale di G. CHIODI, Ad praesumptionem ad plenam fidem? Il valore probatorio della testimonianza del complice nel diritto canonico medievale, in Italian Review of Legal History, 2, 2017, pp. 1-37.

16 Nelle Epitome scientiae naturalis (1618): cfr. W. LeIBBRAnd, A. WettLey, Der Wahnsinn. Geschichte der abendlandischen Psychopathologie, Freiburg im Breisgau-München, 1961, pp. 227-228.

17 ARETEO DI CAPPADOCIA, Le cause e i sintomi delle malattie acute e croniche, [trad. it.], L. Stroppiana (a cura di), Roma, 1973, pp. 87-94.

18 Nella tradizione medica antica soltanto Cornelio Celso, che visse nella prima metà del I secolo d. C., aveva congiunto le diverse infermità di interesse psico- 
no (IV sec. d.C.) seguiva tale schema classificatorio ${ }^{19}$. In questo quadro le Quaestiones di Paolo Zacchia (1584-1659) ${ }^{20}$ sulla melanco-

patologico in un'unica formula definitoria, quella di insania. Cfr. Aulo Cornelio Celso, Della medicina, [trad. it.], a cura di A. Del Lungo, Firenze, 1904, rist. 1985, p. $156(3,18)$.

19 Celio Aureliano, Celerum passionum libri III Tardarum passionum libri $V$, ed. Benz, Berlin, 1990-1993, pp. 22 ss. e 514 ss. Cfr. F. Sток, Modelli e tradizione antica nella psicopatologia di Zacchia, cit., p. 78.

20 Sull'autore si veda L. Allacci, Apes urbanae, sive de viris illustribus qui ab anno MDCXXX per totum MDCXXXII Romae adiverunt ac typis aliquid evulgarunt, Romae, 1633, rist. anast. ed. 1633 a cura di M.P. LERNER, Lecce, 1998, p. 213; Ch. W. KeSTNER, Medicinisches Gelehrten-Lexicon, Jena, 1740, Hildescheim-New York, 1971, p. 928; C.G. JöchER, Allgemeines Gelehrten Lexikon, IV, Leipzig, 1751, ripr. facsim., Hildesheim, 2003, p. 2130; A.V. Haller, Bibliotheca medicinae practicae qua scripta ad partem medicinae practicam facientia a rerum initiis ad a. 1775 recensentur, II, ed. Bernae, 1776-1788, rist. anast., Hildesheim, 1986, pp. 501-503; C. SPRENGEL, Storia prammatica della medicina, VI, Venezia, 1813, p. 77; P.Ém. MAHIER, Les Questions médico-légales de Paul Zacchias médecin romain. Études bibliographiques, Paris, 1872, p. 1; Bibliografia Romana. Notizie della vita e delle opere degli scrittori romani dal sec. XI fino ai nostri giorni [con prolegomeni di G. Amati], I, Roma, 1880, rist. anast., Bologna, 1978, p. 252; S. DE RENZI, Storia della medicina in Italia, Napoli, 1845-1848, rist. anast., Sala Bolognese, III, Bologna, 1988, p. 67; IV, pp. 330, 341347, 349, 442-443, 510, 545; P. CAPParoni, Profili bio-bibliografici di Medici e Naturalisti celebri italiani, II, Roma, 1928, rist. anast., Roma, 1984, p. 235; C. GERIN, La medicina legale nei suoi momenti storici e nel suo sistema, in Zacchia. Archivio di medicina legale, sociale e criminologico, 12, 1949, p. 1; ID., Medicina legale, in Enciclopedia del diritto, XXVI, Milano, 1976, pp. 61-64; MM. Bayle-Thillaye, Zacchias (Paul), in Biographie médicale par ordre chronologique d'après Daniel Leclerc, Éloi etc. mise dans un nouvel ordre, revue et complétée, I, Paris, 1855, p. 551; L. DÉroberT, Histoire de la médecine légale, in Zacchia. Archivio di medicina legale, sociale e criminologico, 48, 1973, pp. 365-367 (anche in Collana Monografica Zacchia, Roma, 1974); C. CoLOMBERo, Un contributo alla formazione della nozione di malattia mentale: le «Questioni medico-legali» di Paolo Zacchia, in A. De Bernardi (a cura di), Follia, psichiatria e società, Milano, 1982, pp. 317-329; ID., Il medico e il giudice, in Materiali per una storia della cultura giuridica, 16, 1986, p. 363 ss.; Z. Traunfellner, Paolo Zacchia Vater der Gerichtlichen Medizin, 400 Jahre nach seiner Geburt, in Zeitschrift für Rechtsmedizin, 94, 1985, p. 159; M. Boari, R. Frold, Paolo Zacchia, il concetto di veleno e $i$ fondamenti della tossicologia forense. Spunti ricostruttivi, in Zacchia. Archivio di medicina legale, sociale e criminologico, 60, 1987, pp. 1-14; C. Pogliano, Zacchia, Paolo, in R. Porter (a cura di), Dizionario Biografico della Storia della Medicina e delle Scienze Naturali (Liber Amicorum), IV, Milano, 1989, p. 238; A. DinI, F.M. Ferro, Il medico e la follia. Cinquecento casi di malattia mentale nella letteratura medica italiana del Seicento, Firenze, 1997, pp. X, 71-80, 157. I manuali di medicina legale non mancano di segnalare l'autore e la sua opera pionieristica: cfr. A. CAZZANIGA, C.M. CATTABENI, R. LuvonI, Compendio di medicina legale e delle assicurazioni, XI ed. rivista e aggiornata, Torino, 1999, pp. 7-8; V. MarCheTt, L'invenzione della bisessualità. Discussioni tra teologi, medici e giuristi nel XVII secolo sull'ambiguità dei corpi e delle anime, Milano, 
nia, nella sua specificità categoriale, segnarono un'importante punto di svolta verso un suo inquadramento più chiaro ed un importante punto di partenza verso la congiunzione fra sapere medico e sapere giuridico in materia di follia morale ${ }^{21}$. Protomedico, archiatra pontificio e consulente del tribunale della Rota Romana oltre che uno dei grandi pionieri della medicina forense in Italia, sulla melancholia afferma espressamente che i giureconsulti avevano usato, per lungo tempo, il termine mentecaptus in luogo del termine melancholicus. Secondo la testimonianza dello Zacchia la scienza del diritto fino ai suoi tempi aveva riconosciuto tra furentes e mentecapti una generica distinzione fra totale e parziale, che il medico romano si propose di affinare con le categorie di furentes e melancholici. Mentre, infatti, l'animo del furiosus appariva agitato, tormentato dalla rabbia e preda di una mania generalizzata, quello del melancholicus restava nella quiete, non mostrava apparentemente alcun segno esteriore di infermità mentale ed era preda di una mania circoscritta alla sfera morale e volitiva ${ }^{22}$. L'immagine che lo Zacchia offriva del folle $m e$ lancholico presentava tutti i tratti peculiari di una mente in grado di nascondere il suo vizio e di mostrare, oltre i confini del suo delirio morale, un intelletto perfettamente lucido e ragionante:

qui circa unam tantummodo rem insaniunt, circa quam firmam habent et falsam opinionem, existimantes illam esse, si non sit, vel e contra, vel alio modo, quam vere sit

2001; G. PIERINI, Venefici: dalle Quaestiones medico legales di Paolo Zacchia, Milano, 2001, p. 101 ss.; A.B. SPITZER, Einleitung, in P. Zacchia, Die Beseelung des menschlichen Fötus, Köln-Weimar-Wier, 2002, pp. 1-28; T. Feola, Profilo storico della medica legale. Dalle origini alle soglie del XX secolo, Torino, 2007, pp. 246-284; da ultimo il prezioso studio archivistico di S. De RenzI, Per una biografia di Paolo Zacchia: nuovi documenti e ipotesi di ricerca, in A. PAstore, G. Rossi (a cura di), Paolo Zacchia, Alle origini della medicina-legale 1584-1659, cit., pp. 50-73. Le Quaestiones medico-legales di Zacchia sono state oggetto anche di quest'ultimo lavoro, frutto di uno studio dedicato che ne ha approfonditamente ricostruito la complessità tematica.

21 Sul rapporto fra la medicina e la giurisprudenza nell'Ancien Régime si rinvia allo studio monografico di A. PASTORE, Il medico in tribunale. La perizia medica nella procedura penale d'antico regime (secoli XVI-XVIII), Bellinzona, 1998; ai contributi di C. Colombero, Il medico e il giudice, cit., pp. 363-381; e a S. De ReNZI, Medical Expertise, Bodies, and the Law in Early Modern Courts, in Isis, XCVIII (2007), n. 2, pp. 315-322.

22 Paolo Zacchia, Quaestiones medico-legales, II, Venetiis, 1751, [q. IX] p. 106. 
[...] rationem laedi circa unam tantummodo rem, dicentem, rationem esse laese, immaginationem vero non: sed dicere me ipsam rationem male ratiocinari circa hoc, bene autem circa illud ${ }^{23}$.

La melancholia nell'universo giuridico iniziava ad essere considerata dai cultori del diritto un'autonoma e peculiare specie di infermità mentale sulla base degli spunti teorici forniti dalla medicina legale e in un contesto storico-culturale che dimostrava forte interesse per tale condizione della mente sul viatico aristotelico ${ }^{24}$. Negli stessi anni in cui Zacchia dedicava ad essa la IX quaestio delle sue Quae-

23 Ivi, p. 105.

24 A fondamento del problema erano alcune pagine di Aristotele che nei Problemata physica proponeva la concezione tetrade della melancolia, colta come uno dei quattro "umori” presenti nella struttura ontologico-naturale dell'essere umano, umore che poteva - in presenza di determinate circostanze - sfociare in una condizione psico-fisica patologica oppure arrestarsi allo stadio precedente di semplice temperamento naturale. Secondo la scienza medica antica la melancolia trarrebbe

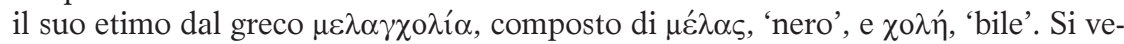
da Aristoteles, Problemata physica, a cura di H. Flashar, Berlin, 1991, [XXX.1] pp. 711-722. Si riteneva che lo stato psicopatologico derivasse da un eccesso di bile nera nell'organismo dovuto ad un cattivo funzionamento della milza, organo-sede di tale sostanza. Il fallimento del processo di emocateresi rendeva stagnante la bile nera collocata nell'area hipochondriaca del corpo, ovvero nel basso ventre. Tale sostanza putrida in eccesso acquisiva in tal modo un forte potere patogeno attraverso i vapori che da essa salivano all'area cerebrale. Il termine hipochondriaco sarebbe derivato da hipochondrio, termine con in quale la scienza medica antica indicava la parte superiore e laterale della cavità addominale, da cui la melancolia e le altre affezioni si pensava traessero origine. Lo Zacchia intitolerà De' Mali Hipochondriaci il suo trattato nosografico in cui la melancholia viene descritta nei suoi aspetti più tecnicamente medici come vera e propria malattia psichica. Cfr. PAOlo Zacchia, De’ Mali Hipochondriaci, Roma, 1651, [L. I, c. I] pp. 1-2. Gli stralci dell'antica concezione della melancolia giungeranno fino al Settecento. Anche nelle pagine introduttive dell'Alberti e del Graebner si ritrovano dei riferimenti alla concezione atrabiliare della malattia: «Melancholiam antiquitas medica derivat a $\mu \varepsilon^{\prime} \lambda \alpha \varsigma$ e $\chi 0 \lambda \eta$, $\mathrm{ab}$ atra nimirum bile. Ansam subministravit dubio procul, quod in excretis vomitu fluxu que alvi humorem actu nigri cantem observaverint medici». Cfr. MichaEL Alberti, Gottfried Lebrecht Graebner, Dissertatio inauguralis medico-forensis de Melancholia vera et simulata, II, Halae Magdeburgicae, 1743, [c. I] p. 2. In generale, sulla storia di tale patologia che trae linfa nella sua multiforme espressività dalla cultura in cui si colloca e dai suoi cambiamenti si vedano R. KLIBANSKY, E. PANOFSKY, F. SAXL, Saturn and Melancholy: studies in the history of natural philosophy religion and art, Nendeln, 1979; P.L. CABras, D. LiPPI, F. LOVARI, Due millenni di melancholia. Una storia della depressione, Bologna, 2005. 
stiones medico-legales, lo scrittore Robert Burton realizzava la sua opera monumentale Anatomy of Melancholy ${ }^{25}$ in cui la melanconia veniva descritta come una patologia psichica in grado di assopire e far precipitare nell'indifferenza emotiva la morale dell'individuo.

Fra le pieghe dei ragionamenti dello Zacchia si coglie perfettamente la specificità della malattia melanconica come follia parziale. Il medico legale definiva i melancholici come soggetti affetti da un delirio circoscritto e li distingueva dai furiosi per il loro delirare in maniera estesa. Egli notò che sullo specifico oggetto della malattia, il melanconico mostrava una mente corrotta, si formava opinioni false, traviate e immutabili ma, al contrario, governava con raziocinio qualsiasi altra questione. Nella fertilissima fase di creazione del penale sostanziale lo Zacchia gettava le radici per l'edificazione di teorie sulla responsabilità penale. Con l'approfondimento scientifico su tale forma di follia affioravano problematiche che ponevano in evidenza l'esigenza di dare un volto via via più delineato alla responsabilità, alla voluntas, al propositum di chi commetteva un crimine in una condizione mentale che appariva sana ma che presentava delle forme di devianza nascoste che si sostanziavano in un irrigidimento interiore della sfera morale. In tali particolari criminali si riscontrava un atteggiamento di indifferenza nei confronti del male che procuravano ${ }^{26}$.

Al fine di comprendere cosa intendesse la scienza medica per malattia circoscritta appaiono illuminanti le parole di Michael Alberti (1682-1757) ${ }^{27}$. La melancholia presentava la lesione e il perturbamento della sfera immaginativa causati da un'idea specifica in grado di interrompere l'ordine e la rettitudine nella volontà di agire dell'infermo criminale ${ }^{28}$. Gli elementi che venivano presi in esame erano il raziocinio e la capacità immaginativa, come facoltà che una mente sana avrebbe dovuto possedere totalmente integre. Il morbo

25 Robert Burton, Anatomia della malinconia, a cura di J. Starobinski, Venezia, 1983; Sul punto cfr. F. STOK, Modelli e tradizione antica nella psicopatologia di Zacchia, cit., p. 84.

26 Paolo Zacchia, Quaestiones medico-legales, cit., [q. IX] p. 106.

27 In generale sulla vita e il pensiero del medico-legale si veda W. KAISER, A. VÖLKER, Michael Alberti (1682-1757), Halle-Wittenberg, 1981.

28 Michael Alberti, Gottfried Lebrecht Graebner, Dissertatio inauguralis medico-forensis de Melancholia vera et simulata, cit., p. 4. 
ne comportava, pertanto, la lesione ma non la distruzione ed in ciò risiedeva la distinzione con la stupiditas ${ }^{29}$. L'accento veniva posto non casualmente sull'errore - circoscritto all'idea delirante - nella comprensione e nella rappresentazione della realtà noumenica che conduceva il criminale malinconico a costruzioni immaginative ingannevoli. Una falsa idea e un falso giudizio costituivano gli impulsi al reato del malinconico. L'operazione definitoria compiuta dall'Alberti si mostrava in perfetta linea di continuità con la sezione psicopatologica delle Quaestiones, non solo rispetto ai contenuti ma anche rispetto all'obiettivo che Zacchia per primo si era proposto: quello di fornire strumenti della scienza medica ai cultori del diritto, in un'ottica di superamento di quella logica binaria che nella prassi giuridica vedeva i due saperi non comunicare.

Le indicazioni definitorie sulla melancholia, fornite da alcuni fra i più illustri esponenti della 'scienza della guarigione' del Seicento, sembravano coincidere, e risentivano della necessità di fornire schemi categoriali utili alla prassi tanto medica quanto giuridica, soprattutto nelle ipotesi di reato perpetrato da malinconici. La multiforme fenomenologia dell'essere infermo di mente veniva, in tal guisa, contenuta in celle concettuali da cui estrarre il fenotipo di volta in volta più calzante rispetto alla prassi. Sotteso a tali classificazioni nosologiche vi era il tentativo dei medici che videro l'alba della medicina legale, di edificare una costruzione sistematica che non si perdeva nei grovigli dell'ermeneutica, e che ambiva a raggiungere il più alto grado possibile di certezza in un universo brulicante di insidie ed insicurezze come quello dell'infermità mentale.

\section{L'ingresso della malinconia nell'universo giuridico}

In questo lavoro di costruzione un ruolo fondamentale e imprescindibile viene giocato dalla scienza giuridica che, verso la fine del

29 Ivi, p. 12. Rispetto alla dementia la differenza nella melancholia sembra risiedere nella lucidità mentale con cui il melancholico asseconda la finzione ponendola in realizzazione, diversamente dagli stupidi che semplicemente si limitano a raccontarla. 
Seicento, inizia a muoversi su questo terreno angusto, ispirato dalla medicina legale.

Ad accogliere la malinconia come autonoma forma di malattia della mente fu il giurista tedesco Peter Heige (1559-1599) che nei primi anni del Seicento, attribuirà alla melancholia i signa individuati dalla scienza medico-legale. Nelle sue Quaestiones Iuris sulla costruzione della responsabilità in maleficiis, essa verrà descritta, in linea di coerenza con la concezione medico-legale, come mania parziale. Parziale perché concerneva solo la sfera della morale, parziale perché non comportava alcuna debolezza intellettiva. Fra i suoi signa, oltre al metus e alla moestitia, egli individuava il tratto peculiare della ossessività di un'idea che, sebbene falsa, con veemenza veicolava la volontà dell'infermo conducendolo al crimine ${ }^{30}$. Nella trattazione del giurista tedesco si ritrovano menzionati diversi esempi di infermi deliranti solo ed esclusivamente su questioni circoscritte.

Tra le correnti della cultura del Seicento le dottrine del diritto naturale presentano idee e posizioni specifiche che confermano la tesi per cui non si può parlare di una scuola nel senso accademico in quanto, accanto ad alcuni profili comuni, ciascuno degli esponenti di questo indirizzo di pensiero mostra un'impostazione teorica individuale. La prospettiva argomentativa dei giuristi giusnaturalisti sul tema della melancholia assumeva, talvolta, connotazioni spirituali. Thomas Hobbes (1588-1679) nel Leviathan, edito nel 1651, poneva in evidenza che nella individuazione delle cause della melancholia si era soliti seguire un doppio binario: quello della follia e quello della possessione diabolica «hodieque eosdem homines Itali vocant Pazzi e Spiritati $»^{31}$. Da una parte il fenomeno veniva inserito in una dimensione laica - medica e giuridica -, dall'altra in una dimensione confessionale - metagiuridica.

Nella prospettiva laica, particolare interesse assumeva la pratica criminale del penalista Benedikt Carpzov (1595-1666) ${ }^{32}$ - giuri-

30 Peter Heige, Quaestionum Iuris tam Civilis, quam Saxonici, Wittebergae, 1630, [q. XXXVIII §. 37] p. 330.

31 Thomas HobBes, Leviathan, sive de materia, forma e potestate civitatis ecclesiasticae et civilis, Amstelodami, 1670, p. 39.

32 Sul giurista si veda W. SchiLd, 'Carpzov, B.', in Deutsche Biographische Enzyklopädie, II, Minden-London, 1995. 
sta di elevato profilo intellettuale considerato uno dei fondatori della scienza giuridica tedesca ${ }^{33}$ - che alla melancholia dedicò un notevole approfondimento teorico con attenzione anche alla prassi giudiziaria, guardando al fenomeno psicopatologico nella sua unicità e specificità. Il Carpzov procedeva ad una riflessione sul furor in generale e sul suo trattamento giuridico - precisando che lo stesso doveva estendersi al frenetico (o maniaco), all'insano, al demente e al mentecatto - e dedicava una sede argomentativa separata alla melancholia e al suo specifico trattamento penalistico ${ }^{34}$. Dalla trattazione del giurista tedesco si rileva la prudenza con cui i cultori del diritto analizzavano e distinguevano le diverse forme di aberrazione mentale, consapevoli delle difficoltà sottese all'intento definitorio. Egli metteva in guardia i teorici, ma soprattutto i pratici del diritto, dal pericolo di confusione della melancholia con il furor confermandone la distinzione che ne faceva la scienza medica tra parziale e totale, e avvertiva, che sono altro dai melancholici i timidi, i bramosi, gli avari e gli iracondi, come era nell'uso comune del termine ${ }^{35}$.

I giuristi imbastivano le trame di un lavoro tutto in fieri, su questo magmatico terreno attraverso le loro interpretazioni orientavano le riflessioni in campo penale, così, il crimine del melanconico si prefigurava come assistito ed incitato da una volontà deviata, da un intelletto integro ma accompagnato da profonde tribolazioni dell'animo. L'indagine sulla condizione mentale del criminale si fondava sul nesso tra atto e coscienza, tra accadimento e volontarietà e si presentava agli interpreti come uno degli aspetti fondamentali cui guardare all'interno della creazione di un penale che germogliava

33 S. Moccia, Carpzov e Grozio. Dalla concezione teocratica alla concezione laica del diritto penale, Napoli, 1988, p. 11; G. KLEINHEYER, J. SchröDER, Benedikt Carpzov, in Deutsche und europäische Juristen aus fünf Jahrhunderten, Tübingen, 2017, p. 92.

34 Dalla struttura formale del trattato si possono comprendere le ragioni giuridiche sostanziali della bipartizione della materia. Alla melancholia viene attribuita una sede particolare pur rientrando nella quaestio dedicata alla follia e agli effetti giuridici delle azioni criminose da essa provenienti. Cfr. BenEDIKT Carpzov, Practicae novae rerum criminalium pars tertia quaestionum fere universarum decisiones in materia processus criminalis, tam ordinarii, quam inquisitorii, torturae executionis et remissionis ac mitigationis poenarum exhibens, Lipsiae, 1695, [q. CXLV] p. 321.

35 Ivi, p. 325. 
e si sviluppava sulla complessa compresenza di diversi fattori che contribuivano a tracciare la complessità della dimensione giuridica del tempo ${ }^{36}$.

Nella prospettiva metagiuridica, alla tesi hobbesiana sulla possessione diabolica dei malinconici si contrapposero qualche decennio più tardi, nella stessa Inghilterra, le idee di un pensatore tra i maggiori dell'Europa moderna, John Locke (1632-1704). Nelle sue pagine, la lettura confessionale della melancholia perde il suo lato oscuro ed assume un profilo divinatorio, essa veniva descritta come una condizione dello spirito e della mente che se unita alle pratiche devozionali conduceva i devoti ad un sentimento di maggiore familiarità con Dio. I melancholici secondo il Locke spesso rimanevano lusingati dalla convinzione di un rapporto immediato con la divinità ${ }^{37}$.

La complessità delle riflessioni dei giuristi in merito non può comprendersi a fondo se si prescinde dall'humus all'interno del quale si sono prodotte. Non si può ignorare il ruolo determinante che la scientia iuris attribuiva alla causa del delinquere quale «criterio primo per la valutazione etico-giuridica dell'atto umano» ${ }^{38}$, fosse essa riconducibile al demonio, alla vicinanza con Dio, o riconducibile ad una malattia dell'animo. Un contributo laico in direzione dell'edificazione di una nuova malattia della mente, che prescindesse da qualsiasi implicazione confessionale, autonoma e diversa ri-

36 Sulla storia della giustizia penale si vedano M. SBRICcoli, Giustizia criminale, in M. FIORAVANTI (a cura di), Lo Stato moderno in Europa. Istituzioni e diritto, Roma-Bari, 2002; M. MecCarelli, Le categorie dottrinali della procedura e l'effettività della giustizia penale nel tardo medioevo, in Pratiques sociales et politiques judiciaires dans les villes de l'Occident à la fin du Moyen Âge, Rome, 2007, on line all'indirizzo: http://books.openedition.org/efr/1842, pp. 573-592; ID., Paradigmi dell'eccezione nella parabola della modernità penale. Una prospettiva storico-giuridica, in Quaderni Storici, 131.2, 2009, pp. 493-521; ID., Dimensions of Justice and Ordering Factors in G. Martyn, A. Musson, H. PihlajamäKi (a cura di), Criminal Law from the Middle Ages till Juridical Modernity, Berlin, 2013, pp. 49-67. In riferimento al peculiare contesto della Repubblica veneziana si veda G. CHIODI, $I l$ giardino dei sentieri che s'incontrano. Processo penale e forme di giustizia nella Terraferma veneta (secoli XVI-XVIII), in Saggi in ricordo di Aristide Tanzi, Milano, 2009, pp. 85-166.

37 John Locke, An Essay Concerning Human Understanding, II, London, 1753, p. 318.

38 E. CorTese, La norma giuridica. Spunti teorici nel Diritto comune classico, II, Ius Nostrum 6, Milano, 1962, rist. anast. 1995, p. 198. 
spetto al furor, venne offerto dal giurista tedesco Christian Wolff (1670-1754) ${ }^{39}$, che discorrendo dell'imputabilità delle azioni umane provenienti dalla melancholia, ne rivelava l'essenza psico-morbosa che trovava la sua patogenesi in un'idea ossessiva, la sola ad imperversare la mente del malato compulsivamente, indebolendo il suo animo $^{40}$. Nelle pagine del Wolff la melancholia veniva descritta come un'inquietudine dell'animo paralizzato da un pensiero fisso e ad esso inscindibilmente aggrappato, senza delirio, originatasi da una rappresentazione immaginaria. Un errore della mente che offre come vera un'idea falsa:

Studio dico, ex melancholia profectae. Neque enim in universum tolli rationis usum, satis constat. Unde Sennertus melancholicorum, inquit, ratiocinatio circa unam rem falsam plerumque, quam veram esse credunt, agerat, cum phantasiae depravatae circa eam assentiantur, de reliquis prudenter et sapiente ratiocinantur ${ }^{41}$.

Nella descrizione propinata dal Wolff sulla scia del Carpzov, la capacità di raziocinio dei melancholici appariva conservata ma cadeva nell'aberrazione a causa di una falsa convinzione che si mostrava ai loro occhi come vera e che le loro fantasie depravate provvedevano a corroborare. Per il resto, venivano descritti come criminali in grado di ragionare con prudenza e avvedutezza. La melancholia era dunque concepita come infermità circoscritta, che riguardava un oggetto ideale particolare e che per tale ragione inficiava solo parzialmente la psiche del soggetto. Coerentemente con la depravatio della facoltà immaginativa ${ }^{42}$ che Zacchia per primo attribuì alla melan-

39 Per un inquadramento generale del pensiero di Christian Wolff si veda T. Opocher, Christian Wolff filosofo del diritto e della politica, Padova, 2013, pp. 3136; Si veda ampiamente il recente lavoro di G. Dioni (a cura di), Christian Wolff. Filosofia Pratica Universale. Redatta secondo il metodo matematico, Milano, 2017.

40 Christian Wolff, Philosophia Practica Universalis methodo scientifica pertractata pars prior theoriam complectens qua omnis actionum humanarum differentia omnisque iuris ac obligationum omnium principia a priori demonstrantur, I, Halae Magdeburgicae, 1744, [c. VI, §. 574] p. 422.

41 Ibidem.

42 Paolo Zacchia, Quaestiones medico-legales, II, cit., [q. IX] p. 106. Anche nella quaestio XXI del libro secondo, che lo Zacchia dedica a quelle particolari tipologie di infermità della mente in cui non risulta carente l'intelletto, i melancholici 
cholia, il malinconico, nella trattazione del Wolff, orienta il proprio agire - relativamente all'oggetto dell'ossessione - seguendo i dettami della sua volontà alterata. D'altronde ciò che assume rilevanza nell'universo giuridico è proprio la sussistenza di un nesso eziologico tra il morbo, nella sua specificità di malattia parziale, e l'azione criminosa circoscritta all'oggetto della follia. Perché si dia rilievo processuale alla melancholia o mania parziale è necessario che il reato concerni l'oggetto specifico della malattia. Le azioni del melancholico, relativamente all'oggetto dell'infermità, vengono compiute in ragione di un errore nella rappresentazione delle circostanze da cui sorge l'impulso criminale, esse muovono i fili di una realtà circoscritta in cui regna la finzione, una sorta di realtà teatrale dove l'oggettività noumenica cede il passo ad una realtà soggettiva artefatta. Risiede proprio nella conservazione dell'intellectus il nodo centrale e aggrovigliato della questione che ruota intorno a tale infermità di difficile inquadramento per la sua natura di follia, potremmo dire, occulta.

\section{Le false credenze dei malinconici}

In questo alveo si muovono le riflessioni dei giuristi che contribuivano a costruire l'identità del criminale malinconico offrendone $\mathrm{i}$ profili più nascosti e meno comprensibili. Le false credenze si affermavano come segnacoli identificativi e diventavano tasselli chiarificatori di un ben più complesso mosaico. Certamente l'aspetto giuridico su cui gli interpreti del diritto intendevano focalizzarsi con-

vengono descritti come infermi in cui non risultano manifesti i prodromi della malattia da cui sono affetti. Sulla base di osservazioni scientifiche egli rilevava che tali infermi sovente mostravano timori non giustificati su questioni esistenziali di lieve gravità. La loro capacità di intendere non risultava mai azzerata benché alterata da una immaginazione corrotta che li induceva inevitabilmente in errore. Più che l'intelletto ad essere alterata era la sfera emotivo-volitiva che presentava un'incostanza patologica. Ciò che in un primo momento veniva scelto come oggetto di amore e di desiderio diveniva presto odiato ed allontanato. L'effimeratezza dei loro sentimenti derivava dall'incostanza immotivata con cui tali infermi si approcciavano alle loro stesse volizioni: amore-odio; amicizia-avversione; desiderio-ripugnanza. Cfr. PAOLO ZAcchIA, Quaestiones medico-legales, II, cit., [q. XXI] p. 125. 
cerneva l'incidenza delle false credenze sulla piena consapevolezza intellettiva delle proprie azioni in criminalibus.

Seguendo le tracce dell'interpretazione del Wolff, a titolo esemplificativo egli offriva due casi di soggetti ossessionati da un'idea chimerica. Il primo credeva di essere il monarca del mondo e il suo delirio era incentrato su tale fallace convinzione. Conseguentemente dissertava su come amministrarlo. Il secondo caso concerneva, invece, un mercante perfettamente in grado di ragionare, eccetto sulla questione delle sue finanze. Questi lamentava di essere stato ridotto all'estrema povertà pur non essendo affatto povero: era l'ossessione per il denaro e la paura di perderlo l'oggetto della sua parziale mania ${ }^{43}$.

L'incapacità di valutare le reali circostanze della realtà per effetto dell'idea ossessiva era stata con acribia già descritta anche dal Carpzov, fortemente seguito nel suo orientamento dalla dottrina giuridica e medico-legale europea di epoca moderna. In quest'ottica, le tribolazioni dell'animo, le convinzioni fallaci e la bassa morale condurrebbero il melancholicus a pensare, a pronunciare e a compiere ciò a cui un uomo, dalla psiche totalmente integra, non arriverebbe:

Quo morbo laborantes vel cogitant, vel loquuntur, vel efficiunt absurda, longeque a ratione et consilio abhorrentia, eaque omnia cum metu et moestitia ${ }^{44}$.

Anche Zacchia aveva addotto, ai suoi tempi alcuni casi concreti di infermi melancholici con delirio parziale. Uno di questi delirava esclusivamente sulla fine della sua vita, avvertendola come imminente. Si trattava di un presbitero. A causa di questo vaneggiamento della mente giaceva talora come morto, steso in terra sopra ad un drappo, con fiaccole accese intorno a sé, ma senza alcun tentativo suicidario si alimentava, mostrava - nel discorrere di altro - di avere integra la mente, appariva in grado di esercitare i suoi diritti e i suoi doveri, di provvedere alla cura dei suoi affari, si mostrava sano di mente per tutto ciò che non concernesse l'oggetto specifico della sua malattia ${ }^{45}$.

43 Christian Wolff, Philosophia Practica Universalis, cit., p. 422.

44 Benedikt Carpzov, Practicae novae, III, cit., [q. CXLV] p. 325.

45 Paolo Zacchia, Quaestiones medico-legales, II, cit., [q. IX] p. 105. 
Alcuni melancholici, come quelli che albergano nelle pagine del giurista Peter Heige, apparivano convinti di essere vasi fittili, cerei, di vetro; altri di essere cani, galli o leoni; altri ancora credevano di essersi trasformati in lupi; allo stesso modo, certuni, fortemente suggestionati dall'idea ossessiva da cui non riuscivano a liberarsi, si convincevano di avere malattie, febbre e idropisia. Il giurista narra anche di un melanconico, a lui coevo, che si professava morto - il caso appare più o meno analogo a quello riportato dallo Zacchia - e che sarebbe morto davvero, di stenti, se non fosse stato ricondotto alla ragione dall'industriosità del suo medico che, fingendosi morto egli stesso, lo convinse ad assumere cibo; un altro appariva persuaso di essere stato trasformato in un seme di grano, e in ragione di ciò se ne stava recluso nella propria abitazione per timore di essere ingoiato dalle galline; altri ancora, sicuri di sostenere il cielo e la terra con il dito mignolo della mano - così come Atlante faceva con la spalla -, apparivano angosciati dal timore di non riuscire ad evitare il crollo del peso sostenuto ${ }^{46}$.

6. Caput melancholicum balneum esse diaboli: la 'bestialis Melancholia'

Nell'Ancien Régime, il rapporto di consanguineità fra la malinconia e la possessione diabolica ${ }^{47}$ si ritrova sia nell'universo teologico che in quello laico. Le prime tracce di tale visione mistica della malinconia si scorgono in alcuni passi delle Sacre Scritture.

Saul, il primo re d'Israele, viene descritto come posseduto dallo spirito maligno e per questo affetto da una profonda malinconia.

46 Peter Heige, Quaestionum Iuris, cit., [q. XXXVIII §. 37] pp. 330-331.

47 Sul tema la letteratura è sterminata. Senza alcuna pretesa di completezza si vedano almeno G. Bonomo, La credenza nelle streghe dal secolo XIII al XIX, Palermo, 1959; S. Clark, Thinking with Demons. The Idea of Witchcraft in Early Modern Europe, Oxford, 1997; C. Ginzburg, Storia notturna: una decifrazione del sabba, Torino, 1989; G. Henningsen, L'avvocato delle streghe. Stregoneria basca e Inquisizione spagnola, Milano, 1990; M. SiefEner, Hexerei im Spiegel der Rechtstheorie. Das 'crimen magiae' in der Literatur von 1574 bis 1608, Frankfurt am Main, 1992; B.P. LEVACK, La caccia alle streghe in Europa agli inizi dell'età moderna, Roma-Bari, 1994. 
Egli sentiva dentro di sé di dover uccidere un innocente. Mentre Davide suonava l'arpa l'avrebbe infilzato con la sua lancia se questi non avesse scansato il colpo voltandosi. Cercò di farlo morire per le mani dei Filistei, mettendolo nelle prime file in combattimento con essi, ma non vi riuscì. Più volte tentò di dargli la morte, lo perseguitò a Nojoth finché per strada non fu investito dallo spirito profetico e iniziò a parlare per ispirazione divina, disteso a terra nudo ${ }^{48}$. In quel momento capì che l'innocente che egli perseguitava era sotto la protezione di Dio, questo non fece che sospendere per poco tempo la sua malvagia volontà senza migliorarla. Quello di Saul è il più antico esempio di ossessione malinconica di cui sia fatta menzione. Nei testi sacri la sua malinconia veniva descritta come un morbo in grado di affievolire la forza dello spirito, capace di asservire la volontà al volere maligno. Essa non doveva confondersi con qualche istante di semplice mestizia perché conduceva a stati violenti ineluttabili colui che si era abbandonato nelle mani di satana ${ }^{49}$.

Il morbo melanconico, in tale prospettiva di pensiero, assume le vesti di demonomania, categoria che racchiude in sé la malattia mentale ed il pensiero esoterico. A generare questa particolare malattia dello spirito e della mente sarebbe il 'bagno del diavolo'. È attraverso la possessione, che satana renderebbe la mente della sua vittima ossessiva e il suo animo indifferente al male. Si tratta di una impostazione giuridico-teologica di stampo spiritualista ${ }^{50}$ che va ad intersecarsi con la concezione laica della melanconia come specie particolare del più generale furor - «Antiquus Theologus escam et balneum Diaboli appellat; quia diabolus crasim et constitutionem humani corporis probe notam et comprehensam habens, sese iusta

481 Sam 19,9-24.

49 B. Catena, Sulle ossessioni e possessioni del demonio, in La Sacra Bibbia di Vence, VI, Milano, 1834, pp. 378-387.

50 Alla base di tale concezione della malinconia vi era il dibattito sul servo arbitrio proprio della dottrina predestinataria fortemente sostenitrice dell'assenza del libero arbitrio che, a partire da Martin Lutero (1483-1546), offre l'immagine di una creatura indebolita nell'intelletto e corrotta nella volontà a causa del peccato, versata irrimediabilmente al male. Sul tema della servitù e libertà dell'arbitrio umano, quale disputa che ebbe un'ampia eco nella cultura del tempo e che incise profondamente sugli sviluppi della storia del pensiero in età moderna si veda ampiamente F.D.M. Pintacuda, Tra Erasmo e Lutero, Roma, 2001. 
Dei permissione, isti humori immiscet et mira phantasmata producit» $-{ }^{51}$.

D'altronde anche il pensiero dello Zacchia sulla malinconia non traccia un vero e proprio spartiacque tra la concezione laica e quella mistica che nelle pieghe dei suoi ragionamenti esse finiscono per intersecarsi. Finanche il medico-legale che esamina la questione da un punto di vista più propriamente laico nel segno delle conseguenze giuridiche della malattia cade nelle trame dello spiritualismo. Egli infatti definisce demoniaco chi venga condotto alla follia da un'alterazione melanconica, quest'ultima costituirebbe lo strumento di cui si serve il demonio per prendere possesso della sua vittima ${ }^{52}$.

Il sodalizio fra la malinconia e la possessione diabolica si ritrova anche nelle pagine di Jean Bodin (1530 circa-1596) giurista francese, docente di diritto romano all'Università di Tolosa, che nella sua opera rivolta ai giudici incaricati di istruire processi di demonomania, discorre dei segni dei malefici [melancholici $]^{53}$. Aubert de Poitiers $^{54}$, avvocato al Parlamento di Parigi, si sarebbe trovato in un processo che vedeva coinvolto un malinconico maniscalco del Castello di Château-Thierry, il quale si trovò un segno diabolico sulla spalla destra che il giorno seguente scomparve, inducendolo così a pensare che il diavolo avesse provveduto a cancellarlo. In tal caso, il procuratore del Re a Ribemont, Claudio Doffai, ravvisò sul corpo dell'imputato lo stesso segno che già aveva verificato in un caso processuale precedente che vide coinvolta l'incantatrice Giovanna Herviller.

Un altro caso di demonomania risale all'anno 1571. Colui che fu condannato dal Preposto della Casa del Re, Trescale du Mayne,

\footnotetext{
51 William Perkins, De Casibus Conscientiae, Hanoviae, 1609, p. 177.

52 Paolo Zacchia, Quaestiones medico-legales, II, cit., [t. I, q. XVIII, §. 4-5] p. 120.

53 Jean Bodin, Demonomania de gli stregoni cioè Furori, et malie de' Demoni col mezo degli Huomini, II, Venetia, 1592, p. 148.

54 Aubert de Poitiers, signore di Massoignes, nato a Poitiers, verso l'anno 1534, avvocato presso il parlamento di Parigi ed in seguito avvocato generale presso la court des aides, acquistò più fama che fortuna con l'esercizio della sua professione. Secondo Lacroix de Maine, passava per uno degli uomini più dotti e più eloquenti del suo tempo, ciononostante visse nella miseria. Cfr. AA.Vv., Biografia Universale antica e moderna, III, Venezia, 1822, p. 403.
} 
ottenne la grazia rivelando l'identità dei suoi complici. Quando fu condotto ad identificarli, sostenne che essi avevano sui loro corpi i segni del demonio. Ed il suo racconto trovò riscontro nelle prove acquisite. Costoro risultarono 'segnati' nella pianta del piede con l'immagine di una piccola lepre incisa nella pelle insensibile al dolore ${ }^{55}$. Uno dei signa della melanconia poteva essere per l'appunto il marchio del diavolo che in tal modo rendeva tangibile il suo possesso della persona. Tra gli effetti della melancholia, il teologo calvinista William Perkins (1558-1602) individuava «monstruosae phantasiae cogitationes et opiniones in animo efformatae ${ }^{56}$. A tale «morbus in cerebro», egli attribuiva il nome di «bestialis Melancholia» a voler rimarcare la vicinanza di tale malattia demoniaca al mondo delle fiere infernali. La malinconia bestiale era in grado di indurre tutti coloro che ne fossero infestati - i lycanthropi $i^{57}$ - ad ululare come lupi in un rituale satanico.

Tale visione esoterica della malattia melanconica finiva per intrecciarsi con quella laica organicistica, come evidenziava il teologo Friedrich Balduin (1575-1627) ${ }^{58}$, le cui interpretazioni furono pienamente accolte più avanti dal giurista Samuel Stryk (1640-1710) ${ }^{59}$, professore nelle Università di Francoforte sull'Oder, di Berlino, di Wittenberg e di Halle. Egli pose in luce le differenze tra le due condizioni pur riconoscendole interconnesse: «I corpi dei posseduti, così come i loro animi, sarebbero afflitti da uno spirito maligno, tuttavia in molti casi i melancolici hanno una grande affinità con i posseduti. Infatti l'umore melancolico è molto conveniente per il diavolo e coloro che sono stati liberati da uno spirito maligno ricadono molto spesso nella melancolia ${ }^{60}$. Si tratta certamente di considerazio-

55 Jean Bodin, Demonomania, II, cit., p. 148.

56 William Perkins, De Casibus Conscientiae, cit., p. 177.

57 Ivi, p. 178.

58 Friedrich Balduin, Tractatus de casibus Consciaentiae, III, Francofurti, 1654, [c. IV] p. 486.

59 Samuel Stryk, Disputatio Juridica Solennis de Dementia et Melancholia, Francofurti cis Viadrum, 1683, [c. IV §. 3] p. 20.

60 Friedrich Balduin, Tractatus de casibus Consciaentiae, cit., p. 486: «Quanquam obsessi, a melancholicis multum differunt; illor nenim corpora, horum animos malignus spiritus affligit: cum obsessis tamen magnam saepenumero cognationem habent melancholici. Nam humor melancholicus est diabolo convenientissimus et demoniaci a maligno spiritu liberati plerum in melancholiam incidunt. Recto 
ni che si sviluppano nelle trame dell'inscindibile legame tra delitto e peccato, inserendosi in un'idea di colpevolezza che non separa le infrazioni criminali dai fatti morali e religiosi. Tale concezione oscura della malinconia si palesa nella riflessione dello Stryk, che nel suo secondo grado la definisce «diabolica». Essa deriverebbe dal demonio che utilizza le sue tentazioni con grandissima forza, inducendo la vittima designata in uno stato di perenne immoralità e malvagità. In altri casi può essere la gravità del peccato e del reato commesso a determinare lo sprofondamento nella malattia ${ }^{61}$. Il crimine commesso dal malinconico sarebbe frutto delle suggestioni malvagie del male che opera attraverso le sue vittime. Tra le maglie di questo discorso si intrecciano con coerenza argomentativa, le parole del giurista Peter Heige secondo il quale «caput melancholicum balneum esse diaboli» ${ }^{62}$. L'animo corrotto dalla melanconia sarebbe il luogo ideale in cui naviga il male. La debolezza di mente e di animo proprie della infermità renderebbero la vittima desiderabile del diavolo, «infatti, poste le fondamenta della tristezza per mezzo della malinconia, il diavolo gode dell'umana fragilità e vi tesse le sue reti; avvolti dunque in esse i malcapitati, li conduce infine alla dissoluzione; tali affezioni sono dunque più pericolose di qualsivoglia infermità corporale» ${ }^{63}$.

Si intrecciano in un coacervo concettuale le dimensioni del peccato e del reato. Ma al di là di ogni partizione disciplinare e di ogni concettualizzazione astratta, il dibattito sulla malinconia presenta un percorso pieno di deviazioni concettuali che meritano parimenti di essere accolte e che non si escludono anzi si rafforzano le une con le altre. La malinconia rappresenta il punto in cui si incontrano le ragioni dei diversi saperi che la descrivono, senza sovrapporsi ma

igitur ordine ab obsessis discedimus ad melancholicos, quibus aeque magnum, interdum etiam maius est periculum quam in obsessis».

61 Samuel Stryk, Disputatio Juridica Solennis de Dementia et Melancholia, cit., [c. IV §. 10] p. 23: «Notanter diabolicam dico. Hac enim hostem nostrum insensissimum in tentationibus suis quam maxime abuti, nobis, meliorem aliorum fortem, peccati olim commissi gravitatem et ante oculos ponendo, exemplorum numero et quotidiana experientia convincimur».

62 Peter Heige, Quaestionum Iuris, cit., [q. XXXVIII §. 45-46] p. 331.

63 Samuel Stryк, Disputatio Juridica Solennis de Dementia et Melancholia, cit., [c. IV §. 3] p. 20. 
influenzandosi. Essa è contestualmente malattia della mente, malattia dello spirito, malattia della morale, malattia della volontà.

\section{Tracce di processi a melancholici (secc. XVII-XVIII)}

Risaltano evidenti i tratti diagnostici prestati dalla medicina ai giurisperiti al servizio della prassi processuale in un'ottica di interrelazione tra saperi. Il carattere parziale della malattia stava ad indicare sia l'unicità e l'esclusività dell'idea ossessiva, sia la sussistenza - eccezion fatta per l'oggetto di delirio - di un esame conservato della realtà. Non vi era dubbio, e lo confermava anche lo Zacchia, che «circa melancholicos maximum, ac multae speculationis dubium pro juristis occurrit». La natura occulta di tale infermità suscitava nei giuristi il forte sospetto della simulazione e l'alto rischio di speculazione processuale proprio perché «si eam peculiaris illius opinionis falsitatem excipias, nihil omnino ab homine sanae mentis differunt $»^{64}$. I criteri diagnostici offerti dai medici-legali e dai giuristi lambivano le ragioni del penale sostanziale per incontrare aspetti processuali fondamentali. Lo scopo precipuo del discorrere era cercare di offrire ai giudici e ai pratici regole certe che ineluttabilmente vacillano quando le riflessioni si dirigono verso la voluntas.

Il giureconsulto del ducato estense Gerardo Mazolli in un suo Consilium del 1575, al fine di scongiurare il rischio di simulazione dell'infermità in un caso processuale che vedeva imputato un presunto melancholico, suggeriva i presunti signa della malattia, interiori ed esteriori ${ }^{65}$. L'inquisito si era macchiato di delitto nel girare di notte con una maschera sul volto e con il corpo camuffato rendendosi così irriconoscibile:

Caesari ascribitur, quod larvam de nocte portare supra faciem repertus fuerit a curia, contra proclamata ducalia veniendo, ideo luat poenas ${ }^{66}$.

64 Ibidem, [§. 17].

65 Gerardo Mazolli, Consiliorum seu responsorum, I, Venetiis, 1575, [c. LVII] pp. 144-146.

66 Ivi, p. 144. 
Tale delitto sarebbe stato punito con la pena corporale ma si discorreva sulla possibilità di non applicare il supplizio in forza della condizione mentale del soggetto. I puncta che vengono sviluppati nella trattazione consulente del Mazolli rivelano le concezioni giuridiche che ruotavano, al tempo, intorno alla melancholia.

Il Mazolli su tale infermità scriveva:

Quod melancholia mentis quedam alienatio est sine febre et melancholico maxime humore nascens, qui mentis sedem occupaverit et consimilem curationem habent melancholici et insani, sic inquiunt Phisici ${ }^{67}$.

I signa della malattia melancholica che emergono dalle consultazioni mediche e le deposizioni testimoniali corrispondono a quelli dell'elaborazione dottrinale prevalente. Si tratta di soggetti che prediligono la solitudine, che non entrano in rapporto di confidenza con i propri consociati, che sono afflitti dalla profonda tristezza, che covano odio, che avvertono una forte paura e si lamentano spesso ${ }^{68}$. La prova della melancholia nei processi criminali non poteva che essere raggiunta attraverso una ricostruzione presuntiva della condizione di aberrazione della mente mediante l'identificazione e l'interpretazione di elementi esteriori del comportamento dell'imputato nell'immanenza del delitto e negli altri fatti che lo avevano preceduto.

Lo stesso attento esame delle circostanze che orbitano intorno al reato, a voler mostrare come la prassi giurisprudenziale si imbattesse nella infermità mentale della melancholia cercando criteri definitori e probatori, viene invocato dal Carpzov nella sua opera magistrale di diritto criminale. Alla luce della straordinaria esperienza di operatore pratico e la puntuale lucidità dei suoi giudizi, il riferimento alle Decisiones criminales su reati compiuti da melancholici può considerarsi una sorta di sintesi conclusiva di una complessa elaborazione teorica del giurista tedesco sulla rilevanza della malattia biliare nella criminalistica ${ }^{69}$. In un caso di uxoricidio dell'ottobre

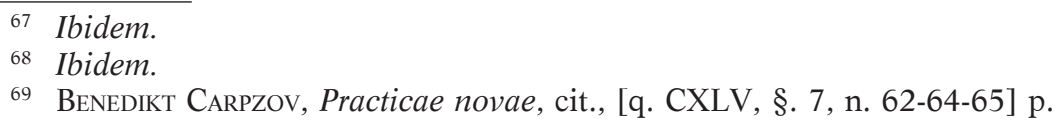


del 1585 gli Scabini [giudici incaricati], riferirono al questore Laurentius le valutazioni giuridiche da essi elaborate sulla condizione mentale dell'omicida, descritto dal questore nelle precedenti interrogazioni come melancholico. L'imputato nel periodo che aveva preceduto l'assassinio della moglie aveva goduto di cattive condizioni di salute. Nella stagione estiva, infatti, cadde più volte in malattia. La vittima quattordici giorni prima della sua fine, da brava moglie si rivolse al parroco affinché liberasse suo marito dal male che della sua anima e della sua mente si era impossessato. Ella supplicò il chierico di consolare e confortare il marito affinché non perdesse la fiducia in una possibile guarigione. La melancholia dell'uomo gli fece risparmiare la pena ordinaria per l'omicidio della moglie. Ma egli tuttavia, a seguito della sua espressa confessione, fu trattenuto volontariamente in custodia presso un tribunale criminale pubblico. Diversamente, qualora alla fine del procedimento penale fosse stato riconosciuto colpevole, come pareva giusto, sarebbe stato a buon diritto passato a fil di spada. Spesso avveniva che $\mathrm{i}$ «trovatori di sentenze» (urteilfinder) rimettessero la complicata questione di diritto direttamente al magistrato. Così avvenne nel giugno dell'anno 1603 ad Augusta, gli Scabini affidarono la mitigazione della pena all'arbitrio del giudice togato. Dalla sentenza emerse che l'inquisita - stando alle disposizioni dei magistrati, formalizzate negli articoli dal quarto al quattordicesimo - aveva compiuto il delitto a seguito dell'ispirazione di un uomo nero comparsole in sogno, lasciando dunque comprendere che il delitto fosse avvenuto a causa della sua tristezza, melancholia e languore. Avvalendosi di una grazia speciale non avrebbe voluto né alleviare né ridurre la giusta punizione per l'omicidio commesso che consisteva in un supplizio simile alla pena cullei di derivazione romanistica, ovverosia nell'esser messa in un'otre insieme con un cane, un gallo, un serpente e un gatto, gettata nell'acqua e annegata, oppure, nel caso in cui il luogo dell'esecuzione non avesse offerto acqua, sarebbe stata condannata a morte per mezzo della ruota.

Fu sempre di diffidenza l'atteggiamento degli Scabini in un caso simile di omicidio perpetrato da una melancholica nel 1615, in alcune ricostruzioni processuali si temeva l'uso capzioso della infermità al fine di avvalersi della benignità del sistema penale nei confronti della follia. 
Analogamente, in un caso di adulterio ${ }^{70}$ consumato nel mese di aprile del 1629 i giurisperiti ritennero che la pena potesse essere alleviata in ragione della melancholia che affliggeva l'adultera e mutata in esilio. Gli Scabini al cospetto del Senato di Oschatz (Ossiciensi) ritennero che a causa di questo adulterio commesso e divenuto di pubblico dominio, costei sarebbe dovuta essere cacciata per sempre a buon diritto dal Land con la fustigazione. Tenendo conto del rapporto del Senato su quanto vi fosse di malinconico e di folle in quella donna, essi invitavano a dimostrare clemenza e a risparmiarle la pubblica tortura. In questo caso gli Scabini chiedevano che l'adultera fosse soltanto sottoposta a esilio perpetuo dal Land.

Appare evidente la rilevanza giuridica di chiarire ed articolare i metodi di individuazione della figura del criminale melancholico, il quale in assenza di tale condizione scusante per il suo reato poteva ricevere - anche sulla base di indizi - gli estremi supplizi delle pene corporali o della pena di morte. Si tratta di secoli in cui prove ed indizi appaiono intrecciati nelle trame di un rigido sistema probatorio fondato sui principi generali delle leggi e sulle varie applicazioni

70 Sull'adulterio mi limiterò a segnalare J. Brundage, Law, sex, and Christian Society in Medieval Europe, Chicago, 1987, pp. 306 e ss. e 388 e ss.; C. Donahue JR., Law, Marriage, and Society in the Later Middle Ages: Arguments About Marriage in Five Courts, New York, 2007; S. Seidel Menchi, D. Quaglioni, (a cura di), Trasgressioni. Seduzione, concubinato, adulterio, bigamia (XIV-XVIII secolo), in Annali dell'Istituto Storico Italo-Germanico in Trento. Quaderni, 64, Bologna, 2004, cui si rinvia per i singoli contributi; M.G. Di Renzo Villata, "Crimen adulterii est gravius aliis delictis...». L'adultera tra diritto e morale nell'area italiana (XIII-XVI secolo), in M. CAVIna, B. Ribémont, D. Hoxha (a cura di), Le donne e la giustizia fra Medioevo ed età moderna. Il caso di Bologna a confronto, Bologna, 2014, pp. 11-45; ID., Dall'amore coniugale 'proibito' all'infedeltà. L'adulterio nelle Summae confessorum italiane (XIV-XVI secolo), in Italian Review of Legal History, 1, 2015, pp. 1-41. Sull'omicidio degli adulteri, G. MinNuccI, Alberico Gentili tra mos italicus e mos gallicus. L'inedito commentario ad legem Juliam de adulteriis, Bologna, 2002; ID., Foro della coscienza e foro esterno nel pensiero giuridico della prima Età moderna, in G. Dilcher, D. Quaglioni (a cura di), Gli inizi del diritto pubblico, 3. Verso la costruzione del diritto pubblico tra medioevo e modernità, Bologna/Berlin, 2011, pp. 58 e ss.; M. CAVINA, Il padre spodestato: l'autorità paterna dall'antichità a oggi, Roma-Bari, 2007, pp. 86 e ss.; M. CAVInA, Nozze di sangue: storia della violenza coniugale, Roma-Bari, 2011, pp. 68 e ss.; A. Massironi, The Father's Right to Kill His Adulterous Daughter in the Late Ius Commune, in M.G. Di Renzo Villata (a cura di), Family Law and Society in Europe from the Middle Ages to the Contemporary Era, Cham, 2016, pp. 187-215, a questi lavori si rimanda per la letteratura sul tema. 
della scienza. Gli indizi oltre che differenziati sulla base della gravità venivano classificati secondo la specie. Questa classificazione rigida è cosa da cui la dottrina moderna rifugge, predominando nel foro criminale il sistema della libertà della prova, non poteva parimenti rifuggirne la giurisprudenza dell'età del tardo diritto comune essendo negata alla coscienza del giudice gran parte di quella libertà che solo più avanti le verrà riconosciuta ${ }^{71}$.

Ma quali elementi indiziari ${ }^{72}$ dovevano sussistere nell'indagine processuale sulle qualità psichiche e spirituali del reo perché si potesse riconoscerlo a buon diritto melancholico, meritevole di un trattamento penale mitigato ed escludere la simulazione?

La questione relativa al pericolo di simulazione della melancholia si ritrova sollevata anche nella decisio CVIII della raccolta di Decisiones criminales del giurista George Friedrich Harpprecht (16761754). Si trattava di un caso di latrocinio nella cui disamina fu sottolineato come non furono infrequenti i casi processuali in cui tale infermità fu utilizzata con scopi fraudolenti:

Da nun aber ex actis so viel ersichtlich, daß Inquisit, seit fürgewährter gefangenschafft, so viel von sich geäussert, daß selbiger wann anderst, wie es dato noch das ansehen hat, seine fraudulente simulation darunter verlirt; prout exempla fictitiae melancholiae vel amentiae non adeo sunt infrequentia ${ }^{73}$.

L'inquisito in questione nel corso dell'interrogatorio aveva descritto in maniera troppo dettagliata le circostanze del reato per non

71 P. Fiorelli, La tortura giudiziaria nel diritto comune, II, Milano, 1954, p. 33. Sull'utilizzo della tortura come mezzo per l'acquisizione della piena confessione del reo si veda G. Rossi, Aspetti medico-legali della tortura giudiziaria nelle Quaestiones di Paolo Zacchia in A. Pastore, G. Rossi (a cura di), Paolo Zacchia. Alle origini della medicina legale 1584-1659, cit., pp. 163-199.

72 Sul concetto e sulle connessioni con il tema degli indizi e della prova legale, anche con l'impiego della tortura quale mezzo processuale inquisitorio ad eruendam veritatem, si vedano le riflessioni di L. Garlati GIUGNI, Il diabolico intreccio. Reo convinto e indizi indubitati nel commento di Bartolomeo da Saliceto (C.4.19.25): alle radici di un problema, in O. Condorell (a cura di), "Panta rei". Studi dedicati a Manlio Bellomo, II, Roma, 2004, pp. 387-419.

73 Georg Friedrich Harpprecht, Decisiones criminales, Tubingae, 1746, [d. CVIII §. 83] p. 957. 
trattarsi di una simulazione. Gli inquirenti avevano sufficienti elementi per ritenere che egli in alcuni momenti si spogliasse della veste del melancholico e che quindi si trattasse di una malinconia fittizia. Sebbene fosse stata sollevata l'eccezione di simulazione si affermò che l'atto derivante da una mente turbata, quale quella melancholica, non poteva dar luogo al supplizio della pubblica tortura ${ }^{74}$ :

solche actus und reden von sich herkommen lassen, worauß eine so starcke turbatio mentis ac judicii zu colligiren seyn will, bey deren die adhibitio torturae nicht wohl platzgreifflich seyn dörffte ${ }^{75}$.

Nonostante il parere dei medici sulla condizione mentale dell'imputato venne espresso in termini troppo generali, senza dubbio la concezione unanime dei cultori del diritto e della scienza della guarigione secondo cui l'affezione melancholica non costituisce un fenomeno monolitico ed uniforme, costituiva un punto di coesione in sede decisionale. Tutti coloro che indagavano sulla melancholia riconoscevano che ad essa non appartiene un solo grado ed una sola consistenza:

Alldieweilen aber gleichwohl (I.) ob angeführtes judicium des Herrn Physici in allzu generaler kürtze verfaßt; Der affectius melancholicus aber, (II.) notorischer machen, an sich nicht uniform aber von einerlen grad und beschaffenheit ist ${ }^{76}$.

74 L'esclusione della tortura nell'ipotesi di sospetta malinconia può considerarsi un aspetto coerente con quel più ampio progresso verso l'umanizzazione che coinvolse il processo criminale protomoderno e di antico regime, poiché risponde ad esigenze di applicazione di una «tortura regolata» e testimonia il tentativo di non infliggere inutilmente al reo una sofferenza maggiore di quella tollerabile. Sul punto si veda G. Rossi, Aspetti medico-legali della tortura giudiziaria, cit., p. 198; Sulla «tortura regolata» come reale elemento di civiltà giuridica e di garantismo introdotto nel processo si vedano le illuminanti riflessioni di M. SBRiccoli, «Tormentum id est torquere mentem». Processo inquisitorio e interrogatorio per tortura nell'Italia comunale, in J.C. Maire Vigueur, A. Paravicini Bagliani (a cura di), La parola all'accusato, Palermo, 1991, pp. 30-32. Nella stessa direzione specificamente per il giurista Egidio Bossi da M.G. DI Renzo Villata, Egidio Bossi. Un grande criminalista milanese quasi dimenticato, in Ius Mediolani. Studi di storia del diritto milanese offerti dagli allievi a Giulio Vismara, Milano, 1996, pp. 438-442.

75 Georg Friedrich Harpprecht, Decisiones criminales, cit., p. 957.

76 Ivi, [§. 95] p. 959. 
Infatti della melancholia vanno tenuti distinti i tre diversi gradi che la caratterizzano e che producono diversi effetti, tanto sul piano psichico quanto su quello giuridico:

Und deßwegen gemeiniglich in 3. gradus distinguit, auch die damit Behaffte, so wohl in puncto tortutae, alß poenae, sehr ungleich tradiert und gehalten zu werden pflegen ${ }^{77}$.

Harpprecht evidenzia come sia un'impresa impervia esprimere un giudizio sull'affezione melancholica, tanto in generale quanto su un caso specifico e distingue la melancholia 'vera e naturale' da quella 'falsa e simulata':

Im gegentheil aber auß denen übrigen actis zu welcherlen grad aigentlich des Inquisiten angebendet affectus melancholicus zu referiren sen? so viel weniger zu determiniren ist, alß alle die jenige actus und reden, welche auß vergleichen affect herzurühren, dem exterieur nach, sich ansehen lassen, an und vor sich selbsten von solch dubios - und weg deutiger beschaffenheit seyn, daß sie wie niemand laugnen wird, sich ebenso wohl, zumahlen bey einem so verschmizten Bößewicht, wie Inquisit ist, ad simulatam ac falsam, alß ad veram ac naturalem melancholiam, referiren lassen ${ }^{78}$.

Nei processi ai melancholici si renderà necessario convocare un Collegio di medici al fine di valutare il grado di gravità della malattia e di comprendere se le azioni criminose in oggetto possano essere imputate a titolo di dolo coadiuvando in tal guisa i giureconsulti e i giudici nelle rispettive funzioni ${ }^{79}$. Quando attraverso la consultazio-

77 Ibidem, [§. 96].

78 Ibidem, [\$. 97].

79 Ibidem, [§. 102]: «Uber das auch ohne vorherige einhohlung eines specialeren Judicii medici (welches, jedoch ohne alle maßgab, am rathsamsten von einer ganzen Medicinischen Fakultät, oder anderem Collegio Medico, observatis observandis requirirt werden könte; [...] sich in dieser so wichtigen, zumahlen ex diversae artis principiis hauptsächlich zu decidieren seyenden, sache, a folis Jureconsultis vel Judicibus nicht wohl ein gewiß und zuverläßiger schluß machen läßt; [...] Unde, Unde, scribit, cum ex domesticis Ictorum principiis haec non promanent, consultum omnino \& hic erit, Collegii medici arbitrium, quoto gradu melancholiae quis laboret, expectare, ex quo \& argumenta doli, qualis ac quantus is sit, depromere, ac quoque de poena (sicque \& de anteambula tortura)». 
ne peritale dei medici si arriva a riconoscere nell'inquisito una condizione di alterazione mentale generata dai sommi gradi della melancholia, gli verrà risparmiata senza dubbio la tortura:

Falls nun solches dahin außfallen sollte, daß selbige, wie jedoch nicht zu vermuthen, den Inquisisten pro melancholico summi gradus zu halten, sattsame gründe anzuführen hätten, so wären alßdann nicht einmahl die von den Herren Ictis G. angerathene zwen gradus torturae mit ihme vorzunemmen, weil, hoc suppolito, er, ob totalem sani judicii defectum, eine rechts-gültige confession oder andere zuverläßige aussage von sich zu geben nullatenus im stand, mithin solcher actus allerdings vanus \& frustraneus seyn würde ${ }^{80}$.

La misura della tortura sarà commisurata al grado della melancholia e al collegio dei medici sarà rimessa anche la valutazione degli eventuali dilucida intervalla ${ }^{81}$. L'indagine dei periti in sede processuale, secondo l'Harpprecht, deve consistere nell'accertamento del grado della malattia, nell'accertamento della veridicità dei signa e nella valutazione della attendibilità delle prove della melancholia così da smascherarne la simulazione ${ }^{82}$. Nel secondo grado della malattia si deve dar luogo ad una pena mitigata rispetto a quella corporale:

Sicut enim melancholici modo memoratorum, ac praeprimis secundi gradus, quaspeciem poenae capitalis, nonnihil moderatius haberi solent ${ }^{83}$.

Nell'Ancien Régime, alcuni fra i giuristi - sulla scia degli orientamenti della medicina legale - non avevano dubbi sul riconoscimento di una condizione di follia parziale ove nel criminale si esclu-

80 Ivi, [§. 105] p. 960.

81 Ivi, [\$. 109] p. 961: «Doch wird hiebey die determinirung deren graduum torturalium gleichermassen nach mehr wohlermeldten Herrn Physici oder eines andern wohl erfahrnen Medici auch hierüber einziehendem guthachten zu reguliren; argum. eorum, quae de talibus intervallis dilucidis, cen utplurimum fallacibus ac dubiis, follicite monet Dn. Alberti».

82 Ibidem, [§. 111].

83 Ibidem, [§. 112]. 
desse oppure si scorgesse un delirio esclusivamente su uno o più oggetti specifici.

Ci si riferisce in primo luogo alla descrizione che Paolo Zacchia propone dei disturbi mentali che interessano in maniera esclusiva una specifica tematica che ha portato il più grande storiografo della psichiatria del XX secolo, Henri Frédéric Ellenberger ad individuare nelle Quaestiones medico-legales del medico romano un «nuovo sistema di diagnostica psichiatrica» ${ }^{84}$.

8. Indeterminismo e assenza di libero arbitrio nei reati dei malinconici

Intorno al dibattito storico-giuridico sulla follia malinconica aleggiava quello sul libero arbitrio, sulla capacità dell'uomo di determinarsi verso il bene o verso il male. La dottrina predestinataria, a partire da Martin Lutero (1483-1546), fortemente sostenitrice dell'assenza del libero arbitrio offre l'immagine di una creatura indebolita nell'intelletto e corrotta nella volontà a causa del peccato, versata irrimediabilmente al male ${ }^{85}$. Tra le pieghe del ragionamento si nascondeva una questione propria del penale sostanziale, se si potesse considerare libero l'arbitrio di chi compiva un reato con l'animo affetto da malinconia; di chi percepiva una realtà falsata fondata su falsi giudizi e di chi, proprio in forza di essi, dava un peso diverso alle circostanze fattuali che ruotavano intorno al reato.

Al problema della libertà del volere Baruch Spinoza (16321677) aveva dedicato due capitoli, già nella Korte Verhandeling, opera di datazione incerta che si fa risalire al 1660, mostrando che la volontà altro non è che il prodotto delle proprie idee e dei propri appetiti. Ma una vera e propria critica alle teorie del libero arbitrio si ritrova nell'Ethica more geometrico demonstrata, pubblicata nel

84 Cfr. H.F. Ellenberger, Psichiatry from Ancient to Modern Time (1974), [trad. it.], in I movimenti di liberazione mitica e altri saggi di storia della psichiatria, Napoli, 1986, p. 62.

85 D. Martin Luthers, Werke. Kritische Gesamtausgabe. Die Deutsche, VII, Weimar, 1906-1961, p. 10. 
$1677^{86}$, in cui la libera volontà cartesiana appare come un'illusione ${ }^{87}$. Ancor di più nella malinconia non può esservi autonomia della volontà in quanto le volizioni - da intendersi come giudizi - non possono considerarsi slegate dai falsi giudizi che la malattia genera. Tale malattia colpirebbe proprio quello che Spinoza definisce il principio fondamentale della vita razionale e propriamente umana, la libertà del volere, a cui sono connesse la responsabilità e la imputabilità delle deliberazioni e delle azioni. Nell'espressione «libertà del volere» si concentra la intrinseca moralità delle azioni umane, essa costituisce il fondamento che sorregge tutti i doveri, tanto propri e personali, quanto consorzievoli e comuni.

Contro ogni ipotesi indeterministica Pierre Bayle (1647-1706) fa valere l'invincibilità delle pulsioni interiori dalle quali l'animo umano è sempre trascinato. E in polemica con la dottrina razionalistica che intende risolvere il problema del male con il libero arbitrio ${ }^{88}$, Bayle mostra l'esistenza di una vera e propria determinazione necessaria dell'uomo al male. L'unico argomento valido in favore del libero arbitrio sembra essere quello della responsabilità morale. Ma nella malinconia medici-legali e giuristi, erano concordi nel considerare le sfere interiori della morale e della volontà in qualche modo corrotte. Da qui l'impossibilità di considerare tali soggetti moralmente e penalmente responsabili delle proprie azioni.

Alla luce di quanto precedentemente argomentato, la misurazione della gravità della malinconia nel criminale attraverso la sua graduazione doveva servire ai pratici del diritto per la ricostruzione del nesso di causalità della malattia con il crimine. In un certo senso riconoscere la malinconia equivaleva ad attribuire al crimine una

86 Baruch Spinoza, Epistolario, a cura di A. Droetto, Torino, 1974, pp. $247-$ 251; ID., Etica, in Etica. Trattato teologico-politico, trad. it. di R. Cantoni e F. Fergnani, Torino, 1972, pp. 297-298, 299-303.

87 René Descartes, Meditazioni metafisiche, in Opere, a cura di M. e E. Garin, I, Bari, 1967, pp. 235-238; ID., Risposte alle Quinte Obiezioni, in Opere, cit., I, pp. 540-542; ID., Correspondence, a cura di C. Adam e P. Tannery, in Euvres, rist. anast., a cura di B. Rochot, P. Costabel, J. Beaude e A. Gabbey, IV, Paris, 19641974, pp. 115-117; ID., Principi della filosofia, in Opere, cit., II, p. 44; ID., Le passioni dell'anima, in Opere, cit., II, pp. 488-489.

88 Pierre Bayle, Réponse aux Quéstions d'un Provincial, in Euvres diverses, III, La Haye, 1723-1731, pp. 781-782. 
causa. La malinconia potrebbe essere la causa del reato ove questa non emerga con evidenza ma nella misura in cui essa riesca, per effetto dei giudizi falsati che tale condizione offre, a rendere schiava la volontà del malinconico.

\section{La imputabilità dei criminali malinconici}

La storia giuridica della melancholia, così come la storia della malattia mentale in generale, è in realtà la storia dell'imputabilità delle azioni criminose ad essa connesse; della presenza o meno del libero arbitrio nel compierle; ma la vicenda delle sue concrete applicazioni ed implicazioni la fa anche rientrare nella più vasta storia delle idee. Essa in ogni tempo si pone al pensiero umano in una luce che non è soltanto medica, né giuridica né soltanto storico-antropologica ${ }^{89}$. Oltre ai numerosi problemi di pratica giudiziaria che naturalmente scaturiscono dalla legale applicazione di misure punitive particolari, si pongono questioni teoriche di grande rilevanza: su quali principi si fonda l'applicazione di misure punitive straordinarie? Rispondono queste alla esigenza di giustizia che si sentono connaturate al procedimento penale? Per sua stessa natura il ragionamento dei giuristi è permeato dal dubbio che invade ogni processo di comprensione che non può mai considerarsi definitivamente risolutivo ${ }^{90}$.

A fondamento della questione vi era quello che la scienza del diritto chiama reato sine animo, in particolare in riferimento all'omicidio $^{91}$, cercando di ancorare la responsabilità alla corrisponden-

89 La scienza giuridica è percorsa da questi meccanismi di ricerca della verità astratta dalle implicazioni logiche del conflitto di prospettive che sostanzia la costruzione dell'esperienza giuridica medievale e moderna. Sul punto cfr. A. Giuliani, La controversia. Contributo alla logica giuridica, in Studi nelle scienze giuridiche e sociali, 143, Pavia, 1966, p. 136.

90 La struttura identitaria del modello giuridico è percorsa incessantemente dall'esigenza logica di chiarificazione dei problemi che si realizza attraverso la divisione, il frazionamento delle questioni.

91 Le opere della dottrina tedesca sono state fondamentali per gli studi sulla responsabilità penale e sui gradi di colpevolezza: A. LöFfLER, Die Schuldformen des Strafrechts in vergleichend-historischer und dogmatischer Darstellung, Leipzig, 
za tra il voluto e il realizzato e di conseguenza limitare l'inflizione della pena sanguinis. Si tratta di considerazioni che ruotano intorno alla forma embrionale della responsabilità in senso soggettivo, che mirano ad individuare il coefficiente minimo di una certa connotazione psicologica sufficiente a costituire quel rapporto di causalità psichica che costituisce l'elemento necessario del giudizio di colpevolezza. Bisogna tener presente, per una corretta ricostruzione storico-giuridica della responsabilità in criminalibus, che si tratta di considerazioni che restano sempre a un'idea di colpevolezza che non separa nettamente le infrazioni criminali dai fatti morali e che non discerne ancora le condizioni di una responsabilità soggettiva in campo penale ${ }^{92}$.

Nel XVII secolo il nucleo centrale del dibattito incipiente tra i giuristi sulla melancholia concerneva, soprattutto, il trattamento punitivo da riservare alle azioni criminose da essa provenienti. La questione giuridica della follia parziale, nei casi - non troppo frequenti - in cui veniva trattata, divideva i cultori del diritto fra chi invocava la esclusione dalla pena e chi ne suggeriva la mitigazione. Le

1895; W. Engelmann, Die Schuldlehre det Postglossatoren und ihre Fortentwickelung. Eine historisch-dogmatische Darstellung der kriminellen Schuldlehre der italienischen Juristen des Mittelalters seit Accursius 2., verbesserte Auflage, Leipzig, 1895; rist. anast. 1965; F. SCHAFFSTEIN, Die Allgemeinen Lehren vorn Verhrechen in ihrer Entwicklung durch die 'Wissenschaft des Gemeinen Strafrechts, Berlin, 1930; G. DAHM, Das Strafrecht Italiens im ausgehenden Mittelalter. Untersuchungen über die Beziehungen zwischen Theorie und Praxis im Strafrecht des Spätmittelalters, namentlich im XIV. Jahrhundert, Berlin-Leipzig, 1931, rist. anast. 2014. Per un panorama completo sull'elemento soggettivo del reato si veda G.P. DEmuro, Il Dolo. Svolgimento storico del concetto, I, Milano, 2007; In particolare sulla storia giuridica del reato di omicidio e sulla dialettica tra volontario e involontario e il versari in re illicita si veda ampiamente R. SoRICE, Vittime colpevoli e colpevoli innocenti. Ricerche sulle responsabilità penali nell'età del diritto comune, Bologna, 2019.

92 Sull'argomento si rinvia al fondamentale volume S. KuTtner, Kanonistische Schuldlehre von Gratian bis auf die Dekretalen Gregors IX. Systematisch auf Grund der handschriftlichen Quellen dargestellt, Città del Vaticano, 1935, p. 69. Sulle profonde implicazioni che il tema della responsabilità penale ha con la filosofia e l'etica di una società cfr. J. GAUDEMET, Le problème de la responsabilité pénale dans l'antiquité, in J. LéAuté (a cura di), La responsabilité pénale. Travaux du Colloque de philosophie pénale, Paris, 1961, pp. 25-26. In riferimento alle tappe che segnano il progressivo allontanamento tra 'fori' e le relative ragioni cfr. P. Prodi, Una storia della giustizia: dal pluralismo dei fori al moderno dualismo tra coscienza e diritto, Bologna, 2000, p. 32 ss. e letteratura ivi citata. 
teorie che guardano all'esclusione della responsabilità entro i confini tracciati dalla causa ${ }^{93}$ rappresentano un ulteriore punto di partenza e delineano altri tragitti interpretativi che guardano con occhi diversi al problema della volontà nel reato, che ha fatto da traghetto a molte costruzioni scientifiche ottocentesche.

Una questione così oscura e delicata, che solo nei primi anni del Seicento iniziava a guadagnarsi un posto nel dibattito giuridico, doveva essere trattata, come suggeriva Zacchia, con un atteggiamento guardingo. D’altronde egli comprendeva i limiti delle classificazioni definitorie che rendevano le infermità realtà monolitiche negando la loro natura di condizioni in perpetuo divenire. Egli metteva in guardia i suoi lettori dal pericolo, non remoto, che la malattia superasse gli argini nosografici che la rigida classificazione medica poteva attribuirgli:

Et ratio est, quia licet de facto melancholicus circa unum quid peculiariter deliret, tamen de momento in momento circa ea ipsa, de quibus ad praesens prudenter se gerit, paratus est insanire, qui mentem sanam non habet, ita ut horum prudentiae minime fidendum sit, cum eorum spiritus intellectioni inservientes a naturali statu iam desciverint et in perpetuo motu et perturbatione sint, ex quo facillime evenit, ut id ipsum, quod modo menti offertur prout vere est, paulo post sub falsa imaginatione raepresentetur, et prout non est: causa autem cur non nisi circa unum quid delirare videantur, ea est, quia interna imaginatio, et assidua praesentatio falsi illius phantasmatis ipsi intellectui indefinenter $\mathrm{sit}^{94}$.

93 La prospettiva della causa posta dai giuristi a fondamento di gran parte delle ragioni giuridiche che sostengono aspetti del penale si intreccia su questi temi con il concetto di causa morale ed entrando a far parte di passaggi fondanti del penale sostanziale sposta la visuale verso la costruzione di nuovi principia delictorum. Sul concetto di non punibilità che è definito nella riflessione di Palazzo come «l'effetto finale comune sia delle cause di esclusione della tipicità-antigiuridicitàcolpevolezza, sia delle cause di non punibilità in senso lato» e sulle ragioni sostanziali per cui l'ordinamento giunge all'esito della non punibilità si veda F. PALAzzo, Il fatto di reato, Torino, 2014, p. 11; inoltre G. VASSALLI, Cause di non punibilità, in Enciclopedia del Diritto, 6, Milano, 1960, p. 609 ss.

94 Paolo Zacchia, Quaestiones medico-legales, II, cit., [q. IX, §. 21] pp. 105106. 
L'atteggiamento dello Zacchia sulle questioni della colpevolezza e della imputabilità penale dei melancholici - sempre ove la malattia mentale presentasse un nesso eziologico con l'azione criminosa - appare senza dubbio di diffidenza. Superata la fase dell'accertamento dell'infermità, il momento topico ove si focalizzava l'esperienza del diritto risiedeva nel suo trattamento giuridico. Nella sua prospettiva di pensiero, tale categoria di pazzi, al pari di tutte le altre, doveva essere esclusa per legge da tutte le attività nelle quali il diritto richiedeva una psiche integra. La misura interdittiva invocata dallo Zacchia, che veniva generalizzata all'intera capacità di agire in ambito giuridico, trovava fondamento nel timore che il delirio dapprima circoscritto potesse, nel tempo, estendersi all'intero intelletto $^{95}$.

Con una diagnosi impetuosa sull'imputazione morale ${ }^{96}$ delle azioni provenienti dalla melancholia, il Wolff argomentava la distinzione tra errore vincibile ed errore invincibile. L'azione criminosa sarebbe rimasta non imputabile solo se l'errore da cui fosse scaturita non potesse essere vinto da alcuna forza di resistenza del suo auto$\mathrm{re}^{97}$. Il concetto di errore (o forza) invincibile, enunciato dal giusnaturalista tedesco, appare strettamente connesso all'intelletto e alla volontà. All'intelletto nella misura in cui l'errore fosse individuabile con le ordinarie facoltà cognitive di cui dispone un individuo sano di mente; e alla volontà nella misura in cui l'errore possa dileguarsi con la messa in opera dei mezzi in potere del soggetto. Ove fossero mancate le facoltà di comprendere ed aggirare l'errore, il melancolico sarebbe stato scusato in quanto inimputabile.

Più avanti nel discorso, come se si trattasse di argomentazioni poste col valore di premesse, il Wolff giungeva ad affermare con tono perentorio che le azioni dei melancholici non si sarebbero dovute porre a fondamento di alcuna imputazione penale, né di dolo né di

95 Ibidem.

96 La dimensione volontaristica appare in questa prospettiva fortemente connessa alla responsabilità morale delle proprie azioni che si misura in relazione alla forza interiore del soggetto di ostacolare la volontà criminogena e che determinerebbe un giudizio di non colpevolezza proprio per il fatto che nel criminale melancolico la forza morale risulta corrotta.

97 Christian Wolff, Philosophia Practica Universalis, cit., [§. 552] p. 410. 
colpa ${ }^{98}$, proprio per l'incapacità del malinconico di comprendere il peso morale delle proprie azioni, di scindere le idee vicine alla realtà da quelle oggetto del proprio delirio interiore:

Etenim in melancholia depravari ratiocinationem in confesso est apud omnes, ut ideo pro specie delirii habeatur. [...] actiones suas imputari non posse iis, qui melancholia laborant, quae scilicet ex melancholia proficiscuntur ${ }^{99}$.

Mentre il Wolff rendeva il criminale malinconico esente da qualsiasi pena il Carpzov, sebbene riconosceva nei melancholici una condizione di aberrazione parziale della mente, affermava «quod licet reus ob delictum ex melancholia commissum, impunitus nequam remanere debeat, poena tamen ordinaria ipsi propterea remitti, aliaque mitior tuto irrogari queat» ${ }^{100}$, scegliendo così la strada della mitigazione. Nelle pagine dedicate alla melancolia, egli ne offre una delle più complete trattazioni. Questi enunciava difatti diversi principia da seguire allorquando a causa della melancholia alcuno si fosse macchiato di delitto. La premessa fondamentale da cui dovevano partire in tali ipotesi criminose i pratici del diritto era che, mai impunito il reato, la pena dovesse essere mitigata. La puntuale argomentazione del Carpzov si fondava sulla natura particolare di tale specie di follia, sulla diversa concezione di essa rispetto al furor che doveva condurre all'applicazione di regole giuridiche diverse - «quare quod regula praecedenti de furiosis dictum, istud ad melancholicos haud extendendum est: neque hi aeque ac illi ab omni poena immunes esse debent» ${ }^{101}$. Il furor, in quanto mania generalizzata, avrebbe dovuto condurre il criminale alla totale esenzione dalla pena mentre la melancholia, in quanto mania parziale, lo avrebbe condotto soltanto ad una sua mitigazione.

98 Sulla emersione del concetto di colpa penale estranea al diritto giustinianeo e che fu questione che interessò i doctores medievali si veda G.I. LuzzATTO, Colpa penale (diritto romano), in Enciclopedia del diritto, VII, Roma, 1960, pp. 614 e ss.; A tal proposito si veda in particolare R. SORICE, Vittime colpevoli e colpevoli innocenti, cit., p. 109 e ss.

99 Christian Wolff, Philosophia Practica Universalis, cit., p. 422.

100 Benedikt Carpzov, Practicae novae, III, cit., [q. CXLV] p. 325.

101 Ibidem. 
Gli incerti signa della melancholia, il rilievo probatorio ${ }^{102} \mathrm{di}$ questi e il giudizio dei medici nella graduazione dello stato morboso della mente ${ }^{103}$ emergono in superficie come le questioni che, a giusto titolo, risultano più difficoltose e severe nell'indagine giuridica volta a individuare la natura più intima dell'infermità psichica parziale. I rei melancholici, ribadiva il Carpzov, restano penalmente imputabili per dolo in quanto in possesso delle facoltà intellettive necessarie per dirigere le loro azioni, ciononostante si riconosce nella loro condizione mentale una lesione della capacità immaginativa. La conservazione dell'intelletto impedisce la rimozione completa della pena, ma la distorsione nella sfera immaginativa del reo ne giustifica la mitigazione ${ }^{104}$.

In sede di accertamento peritale della condizione mentale del criminale l'indagine deve concernere primariamente il grado della melancolia, da cui far scaturire l'entità dell'accusa. Se perfino i dementi o coloro che sono integralmente pazzi per il delitto commesso andrebbero trattenuti e costretti alla pena, ancor di più tale principio andrà confermato per quanto concerne i melancholici. Tuttavia,

102 Il dibattito sul valore probatorio dei signa della follia della volontà mette in luce quanto elastica fosse la concezione del sistema di prova legale anche in riferimento all'apprezzamento del giudice, elasticità messa in crisi e frenata dalla criminalistica moderna propensa a giustificare di fatto un largo uso della discrezionalità del giudice compresso però dalla individuazione in termini rigidi e quantificati dei criteri probatori attraverso anche una graduazione della malattia. Sull'argomento si rinvia estesamente a A. GiUliani, Il concetto di prova. Contributo alla logica giuridica, Milano, 1961, in particolare pp. 160 e ss.

103 Per un approfondimento sulla posizione del medico in tribunale e sul valore processuale della perizia medica nell'Ancien Régime si veda A. PASTORE, Il medico in tribunale, cit.; M. AsCHERI, «Consilium sapientis» perizia medica e «res iudicata»: diritto dei «dottori» e istituzioni comunali, in S. KutTner, K. Pennington (eds), Proceedings of the Fifth International Congress of Medieval Law, Salamanca, 21-25 September 1970, Città del Vaticano, 1980, pp. 533-579; M. BOARI, Qui venit contra iura. Il furiosus nella criminalistica dei secoli XV e XVI, cit.; C. CRAWFord, Legalizing medicine: early modern legal systems and the growth of medico-legal knowledge, in M. Clark, C. CRAWFORD (a cura di), Legal medicine in history, Cambridge, 1984, pp. 89-117; A. PASTORE, Maladies vraies et maladies simulées. Les opinions des juristes et des médecins (XVI e XVII siècles), in Equinoxe. Revue de sciences humaines, XXII, 1999, pp. 11-26; S. DE RENZI, La natura in tribunale. Conoscenze e pratiche medico-legali a Roma nel XVII secolo, in Quaderni storici, XXXVI, 2001, pp. 709-822.

104 Benedikt Carpzov, Practicae novae, III, cit., [q. CXLV] p. 325. 
va loro prestato soccorso: il supplizio ordinario previsto per il delitto dovrà essere mitigato e sostituito da una pena più tenue, previa valutazione da parte del giudice della specificità del fatto, della tipologia della melancholia e della perturbazione mentale, nonché della disposizione d'animo del reo.

L’impostazione del Carpzov si colloca, più genericamente, in una restrittiva e diffidente concezione giuridica della malattia mentale, strumento talvolta utilizzato per dissimulare una volontà piena e cosciente di delinquere, il che rendeva l'azione processuale estremamente difficoltosa.

Non sulla questione morale dell'imputabilità delle azioni bensì sulla graduazione della malattia si fonda la esclusione dalla pena nel discorso sulla melancholia del giurista Samuel Stryk. Egli invita i pratici del diritto a procedere sul piano probatorio come nei casi di demenza quando si tratti di quel grado di melancholia, il cui confine con la dementia diventa estremamente sottile:

Idem probandi modus, qui in dementiae probatione observandus, in melancholia probanda obtinet, ideoque caeteris paribus, juste huc spectabunt, praeprimis quod melancholia primaria in dementiam degeneret, ac eo quaecunque superius de dementia prolata, eidem omni iure competant ${ }^{105}$.

A tal proposito lo Stryk coglie l'occasione per proporre una classificazione dei melancholici fondata su tre diversi gradi della loro condizione mentale ${ }^{106}$. I tre gradi della melancholia scandiscono su una linea di avanzamento nosografico - la diversa gravezza della condizione psichica che da semplice temperamento umorale può divenire infermità della mente. Di tale graduazione aveva fatto cenno con tono lapidario anche il Carpzov ma con finalità diverse. La condizione melancholica, nella sua triplice articolazione, poteva dal giudice essere sottoposta ad un solerte esame entro i termini dell'equità fino a convincerlo di mitigare leggermente la pena, mai di que-

105 Samuel Stryk, Disputatio Iuridica Solennis de Dementia et Melancholia, cit., [c. V, §. 1] p. 25.

106 Ivi, p. 19. 
sta avrebbe potuto giustificarne l'esclusione ${ }^{107}$ soprattutto nell'ipotesi di crimini enormi ${ }^{108}$.

Seguendo le orme dello Stryk, anche il giurista Cristoforo Andrea Remer seguirà la tripartizione della melancholia ${ }^{109}$, a cui assegna non solo un valore empirico-descrittivo bensì anche un valore sistematico-sostanziale che si riflette nelle vicende del processo. Al primo grado appartengono i melancholici per temperamento umorale ai quali verrà riservato un trattamento penale ordinario. Nel suo primo grado la melancholia non è considerata malattia e pertanto non esclude la capacità giuridica sul piano civile, né fornisce alcun beneficio sul piano penale ${ }^{110}$.

Nel suo secondo grado, invece, la melancholia viene considerata possessione diabolica. Questi sono i melancholici che subiscono influenza satanica e su istigazione del maligno sono spinti a nuocere sé stessi e gli altri ${ }^{111}$. Da un punto di vista medico, questo grado della melancholia si genera ogni volta che la bile nera si riversa in qualche modo fuori dalla milza - organo emocateretico - con grande veemenza, e conduce l'uomo ad una tristezza di origine diabolica. Tuttavia, secondo lo Stryk non avviene nessuna lesione alla razionalità. Si può riscontrare in questi melancolici una mente retta ed incorrotta in ogni affare giuridico, ma lasciati a sé stessi cadono in una condizione di profonda disperazione cosicché la loro immaginazio-

107 Benedikt Carpzov, Practicae novae, III, cit., [q. CXLV] p. 325.

108 Sulle limitazioni al diritto di difesa dell'imputato nel rito inquisitorio quale pratica eversiva messa in opera dai giudici muniti di arbitrium si vedano le riflessioni di G. CHIodi, Crimini enormi e tortura ex processu informativo: una violazione del diritto di difesa dell'imputato?, in Glossae. European Journal of Legal History, 13, 2016, pp. 71-107.

109 Christoph Andreas Remer, Disputatio iuridica inauguralis de Imputatione Actionum ex Melancholia Provenientium, Traiecti ad Rhenum, 1710, [c. I, §. XVIII] p. 12: «Melancholiae morbo laborantes in tres hac fiducia collocavit classes a Stryck [...] Ut adhibita hac distinctione, diversas theologorum, iure consultorum, et medicorum (circa hanc materiam sententias conciliare velit. Primae classi annumeravit, praeter modum timidos, cupidos, avaros, in quibus nunquam tristitia ab est, quae ex intolerabilibus doloribus originem traxit».

110 Samuel Stryk, Disputatio Iuridica Solennis de Dementia et Melancholia, cit., [c. V, §. 3] p. 26.

111 Ivi, p. 23; Si veda anche Christoph Andreas Remer, Disputatio iuridica inauguralis de Imputatione Actionum ex Melancholia Provenientium, cit., [c. I, §. $\mathrm{XX}]$ p. 13. 
ne soffre l'influenza di una forza imprecisata. A questi soggetti viene concessa pertanto la piena capacità di agire. Riprendendo l'idea dello Zacchia ${ }^{112}$, Stryk nega però ai melancholici di secondo grado il diritto di testare, mentre sul piano penale suggerisce di tener conto delle suggestioni demoniache in chiave aggravante. La loro volontà sotto l'influenza del demonio è costantemente tentata di commettere crimini. In questa prospettiva appare chiaro al giurista tedesco che la grande perturbazione dello spirito generata dal maligno con facilità conduce la mente dei malcapitati all'errore ma ciò non vale a giustificarli, anzi costituisce una colpa più grave. Pertanto, egli conclude che, se sorpresi in un crimine commesso per seduzione diabolica, si commini loro una pena più severa ${ }^{113}$. L'istigazione satanica, ove ve ne sia la prova plena ${ }^{114}$, costituisce dunque nella trattazione del giurista d'oltralpe una circostanza aggravante della pena che si concretizza in un severo supplizio. In caso contrario si deciderà per la relegatio vel mitior poena ${ }^{115}$. In presenza di semplici indizi, invece, la pena doveva essere mitigata e normalmente convertita nella relegazione al confino.

$\mathrm{Al}$ terzo ed ultimo grado, la melancholia diventa malattia della mente ${ }^{116}$.

112 Paolo Zacchia, Quaestiones medico-legales, II, cit., [t. I, q. IX, §. 23-24] p. 106: «His non obstantibus dubitari adhuc posset, an ad testamentum conficiendum, ad testimonium dicendum, ad matrimonium contrahendum admitti possint: et quoad matrimonium fortasse incassum dubitatur, quia manifestum est sufficere in iis prudentiam ad hoc; et favere potest etiam, quod tales ex matrimonii consuetudine interdum melioris mentis fiunt, et aliquando etiam in totum sanantur».

113 Samuel Stryk, Disputatio Iuridica Solennis de Dementia et Melancholia, cit., [c. V, §. 3] p. 26.

114 Una prova non è veramente tale se non è piena e quindi immune da ogni dimostrazione del contrario. È vero però che nel concetto di prova piena si facevano rientrare tutte le prove sufficienti a un giudizio definitivo, anche se lontane da quella pienezza che era propria, a rigore, del solo notorio. Cfr. P. Fiorelli, La tortura giudiziaria nel diritto comune, II, Milano, 1954, p. 49; In generale, sul sistema probatorio nell'Ancien Régime si veda J.P. Lévy, La hiérarchie des preuves dans le droit savant du moyen-age, Paris, 1939.

115 Samuel Stryk, Disputatio Iuridica Solennis de Dementia et Melancholia, cit., [c. V, §. 3] p. 26.

116 I melancholici di terzo grado vengono equiparati ai dementi nella classificazione tripartita della malattia melancholica dello Stryk, concezione che sarà ripresa fedelmente da Cristoph Andreas Remer, Disputatio iuridica inauguralis de Imputatione Actionum ex Melancholia Provenientium, cit., [c. I, §. XXI] p. 13: 
Scrive Stryk:

Nam qui se gallum, lupum et mortuum fingit, in tantum abest, ut rationis compos sit, ut potius contrarium unicuique nullo explicante innotescat ${ }^{117}$.

Nessuno potrà negare la sussistenza di una condizione di follia, sia pur parziale, in chi crede di essere un gallo, un lupo o in chi si persuade di essere cadavere. Questi melancholici vengono assimilati ai dementi perché non conservano integra la loro mente sotto al profilo in cui delirano e - al pari di quelli - viene concessa loro la esclusione della pena. La complessa articolazione proposta dallo Stryk rende chiara la difficoltà che la cultura giuridica incontrava nel riconoscimento e nella definizione della infermità parziale di mente, questione ancora troppo oscura per il sapere giuridico così come per il sapere medico.

Al contrario, a sostegno della tesi secondo cui la melancholia non incide neppure parzialmente sull'intelletto, si schiera - come abbiamo rilevato in precedenza - il Carpzov, il quale considera intatte la sfera intellettiva, coscienziale e volitiva del reo. La conservazione dell'intelletto, nella prospettiva carpzoviana, è tale da rendere inopportune la misericordia del sistema penale ogniqualvolta si indulga nei confronti degli autori di crimini commessi per melancholia. Tuttavia non bisogna far ricorso nemmeno al criterio diametralmente opposto, vale a dire ad un aggravamento della pena ${ }^{118}$. A tal fine, la prima preoccupazione dei giudici deve essere rivolta a vagliare l'effettiva esistenza di tale condizione della mente e dello spirito, per poter poi, più fecondamente, applicare la legge penale. Tale preoccupazione non può che risolversi attraverso un riscontro probato-

«Tertius melancholiae gradus ex Strych. d.1. §.11. est, si atrabilis cerebrum occupaverit, quae omnem facultatem rationale abstulerit, et in ejus locum impetum non raro protulerit. Quia autem hic è melancholicorum numero eximendus, et ex relatione Stryckii dementibus, sive furiosis, sive mentecaptis pro diversitate paroxismi, eo tempore, quo intervalla non habet, annumerandus. Hunc morbum inter melancholiae gradus minus accuratè retulit autor».

117 Samuel Stryk, Disputatio Iuridica Solennis de Dementia et Melancholia, cit., [c. V, §. 7] p. 28.

118 Benedikt Carpzov, Practicae novae, III, cit., [q. CXLV] p. 325. 
rio ottenuto con mezzi di prova idonei a mostrare lo stato di corruzione delle facoltà percettive del criminale, procedendo con cautela in un terreno pullulante di incertezze.

Nella dinamica processuale il problema di distinguere la vera melancolia da quella simulata assumeva un'importanza decisiva, tanto che Michael Alberti suggerì di indagare sui signa que melancoliam antecedunt da quelli quae melancholiam comitantur ${ }^{119}$. I giudici e i periti al fine di individuare la presenza nel criminale di tale malattia occulta dovevano indagarne le cause e i sintomi. L'eziopatogenesi doveva essere incentrata dapprima sugli eventuali segni distintivi che precedevano la melancholia e fra questi: la «dispositio haereditaria» in grado di svelare una matrice ereditario-genetica della patologia; le «passiones animae» intese come stati passionali di entità traumatica; l'«ingens et diuturna tristitia» diversa dalla tristezza come sentimento naturale per entità e durata; l'«improvisus metus» e l'«ingens et immodica et improvisa laetitia» indici rivelatori di malattia per la loro natura improvvisa ed immotivata. In un secondo momento, periti e giudici dovevano spostare l'attenzione sui segni rivelatori che accompagnavano la malattia, guardando: «ad actus extrinsecos» ovvero ad azioni e circostanze esterne; «ad animi passiones» per comprendere se lo stato passionale in cui versava il criminale poteva risultare motivato o meno e l'eventuale assenza di motivazione rivelava la presenza dell'infermità; «ad verba seu sermonem» in grado di svelare pensieri deviati; «ad habitum corporis» in cui rinvenire eventuali bizzarrie frutto di una mente alienata; «ad temperamentum» per comprendere in quale misura esso aveva inciso sull'agire criminale del soggetto ${ }^{120}$.

Nella sua Practica criminalis il Carpzov si dilunga a criticare sul piano etico la condotta degli avvocati, i quali solevano istruire, comunemente, le cause in maniera talmente artificiosa da invocare la melancolia al fine di permettere ai propri assistiti di sfuggire alla pena capitale. In casi simili, gli appare opportuna la presenza di un arbitro che coadiuvi il medico nell'accertamento della infermità par-

119 Michael Alberti, Gottfried Lebrecht Graebner, Melancholia vera et simulata, cit., [c. XXII] p. 18.

120 Ibidem. 
ziale di mente, per mezzo del quale riuscire a discernere se la prova della malattia sia sufficiente ovvero ci si trovi in presenza di un espediente o di una melancolia simulata, come anche nei crimini commessi per causa lievissima o senza causa. Quest'ultima è l'ipotesi di chi commetta un crimine per mera malvagità: quale che sia l'utilità di una consultazione medica, di un simile caso dovrebbe disputare un collegio di giureconsulti ${ }^{121}$.

Come vedremo, lo snodo concettuale dell'assenza di causa nel crimine verrà assumendo un ruolo assolutamente centrale nel dibattito sette-ottocentesco sulla infermità parziale di mente.

Di qualunque specie siano i malinconici, i loro crimini non possono restare impuniti giacché commessi con dolo e per impulso malvagio. Anche a detta di Peter Heige, nonostante la profonda mestitia perturbi i loro animi, la conservazione delle facoltà razionali fa presumere che delinquano volontariamente e per pura malvagità ${ }^{122}$. Certo non è sempre immediatamente determinabile la linea di demarcazione fra la piena imputabilità e la imputabilità 'ridotta' del melancolico. Il problema giuridico consiste anche nella prospettiva da cui si osserva la condizione psichica in cui versa il criminale. Può un atto atroce commesso senza motivi apparenti, senza un interesse apparentemente rilevante, essere qualificato un atto di follia, sia pure parziale? L'interesse rilevante, il motivo criminale, la passione ragionevole: sembrano questi i fattori in presenza dei quali l'azione delittuosa si inquadra nell'universo penale. Al di fuori di questo orizzonte c'è l'abisso insondabile della follia, dell'omicidio senza causa, del delitto compiuto senza scopo apparente e senza motivi visibili.

Misconoscere l'infermità nel crimine senza causa conduce ad una grave imputazione: per dolo e per pura malvagità. Il punto nodale concerne proprio la valutazione della rilevanza penale delle motivazioni che hanno condotto il criminale a protendere verso il reato. Certamente cambia l'angolazione da cui si osserva il fenomeno criminoso se la motivazione, che all'esterno sembra mancare, risiede all'interno del soggetto e consiste in un'infermità parziale di mente. Sono evidenti gli effetti penali antitetici a cui può condurre l'una o

121 Benedikt Carpzov, Practicae novae, III, cit., [q. CXLV] p. 325.

122 Peter Heige, Quaestionum Iuris, cit., [q. XXXVIII] p. 330. 
l'altra scelta giuridica, che diventa anche scelta di politica criminale. Infatti, sul piano del trattamento penale da una parte la etichetta giuridica della follia, sia pure parziale, posta sul crimine dovrebbe condurre ad una attenuazione punitiva; dall'altra l'assenza di una causa apparente nel crimine commesso per pura malvagità dovrebbe condurre ad un inasprimento della pena.

Forse ciò che appariva ostico da assimilare per i giuristi, che non avevano esperienza in materia di follia lucida e ragionante, è questa zona grigia che irrompe nella consolidata dicotomia fra l'azione delittuosa tipica, connotata dalla felice trasparenza dei moventi e delle finalità, e il crimine compiuto dal folle. In quella zona di confine si cela un luogo ancora più oscuro e insondabile che è quello del criminale parzialmente folle di fronte al quale gli strumenti della comprensione giuridica rivelano i loro limiti e la loro impotenza. Il collegamento fra il malinconico criminale che commette il reato per corruzione della volontà e il criminale che commette un omicidio senza causa venne assorbito nell'impalcatura della giustizia punitiva solo nell'alba dell'Ottocento quando il concetto di volontà corrotta viene accolto dalla scienza giuridica. Si trattava di due prospettive diverse da cui guardare il regime di responsabilità dell'agente ${ }^{123}$.

Nei primissimi anni dell'Ottocento l'omicidio commesso dal cri-

123 L'indagine sull'animus e la voluntas nei reati aveva, sin dall'epoca bassomedievale, condotto la dottrina a tessere teorie infinite, minuziosamente elaborate. I doctores avevano lavorato su più fronti costruendo pensieri sulla personalità e la volontarietà della responsabilità in maleficiis anche sui delicta sine animo. In generale come essenziali punti di partenza su tali temi si guardi T. GATт, L'imputabilità, i moventi del reato e la prevenzione criminale negli statuti italiani dei sec. XII-XVI, Padova, 1993; A. Marongiu, Colpa penale (dir. intermedio), in Enciclopedia del Diritto, 13, Milano, 1964, pp. 731-738; I. MEREU, Nullum crimen sine culpa, semantica della colpevolezza nella dogmatica penale del '500, Bologna, 1970; G. DiURNI, Omicidio (dir. intermedio), in Enciclopedia del Diritto, 29, Milano, 1979, p. 910 e ss; F. Cordero, 'Criminalia'. Nascita dei sistemi penali, Roma-Bari, 1986; M. LucCHESI, Si quis occidit occidetur. L'omicidio nelle fonti consiliari (secoli XIV-XVI), Padova, 1999; L. KérY, Non enim homines de occultis, sed de manifestis iudicant. La culpabilité dans le droit pénal de l'Église à l'époque classique, in Revue de droit canonique, 53.2, 2003; M. PIfFeri, Generalia delictorum. Il «Tractatus delictorum» di Tiberio Deciani e la «Parte generale» di diritto penale, Per la Storia del Pensiero Giuridico Moderno 66, Milano, 2006; O. Descamps, Quelques remarques sur la distinction entre homicide volontaire et homicide involontaire en droit canonique médiéval, in Der Einfluß des Kanonistik, cit., pp. 107-134; R. Sorice, Vittime colpevoli e colpevoli innocenti, cit. 
minale malinconico verrà dai giuristi e dai medici legali accostato all'omicidio senza causa ponendo l'accento sulla comune condizione di «reato commesso per deviazione dalla morale», che vede coinvolte pienamente entrambe le fattispecie. L'omicidio per deviazione dalla morale nasce nell'ambiente teologico influenzato dalla morale cristiana dove il fondamento della responsabilità umana si basa sull'idea che l'imputabilità di un peccato dev'essere legata alla responsabilità morale e personale del peccatore. Si tratta certamente di considerazioni che restano contenute all'interno dell'inscindibile legame tra delitto e peccato, a un'idea di colpevolezza che non separa le infrazioni criminali dai fatti morali e religiosi ${ }^{124}$. Per comprendere il dibattito giuridico puramente ottocentesco che avvicinerà la follia morale/melanconia alla condizione soggettivo-psicologica in cui verte l'omicida che uccide senza una causa è forse utile un primo cenno di ordine semantico. La varia dialettica degli appellativi e delle loro sfumature accompagna tutta la storia di tale fattispecie criminosa ma l'elemento principale che la caratterizza resta la condizione psicologica del criminale ovverosia la «deviazione dalla morale», posto che una morale deve appartenere a tutti gli uomini. Atroce un omicidio può essere definito - e lo è stato - per le considerazioni più diverse, perché commesso con la più profonda malizia, o con la più fredda crudeltà, o con la più brutale indifferenza. Le parole del diritto cercarono aggettivi. In particolare, nella normazione penale dello Stato Pontificio l'omicidio compiuto in assenza di motivazioni fu aggettivato come bestiale a voler rimarcare la propinquità di tali criminali al regno delle 'fiere' piuttosto che al regno degli uomini.

\section{Follia morale o immoralità nella dottrina}

A cavaliere fra XVIII e XIX secolo, l'assenza di una causa o, per meglio dire, la mancata individuazione della causa nel reato di omicidio costituiva presunzione di «pura malvagità»e conseguente

\footnotetext{
124 Sul punto si veda S. KUTTNER, Kanonistische Schuldlehre, cit., p. 4 e ss.
} 
presunzione di elevata pericolosità sociale ${ }^{125}$. In più testi normativi definito anche bestiale, a volerne rimarcare la propinquità al mondo delle fiere, si ritrova anche descritto come omicidio commesso per deviazione dalla morale, qualificato come reato integrante il pieno dolo ${ }^{126}$.

$\grave{E}$ in virtù dell'uso penalistico di tali meccanismi presuntivi ${ }^{127}$ che risulta possibile oltrepassare la puntuale dimostrazione di ogni singolo aspetto del thema decidendum ${ }^{128}$, affidandosi in maniera fideistica a valutazioni già operate in astratto sul piano normativo ${ }^{129}$. Il reato commesso senza una causa razionale e per motivi futili destava maggiore allarme sociale per la sua imprevedibilità. Già intorno alla metà del secolo XVIII, nella sua Pratica criminale l'avvocato e giureconsulto di Gallipoli, Tommaso Briganti (1691-1762) ${ }^{130}$ ana-

125 Sul complesso assetto interpretativo del penale contemporaneo, cui si può per ovvie ragioni solo accennare, e sul peso interpretativo che assume il concetto di pericolosità sociale si vedano in generale B. Petrocelli, La pericolosità criminale e la sua posizione giuridica, Padova, 1940; F. Tagliarini, voce Pericolosità, in Enciclopedia del diritto XXXIII, Milano, 1983, p. 6 e ss.; G. Dell'Osso, Capacità a delinquere e pericolosità sociale, Milano, 1985; A. CALABRIA, voce Pericolosità sociale, in Digesto delle discipline penalistiche, Torino, 1995, p. 451; T. PAdovani, La pericolosità sociale sotto il profilo giuridico, in F. FERRACUTI (a cura di), Trattato di criminologia, medicina criminologica e Psichiatria forense, XIII, Milano, 1990, p. 313 e ss.; Più di recente sul tema A. Procaccino, voce Pericolosità sociale (accertamento della), in Digesto delle discipline penalistiche, Torino, 2005, p. 1051 e ss.; M. Pelissero, Pericolosità sociale e doppio binario. Vecchi e nuovi modelli di incapacitazione, Torino, 2008; R. BARToli, Pericolosità sociale, esecuzione differenziata della pena, carcere, (appunti "sistematici" per una riforma "mirata" del sistema sanzionatorio), in Rivista italiana di diritto processuale penale, 2013, p. 715 e ss.

126 Sul dolo e sulla costruzione della sistematica del reato si vedano G. DeLItala, Dolo eventuale e colpa cosciente, in Diritto penale. Raccolta degli scritti, I, Milano, 1976, p. 436; D.P. Demuro, Il Dolo, cit.

127 Sul valore giuridico probatorio delle presunzioni nel penale contemporaneo si veda G. BetTiol, Sulle presunzioni nel diritto e nella procedura penale, in Scritti giuridici, I, Padova, 1966, p. 344; Più recentemente E.M. Catalano, Prove, presunzioni ed indizi, in La prova penale, diretto da A. Gaito, I, Torino, 2008, p. 260.

128 I. Rosoni, Quae singula non prosunt collecta iuvant. La teoria della prova indiziaria nell'età medievale e moderna, Milano, 1995, p. 103.

129 Nello stesso senso A. Giuliani, Il concetto di prova. Contributo alla logica giuridica, cit., p. 165 ss.

130 Sulla biografia del giurista Tommaso Briganti si vedano G.M. MazzuchelLI, Gli scrittori d'Italia, II, Brescia, 1763, p. 2096; L. Giustiniani, Memorie istoriche degli scrittori legali del Regno di Napoli, I, Napoli, 1787, p. 139; E. D’AfflitTo, Me- 
lizzando il crimine nella prospettiva eziologica suggeriva una distinzione fra «delitti deliberati»e «delitti improvisi»:

ne' delitti deliberati, essendovi tutto il tempo di ben riflettere e meditare, non si devono attendere le cause possibili impulsive; ma le raziocinative e proporzionate alla gravezza del delitto. Ma trattandosi de' falli improvisi, che per impulso ed impeto d'ira si commettono, basterà qualunque causa, benche ingiusta, irragionevole e inadequata ${ }^{131}$.

Nelle sue pagine destinate alle corti regie e baronali del regno di Napoli, il discrimine fra queste tipologie dicotomiche di crimini trovava il suo fondamento nella diversa causa che sommuoveva il criminale a delinquere. A parer suo, la forza propulsiva a commettere il reato nei «falli improvvisi» presentava i tratti dell'ingiustizia, dell'irragionevolezza e dell'inadeguatezza. Il reato d'impeto era necessariamente irragionevole perché commesso seguendo gli impulsi improvvisi e incontrollabili dell'animo umano.

Nella prospettiva del Briganti si cadrebbe in errore se si cercasse di oggettivare la fattispecie criminosa perpetrata senza causa, al pari di quella perpetrata in presenza di altre circostanze come l'ira, l'ubriachezza, l'alienazione. La misura della malvagità dell'animo sarebbe inversamente proporzionale alla entità dell'impulso propulsivo ad uccidere. Ma non può graduarsi la causa del crimine con la stessa facilità con cui si procede alla graduazione del fatto criminoso - grave o meno grave a seconda del danno cagionato. L'entità dell'impulso che si genera nell'animo dell'omicida per la sua continua mutevolezza ed imprevedibilità si svela questione imperscrutabile con i soli strumenti d'indagine dei giuristi.

Converrà dimostrare, che gl' uomini benche tutti della istessa creta, sono tutti però di diverso calibro: ed i spiriti del loro

morie degli scrittori del Regno di Napoli, II, Napoli, 1794, p. 273; Più recentemente E. LeuccI, Tommaso Briganti: un precursore di Beccaria, in Il Giannone, III, n. 5, gennaio-giugno 2005, pp. 129-141; G. Vallone, Briganti, Tommaso, in Dizionario Biografico dei Giuristi Italiani (XII-XX secolo), I, Milano, 2013, pp. 338-339.

131 Tommaso Briganti, Pratica criminale delle corti regie, e baronali del regno di Napoli, III, Napoli, 1770, [§. II] p. 82. 
sangue di diversa configurazione sono la principale causa del di loro vario temperamento, ed inclinazione. Alcuni sono tanto ruvidi, e selvaggi nelle loro maniere, e sono sì pronti all'ira, che poco ci vuole per accendere il di loro fuoco, e che rapido voli, e svegli gran commozione nel loro cuore: basta una sola parola, un gesto solo, una sola occhiata, per far divampare, ed accendere il nitro della loro collera: ogni picciola scintilla è bastevole, per muoverli nell'interno fieri incendi d'impazienza. Proviene ciò da' loro sottilissimi spiriti carichi di nitro, e di solfo, e di figure aculeate, simili a corpicciuoli ignei vivacissimi e sciolti ${ }^{132}$.

Alla luce della diversa natura e dei diversi temperamenti umorali degli uomini, il Briganti suggerisce di imprendere a difendere il reo che per impulso ricevuto dall'ucciso - sia pure lieve, ingiusto, irragionevole e sproporzionato - abbia compiuto il crimine ${ }^{133}$. Quella che per alcuni può considerarsi una piccola provocazione potrebbe essere per altri una scintilla pronta a divampare, ed è in ragione di tali aspetti soggettivi che non può una uccisione considerarsi totalmente priva di impulso causale. E lo insegnava già Giovanni Domenico Rainaldi ${ }^{134}$ quando scriveva che $«[\ldots]$ etenim ubi extat aliqua

132 Ivi, p. 167.

133 La concezione del Briganti risulta fedele alla più risalente communis opinio della fase di costruzione del penale delle origini che sosteneva la legittimità dell'omicidio commesso per provocazione, si pensi all'omicidio dei banditi o degli adulteri, in cui colui che uccide si vede costretto a farlo. In generale sui banditi C. Ghisalberti, La condanna al bando nel diritto comune, in Archivio Giuridico, 27, 1960, pp. 69-74; D. CaValca, Il bando nella prassi e nella dottrina giuridica medievale, Milano, 1978, p. 95, p. 206 ss., G. Milani, L'esclusione dal comune. Conflitti e bandi politici a Bologna e in altre città italiane tra XII e XIV secolo, in Istituto Storico Italiano per il Medioevo, Studi Storici 63, Roma, 2003; ID., Giuristi, giudici e fuoriusciti nelle città italiane del Duecento. Note sul reato politico comunale, in J. Chiffoleau, C. Gauvard, A. Zorzi (a cura di), Pratiques sociales et politiques judiciaires dans les villes de l'Occident à la fin du Moyen Âge, Collection de l'École française de Rome 385, Roma, 2007, pp. 595-642; ID., Banditi, malesardi, ribelli. L'evoluzione del nemico pubblico nell'Italia comunale (secoli XII-XIV), in Quaderni Fiorentini per la Storia del Pensiero Giuridico Moderno, 38, 2009; Più recentemente C. ZENDRI, Banniti nostri temporis. Studi su bando e consuetudine nel diritto comune, Collana della Facoltà di Giurisprudenza dell'Università degli Studi di Trento 9, Napoli, 2016; R. Sorice, Vittime colpevoli e colpevoli innocenti, cit., p. 1-26.

${ }_{134}$ Giovanni Domenico Rainaldi, abruzzese, fu uditore del tribunale del Torrone dal 1671 al 1676, protetto da papa Clemente X. Fu anche luogotenente crimi- 
causa, licet non justa proveniens ab actu positivo facto ab eo, qui offenditur, utique poterit reus excusari, si in illo instanti occidit ${ }^{135}$. Per tali ragioni non può ammettersi l'esistenza giuridica dell'omicidio sprovvisto di una causa e quest'ultima non può rinvenirsi nella pura malvagità, ciò equivarebbe a spostare la valutazione giuridica del reato in un campo extragiuridico, si potrebbe dire metagiuridico, che guarda all'animo umano con strumenti diversi da quelli propri della scienza penalistica e della scienza medica. Sebbene nascosta e non condivisa dal pensiero razionale dominante, una qualsivoglia causa provocatoria deve pur esserci in un fatto così atroce come un omicidio. Gli interrogativi che si affollano sul tavolo dei doctores sono numerosi e necessitano di risposte in riferimento alla qualificazione sostanziale del delitto. Si tratterebbe di assassini colpevoli, più colpevoli di altri per maggiore malvagità, come se la scienza giuridica avesse gli strumenti per pesare il grado di malvagità presente nell'animo di un assassino. Si comprendono più facilmente le ragioni di utilitas publica, quale grimaldello più volte utilizzato per aprire le porte di molte operazioni teoriche, nella prospettiva repressiva di quelle politiche criminali che avevano portato a disciplinare una tale fattispecie giuridica. L'omicidio commesso per deviazione dalla morale era considerato delitto atrocissimo e la sua gravezza si riverberava nella dinamica processuale tanto da rendere meno credibile la deposizione di un teste. La credibilità di un testimone era tanto sensibilmente minore quanto più cresceva l'atrocità di un delitto, come nel caso di azioni gratuitamente crudeli. Nel Dei delitti e delle pene lo sostenne con forza anche Cesare Beccaria (1738-1794) ${ }^{136}$, che il più «ferreo assioma dettato dalla più crudele imbecillità» era quello

nale a Fermo e, dopo l'incarico a Bologna, pare che si stabilisse definitivamente a Roma. Cfr. M. CAVIna, La giustizia nella città dei dottori, in P. Bonacini, N. SARTI (a cura di), Diritto particolare e modelli universali nella giurisdizione mercantile, Bologna 2008, pp. 87-94; ID., La soluzione dei conflitti a Bologna in età moderna, in Ai confini del problema criminale. Saggi storico-giuridici, Bologna 2015, pp. 32-34.

135 Giovanni Domenico Rainaldi, Syntaxis rerum criminalium, Romae, 1688, [c. VII, §. 60] p. 425.

136 Sul Beccaria e le sue opere si vedano N. CAtelan, L'influence de Cesare Beccaria sur la matière pénale moderne, Aix-en-Provence, 2004; P. Audegean, La philosophie de Beccaria. Savoir punir, savoir écrire, savoir produire, Paris, 2010; M.L. Lanzillo, Des délits et des peines: Beccaria et Voltaire entre politiques de réforme et théorie moderne de l'Ėtat, in Corpus, 2012, 62, pp. 177-196; I. BIROCCHI, 
per cui «in atrocissimis leviores coniecturae sufficiunt, et licet iudici iura transgredi» ${ }^{137}$. I delitti atrocissimi, quindi, seguivano regole diverse anche sul piano probatorio e le più leggere congetture di colpevolezza erano sufficienti ad incriminare il sospettato e ad investire il giudice del potere di oltrepassare i confini del diritto:

Impauriti i legislatori per la condanna di qualche innocente, caricano la giurisprudenza di soverchie formalità ed eccezioni, la esatta osservanza delle quali farebbe sedere l'anarchia impunita sul trono della giustizia; impauriti per alcuni delitti atroci e difficili a provare, si credettero in necessità di sormontare le medesime formalità da essi stabilite e così or con dispotica impazienza, or con donnesca trepidazione trasformarono i gravi giudizi in una specie di giuoco, in cui l'azzardo ed il raggiro fanno la principale figura ${ }^{138}$.

La sussistenza o meno di una causa a delinquere, la sua qualificazione come causa futile risulta dunque connessa, come suggerisce il Briganti, alla personalità e alla sfera emotiva e percettiva dell'autore del reato. Di fronte ad un simile caso processuale il problema giuridico della volontà originaria e istintiva oppure indotta e provocata di delinquere si intreccia, quindi, con un'indagine sull'animo umano che trascende i confini dell'universo giuridico. Prima ancora di stabilire quale sia la pena da infliggere a misura e proporzione dell'omicidio immotivato occorre focalizzarsi sulla causa propulsiva che lo precede.

Discorrendo della causa nell'omicidio in relazione al discorso della graduazione del dolo, Gaetano Filangieri (1753-1788) ${ }^{139}$ mostrava schematicamente le coordinate che furono offerte dalla poli-

Beccaria, Cesare, in Dizionario Biografico dei Giuristi Italiani (XII-XX secolo), I, Milano, 2013, pp. 200-204.

137 Cesare Beccaria, Dei delitti e delle pene coi commenti di vari insigni scrittori, Livorno, 1834, p. 51.

138 Ibidem.

139 Cadetto di una delle più antiche famiglie dell'aristocrazia napoletana, si dedicò intensamente a partire dal 1776 alla stesura della sua monumentale Scienza della Legislazione, pubblicata in cinque tomi (suddivisi in otto volumi). Scritta fra due rivoluzioni, quella americana e quella francese, è stata nel tempo considerata talora opera di sintesi, mentre le letture critiche più recenti ne hanno sottolineato la funzione di svolta nella riflessione politica e giuridica del tardo Illuminismo eu- 
tica criminale ecclesiastica in un quadro di inasprimento delle misure punitive rispetto ai crimini che suscitavano maggiore allarme sociale:

1. causa impellente forte, connessa alle passioni, che rende infimo il grado del dolo;

2. la causa impellente debole che rende 'medio' il grado del dolo;

3. l'assenza di una causa o la presenza di una causa futile che pone al massimo grado il dolo ${ }^{140}$.

Secondo tale quadro di procedura criminale, i giudici per stabilire il grado di responsabilità, avrebbero dovuto combinare le circostanze del fatto di reato con questi tre canoni. Il complesso sistema di fonti su cui si articolava la giustizia penale di età moderna appare segnato da evidenti contraddizioni. Lo stesso criterio della causa che qui conduceva al dolus maximum era stato utilizzato dai giuristi medievali per giustificare omicidi anche efferati in nome delle perturbationes animi ${ }^{141}$. La deviazione dell'animo dalla morale che veniva invocata negli omicidi senza causa trovava origine certamente in una condizione di perturbamento dell'animo.

L'esigenza di una causa posta dai giuristi a fondamento di gran parte delle ragioni giuridiche che sostengono aspetti del penale appare indispensabile. Alcuni giuristi insegnavano esservi delitti commessi con maggiore o minore causa. Ma a ben riflettere un delitto senza causa, sul piano filosofico e giuridico appare un assurdo ${ }^{142}$, la causa è da rinvenirsi nella condizione morale dell'animo del reo.

Nella Genesi del diritto penale del 1791 Gian Domenico Romagnosi (1761-1835) $)^{143}$ in merito scriveva:

ropeo. Cfr. A. Trampus, Filangieri, Gaetano, in Dizionario Biografico dei Giuristi Italiani (XII-XX secolo), I, Milano, 2013, pp. 860-863.

140 Gaetano Filangieri, La scienza della Legislazione e gli opuscoli scelti, III, Livorno, 1827, p. 143.

${ }_{141}$ Sul punto cfr. R. Sorice, Vittime colpevoli e colpevoli innocenti, cit., p. 92.

142 Gian Domenico Romagnosi, Genesi del diritto penale nuova edizione arricchita d'altri suoi scritti in materia criminale ed illustrata di note ricavate dai più celebri criminalisti e di cenni sulla vita e le opere dell'autore, IX-X, Milano, 1857, p. 699.

143 Una delle personalità di spicco maggiore tra i giuristi italiani del primo Ottocento, piacentino, allievo del Collegio Alberoni gestito dai padri di San Vincenzo, 
La misura del turbamento che il delitto apporta all'ordine sociale non consiste tutta nella grandezza del male obbiettivo e della probabilità che risulta dalle cause. Bisogna anche considerare la probabilità che risulta dallo stato morale del delinquente. L'omicidio, che si chiamò bestiale, è una causa di pubblico terrore. Tutti paventava uno scellerato che, senza alcun motivo plausibile, o che almeno spieghi il suo delitto, uccide i suoi simili. È una tigre scatenata in mezzo alle vie delle nostre pacifiche città ${ }^{144}$.

I giureconsulti con il concetto di causa intendono denotare l'interesse che spinge a delinquere. Ma con questa troppo generica definizione lasciano tuttavia sussistere l'assurdo di cui parla il Romagnosi, dato che anche i delitti cosiddetti gratuiti non possono accadere senza un qualche incitamento, senza una qualche forza esterna o interna che sospinga a commettere il reato. A titolo esemplificativo, si può prendere in prestito l'ipotesi criminosa di colui che per far prova della forza del suo archibugio, o per semplice passatempo, uccida un passante. Si dirà che si tratti di omicidio commesso senza causa. Certamente in tale caso non si ravvisa alcun motivo di vendetta, di gelosia, di spoglio, di difesa e si potrebbe andare avanti con l'elencazione, ma pur sempre vi fu motivo di provare l'archibugio o di concedersi un passatempo ${ }^{145}$. Se si esaminano da tutte le angolazioni i concetti, si discopre, senza avvedersene, che essi riflettono il consueto modo di sentire, di volere e di operare degli uomini a loro noto come termine di paragone, onde pronunziare che un reato fu praticato con causa grave, lieve o nulla. Consta dunque che non as-

Giandomenico Romagnosi fu autori in anni giovanili di un importante saggio su $\mathrm{La}$ genesi del diritto penale (1791). Insegnò a Pavia, a Parma e a Milano e svolse negli anni napoleonici un ruolo determinante nella messa a punto dei progetti di Codice penale e di procedura penale: due progetti che estesero la loro influenza ben al di là degli anni napoleonici, sino alle codificazioni post-unitarie e al Novecento cfr. A. Padoa Schioppa, Storia del diritto in Europa. Dal medioevo all'età contemporanea, Bologna, 2007, p. 489. In generale si veda anche A. Cavanna, Storia del diritto moderno in Europa. Le fonti e il pensiero giuridico, I-II, Milano, 1982-2005; Per un approfondimento biografico sul giurista del tardo illuminismo italiano si veda anche L. Mannori, Romagnosi, Gian Domenico, in Dizionario Biografico dei Giuristi Italiani (XII-XX secolo), II, cit., pp. 1723-1726.

144 Gian Domenico Romagnosi, Genesi del diritto penale, IX-X, cit., p. 222.

145 Ivi, p. 699. 
soluto ma relativo è il criterio con il quale viene misurata la causa a delinquere, desunto dagli usi e costumi o dal senso comune in un dato momento della storia giuridica.

Certamente l'omicidio viene in tutti i tempi percepito come il più deplorevole fra i reati ma vi sono nel sostrato culturale di una società dei valori che consentono di comprendere più facilmente le ragioni del gesto. Per tali ragioni il Romagnosi ritiene che desti maggiore allarme sociale un omicidio compiuto per ragioni oscure, lievi, non condivisibili e individua proprio nella paura sociale le ragioni di siffatte scelte di politica criminale che hanno portato a punire più severamente tali omicidi.

In linea di continuità con il Romagnosi, Giovanni Carmignani (1768-1847) $)^{146}$ restituisce alla formula penalistica polisemica dell'omicidio senza causa una interpretazione misurata con concetti giuridici strictu sensu. Quello che alcuni giuristi avevano chiamato «piena e perfetta malvagità» altro non era che «la forza morale del delitto». La forza dell'animo umano che, come tutte le altre forze in natura, è soggetta ad anomalie, ad aberrazioni, a perturbazioni, le quali quasi episodiche alla principale si innestano, la modificano, e talvolta ne cambiano l'indole ${ }^{147}$. Nella sua Teoria delle leggi della sicurezza sociale egli suggellò la sua intera attività scientifica ${ }^{148}$. Maestro di scienze criminali e pratico del foro si colloca in una chiara prospettiva deterministica, inclinando a sostituire il concetto classi-

146 Fra i contributi di carattere biografico, E.C. Dingli, Biografia dell'avvocato Giovanni Carmignani scritta e recitata nella società medica maltese il 16 novembre 1847, in Elementi di diritto criminale [trad. Caruana Dingli], I, Malta, 1847, p. 12; F. Ambrosoli, Cenni intorno alla vita alle opere di Carmignani, Milano, 1863; O. Scalvanti, Saggio sopra alcune opere inedite di Carmignani, Perugia, 1892; P. Comanducci, La scuola criminalistica pisana tra Sette e Ottocento, in Illuminismo e dottrine penali, L. Berlinguer, F. Colao (a cura di), Milano, 1990, pp. 241 ss. Le note contenute nella Biographie Universelle di Alphonse Rabbé erano state visionate e apprezzate dallo stesso Carmignani, che aveva dato l'assenso al loro utilizzo nel manifesto dell'iniziativa editoriale della pubblicazione delle Cause celebri. Sul punto si veda M. P. Geri, Il magistero di un criminalista di foro. Giovanni Carmignani «avvocato professore di Leggi», in Iura. Temi e problemi del diritto, Pisa, 2016, p. 23.

147 Giovanni Carmignani, Teoria delle leggi della sicurezza sociale, II, Pisa, 1831, p. 70.

148 Sul punto si veda A. Padoa Schioppa, Storia del diritto in Europa. Dal medioevo all'età contemporanea, cit., p. 490. 
co di responsabilità individuale con il principio della sicurezza e difesa sociale.

Sull'omicidio, egli sovverte l'orientamento prevalente fra i criminalisti, i quali pongono il delitto «sulla bilancia della moralità dell'azione al fine di formarsene una retta idea». A suo dire, spesso essi confondono la forza morale del delitto con la moralità dell'azione umana. La forza morale che distingue il delitto sarebbe la brutale energia dell'impulso che lo produce, sarebbe una tensione di volontà cui nessun ostacolo può far retrocedere. La moralità dell'azione, invece, dipende tutta dalla capacità intellettiva di apprezzare la connessione delle cause con i loro effetti, dei mezzi con i loro fini. La malvagità nell'omicidio, di cui parlano i criminalisti, designa una segreta preordinazione dell'animo, dall'occhio umano non facilmente ravvisabile, che fece desiderare ai moralisti antichi - scrive il Carmignani - una finestra nel petto dell'uomo e che per essere scovata richiede una indagine di fronte alla quale l'umana giustizia mostra tutti i suoi limiti, essendole impossibile riconoscere il vero grado di coscienza con cui da alcuno sia stato commesso il delitto. L'assassino che si accinge a spargere l'altrui sangue versa in una condizione di grande pericolo perché è, solo apparentemente, libero nell'agire. Egli sa scorgere quel che ha da fare o non fare per raggiungere il proprio scopo ma vi è nella sua volontà un'affezione di spaventevole carattere, la quale è ben altro e ben più della moralità dell'azione, si tratta della forza d'animo con cui il delinquente concepisce ed esegue il proprio disegno criminoso. Mentre i dati della moralità dell'azione sono sempre gli stessi, i dati della 'prava' coscienza variano e diventano più intensi a seconda degli ostacoli da superare.

Due forze dunque compongono l'offesa. Una «forza di corpo, fisica» ed una «forza di animo, morale» sempre alla prima proporzionata. Dunque, l'omicidio commesso con «causa leggiera» e «brutale» non è certamente equiparabile all'omicidio commesso con causa proporzionata a commetterlo. Queste riflessioni, afferma il Carmignani, svelano l'errore di quei criminalisti che insistevano per la esasperazione della pena nei delitti commessi con una esemplare ferocia e pretendono che il più alto grado della forza morale della offesa si debba collocare nel delitto brutale. Il Carmignani afferma che si tratta di una erronea massima, un «luogo comune» dei criminalisti. 
La squisita crudeltà - individuata nell'assenza di una causa o nella sussistenza di una causa futile, leggera - non può essere valutata, nella prospettiva del Carmignani, per un aumento di imputazione o di pena, sia che si tratti di morte sia che si tratti di perdita perpetua di libertà.

Dietro tutta la pregnanza concettuale di queste riflessioni emergono i due riferimenti normativi che convivono nel giudizio penale, l'uno di carattere positivo e l'altro di matrice morale. Per poter osservare il fenomeno dell'omicidio senza causa nella sua peculiarità fenomenologica occorre interrogarsi proprio sul modo in cui il sapere giuridico abbia qualificato l'assenza di motivazioni impulsive, tenendo conto dei codici di riferimento in tutta la loro volubilità e mutevolezza nell'ambito della storia delle idee. Ma la scienza del criminale ha presentato tale specie di omicidio con rivestimenti definitori contigui, che si distinguono in virtù di sottigliezze.

A voler rimarcare l'assenza di una volontà integra, negli stessi anni, il Romagnosi offriva l'immagine di un uomo «abbandonato al delitto come uno schiavo incatenato ad una bestia feroce» ${ }^{149}$. Dinanzi ad un omicidio commesso senza una causa, non poteva non vedersi un animo sopraffatto da una forza irresistibile, il colpevole è al contempo vittima «di una inquietudine ardente, precipitata, irriflessiva», «questo sventurato altro non è che un pazzo» ${ }^{150}$. Sebbene, nell'ipotesi di specie, si riconosca la condizione di follia del colpevole, da intendersi come un parziale soffocamento della sua ragione, l'uccisione da esso perpetrata deve essergli imputabile, perché costituisce il risultato della sua vita intera, di una vita tutta di libertà e di responsabilità morale. Il Romagnosi con tono sferzante ricorda che i giuristi, lui compreso, non si sono mai scandalizzati né sorpresi nel vedere la giustizia colpire con la morte parricidi e che non soltanto sembrò loro utile una severa punizione, ma, oltre che utile, giusta. Il discorso del Romagnosi introduce nella storia del pensiero giuridico argomentazioni che travalicano i rigidi argini della scientia iuris per diventare letteratura propria della storia delle idee. Considerata sotto il profilo politico, una severa punizione certamente sortisce

149 Giovanni Carmignani, Teoria delle leggi della sicurezza sociale, cit., p. 79.

150 Gian Domenico Romagnosi, Genesi del diritto penale, IX-X, cit., p. 222. 
l'effetto di dare soddisfazione alla coscienza pubblica e di prevenire il delitto in generale. Se non il dolo, sarà la colpa a costituire la base dell'imputazione del fatto. La colpa per la responsabilità morale delle proprie azioni.

Ma secondo il Romagnosi il reato del maniaco desta ancora più imbarazzo dinanzi all'architettura del sistema penale laico.

Come punire un uomo che ha ceduto a delle impulsioni che la legge penale non ha alcun mezzo di controbilanciare? Di che lo si vuole punire? Del non aver resistito alle prime seducenti apparizioni del pensiero criminoso? Ma, se in lui non havvi libertà, e se la legge nulla ha opposto a quelle prime impressioni, perché punirlo ${ }^{151}$ ?

Il teorema dell'assenza di una causa, che nasce nel mondo teologico nei bandi e nelle costituzioni ${ }^{152}$ dello Stato Pontificio, e si ritrova nei dibattiti dottrinali sul penale sostanziale laico, a cavaliere fra XVIII e XIX secolo, fu oggetto di indagine anche da parte della allora nascente scienza psichiatrica che ne trovò il riflesso in una nuova, almeno sul piano terminologico, categoria nosologica: la monomania. Si trattava di una forma di mania circoscritta che con tutta evidenza ricalcava la più antica malattia che medici-legali e giuristi più risalenti avevano chiamato melancholia. A far da ponte nel nostro discorso - che affonda le sue radici anche nella psicopatologia forense - il Romagnosi, che già alla fine del Settecento nella Genesi del diritto penale accosterà l'omicidio atroce e immotivato alla follia parziale o mania circoscritta.

Tutti coloro i quali sottomisero i fatti criminosi ad una attenta osservazione non possono ignorare, che un certo numero di delitti, soprattutto dei più atroci e dei più spaventosi, sono, al momento della loro esplosione, l'effetto di una vera monomania. Esse sono il risultato di una di quelle funeste idee bizzarre, le quali possono tutto ad un tratto attraversare lo spirito di ognuno. L'uomo forte e morale la respinge con

151 Ibidem.

152 Sul punto mi sia consentito il rinvio a S. ABIS, L'omicidio bestiale nella seconda metà del XVIII secolo (con particolare riferimento alla Bologna pontificia), in Historia et ius, 18 (2020), paper 16, pp. 1-18. 
orrore; essa non è per lui che un momentaneo pensiero, e fuggitivo. Non gli lascia che lo sbalordimento di averla veduta passare rapidamente davanti a lui. L'uomo debole o immorale non la respinge ${ }^{153}$.

Nell'indagine dei processi eziologici di insorgenza di tale impulso cieco ad uccidere, il giurista Raffaele Ala (1780-1846) ${ }^{154}$ lo riconduce ad una causa disonesta, ingiusta oppure tanto leggera e futile da ritenersi che non ci sia proporzione tra questa e un'azione atrocissima quale l'uccisione di un uomo. Questo sarebbe il crimine di colui che senza essere provocato da un'offesa ricevuta, senza l'ardore della collera, bensì per un piacere efferato e brutale desidera spargere il sangue di un uomo innocente. E non vi è legge, umana o divina, che non lo condanni severamente con la pena di morte ${ }^{155}$.

Due appaiono le questioni principali su cui si ritiene debba vertere l'indagine: la provocazione e la volontà. Si ponga il caso in cui un'offesa sia stata rivolta dalla vittima al suo assassino, quale intervallo di tempo deve intercorrere tra l'ingiuria e l'omicidio perché non si consideri più sussistente il nesso causale tra le due condotte?

153 Giandomenico Romagnosi, Genesi del diritto penale, IX-X, cit., p. 78.

154 Avvocato dei rei ad Ancona e Macerata, poi procuratore per i carcerati, dei poveri e per la carità a Roma. Dal 1820 fu avvocato curiale e difensore pubblico presso la Sacra Consulta. Dal 1821 fu uditore criminale del cardinale Giulio Maria della Somaglia, vescovo e governatore di Velletri. Nel 1838 successe a Giuseppe Capogrossi come professore sostituto di Istituzioni di diritto criminale nell'Università romana. Insieme a Carlo Contoli, fu uno dei due penalisti pontifici più importanti operanti nello Stato nel primo trentennio del secolo. Nell'opera principale, Il Foro criminale redatta tra il 1825 e il 1826, Ala si occupò di raccogliere e sistemare in dieci trattati le plurime fonti dell'ambito penale dello Stato pontificio, tanto che l'opera venne consigliata agli impiegati di giustizia da Leone XII. Tuttavia, il riordino delle leggi comuni, del diritto canonico, dei bandi e delle costituzioni apostoliche che si propose non superò la vecchia concezione legata al diritto comune e ancor più al diritto divino. Ciò, nonostante il dibattito si stesse aprendo, pure se negli angusti confini dello Stato pontificio, ad una certa laicizzazione del diritto penale e si profilassero all'orizzonte le prime riforme legislative che avrebbero portato alla svolta "codicistica" di Gregorio XVI. Sulla legislazione penale gregoriana nel 1839 scrisse un commento diretto agli avvocati e agli studenti: Criminalis iuris et praxeos instituta usui etiam forensi accomodata, intitolando il terzo volume Universi criminalis iuris epitome seu theses. Cfr. N. Contigiani, Ala, Raffaele, in Dizionario Biografico dei Giuristi Italiani (XII-XX secolo), I, cit., pp. 16-17.

155 Raphaele Ala, Criminalis iuris et praxeos instituta usui etiam forensi accommodata, Romae, 1839, I, p. 141. 
Una volta esclusa l'induzione a delinquere per un'ingiuria ricevuta, l'attenzione del giurista dovrebbe spostarsi sulla volontà. Ala precisa che la volontà va tenuta distinta dal proposito a delinquere. La volontà non coincide pienamente con la fervente disposizione dell'animo che fa sorgere il proposito. L'animo in fervore avverte una forza irresistibile, non richiama i pensieri alla deliberazione, non pensa ai pericoli: l'animo in fervore esegue, vuole e non medita. Invece colui che forma un pensiero di vendetta, si interroga, delibera in tal senso medita sull'azione, ne prepara le modalità di esecuzione, sceglie il luogo e sceglie in anticipo il tempo. Costui vuole e medita sul proprio volere. In altre parole, se l'omicidio non sia provocato, occorre indagare se sia almeno premeditato, per escludere l'ipotesi di omicidio bestiale. Da una parte si ha l'omicidio provocato e per questo scusato; dall'altra quello premeditato; ed in terza ipotesi l'omicidio voluto da un animo in preda ad un impulso intenso e immotivato. Nella tradizione romanistica la pena prevista per siffatti crimini era la deportazione su un'isola, la confisca dei beni, a cui si sostituì poi la condanna a morte. I più umili invece venivano gettati alle 'bestie' e sottoposti ai supplizi ${ }^{156}$.

Quella che dal Romagnosi viene definita «febbre del delitto» in grado di «sbalordire, spaventare e confondere la ragione umana» nelle pagine del giurista di Carrara, Pellegrino Rossi ${ }^{157}$ (1787-1848) diviene pura immoralità. Nell'omicidio commesso senza alcun apparente motivo il Rossi non vede che un omicidio premeditato. E coloro che furono condannati per omicidio bestiale erano uomini profondamente immorali, ma non mentalmente malati ${ }^{158}$.

Tra le cause rese celebri dalla enormità del delitto non soltan-

156 Ivi, p. 142.

157 Sul giurista carrarese la bibliografia è assai vasta ma si vedano almeno: L. LACCHÉ, Tra politica e diritto, ovvero Rossi e la Monarchia di Luglio, in Un liberale europeo: Pellegrino Rossi (1787-1848). Atti della giornata di studio (Macerata 20 novembre 1998), Milano, 2001, pp. 69-108; ID., "All'antica sua patria”. Pellegrino Rossi e Sismonde de Sismondi: relazioni intellettuali fra Ginevra e la Toscana, in Atti del Convegno di Pescia, 13-15 aprile 2000, Firenze, 2001; ID., Rossi Pellegrino, in Il contributo italiano alla storia del pensiero. Il diritto, Roma, 2012; ID., Rossi, Pellegrino Luigi Edoardo, in Dizionario biografico dei giuristi italiani (secoli XII$X X)$, II, cit., pp. 1741-1744.

158 Pellegrino Rossi, Trattato di diritto penale tradotto dal francese dal Dottor in Legge R. M. con alcuni cenni sulla vita dell'autore, Milano, 1852, p. 250. 
to per la singolarità del fatto ma anche per la condizione del delinquente, certamente rientra quella di cui ebbe a discorrere il Carmignani che di fronte a tali nefandezze «per la prima volta gettando in disparte le difensive dei patrocinatori degli accusati, alzò le armi offensive degli accusatori» ${ }^{159}$.

Un giovane solitario aveva fatto dei boschi la propria stabile dimora «vivendo de' crudi e sanguinolenti lembi di fere bestie». Un giorno una giovane donna attraversando il bosco fu avvistata dall'uomo che iniziò a inseguirla fino a che la raggiunse. Alle sue grida nessuno, se non l'eco in lontananza, rispose. L'assassino spinse la sua vittima con forza in una grotta, la prostrò ed abusò brutalmente di lei. Consumato lo stupro, le immerse un coltello nel collo e data mano ad un bicchiere ne raccolse il sangue spruzzante e se ne dissetò:

mette in pezzi il corpo della vittima semiviva: ne azzanna, e ne divora con ansietà di cannibale i lembi ancor palpitanti: satollo e preso dal sonno si sdraia, facendo de' lembi avanzati al pasto nefando origliere al suo capo ${ }^{160}$.

Quando gli agenti della forza pubblica accorsero, trovarono il mostro immerso nel sonno tranquillo sul 'letto della strage'. Si tratta di un caso su cui per stessa ammissione del giurista, per la prima volta, il Carmignani invocando tutto il rigore che la legge decretò ad un simile delitto, rigettandone ogni scusa e mostrandolo in tutta la sua nefanda bruttura dipingendolo «come vomitato dall'Averno ad infettarne la terra» chiede ai giudici inesorabile severità e non dolcezza. Proprio il Carmignani che i fremiti del senso morale aveva giudicato un fallace criterio per giudicare i delitti arriva ad affermare:

in un delitto [siffatto] la profonda immoralità del quale ne costituisce, il distintivo carattere, la morale è il suo miglior giudice, e la guida migliore di chi dee giudicarne ${ }^{161}$.

159 Cause celebri discusse dal cav. commendatore Giovanni Carmignani professore dell'I. e R. Università di Pisa socio di più accademie italiane e straniere, IV, Pisa, 1847, p. 389.

160 Ibidem.

161 Ivi, p. 390. 
Di fronte a tanta impetuosa veemenza anche l'indulgente giurista ammette che i fremiti del senso morale in tali casi costituiscono il filo d'Arianna per penetrare nel tenebroso labirinto in cui l'iniquo crimine è stato consumato.

La causa motrice dell'omicidio può, infatti, imprimere ad una già così grave offesa, un carattere di maggiore gravità politica e renderla qualificata se si presenta in una duplice veste: causa idonea ad armare più facilmente la mano del criminale; causa idonea a rendere più universale il timore di essere vittima dell'uccisione. Così l'avvocato e professore di diritto criminale della Restaurazione, Giuseppe Giuliani (1794-1878) ${ }^{162}$, affrontava il discorso relativo all'omicidio per causa irragionevole. L'omicidio commesso «per una causa del tutto irragionevole e fuori del comune pensare degli uomini» ${ }^{163}$ rientra nella seconda ipotesi prospettata dal giurista. La stravaganza del crimine in ispecie risiede nella sua atroce imprevedibilità, nella impossibilità di controllare la sua verificabilità. Pertanto, tali omicidi si qualificano in forza di due elementi: della imprevedibilità e della ingiustizia morale subite dalla vittima. Si potrebbe obiettare che qualsiasi morte inflitta da altri nell'attimo prima di subirla non sia avvertita dalla vittima come verificabile. È pur vero però che se talu-

162 Sul criminalista di origini lombarde ma maceratese d'adozione, attivo nella scienza e nella prassi del diritto entro i confini dello Stato pontificio in pieno Ottocento si vedano M. Sbriccoli, Giuseppe Giuliani, criminalista. Elementi per una biografia, in S. Vinciguerra (a cura di), I Regolamenti penali di papa Gregorio XVI per lo Stato pontificio (1832), Padova, 2000, pp. 259-293; ID., La vicenda di un penalista moderato nell'Italia del XIX secolo, in Annali della Facoltà di Giurisprudenza, Università degli Studi di Macerata, n.s., 2000-2002, Milano, 2004; Si veda anche N. Contigiani, Giuliani, Giuseppe, in Dizionario Biografico dei Giuristi Italiani (XII-XX secolo), I, cit., pp. 1029-1030.

163 Il Giuliani ritorna su esempi già fatti. Si verifica la causa irragionevole se taluno rinnovasse il caso che il Filangieri dice di colui che per provare la forza della sua polvere uccise un passeggero che gli era ignoto; oppure nel caso di vendetta trasversale, quando qualcuno per trarre vendetta del suo nemico uccide un suo prossimo congiunto. Appare manifesto che in questi due casi si rivela più generale il pericolo di essere vittima di un attentato criminoso. Infatti, il cittadino onesto potrebbe pensare di non avere nemici nella società per non aver recato offesa a nessuno, potrebbe dire fra sé di non temere il pugnale del ladro perché la propria ricchezza è inaccessibile all'altrui avidità; ma potrà sempre temere di essere vittima di una causa irragionevole o di una vendetta trasversale, perché contro questo pericolo non vale alcuna umana previdenza. GIUSEPPE GIULIANI, Istituzioni di diritto criminale col commento della legislazione gregoriana, II, Macerata, 1841, p. 199. 
no commette un'ingiuria avverte come possibile il verificarsi di una azione/reazione altrettanto malevola, in un certo senso ne assume il rischio, mentre colui che non abbia commesso alcuna cattiva azione non avverte per sé, neppure latentemente, alcun pericolo. Stando alla dottrina dell' allarme' viene agevolmente dimostrato che le cause di cui parliamo imprimono all'omicidio una qualità gravante che giustifica un aumento della pena.

L'atrocità dell'omicidio irragionevole non risiede - o quantomeno non soltanto - nelle modalità di esecuzione, bensì nell'assenza di una causa, cioè nell'assenza di una ragione in grado di rendere manifesta la eziologia del crimine, moralmente prima ancora che giuridicamente. Il motivo è imprevedibile e incomprensibile, è - entro certi limiti - futile. Esso risiede, al di fuori del razionale, nell'azione 'cervellotica' dell'omicida. Che poi col termine di cervellotico si debba intendere l'impulso ad uccidere sotto il profilo morale e quindi come malvagità, ovvero che lo si debba intendere sotto il profilo psicopatologico è uno dei grandi problemi affrontati nel dibattito che si arricchì in modo decisivo nell'Ottocento, al crocevia fra diritto e medicina legale. Nei primissimi scorci del XIX secolo, infatti, sulla scia delle teorizzazioni della psichiatria francese concernenti la follia parziale, l'omicidio senza causa trovò collocazione nella nuova categoria patologica della monomania omicida. La scienza giuridica ottocentesca si apre alle 'monomanie'. 



\section{CAPitolo II \\ MONOMANIA OMICIDA \\ LE METAMORFOSI DELLA MALINCONIA (SEC. XIX)}

I. Le ragioni della scienza medica

\section{Deviazioni dalla morale}

Innumerevoli possono essere le prospettive storiche-giuridiche da cui guardare il fenomeno della immoralità nel crimine, sarebbe impensabile e riduttivo risolvere tale ardua questione guardando alla sola dicotomia tra atto volontario e involontario, ma l'osservazione di un piccolo segmento - quale la prospettiva medico-legale - permette di cogliere alcuni momenti salienti del lento processo di rinnovamento del penale sostanziale.

In questa direzione un punto di osservazione particolare è rappresentato proprio dallo studio delle riflessioni che la nascente scienza psichiatrica, nei decenni centrali dell'Ottocento, aveva riservato ai crimini mostruosi perpetrati senza una causa apparente. Il bisogno di capire cosa ci fosse negli oscuri meandri degli omicidi commessi senza un movente condusse i dottori della psiche ad avvalersi di una nuova categoria diagnostica, quella della follia morale. ${ }^{1}$ In tal modo fu aperto nell'universo penalistico un varco di accesso per nuove categorie

1 Cfr. P. MarchetTI, La confessione dell'imputato tra ricerca della verità ed ermeneutica del soggetto, in Confessione, liturgie della verità e macchine sanzionatorie: Scritti raccolti in occasione del Seminario di studio sulle 'Lezioni di Lovanio' di Michel Foucault, Torino, 2015, p. 11. 
che inevitabilmente portarono il percorso interpretativo dei giuristi a dare forma ad aspetti sostanziali del penale. Per comprendere a fondo il dibattito dottrinale che divise la scienza del diritto in due scuole di pensiero è indispensabile comprendere a quali scoperte sull'animo umano era approdata la scienza psichiatrica.

\section{Influssi medico-legali}

Il processo di rinnovamento che interessò la scienza psichiatrica nell'ultimo scorcio del XVIII secolo, in cui a pieno titolo rientrava la controversa questione della follia parziale, ebbe certamente come pioniere il medico psichiatra francese Philippe Pinel (1745-1826), che descrisse tale fenomeno morboso con il nome di «manie sans délire» o 'mania ragionante' 2 . Con tale concetto, il medico francese intendeva descrivere la condizione mentale caratterizzata dalla assenza di ragione/cognizione del bene e del male esclusivamente in relazione ad uno o più 'oggetti', da intendersi come specifici ambiti emotivi e relazionali, senza che si possa riscontrare - al di fuori di essi - alcuna alterazione sensibile nell'esercizio delle facoltà volitive e intellettuali.

L'etiopatogenesi morale di tale infermità della mente condusse l'allievo di Pinel e medico alla Salpêtrière, Jean-Étienne-Dominique Esquirol (1772-1840), a costruire negli anni successivi e con passaggi progressivi la categoria nosografica della monomania. Ad un certo punto della sua carriera, Esquirol riteneva che i casi descritti da Pinel sotto il nome di 'mania senza delirio' - se non tutti almeno in parte - non fossero in realtà che casi di monomania o melancolia, caratterizzati da un delirio fisso ed uniforme, e che vi si accompagnasse un reale disturbo dell'intelligenza. Tale è l'opinione da lui espressa nel Dizionario delle Scienze Mediche del 1828, ma ulteriori osservazioni lo condussero ad abbandonare tale orientamento.

In tal modo, Esquirol introdusse nella nosografia psichiatrica e sistematizzò come entità nosografiche autonome le 'lesioni della volontà', già descritte da Étienne-Jean Georget (1795-1828) in ambi-

2 Philippe Pinel, Traité médico-phylosophique sur l'aliénation méntale ou la manie, Paris, 1800, p. 155. 
to psichiatrico-forense nel 1826. Le 'lesioni della volontà' secondo il medico francese potevano esistere indipendentemente da un disordine delle idee o dal delirio. «Nous croyons avoir prouvé que des aliénés» afferma Georget «sont morts sur échafaud» ${ }^{3}$.

In molti casi di omicidio senza causa apparente il soggetto appare in pieno possesso delle facoltà intellettive, e in forza di ciò si potrebbe pensare che non delirando nemmeno parzialmente, il criminale, potrebbe orientare in maniera più accorta la sua condotta, se «le meurtrier raisonne» potrebbe essere «prévoyant». Ma il medico della Salpêtrière, in trent'anni di studi teorici e pratici sull'alienazione mentale, aveva visto «aliénés qui parlént très-sensément, qui tiennent des discours très-suivis, qui discutent sur des matières très difficiles, qui ourdissent un complot avec beaucoup de finesse, mais dont les actions sont toutes désordonnées, dont les affections sont perverties, qui sont dangereux pour les autres et pour eux-même s'ils sont rendus à la liberté» ${ }^{4}$. Georget dimostrò, in linea di continuità teorica con i suoi predecessori, che l'uomo può essere privato della libertà morale senza che la sua intelligenza sia lesa. In tutti i casi di monomania omicida, - che si tratti di una 'alterazione parziale dell'intelletto' o di una 'lesione della volontà'- la libertà morale dell'omicida è annientata. La battaglia del Georget in ambito forense si incentra sul sostenere la rilevanza della 'monomania affettiva o follia morale' come causa che esclude l'idea di azione criminale e di colpabilità e sottrae colui che ne è colpito dalla responsabilità della sua condotta. Egli fu senz'altro il primo psichiatra ad elaborare la tesi secondo cui un reato può essere commesso essendo ammalata soltanto la volontà e a reclamare strenuamente l'introduzione nella pratica forense della nozione di 'monomania senza delirio' accanto a quella 'delirante'5. In tale condizione di alterazione della volontà le azioni appaiono istintive, irresistibili, involontarie, e la migliore pro-

3 Étienne-Jean Georget, Nouvelle discussion médico-légale sur la Folie ou Aliénation mental souivie de l'examen de plusieurs procès criminels dans lesquels cette maladie a été alléguée comme moyen de défense, Paris, 1828, p. 45.

4 Ibidem.

5 Paul Émile Dubuisson, De l'évolution des opinions en matière de responsabilité in Archives de l'Anthropologie Criminelle et des Sciences Penales. Médecine légale, judiciaire. - Statistique criminelle. - Législation et Droit, II, Lyon, 1887, p. 101. 
va consiste nel fatto che colui che le pone in essere ha piena consapevolezza di fare del male e non può impedirselo.

\section{Tentativi definitori}

La distinzione fra monomania intellettuale (monomania per delirio parziale) e monomania affettiva (per forza interna indipendente dalla volontà) di matrice francese si ritrova anche nelle pagine dedicate alle dissertazioni sulla volontà di delinquere dei medici legali italiani che si avvalgono di diversi concetti per descriverla. Il professore presso la reale Università di Modena, Giovanni Battista Giacomo Gandolfi (1806-1875), rilevava un duplice orientamento di pensiero nei casi di omicidi senza un chiaro movente ed evidenziava come gli psichiatri italiani in questa casistica tendevano ad individuare come causa da una parte il furore maniaco (monomania omicida intellettuale); dall'altra la tendenza irresistibile, la disperazione, il dolore, la passione imprevista e violenta (monomania omicida istintiva) ${ }^{6}$.

Le opinioni intorno alla moralità delle azioni degli omicidi vedevano, pertanto, contrapposti i cultori del diritto e quelli della scienza psichiatrica. Questi ultimi, infatti, arrogandosi la conoscenza del funzionamento della mente umana sostenevano che siffatte infermità non potevano non essere considerate nel Foro motivi attenuanti del reato o persino di compiuta esclusione della imputabilità per l'applicazione delle pene ai delitti e della interdizione o semi-interdizione ad alcuni atti civili qualora eseguiti nel senso della follia parziale. I giuristi ottocenteschi al contrario sono giunti fino a negare la esistenza di tali malattie psichiche, ritenendole affezioni bizzarre immaginate da medici innovatori per sottrarre i colpevoli di crimini atroci al rigore delle leggi penali ${ }^{7}$.

Fra i più strenui sostenitori della esistenza della follia morale

6 Giovanni Battista Giacomo Gandolfi, Memorie originali sunti di opere e dissertazioni sulla monomania omicida. Discussioni Medico-Legali, in Bullettino delle scienze mediche pubblicato per cura della società medico-chirurgica di Bologna, XIX, Bologna, 1851, pp. 6-7.

7 Ivi, p. 526. 
come autonoma categoria nosologica, Biagio Miraglia (1814-1885) il quale intendeva decostruire l'immagine - che a suo dire il diritto forniva - del folle come individuo necessariamente privo di memoria, di intelletto, di coscienza, di volontà. Egli teneva ben distinte le facoltà percettive e riflessive guidate dall'intelletto, dalle facoltà morali e istintive guidate dagli affetti. L'autonomia delle due sfere presupponeva la possibilità che queste cadessero in una condizione patologica anche separatamente ${ }^{8}$. Quanto alla monomania omicida riposta nella tendenza distruttiva irresistibile, essa veniva inclusa nel novero delle follie delle facoltà affettive, in particolare veniva descritta come una particolare specie di lipemania o melancolia ${ }^{9}$.

In linea di continuità con tale prospettiva dualistica si pose anche uno dei fondatori della Società Italiana di Freniatria, Carlo Livi (1823-1877) ${ }^{10}$. Nel suo intervento sulla monomania egli poneva in luce la situazione di conflitto che, ai suoi tempi, coinvolgeva la scienza medica e il diritto. Tale conflitto fra saperi traeva origine, a suo dire, dal mancato riconoscimento da parte dei giuristi delle nuove forme di pazzia che l'analisi clinica aveva rilevato continuando a punirle «con atroci supplizi e col rogo». Appariva comprensibile, continuava il Livi, che di fronte a tale nuova e controversa patologia della mente i ministri della giustizia temessero che, adducendola come scusa nei processi, i crimini più atroci potessero dilagare impunemente nella società. Ma il problema risiedeva nell'errore che alcuni giuristi commettevano nel confondere la pazzia morale con la immoralità. La questione si fa ardua, certo non nelle forme innocue o latenti di follia morale bensì in quelle terribilmente sanguinose, di fronte alle quali i giudici «si affannano a mettere nelle mani del boia il mostro esecrato». Nella sua perorazione, il Livi cercava precipuamente di chiarire il concetto di follia morale. Nonostante ammettesse l'esistenza del libero arbitrio nell'individuo, contemplava la pos-

8 Biagio Gioacchino Miraglia, La legge e la follia ragionante ossia considerazioni medico-legali su lo stato di mente della signora Teresa Santoro querelante di sequestro della propria persona in un manicomio, Napoli, 1871, p. 44.

9 Ivi, p. 113.

10 Carlo Livi, 'Della monomania in relazione col foro criminale' in Rivista sperimentale di Freniatria, 1876, p. 645. Sul punto si veda E. Musumeci, Emozioni, crimine, giustizia. Un'indagine storico-giuridica tra Otto e Novecento, Milano, 2015, p. 65. 
sibilità di impedimenti all'esercizio della facoltà morale in grado di ledere la facoltà volitiva.

Ma quali sarebbero gli atti compiuti da un folle morale? A detta del Livi i folli morali compiono «atti innormali e malvagi e crudeli d'ogni specie, non già per impeti istintivi speciali che soggioghino in quel punto la coscienza e le forze volitive, ma per vera e propria paralisi del senso morale, che rende l'intelletto stesso cieco all'idea del bene e del male, o sordo il sentimento alla vergogna e al rimorso» ${ }^{11}$. Con queste parole egli tratteggiava la differenza che intercorre fra la pazzia morale e la monomania istintiva, le quali non vanno confuse non fosse altro perché da questa si poteva guarire non altrettanto poteva dirsi per la prima. Il folle morale «l'ha nel sangue».

Fra i giuristi che sul tema della follia morale sembrano accogliere pienamente le teorie della medicina sperimentale, Antonio Buccellati (1831-1890) il quale parlò di «demoralizzazione o smarrimento morale» invocando per tali soggetti la non imputabilità penale, ove risulti dall'indagine peritale la conservazione delle facoltà intellettuali accompagnata da uno sconvolgimento dei processi volitivi ${ }^{12}$.

Questi risultati della ricerca medica non potevano non interessare i penalisti della scuola positiva, che si introdussero sin nei meandri di tale - ancora acerbo - dibattito. Lo stesso Cesare Lombroso $(1835-1909)^{13}$ identifica nella follia morale il morbo della mostruosità criminale. Individuandola come malattia atavica della sfera morale, la attribuisce a quello che egli definisce il «delinquente nato»

\section{Ibidem.}

12 Antonio Buccellati, Istituzioni di diritto e procedura penale secondo la ragione e il diritto romano, Milano, 1884, p. 172; Sul giurista si veda A. SANTANGELo Cordani, Alla vigilia del Codice Zanardelli. Antonio Buccellati e la riforma penale nell'Italia postunitaria, Milano, 2008.

13 La sua metodologia sperimentale, che andrà incontro a non poche - e fondate - critiche, viene presto diramandosi verso l'ambito medico-legale aprendosi ad un più comprensivo interesse antropologico. Giurista honoris causa, nonostante fosse medico, viene spesso incluso in tale novero, Lombroso non riuscì però ad influenzare la legislazione dell'epoca e fu in particolare deluso dal varo del primo codice penale italiano che - negli anni del trionfo - gli sembrava aver sostanzialmente ignorato le istanze del positivismo penale. Cfr. D.V. Dalbrenta, Lombroso, Cesare, in Dizionario biografico dei giuristi italiani (XII-XX secolo), II, cit., pp. 1189-1192. 
distinto dal «delinquente occasionale o per passione» ${ }^{14}$. La follia morale si mostra come una patologia scomoda ${ }^{15}$ proprio per il suo confondersi con la mera malvagità. Pur non seguendo pedissequamente le teorie lombrosiane, Ludovico Fulci (1845-1934) nel suo scritto dedicato all'evoluzione storica del diritto penale e alla forza irresistibile del $1891^{16}$, ammetteva l'esistenza di tale patologia della morale ma non conveniva con la scuola positiva che finiva per far coincidere, perfettamente ed in ogni caso, la follia alla delinquenza generica: il folle morale al delinquente nato. ${ }^{17}$ Quando la scuola positiva riconobbe la figura del delinquente d'occasione, ammettendo altre possibilità in termini di soggettività criminale rispetto al binomio folle morale-criminale nato, Fulci si sentì di aderire in modo completo alle teorie dell'antropologia criminale di stampo lombrosiano. I tratti distintivi di tale patologia della morale e della volontà accolti dal Fulci derivano dalle indagini condotte, negli anni, dalla scienza psichiatrica. In questa prospettiva, le capacità cognitive connesse al ragionamento logico appaiono integre benché «la luce della moralità non si riverbera più sulle idee e sui giudizi». Non spetta alla legislazione penale occuparsi di tali individui, sostiene il Fulci, essi non sono dei colpevoli. Il trattamento giuridico differenziale rispetto a quello della criminalità generica consiste nel loro trasferimento sotto la responsabilità di psichiatri, soggetti al controllo ed alle procedure approntate dall'autorità amministrativa: devono «sequestrarsi lì in un manicomio» ${ }^{18}$. Secondo il Fulci, il folle morale merita di essere segregato in un manicomio per due ragioni: la prima risiede

14 Cesare Lombroso, 'Pazzia morale e delinquente-nato', in Archivio di psichiatria, scienze penali, antropologia criminale per servire allo dell'uomo alienato e delinquente, V, 1884, [f. I] p. 29.3; Per una riflessione sull'autonomia delle emozioni rispetto all'intelletto sul piano criminale si veda E. Musumeci, Emozioni, crimine e giustizia. Un'indagine storico-giuridica tra Otto e Novecento, Milano, 2015, p. 65-70.

15 V.P. BABINI, La responsabilità nelle malattie mentali, in V.P. BABINI, M. Cotti, F. Minuz, A. TAgliavini, Tra sapere e potere: la psichiatria in Italia nella seconda metà dell'Ottocento, Bologna, 1982, p. 168.

16 Tale opera fu considerata importante per la scienza giuridica e fu apprezzata, in particolar modo, da Francesco Carrara che ne recensì il lavoro.

17 Ludovico Fulci, Prolusione al corso di Diritto penale dettato nella R. Università di Messina (1884-1885), Roma, 1885, p. 14.

18 Ivi, p. 16. 
nella necessaria difesa sociale; la seconda consiste nel favorire una «benedicta selectionis»:

Gli uomini moralmente sani hanno il diritto di vincere in questa concorrenza vitale gli uomini ammalati, che rappresentano una anomalia psichica, questi esseri che sono $\mathrm{i}$ mostri del mondo morale ${ }^{19}$.

Il problema, ovviamente, era intriso di valenze giuridiche. Con parole ancora più esplicite - ma siamo ormai quasi agli albori del nuovo secolo - il concetto di «mostruosità morale di tipo congenito» ${ }^{20}$ si ritrova nelle pagine di Arrigo Tamassia (1849-1917), psichiatra mantovano che contestava la fondatezza dell'istituto della seminfermità nel codice penale. Quale sarebbe la ragione per cui la macchina penale debba attribuire la responsabilità penale, sia pure ridotta, ad un individuo dotato solo in «apparenza della ragione», tanto che il momento psicologico morboso si può confondere «colla scelta abbracciata da una volontà libera e cosciente»? ${ }^{21}$.

Il problema dell'accertamento della forza irresistibile interna al foro della coscienza del criminale descritta da certuni come malvagità e da altri come follia morale o monomania si pone al cospetto non solo della cultura giuridica 'dotta' degli operatori del diritto, ma anche - della cultura medico-psichiatrica.

Sussiste una condizione di malattia nella sfera morale dell'individuo quando questi per le più diverse ragioni si trovi privo della libertà morale intesa come «reminiscenza confusa, di quel complesso di esigenze, di postulati, di precetti, che in ragione di brevità si suole chiamare coscienza morale» ${ }^{22}$. Tutte le questioni scientifiche intorno alla libertà interna hanno a loro primo fondamento una presunzione generale: che esista in ogni uomo la capacità di potersi regolare da sé negli atti della propria vita e di poter assumere sopra di sé la responsabilità piena degli atti stessi. Dal punto di vista giuridico il concetto

19 Ibidem.

20 Arrigo TAmassia, 'La pazzia morale', in Rivista sperimentale di freniatria e di medicina legale, 1877, p. 164.

21 Arrigo TAmassia, 'Il nuovo codice penale Italiano e la pazzia parziale', in Rivista sperimentale di freniatria e di medicina legale, 1876, p. 193.

22 Cfr. Antonio Labriola, Della libertà morale, Napoli, 1873, p. 9. 
della libertà morale si fonda sopra una base assai più larga di quella che s'è andata cercando di attribuirgli in parecchi sistemi scientifici. La libertà morale non è qualcosa di puntuale nell'animo umano, qualcosa di dato immediatamente in esso, una facoltà astratta e generica, è invece una condizione di essere ovvero una condizione che risulta da un complesso di forme della vita interiore considerate in rapporto fra loro. Si tratta di quella forza interiore 'morale' che si contrappone e resiste a un'altra forza, quella dei bassi istinti e della volontà disordinata e spesso ribelle ad ogni freno etico o giuridico ${ }^{23}$.

I risultati conseguiti dalla psicopatologia forense del tempo si ritrovano compendiati nella Teoria antropologica dell'imputabilità di Pietro Cogliolo (1859-1940) in cui i folli morali vengono fatti coincidere con i delinquenti nati. Gli individui che presentano patologie nella sfera morale mostrerebbero tutti i segni peculiari della condizione di chi è destinato a compiere imprese criminali: un numero elevato di anomalie organiche (o presunte tali) che si intersecano con condizioni biologiche e psicologiche. Queste caratteristiche rivelerebbero una stretta connessione tra il folle morale e le forme ataviche di umanità. Come già aveva osservato Lombroso, risulterebbero deficitari di quei dettami necessari a reprimere desideri contrastanti con l'ordine sociale, dettami che risultano saldi negli individui sani. Pur non godendo di una volontà libera, ricordiamo che la scuola positiva a differenza di quella classica nega il libero arbitrio nell'uomo, gli individui sani nella sfera morale assecondano esclusivamente le tendenze conservatrici della società, favorevoli al benessere della comunità per effetto di una ginnastica morale continua ${ }^{24}$.

In tale prospettiva e seguendo questa chiave di lettura, il folle criminale non viene percepito solo come socialmente pericoloso bensì anche come inguaribile nelle sue inclinazioni ed impulsioni antigiuridiche, tanto da rivelarsi una «belva con la maschera di un uomo». Anche la pena perderebbe la sua funzione preventiva per risolversi in un'operazione di neutralizzazione.

23 Ivi, p. 69.

24 PaOlo RicCARDi, Teoria antropologica della imputabilità e dati fondamentali di antropologia criminale, in Completo trattato teorico e pratico di diritto penale secondo il codice unico del Regno D'Italia, pubblicato da Pietro Cogliolo con la collaborazione di avvocati e professori, I, 3, Milano, 1888, p. 242. 
Così scriveva Giuseppe Carnazza Rametta:

alcune manie $[\ldots]$ hanno il triste privilegio della coscienza; cleptomani, piromani, suicidi, omicidi, difficilmente conoscono ciò che fanno, come del pari alcune anormalità psicologiche $[. .$.$] danno casi d'una cosciente azione senza che$ per ciò stesso sia imputabile ${ }^{25}$.

\section{Il problema probatorio}

Una volta entrati in lizza sulla controversa questione della esistenza di una pazzia morale, restava da affrontare un problema più strettamente giuridico, quello probatorio.

Non bisogna trascurare il fatto che tale dibattito nasceva sostanzialmente per la risoluzione di problemi giuridici. In questa fertilissima fase di rinnovamento del penale sostanziale in cui si gettano le radici per l'edificazione di nuove teorie sulla responsabilità penale, gli interpreti avvertono l'esigenza di dare suono e voce a spartiti non suonati da tempo. Per la risoluzione del complesso problema giuridico della analisi delle ipotesi criminose sprovviste di un evidente movente, la scienza medico-legale individuò una serie di segnacoli dal valore indiziario di cui si sarebbero potuti avvalere $i$ giuristi in ambito processuale. Quando ci si trovava di fronte a omicidi di tal specie che facevano sorgere il dubbio sulla integrità mentale dell'imputato come avrebbero dovuto i periti «determinare per lume del Foro» se tali delitti fossero l'effetto di monomania o al contrario di malizia e malvagità?

Nel suo trattato medico-filosofico sulle alienazioni mentali, Philippe Pinel forniva una definizione della mania ragionante fondata sui tratti caratteristici che tali alienati mostravano in sede sperimentale. Dall'analisi clinica di tali pazienti egli aveva individuato costantemente la presenza di una «impulsion aveugle à des actes de violence, ou même d'une fureur sanguinaire», senza che però emer-

25 Giuseppe Carnazza Rametta, Il Positivismo e le riforme nel diritto e nella procedura penale, Messina, 1884, p. 300. 
gesse alcun vizio che interessasse «l'entendement, la perception, le jugement, l'imagination, la mémoire» ${ }^{26}$. L'Esquirol colse il cuore del problema nella sfera morale dell'uomo attribuendo a tale forma di follia il nome di monomania affettiva o pazzia morale. In questa prospettiva, l'omicidio trovava il suo nesso eziologico in una volontà lesa, che aveva coscienza dell'orrore che andava a commettere.

1. Dans quelques cas, le meurtre est provoqué par une conviction intime, mais délirante; par l'exaltation de l'imagination égarée; par un raisonnement faux, ou par les passions en délire. Toujours le monomaniaque est mû par un motif avoué et déraisonnable, et toujours il offre des signes suffisans du délire partiel [...] des affections.

2. Dans d'autres cas, le monomaniaque homicide ne présente aucune altération appréciable de l'intelligence ou des affections. Il est entraîné par un instinct aveugle, par une idée, par quelque chose d'indéfinissable qui le pousse à tuer, et même alors que sa conscience l'avertit de l'horreur de l'acte qu'il va commettre, la volonté lésée est vaincue par la violence de l'entraînement; l'homme est privé de la liberté morale, il est en proie à un délire partiel, il est monomaniaque, il est fou ${ }^{27}$.

Nell'omicidio senza causa apparente l'omicidio si riteneva derivare da un intimo convincimento delirante, frutto di una immaginazione smarrita, di un ragionamento falso oppure di uno stato emotivo disordinato. L'omicidio costituirebbe l'opera di un moto dell'animo invincibile e irragionevole che nasce in alcune circostanze per effetto di una morale corrotta.

Nel 1818 comparve a Pisa l'opera di uno dei pionieri della medicina legale ottocentesca italiana, la Medicina legale secondo lo spirito delle leggi civili e penali veglianti nei governi d'Italia di Giacomo Barzellotti (1768-1839) ${ }^{28}$, in cui si coglie tutto il peso di tale ardua

26 Philippe Pinel, Traité médico-phylosophique sur l'aliénation méntale ou la manie, cit., p. 155.

27 JeAn-Étienne-Dominique Esquirol, Note sur la monomanie-homicide, Paris, 1827, pp. 5-6.

28 Giacomo Barzellotti, Questioni di medicina legale secondo lo spirito delle leggi civili e penali veglianti nei governi d'Italia. Opera rifatta sulla forma antica e portata al livello delle cognizioni attuali, I, Pisa, 1835, p. 406. 
questione affrontata nei suoi risvolti giuridico-probatori. L'indagine processuale del perito forense si sarebbe dovuta incentrare sulle modalità con cui il supposto alienato aveva provocato la morte della vittima. Il medico-legale individuava una serie di segnacoli comprovanti tale particolare tipologia di follia:

1. Il numero di ferite: se ne sono state inferte molte, laddove una sola poteva condurre l'uccisore al suo scopo;

2. Il luogo della uccisione: se è stata perpetrata in un luogo non pericoloso;

3. Le modalità dell'uccisione: se è stata perpetrata con strazio e brutalità;

4. La circostanza della provocazione, cioè l'assenza di una causa.

5. La comprovata innocuità della vittima, in modo da escludere la necessità di difesa legittima.

L'assenza di una causa, la sussistenza di un movente futile, la innocuità della vittima, la efferatezza esecutiva dell'omicidio assurgevano a prova di una forma di follia della sfera morale in grado di indurre chi ne risultasse affetto a compiere reati di sangue per motivazioni di poco peso. L'ultimo e il più forte indizio sul piano probatorio era costituito dal fatto che l'omicida avesse «oltrepassato il bisogno di togliere di vita il soggetto. Questo modus operandi costituiva indizio di follia morale nell'uccisore e la sua forza probatoria si fondava sulla presunzione che coloro che commettono questi delitti con mente sana si fermano una volta raggiunto il loro triste fine, «nascondendo quanto più possono il modo con cui vi sono riusciti» ${ }^{29}$.

Secondo il Barzellotti, se dall'esame della vittima come dell'uccisore fosse risultato che l'uno non conosceva l'altro; che l'uno non aveva provocato l'altro; che la vittima fosse totalmente innocua: l'omicida, che inferociva senza bisogno e al di là del suo fine, doveva ritenersi affetto da monomania omicida ${ }^{30}$. In questa prospettiva poteva affermarsi con ragionevole certezza l'esistenza di un peculiare stato dell'animo in cui si mostra senno, giudizio e discernimento, pur potendo commettersi atti 'da folli' attribuibili alle aberrazioni

29 Ivi, p. 408 .

30 Ivi, p. 409. 
della mente nella sua dimensione morale e non ad una volontà libera. Per gli obiettivi del Foro, nella prospettiva del Barzellotti, coloro che partecipavano al funzionamento della macchina giudiziaria avrebbero dovuto tenere sempre presente che «se gli uomini alcune volte delirano ragionando, molte volte essi ragionano delirando per coprire la colpa, che per poco si cela ${ }^{31}$. Tale metodo di logica argomentazione apparentemente chiaro ed esaustivo non risolveva il problema della perfetta coincidenza dei signa tra l'omicidio dell'immorale e quello messo in atto dal folle morale. I criteri di individuazione della follia morale coincidevano perfettamente con quelli che i giuristi avevano individuato per l'omicidio bestiale. I giuristi si trovarono spesso di fronte a casi processuali di pretesa monomania omicida in cui emergevano tutti gli elementi costitutivi dell'omicidio bestiale. Non era certo un caso che il professore Francesco Puccinotti (1749-1872) nelle sue lezioni di medicina-legale confidava nei giuristi definendoli «conoscitori delle circostanze morali» che accompagnano i più orrendi crimini con pieno dolo. Confidava nella loro abilità di comprendere che la concomitanza dei signa della follia morale con quelli del 'delitto pienamente imputabile' fu ed è possibile. Ed è in forza di tale consapevolezza che il Puccinotti si limitò ad individuare sei criteri per distinguere i casi di monomania omicida dai più atroci ed imputabili misfatti, riponendo fiducia nei cultori della scienza penale ma soprattutto nei giudici a cui sarebbe spettata l'ardua sentenza:

1. Che l'atto volitivo sia inusuale e che, indipendentemente dalla sua moralità, sia in contrapposizione con le ordinarie tendenze degli uomini;

2. Che tali monomaniaci siano nervosi e suscettibili di temperamento e che abbiano aspetti eccentrici nel carattere e nello spirito;

3. Che nessuno di essi avesse mai manifestato segni di propensione a delinquere prima dell'impulso irresistibile;

4. Che avvertano l'orrore dell'idea predominante che li trascina;

5. Che non abbiano complici a differenza dei delinquenti ordinari;

31 Ivi, p. 411. 
6. Che presa la determinazione e mandatala ad effetto sentano una calma insolita, a riprova dell'aver essi non potuto fare altrimenti, «e che li fa riguardare con freddezza la vittima de' loro accessi, e dà loro insuscettibilità al pentimento ${ }^{32}$.

Un ulteriore elemento caratterizzante che avrebbe discriminato in modo esclusivo la monomania omicida da qualunque altra azione criminosa era la «manifestazione supplice ed ingenua» dell'idea terribile che li domina col fine di esserne liberati, ovvero di essere aiutati a porre in salvo se stessi e la vittima designata dal pericolo che li minaccia. Questo sarebbe un ulteriore indizio rivelatore della presenza della monomania omicida, cioè - in altri termini - l'opporre ragione e volontà contro l'azione che il maniaco si sente spinto e forzato irresisti bilmente a commettere. Nel processo di formazione della 'volontà omicidiaria', sosteneva il Puccinotti, arriva un momento in cui alla volontà soggiogata l'operato criminoso appare 'giusto'. L'idea di uccidere si presenta e via via si ingigantisce fino al punto in cui essa prevale sulle reazioni «della ragione e del libero volere».

Mentre invece nell' 'omicidio criminoso' qualsiasi manifestazione del criminale - nella fase preparatoria - non sarà mai diretta ad allontanare la vittima designata. Si tratta, secondo il Puccinotti, di un criterio medico-legale che può servire 'ai periti del diritto e a quelli della mente' da argine insormontabile agli abusi della ignoranza e della pretensione scientifica intorno al controverso tema della monomania omicida. Tale criterio medico-legale manifesta i suoi limiti giuridici rispetto all'ipotesi particolare di nostro interesse dell'omicidio criminoso senza causa', se si accoglie la definizione di monomania omicida istintiva unanimemente riconosciuta dalla comunità scientifico-freniatrica, cioè quella in cui l'impulso omicida sorge imperioso senza causa nota e si connette all'atto concreto della uccisione senza altri motivi se non quello di conferire espressione empirica all'impulso. È, pertanto, necessario che nella condizione

32 Francesco PuccinotTi, Lezioni di medicina-legale, edizione quinta riveduta e corretta dall'autore coll'aggiunta di nuove lezioni inedite e nuovi consulti medicolegali, Livorno, 1847, p. 344. 
monomaniacale l'idea di omicidio non sia derivata da «fattori esterni o da un'idea motivata». Questa è la vera monomania omicida, sostiene il Puccinotti ${ }^{33}$. Diverse erano le ipotesi in cui la monomania fosse seguita da omicidio, in tal caso non si trattava né di tendenza irresistibile né di monomania omicida, bensì di «monomania triste». Questa non sarebbe seguita da omicidio se l'eccessiva sensibilità morbosa dell'individuo non prestasse tanta forza alle lievissime ragioni che lo spingono ad uccidere.

Perché si potesse parlare di tendenza irresistibile e di follia morale non doveva sussistere alcun fattore esterno di rilievo. Negli omicidi che accompagnavano tali condizioni doveva restare esclusa, a suo avviso, non solo la imputabilità ma anche la colpa morale ${ }^{34}$. Si potrebbe obiettare che trattandosi di 'vizi parziali della mente' l'imputabilità criminale non debba essere totalmente esclusa, ma il medico legale precisava

noi non siamo di quelli che sostengono il diritto penale non avere altra base originaria, né altra regola primitiva che quella della espiazione. La teoria dei delitti colposi nella presente età che tanto favoreggia il trascendentalismo psicologico potrebbe avere delle sinistre conseguenze sulla parte chiara, positiva e civile dei codici penali ma crediamo altresì che il non lasciare di prendere in considerazione la colpa morale nei delitti, che si commettono nelle varie specie di monomanie, contribuir possa efficacemente a tener lontano il pericolo di mandar impuniti orrendi misfatti, oggi che tra coteste monomanie si va con troppa frequenza e facilità ricercando $\mathrm{a}$ quelli una escusazione ${ }^{35}$.

Nella monomania omicida non esiste un disegno criminoso che possa comprendere anche il concorso di un complice immorale e dissoluto nell'ideazione e nell'esecuzione del reato. Quello del folle morale è un omicidio senza causa apparente, il motivo dell'uccisione appare irragionevole, non è volto a soddisfare alcuna passione e non risulta connesso ad un altro atto di colpevolezza. Le vittime sono per

\footnotetext{
33 Ivi, p. 345.

34 Ibidem.

35 Ivi, p. 346.
} 
tale omicida indifferenti, si tratta di persone che hanno la sfortuna di trovarsi sui suoi passi nel momento dell'accesso monomaniacale oppure si tratta, al contrario, di persone care sul piano affettivo ma che ugualmente non hanno in alcun modo concorso a provocare l'impulso omicida.

Charles Chretien Henri Marc (1771-1840) individuò tre elementi in presenza dei quali l'omicida si sarebbe dovuto considerare un folle morale:

1. L'assenza di complici nell'ideazione e nell'esecuzione dell'omicidio ${ }^{36}$;

2. L'assenza di un motivo apparente ${ }^{37}$;

3. L'irrilevanza nella individuazione della vittima, salvo la presenza di una relazione sul piano affettivo ${ }^{38}$.

I tentativi di individuare degli aspetti soggettivi ed oggettivi dell'omicidio comprovanti la follia morale mostrano con evidenza lampante i propri limiti nel far luce sulla accesa diatriba - strettamente giuridica nei suoi aspetti pratici processualistici - fra scienza psichiatrica e scienza giuridica sulla distinzione fra omicidio dell'immorale e omicidio del folle morale, diatriba in fondo rimessa all'arbitrio del giudice.

Appare evidente che la questione della responsabilità penale dell'omicida monomaniaco ruota intorno al concetto di libero arbitrio. Lo confermò negli anni precedenti anche Georget, che nel disturbo monomaniacale il desiderio sanguinario soggioga non la

36 Charles Chretien Henri Marc, De la folie, considerée dans ses rapports avec les questions médico-judiciares, Paris, 1840, p. 65: «Les monomaniaques homicides sont isolés, sans complices qui puissent les exciter par leurs conseils, ou leurs exemples. Les criminels ont des camarades d'immoralité, de débauche, et ont ordinairement des complices».

37 Ivi, pp. 65-66: «Le criminel a toujours un motif; le meurtre n'est puor qu'un moyen pour satisfaire une passion plus ou moins criminelle. Presque toujours l'homicide du criminel est compliqué d'un autre acte coupable; le contraire a lieu dans la monomanie homicide».

38 Ivi, p. 66: «Le criminel choisot ses victimes parmi les personnes qui peuvent faire obstacle à ses desseins ou qui puorraient déposer contre lui; les monomaniaque immole des êtres qui lui sont indifférents, ou qui ont le malheur de se rencontrer sous ses pas, au moment où il est saisi par l'idée du meurtre; mais plus souvent, il choisit ses victimes parmi les objets qui lui sont les plus chers». 
mente bensì la volontà dell'omicida. Soggioga il suo - non più libero - arbitrio:

Si le meurtre dépend de la force d'impulsion, il n' y a plus de libre-arbitre [...] puis qu'il y a délire, il n'y a plus de liberté morale et le meurtrier n'est plus responsable ${ }^{39}$.

\section{L'omicidio come mezzo}

La questione della monomania omicida che nell'Ottocento si incuneava nelle aule di tribunale fu definita - come scriveva il primo grande esponente della medicina legale del XIX secolo, Mathieu Joseph Bonaventure Orfila (1787-1853) - una «affection bizarre imaginée par les novateurs», «un fantôme» che, al dire dei giuristi, si voleva far aleggiare nei processi criminali tanto per sottrarre il colpevole alla giusta severità della legge quanto per privare arbitrariamente un cittadino della sua libertà. Ma, a suo parere, l'esistenza di tale affezione della volontà è un fatto incontestabile. I magistrati dell'epoca vennero a conoscenza di molti omicidi commessi da «personnes honnêtes, sans motifs réels, sans intérêt, sans esprit de vengeance ou de cupidité». Si potrebbe obiettare che si tratta di casi isolati, di eccezioni rispetto agli innumerevoli casi di crimini in cui l'omicidio costituisce un «moyen»e non un «but»:

N'est-ce point calomnier l'espèce humaine que de supposer ainsi l'homme bien portant capable de commettre d'horribles forfaits, par l'unique plaisir de se baigner les mains dans les sang de ses semblables ${ }^{40}$ ?

Nelle parole di Orfila si coglie il filo rosso del discorso che si vuole portare avanti in questa sede. Anche nell'omicidio 'senza causa o bestiale', il cui impulso si vuole far derivare dalla malvagità

39 Étienne-Jean Georget, Nouvelle discussion médico-légale sur la Folie, cit., p. 67.

40 Mathieu Joseph Bonaventure Orfila, Leçons de médecine légale, II, Paris-Bruxelles, 1828, p. 65. 
dell'animo umano, l'atto dell'uccisione costituisce il 'mezzo' e non il fine, attraverso cui la sete di sangue trova espressione. Infatti, in assenza di una causa e conseguentemente di un fine, l'atto di uccidere serve al criminale soltanto per placare la propria sete di sangue. Lo stesso accade nella monomania omicida. Ed è proprio l'«absence des motifs» che della monomania costituisce, secondo Orfila, uno dei fondamentali signa ${ }^{41}$.

Fuori dai confini italici, il dibattito sulla oscura e controversa questione della 'monomania omicida senza delirio' - considerata nei suoi rapporti con le questioni giuridiche della colpevolezza e della imputabilità - si protrarrà per tutto il XIX secolo. Molti celebri psichiatri prenderanno posizione sul tema della responsabilità penale in processi criminali. Oltre ai già citati pionieri, basti ricordare Regnault $^{42}$, Leuret ${ }^{43}$, Marc ${ }^{44}$, Pereira ${ }^{45}$, Griesinger ${ }^{46}$, Maudsley ${ }^{47}$, Dubuisson $^{48}$, Vigouroux ${ }^{49}$. A dirla con il Pereira, protagonisti ne erano soggetti in cui si ravvisavano i segni del «délire des instincts», in contrapposizione al «délire de l'intelligence» ${ }^{50}$.

L'«erreur capitale» compiuto da Regnault, secondo Leuret, risiede nell'aver fatto coincidere in tutti i casi di monomania omicida

41 Ibidem.

42 Si veda Elias Regnault, Du degré de compétence des médecins dans les questions judiciaires relatives aux aliénations mentales, et des théories physiologiques sur la monomanie, Paris, 1828; Elias Regnault, François Leuret, Sur la monomanie homicide in Annales d'Hygiène Publique et de Médecine Légale, III, Paris, 1830, p. 231.

43 François Leuret, Du traitement moral de la folie, Paris, 1840.

44 Charl Chretien, Henri Marc, Considérations médico-légales sur la monomanie in Annales d'Hygiène Publique et de Médecine Légale, X, 1833, p. 357; ID., De la folie, considerée dans ses rapports avec les questions médico-judiciares, $\mathrm{Pa}$ ris, 1840.

45 Auguste Pereira, Discussion médico-légale sur la monomanie homicide, in Annales d'Hygiène Publique et de Médecine Légale, XXXIII, Paris, 1845, p. 399.

46 Wilhelm Griesinger, La pathologie mentale au point de vue de l'école somatique allemande in Annales Médico-Psychologique, XXIII, 1865, p. 1.

47 Henry MaudsLey, Responsibility in mental disease, London, 1874.

48 Paul Émile Dubuisson, De l'évolution des opinions en matière de responsabilité, cit., p. 101.

49 Paul Emile Dubuisson, Auguste Vigouroux, Responsabilité pénale et folie: étude médico-légale, Paris, 1911.

50 Auguste Pereira, Discussion médico-légale sur la monomanie homicide, cit., p. 401. 
la coscienza (delle proprie azioni) con la libertà (di compierle). In una lettera datata 20 gennaio 1830 Regnault rispose alle osservazioni di Leuret sulla questione:

Lorsque le médecin établirait savamment coram judice, qu'il se peut rencontrer des cas où un homme soit fou et conserve sa conscience, comme il n'y aurait alors aucune différence entre la raison et la folie, l'embarras du juge augmenterait en proportion de l'incertitude de la science ${ }^{51}$.

Secondo Regnault non può esservi follia con conservazione della coscienza nella sua integrità. Ma Leuret nel suo réponse evidenziò che «il y a des impulsions instinctives qui privent quelquefois l'homme de sa liberté, mais non de sa conscience. Et ce qui distingue le criminel du monomaniaque homicide, c'est que, chez le premier, il y a conscience, liberté, volonté; tandis que, chez le second, il y a conscience sans liberté. Cette distinction est réelle, parce que, je le répète, la conscience et la liberté sont distinctes et séparables l'une de l'autre $\gg^{52}$. E a sostegno della sua tesi, secondo cui nella monomania omicida c'è coscienza ma non c'è libertà, egli prende ad esempio alcuni casi risolti anteriormente alle teorie dell'Esquirol e del Georget. Un uomo malato fece un bagno e salì in camera per dormire, ma non riusciva a trovare la tranquillità. Affondò la testa sotto la cuffia, convinto che l'aria gli nuocesse. Si guardò allo specchio e disse ai suoi servitori che capiva avessero paura di lui, ma che non ce n'era motivo. E aggiunse che invero egli sentiva un irrefrenabile bisogno di mordere, ma che avrebbe morso sé stesso, e così fece alle mani e alle braccia ${ }^{53}$. In un altro caso, una ragazza frequentava normalmente i suoi numerosi amici, tranne nei momenti in cui era presa dai suoi 'accessi'. In questo caso si rinchiudeva nella sua stanza, nel timore di procurare danni agli altri contro la propria volontà. Nel corso degli anni, gli episodi maniacali si prolungarono sempre

51 Elias Regnault, François Leuret, Sur la monomanie homicide, in Annales d'Hygiène Publique et de Médecine Légale, III, Paris, 1830, pp. 233-234.

52 Ivi, p. 236.

53 Ibidem. Leuret riporta dei casi clinici ritrovati in M. EMPEREur, Observations recueillies au mois de juillet 1781, II parte, in Mémoires de la Société royale de Médecine, 1783, p. 224. 
più. A chi dall'esterno della stanza le chiedeva se avesse bisogno di aiuto rispondeva di non entrare perché avrebbe potuto divorarli ${ }^{54}$.

Si tratta di casi in cui gli impulsi feroci coesistono con una condizione integra dell'intelligenza e della affettività, tanto l'uomo 'mordace' quanto la donna 'divoratrice' hanno piena coscienza dei loro atti e conservano integra la libertà morale.

Sarebbe, pertanto, ingiusto ed assurdo, afferma il Leuret, condannare in un idrofobo azioni impulsive, feroci ma involontarie, e parimenti ingiusto e assurdo lo sarebbe in un monomaniaco omicida, «supposé que celui-ci n'ait obéi qu'à une impulsion involontaire». I monomaniaci omicidi sono scusati «comme ayant agi sans liberté, et par conséquent, comme fous». Non si può dire che un uomo sia pazzo a meno che non abbia perso la coscienza sia del suo essere, sia della sua maniera di essere, sia della sua posizione sociale, sia dei suoi rapporti normali con il mondo esteriore. Altrimenti secondo il Leuret non è possibile parlare di follia ${ }^{55}$.

\section{Monomania id est Melanconia}

Non solo sul piano formale ma soprattutto su quello sostanziale la categoria della monomania dei primi anni dell'Ottocento coincideva perfettamente con la antica categoria della melanconia, con una più dettagliata individuazione del punto focale della questione, l'assenza della libertà morale.

Nel XIX secolo con altri involucri definitori la scienza medica e quella giuridica ripresero a discutere su questioni già affrontate e rimaste irrisolte. È importante precisare che il termine melanconia non verrà completamente sostituito da quello di monomania e si ritroverà nei trattati di medicina legale quanto in quelli dei giuristi oltre che nelle perizie mediche di quei criminali che dalle carceri verranno trasferiti nei manicomi in quanto non imputabili per difetto di volontà.

La monomania, nello specifico quella omicida, veniva inclusa nel

54 Ivi, p. 303.

55 Elias Regnault, François Leuret, 'Sur la monomanie homicide', cit., p. 238. 
novero delle follie delle facoltà affettive, in particolare veniva descritta come una peculiare specie di lipemania o melanconia. La malattia della volontà riacquista il suo antico nome. La si ritrova come melanconia, per esempio, nelle considerazioni medico-legali di Biagio Gioacchino Miraglia (1814-1885) sullo stato di mente della signora Teresa Santoro querelante di sequestro della propria persona nel manicomio di Napo$1 i^{56}$, la cui condizione della psiche risultava connotata da pervertimenti affettivi, impulsi morbosi dominanti e cupi, nella quale restava pressocché intatta l'attività psichica su tutto ciò che non aveva rapporto col turbamento mentale circoscritto che costituiva la psicopatia. La follia parziale si ritrova classificata come mono-mania o mono-malinconia a seconda che sia accompagnata da stati di eccitazione da impulsi irresistibili degli istinti oppure da stati depressivi per emozioni eccessive e tendenzialmente cupe. La particolare tipologia di mono-mania in cui l'idea ossessiva è l'omicidio viene da diversi alienisti accostata alla melanconia, per essere al contempo follia parziale e cupa.

Non si trattava di una scelta puramente italiana. Anche nelle pagine di Auguste Pereira il délire des instincts si ritrova descritto con l'originario termine melancholia. Pertanto, per descrivere tale forma di follia si utilizzava anche la formula definitoria più antica a cui Esquirol aveva attribuito il nuovo nomen di manie raisonante a voler rimarcare uno degli elementi caratterizzanti della malattia. Pertanto si preciserà che la monomania costituiva una delle «variétes du délire lypémaniaque» ossia una particolare specie del disturbo della mélancolie, i cui sintomi costituivano «expression du désordre des affections» ${ }^{57}$.

La perfetta coincidenza fra la monomania e la melanconia venne evidenziata anche dal medico-legale americano Horatio Curtis Wo$\mathrm{od}^{58}$ che scelse di inserire nel titolo della sua opera sull'impulso irresistibile ad uccidere ${ }^{59}$, entrambi i termini. p. 113.

56 Biagio Gioacchino Miraglia, La legge e la follia ragionante, Napoli, 1871,

57 Auguste Pereira, Discussion médico-légale sur la monomanie homicide, cit., p. 403.

58 Per i riferimenti biografici si veda F.A. CAStle, C. Rice, New Remedies an illustrated monthly trade journal of materia medica, pharmacy and therapeutics, X, New York, 1881, p. 257.

59 Horatio Curtis Wood, Melancholia, Monomania. Two clinical lectures delivered November, 1885, at the Philadelphia Hospital, Philadelphia, 1885, p. 3. 
E sulla questione della responsabilità penale relativamente ai crimini commessi dai melanconici il Pereira scrisse che «tous le malades de cette catégorie sont aujourd'hui légalement déchargés de la responsabilité de leurs actions, tant dans l'ordre civil que dans l'ordre criminel, e la loi n'est en ceci qu'une judicieuse consécration des faits ${ }^{60}$. La sua trattazione prendeva le mosse da un caso processuale in cui la melanconia, che a dire dei periti affliggeva l'imputato, veniva invocata come «moyen de défense dans le procès criminel». Lungi dall'intenzione, come lui stesso ebbe a dire, di minare la 'cosa giudicata', il Pereira rilevava che nel processo si affrontava una delle questioni scientifiche più dibattute dalla medicina legale ${ }^{61}$.

Il 21 luglio del 1844, Jean-François Blottin, bracciante agricolo di quarant'anni, veniva accusato di avere sgozzato la nipote con un rasoio da barba. Questi fu condannato dalla Corte d'Assise di Loiret alla pena dei lavori forzati a vita. Il Pereira, prima di addentrarsi nella delicata questione giuridica della follia parziale nell'omicidio, invoca i principi della legislazione che regolano l'alienazione mentale in materia penale, nonché alcune classificazioni mediche stabilite dagli alienisti nello studio della melanconia. Nel codice penale napoleonico, in particolare nella prima parte dell'art. 64 si ritrovava disciplinato il reato commesso dall'infermo di mente: «il n'y a ni crime ni délit lorsque le prévenu était en démence au moment de l'action ${ }^{62}$. Il legislatore utilizzava il termine generico démence per indicare, sottolinea il Pereira, «une aliénation d'esprit de quelque nature qu'elle soit». Il concetto di demenza viene utilizzato genericamente a comprendere tutte le categorie dell'alienazione mentale che la scienza medica aveva individuato. Ma la «loi va même encore plus loin» scrive il Pereira, essa non esige che si tratti di una demenza abituale, l'unica specificazione che si ritrova nel testo di legge è che lo stato di alienazione sia riscontrabile au moment de l'action. Dun-

60 Auguste Pereira, Discussion médico-légale sur la monomanie homicide, cit., p. 404.

61 Ivi, p. 399.

62 Code Pénal, Paris, 1810, art. 64; In generale si veda J.S.G. NYPELs, Le droit pénal français progressif et comparé. Code pénal de 1810 accompagné des Sources, des Discussions au Conseil d'État, des Exposés des motifs et des Rapports faits au Corps législatif, Bruxelles, 1863. 
que, tale formula racchiude qualsiasi forma di follia, anche quella 'temporanea' che è in grado di «enlèver à celui qui en est atteint la responsabilité morale de son acte» ${ }^{63}$. Ma la riflessione su tale disposizione généreuse merita approfondimenti dettati «par un haut sens philosophique», vedendosi quotidianamente magistrati condannare severamente «des actions entachées d'une véritable folie, sous le seul prétexte de l'apparente raison de leurs auteurs avant et après elles». In tal modo viene posta in evidenza la causa che induceva $\mathrm{i}$ magistrati a negare la scusante della follia in questi casi, cioè la sussistenza di un'apparente ragione e la conservazione dell'intelletto.

Malgrado la protezione che la legge sembra riservare, secondo il Pereira, alla follia in tutte le sue forme e pertanto implicitamente anche alla monomania, vi sono magistrati che negano l'esistenza della follia parziale considerandola un'astrazione metafisica ${ }^{64}$. Se restavano ignote le modalità di eccitazione cerebrale che determinano le funzioni della intelligenza e della volontà, innegabile appariva la loro precisa localizzazione nella massa encefalica. Infatti, se queste funzioni sono distinte, perché non si dovrebbe ammettere che possano autonomamente incorrere in patologie? La risposta è netta:

Il est vrai que ces divisions pathologiques, réelles en principe, ne sont pas toujours nettement tranchées, et que la solidarité des diverses parties d'un même tout peut finir par généraliser un trouble primitivement partiel; mais il n'est pas moins vrai qu'à chaque lésion circonscrite soigneusement étudiée se rattache, au moins au début, un ordre particulier de symptômes ${ }^{65}$.

Henry Maudsley (1835-1918), professore di medical jurisprudence all'Università di Londra, nel suo trattato Responsibility in mental disease del 1874 dedicò il V ed il VI capitolo alla Partial Insanity discorrendo nel V dell'Affective Insanity e nel VI della Partial Intellectual Insanity. Nell'Affective Insanity colloca la Homicidal Monomania e la descrive come una malattia che può in alcuni casi inficiare so-

63 Auguste Pereira, Discussion médico-légale sur la monomanie homicide, cit., p. 400.

64 Ibidem.

65 Ivi, p. 401. 
lo la volontà e non l'intelletto ${ }^{66}$. Nel tempo, a partire dall'Esquirol, il termine monomania è stato impiegato in due sensi diversi: l'uno per indicare un delirio fisso e l'altro per designare la forma di alienazione mentale in cui, pur mancando il delirio, il paziente è tiranneggiato da una impulsione folle e irresistibile all'omicidio. Il Maudsley definì tale patologia come impulsive insanity e non instinctive insanity, per non implicare nel maniaco un istinto naturale verso il delitto.

Nel comune sentire, sembra inconcepibile che un individuo in tali condizioni non abbia il dominio dei propri impulsi. Il Maudsley, però, riporta due fra i numerosi casi a lui noti. Egli racconta di essere stato consultato da un uomo sui cinquant'anni dotato di una grande robustezza fisica, questi aveva condotto una vita attiva e percorso molte parti del mondo, ma da molti anni diceva di essere tormentato dall'impulso all'omicidio e di vivere in una angoscia inesprimibile. La sete di sangue lo agitava continuamente e talvolta risultava così potente, che egli si vedeva costretto a separarsi dai suoi familiari per il timore di divenirne l'uccisore. Quando l'impulso iniziava a farsi largo nella sua mente, vestiva la forma di una 'idea' ingombrante e ossessiva, ma al di fuori di una reale inclinazione di tradurla in atto. Si trattava di «a homicidal idea rather than a homicidal impulse» ${ }^{67}$. Ma questa idea pian piano cresceva di intensità e giungeva al parossismo. In quegli istanti il sangue gli saliva al cervello ed egli provava una sensazione di ingombro al capo e di confusione, con un orribile sentimento di disperazione e con un tremito violento di tutto il corpo. La crisi si scioglieva con un profluvio di lacrime, seguito da uno spossamento profondo. Questi accessi lo coglievano durante la notte e allora balzava dal letto in uno stato di mortale terrore. Secondo il Maudsley il paziente non offriva alcun segno di disturbo mentale, nessun danno all'intelletto:

He was manifestly a person of great decision and energy of character, and he did not exhibit any further evidence of intellectual derangement unless it were a morbid tendency to a groundless suspicion and distrust ${ }^{68}$.

66 Henry Maudsley, Responsibility in mental disease, cit., p. 142.

67 Ivi, p. 144.

68 Ibidem. 
Il secondo caso riguardava un'anziana donna soggetta a frequenti parossismi di collera convulsiva, che la portavano a desiderare con veemenza di strangolare sua figlia, la quale peraltro le era assai affezionata, la curava, ed era da lei molto amata. Su tale condizione il medico «no one could detect any delusion in her mind». Della sua tendenza omicida «she felt the greatest horror» ${ }^{69}$.

Il nesso eziologico fra la monomania-melancholia e l'impulso irresistibile ad uccidere emerge con lampante chiarezza nell'opera realizzata nel 1885 dal medico-legale americano Horatio Curtis Wood in cui si legge:

When we go a step further in melancholia we have both hallucinations and delusions. These appear sometimes earlier and sometimes later, but they always take the depressive type. Hallucinations of hearing are the most frequent. The patient hears voices, but these are evil voices. Those who have committed murder have sometimes asserted that they had two voices in them, one saying, 'Kill! Kill!' the other voice trying to restrain them. Men have held their hands in the fire until they were burnt black, because they have heard voices telling them that it was better to enter into the next world maimed than to go with a whole hand guilty of blood or other offence $^{70}$.

La melancholia o monomania talvolta conduce ad un delirio allucinatorio che genera una forza impulsiva irresistibile con contenuti depressivi spingendo il malato ad uccidere apparentemente senza alcuna ragione se non a causa di quell'idea ossessiva che recondita alberga il suo animo. Due voci talvolta soggiogano la sua mente, una che lo spinge ad uccidere ed un'altra che prova a trattenerlo come fosse ostaggio di «troops of demons».

Paul Emile Dubuisson sull'«impulsion irrésistibles a l'homicide» scriverà:

Le grand point par lequel ces prétendus homicidomanes diffèrent des impulsifs construits suivant la formule, c'est

69 Ivi, p. 145.

70 Horatio Curtis Wood, Melancholia, Monomania, cit., p. 3. 
qu'ils résistent toujours à leur impulsion criminelle. Et nous nous demandons dès lors, pourquoi on qualifie cette impulsion d'irrésistible. [...] Les hasards cliniques nous ont mis quelquefois en présence d'individus présentant des impulsions homicides, mais jamais nous n'avons rencontré d'homicidomanies offrant les caractères indiqués plus haut, bien que tous nous soient arrivés avec des certificats médicaux constatant des impulsions irrésistibles avec intégrité de l'intelligence ${ }^{71}$.

Appaiono, pertanto, manifesti i risvolti strettamente giuridici che l'accoglimento scientifico di tali teorie sulla follia morale comportano, in riferimento alla dimensione soggettiva del reato, alla volontà di uccidere e all'imputabilità dell'omicida. L'imputabilità non viene più definita solo attraverso l'analisi del regime di materialità del reato ma anche attraverso la conoscenza del regime di responsabilità dell'agente, persino quando il criminale non appare folle sul piano intellettivo. L'inclusione della dimensione psicologica individuale nella dinamica tra il crimine e la pena ${ }^{72}$ apre alla follia le porte del Foro. Si riproposero antichi problemi che mostravano nella teoria e nella prassi le difficoltà di distinguere la follia dalla semplice immoralità nel crimine ${ }^{73}$. Sarebbe riduttivo ed errato tenere nettamente separati gli orientamenti della scienza medica da quelli della scienza giuridica. Tale ardua questione non può risolversi sic et simpliciter con l'ammissione da parte della scienza medica dell'esistenza di una dimensione malvagia dell'animo umano, né tantomeno con il pieno e cieco accoglimento da parte della scienza giuridica della follia morale. Dopo secoli di storia perdurano le difficoltà per entrambi i saperi di delineare esattamente la linea di confine fra queste due dimensioni.

71 Paul Emile Dubuisson, Auguste Vigouroux, Responsabilité pénale et folie: étude médico-légale, cit., pp. 276-277.

72 L'omicidio, dal punto di vista psichiatrico, costituisce una delle possibili reazioni «morbides, volontaires ou automatiques» messe in opera da individui con affezioni mentali. "C'est un symptôme», un disturbo dell'agire correlato a stati di perversione o indebolimento delle facoltà psichiche. Cfr. D. Vladoff, L'homicide en pathologie mentale. Étude clinique et médico-légale, Paris, 1911, p. 1.

73 Étienne-Jean Georget, Nouvelle discussion médico-légale sur la Folie ou Aliénation mental, cit., p. 70. 
7. Un fantôme?

Anche all'interno della medicina-legale sulla questione non mancarono orientamenti più scettici.

Collard de Martigny cercherà di dimostrare che se la monomania nell'omicidio è possibile, gli esempi non contestabili sono rarissimi; che è molto difficile costatarla ma agevolissimo fingerla. Il medico francese la definisce un movente passionale particolare, al pari della gelosia. Pertanto i giudici conseguentemente dovrebbero rigettare un sistema giuridico che pare voglia ricoprire tutti i delitti con l'egida della pazzia. Prima di addentrarsi nella discussione sulla monomania omicida, il Martigny precisa che il fine della sua trattazione lungi dall'essere quello di desiderare la pena capitale per coloro che con la scusa della monomania potrebbero sottrarvisi. Questi divide in tre classi i casi che i diversi psichiatri hanno menzionato a comprova della esistenza di tale psicopatologia:

1. Nella prima classe rientrano i casi che non presentano il carattere né della follia né della monomania;

2. Nella seconda i casi di delirio furioso, mania 'estesa' con allucinazioni accompagnate e seguite da furore;

3. Soltanto nella terza i veri casi che possono dar luogo a discutere di tale patologia.

Nella prima classe rientra certamente il caso di Enrico Feldtman, di anni cinquantasei, sartore di professione. Questi compariva il 24 marzo 1823 avanti la Corte d'assise della Senna con l'accusa di aver ucciso la propria figlia.

Nelle perizie psichiatriche Feldtman veniva descritto come un uomo collerico e dotato di una intelligenza limitata, affetto da una forma di idiotismo. L'imputato avrebbe concepito e nutrito sin dal 1815 un amore incestuoso per la propria figlia Vittoria. La moglie e le figlie in più occasioni furono obbligate a fuggire per sottrarre Vittoria agli impudici attentati e ai trasporti erotici del padre. Avendo scoperto il luogo in cui si erano rifugiate minacciava di compiere atti di violenza qualora non fossero stati soddisfatti i suoi desideri. Così il 24 marzo 1823 si munì di coltello e andò a trovare la sua famiglia 
e rinnovò le sue idee criminose per determinarla a seguirlo. Dopo il rifiuto ferì al cuore la figlia Vittoria e ugualmente non risparmiò la moglie e l'altra sua figlia.

Feldtman si lasciò arrestare senza opporre resistenza, lucido e convinto di aver fatto la cosa giusta. In sede di interrogatorio confessò di aver acquistato il coltello con l'intenzione di ferire la figlia che era solita non obbedirlo.

Nel corso dell'udienza Feldtman «non dette alcun segno di aberrazione mentale». Anche la moglie dichiarò al giudice d'istruzione che il marito non era affetto da alcun disordine intellettuale se non quando si trattava di sua figlia Vittoria. Fatta eccezione per uno, nessun testimone tra quelli che conoscevano l'accusato aveva mai notato in lui alcun segno di alienazione mentale. Ciononostante la difesa descrive un soggetto affetto da un intelletto debole e disordinato da una violenta passione.

Per il Martigny si tratta di un soggetto 'sano' innamorato della figlia che è giunto a sacrificarla a causa della resistenza da questa oppostagli. Nell'incestuoso amore di costui che si sviluppa in una sequela di anni; nell'odio che sfocia in furore omicida per la resistenza della figlia, il medico vede una violenta passione e non una alienazione mentale. Il medico-legale descrive il delitto come 'volontario e premeditato' anche perché l'imputato aveva minacciato in più occasioni di voler giungere ad atti di violenza. Questi acquista un coltello e raggiunge la figlia con intenzione di ucciderla; come provvisto di causa e la rinviene nella resistenza della figlia Vittoria ai suoi perversi desideri; come eseguito con tutte le precauzioni che potevano assicurarne il succes$\mathrm{so}^{74}$. Pertanto se precauzioni e circostanze così orribili, se una volontà così perseverante, una cognizione così esatta dell'atto commesso, una sequela di idee criminogene così perfetto non escludono l'alienazione mentale, quando ci si trova davanti ad un vero criminale?

Il Martigny rileva una forte rassomiglianza fra i tratti della monomania omicida e i tratti degli stati passionali fino ad affermarne una perfetta coincidenza.

74 Collard de Martigny, Tre questioni di giurisprudenza medico-legale. La vitalità in materia civile e criminale, la monomania nell'omicidio e la libertà morale, la responsabilità legale nei medici, trad. di A. Pierotti, Firenze, 1847, p. 45. 
II. Le ragioni della scienza giuridica

\section{Il male per amore del male: la Scuola classica}

La scienza giuridica ottocentesca si muove su questo terreno, ispirato dal sapere psichiatrico, seguendo orientamenti che mostrano talvolta diffidenza talaltra apertura nei confronti delle nuove scoperte che interessano l'animo umano. Le ragioni per cui i cultori del diritto si muovono con maggiore prudenza sull'affannoso problema del fondamento psicologico della responsabilità penale si rinvengono nella natura stessa del ragionamento giuridico. Esso non è destinato a definire, a determinare l'essenza delle cose, piuttosto è rivolto a comprendere i fenomeni criminosi nella molteplicità e varietà della esperienza umana. La scienza giuridica sceglie di essere pervasa dal dubbio, si concepisce come logica del probabile, del certamente vero e del certamente falso ${ }^{75}$.

Intorno al più ampio problema giuridico della imputabilità orbita quello dell'individuazione della natura dell'impulso che spinge a delinquere.

Un dilemma è dominante e imperversa, variamente declinato, nelle pagine dei giuristi. Da un lato sussiste il pericolo di mancare per troppa larghezza alle esigenze di quella necessità sociale di repressione dei crimini propria della responsabilità penale; dall'altro sussiste il pericolo che per eccessivo rigore si assoggetti a pena un infelice, a cui le alterate facoltà della mente velavano la coscienza del crimine commesso ovvero paralizzavano il libero arbitrio di commetterlo o astenersene. La soluzione del problema penale essenzialmente processuale - risiede quindi nella «conciliazione di questi due principi a prima vista contrastanti, il pronto ed esatto punimento dei rei e la libertà civile» ${ }^{76}$.

Nell'Italia dei primi decenni dell'Ottocento, il dibattito sulla de-

75 Sul punto si veda A. Giuliani, Imputation et justification, in Archives de philosophie du droit, 22, La responsabilité, 1966, pp. 94-95.

76 Sul giusto mezzo che unisca l'esigenza di sicurezza pubblica a quella di esatto castigo dei rei si veda Mario Pagano, Considerazioni di Francesco Mario Pagano sul processo criminale, Napoli, 1787, p. 18. Sul punto si veda E. Dezza, Saggi di storia del diritto penale moderno, Milano, 1992, p. 55. 
terminazione dell'imputabilità nelle alienazioni di mente trova voce attraverso il celebre giurista Pellegrino Rossi che accosta la questione dell'omicidio bestiale al fenomeno di rilevanza medico-legale della mania parziale o monomania ricordando che dai giuristi della criminalistica seicentesca essa era denominata «delirio esclusivo su un oggetto» o melancholia ${ }^{77}$. Il Rossi, come il Romagnosi, ma con altri intenti e in un'ottica antitetica ${ }^{78}$, parlerà espressamente di crimini commessi da una particolare tipologia di criminali: i monomaniaci, che fanno così la loro comparsa nel mondo del diritto. Interrogandosi sulla natura dei reati compiuti da questi ultimi, egli scrive:

In effetto quali sono questi atti? Dei fatti isolati, un enorme misfatto, un omicidio commesso senza verun motivo apparente, senza che si ravvisi veruna delle cagioni che ordinariamente spiegano, senza giustificarla, l'azione criminosa. Questi fatti erano conosciuti dagli antichi criminalisti; e parecchi fra di loro disegnavano l'omicidio senza cagione sotto il nome di omicidio bestiale ${ }^{79}$.

Appare chiaro che il giurista toscano riprende il concetto di monomania di derivazione psichiatrica. La questione nodale risiede nel duplice e antitetico volto che a tale fenomeno omicidiario è stato attribuito sulla base di diversi orientamenti di politica criminale: quello conferitogli da giuristi focalizzati sulla dimensione morale dell'agire umano; quello conferitogli da giuristi propensi ad accogliere approcci interpretativi propri della psicopatologia forense. Pellegrino Rossi certamente appartiene alla prima cerchia di intellettuali e lo si rileva agevolmente quando scrive:

77 Anche il celebre psichiatra Philippe Pinel, sulla scia dell'antica medicina-legale e criminalistica, definiva con il termine «mélancolie» il «délire exclusif sur un objet, ou sur une série particulière d'objets; nul penchant à des actes de violence que celui qui peut être imprimé par une idée dominante et chimérique; d'ailleurs, libre exercice de toutes les facultés de l'entendement, cfr. Philippe PInel, Traité médico-phylosophique sur l'aliénation méntale ou la manie, cit., p. 149.

78 Più incline a riconoscere la fonte psicopatologica di alcuni crimini, fra $\mathrm{i}$ più atroci e spaventosi, era il Romagnosi che li descriveva, nel momento della loro esplosione, come l'effetto di una vera monomania. Vedi Gian Domenico RomagnoSI, Genesi del diritto penale, cit., p. 78.

79 Pellegrino Rossi, Trattato di diritto penale prima versione italiana di Antonio Fazzini, II, Napoli, 1832, pp. 23-24. 
L'uomo finché è dotato di ragione, non opera mai senza un motivo. Sta bene. Ma ci fa mestieri dichiarar folli tutti gli uomini che commettono un fatto isolato per un motivo che ci è incognito, il cui impulso non è da noi ravvisato? Ei fa il male per amor del male ${ }^{80}$.

Egli rinviene nell'intelletto la guida suprema dell'agire umano. Pertanto, se nel criminale l'intelletto appare integro e conservato, le sue azioni di riflesso non potranno essere immotivate e disordinate. L'omicidio commesso per una causa incognita non può che essere qualificato come omicidio perpetrato per malvagità perché l'assassino sceglie di «accarezzare e di non respingere un desiderio criminoso irresistibile» che lo terrà a sé ancorato «come uno schiavo incatenato ad una belva». Il Rossi non esclude che si possa trattare di omicidi commessi da monomaniaci che nell'atto di uccidere avessero la ragione traviata, ma eleva la condizione di alterazione della mente ad effetto dell'esecuzione del delitto ${ }^{81}$ :

I monomani conoscono l'immoralità della loro inclinazione, hanno la coscienza di loro medesimi e del male che si fanno a commettere; non cadono nello stato di traviamento se non quando il desiderio che han trascurato di padroneggiare li sospinge all'ultimo termine del cammino; sono spaventati dal delitto che han commesso; conoscono d'aver fatto il male e ne sentono rimorso: cose tutte incompatibili con la vera follia ${ }^{82}$.

Risulta con chiarezza l'atteggiamento di diffidenza del Rossi nei confronti dell'esistenza di una follia parziale. Al contrario nel caso di accertamento di una demenza parziale non dovrebbe conseguire, soltanto per tale ragione, che tutti gli atti con causa ignota siano atti di demenza e che i loro autori li abbiano compiuti avendo smarrito ogni coscienza di sé stessi e della natura dello loro azioni.

Tali argomentazioni derivano dalle concezioni sul libero arbitrio e sulla libertà morale della Scuola classica, a cui il Rossi certamente

80 Ivi, p. 24.

81 In questa prospettiva la colpevolezza del folle morale risiederebbe nel non aver governato e messo a tacere sul nascere gli impulsi criminali.

82 Pellegrino Rossi, Trattato di diritto penale prima versione italiana di Antonio Fazzini, cit., p. 25. 
appartiene ${ }^{83}$. Sostenere che la responsabilità penale derivi dal fatto che il criminale abbia scelto di non respingere l'impulso criminale significa considerare il criminale sempre libero di scegliere, sempre meritevole di punizione per il cattivo uso che abbia scelto di fare della sua libertà morale. D'altra parte vi sono le esigenze insopprimibili della vita sociale, per la società l'irresponsabilità penale soprattutto nei delitti atrocissimi è inammissibile. Da un punto di vista astratto può negarsi la libertà e la responsabilità, ma non da un punto di vista etico-sociale, «questa è indispensabile per la vita dei popoli, oltre che postulata dalla nostra coscienza» ${ }^{84}$. Da questa angolazione ogni effetto criminoso consegue sempre ad una sua causa corrispondente. Sono le esigenze della società che ci assicurano che esiste la liber-

83 Sulla Scuola Classica e la Scuola Positiva si indicano, senza pretesa di completezza, M. Sbriccoli, Il diritto penale sociale, 1883-1912, in Quaderni fiorentini per la storia del pensiero giuridico moderno, 2, 1973, pp. 556-642; ID., Dissenso politico e diritto penale in Italia tra Otto e Novecento. Il problema dei reati politici dal Programma di Carrara al Trattato di Manzini, in Quaderni fiorentini per la storia del pensiero giuridico moderno, 3/4, 1974-75, pp. 607-702; ID., Elementi per una bibliografia del socialismo giuridico, in Quaderni fiorentini per la storia del pensiero giuridico moderno, 3/4, 1974-75, pp. 873-1035; G. NeppI Modona, Legislazione penale, in Il mondo contemporaneo, Storia d'Italia 2, II, Firenze, 1978, pp. 588-605; ID., Diritto penale e positivismo, in E.R. PAPA (a cura di), Il Positivismo e la cultura italiana, Milano, 1985, pp. 47-61; F. ColaO, Le ideologie penalistiche fra Ottocento e Novecento, in A. Mazzacane (a cura di), I giuristi e la crisi dello Stato liberale in Italia fra Otto e Novecento, Napoli, 1986, pp. 107-123; M. SBriccoli, Il diritto penale liberale. «La Rivista penale» di Luigi Lucchini 1874-1900, in Quaderni fiorentini per la storia del pensiero giuridico moderno, 16, 1987, pp. 105-183; L. LAcCHÈ, La giustizia per i galantuomini. Ordine e libertà nell'Italia liberale: il dibattito sul carcere preventivo (1865-1913), Milano, 1990, pp. 123-193; M. SBriccoli, La penalistica civile. Teorie e ideologie del diritto penale nell'Italia unita, in A. Schiavone (a cura di), Stato e cultura giuridica in Italia dall'Unità alla Repubblica, Roma-Bari, 1990, pp. 147-232; E. DezzA, Tra scuola classica e scuola positiva: Antonio Buccellati e le sue istituzioni di diritto e procedura penale (1884), in ID., Saggi di Storia del Diritto penale moderno, cit., pp. 391-423; ID., Imputabilità e infermità mentale: la genesi dell'articolo 46 del codice Zanardel$l i$, in ID., Saggi di storia del diritto penale moderno, Milano, 1992, pp. 281-316; C.F. Grosso, Le grandi correnti del pensiero penalistico italiano fra Otto e Novecento, in Storia d'Italia. Annali 12, Torino, 1997, pp. 7-34; M. SBriccoli, Caratteri originari e permanenti del sistema penale italiano (1860-1990), in Storia d'Italia. Annali 14, Torino, 1998, pp. 487-551.

84 Luigi Scarano, Libera volontà e libero arbitrio nel diritto penale, Milano, 1937 , p. 56. 
tà e la responsabilità nell'agire umano, senza delle quali non potrebbe sussistere alcun ordinamento giuridico ${ }^{85}$.

In un certo senso la questione ruota intorno all'accettazione della coesistenza - ibrida e per tale ragione temibile - di ragione e follia: nel caso della monomania o follia parziale siamo di fronte ad una catastrofe della volontà e della morale compatibile con l'integrità delle funzioni intellettuali.

Sulla monomania omicida, definita «la più terribile di tutte le monomanie» per gli effetti pericolosi che produce, Nicola Nicolini $(1772-1857)^{86}$, avvocato generale del re presso la corte suprema di giustizia del regno di Napoli e professore di diritto penale nella regia università, ebbe a dire trattarsi di «una intima convinzione nata da falsi principii e da passioni in delirio, ovvero un cieco impulso, un'idea strana che non può scacciarsi di mente». Un non so che di fatale e d'indefinibile che trascina l'uomo al misfatto. Con questa denominazione, afferma il Nicolini, si è cercato di descrivere la con-

85 In questa prospettiva le esigenze della vita sociale proclamano la responsabilità penale e il libero arbitrio dell'individuo. Lo Stato fondandosi su una «finzione» presuppone che il delinquente possa agire sempre liberamente. La libertà morale costituisce per il diritto un'utile finzione, per un approfondimento su tali argomentazioni si vedano, Henry Maudsley, Phisiologie de l'esprit, Paris, 1879, pp. 393-394; A. Pozzolini, Contributo alla teorica della responsabilità penale, Volume di onoranze per Pessina, Lucca, 1899, p. 50; M. MAYER, Die Schuldhaftung und ihre Arten im Strafrecht, Leipzig, 1901, p. 92; P. Cuche, La responsabilité des criminals, in Revue Pénitentiaire, 1908, p. 144; J. MAXwELL, Le crime et la société, Paris, 1909, p. 128; F.W.G. Kohlrausch, Sollen und Können als Grundlagen der strafrechtlichen Zurechnung, Festgabe für Güterbock, Berlin, 1910, p. 10; A. CARDONE, La responsabilità nel relativismo contemporaneo, Palmi, 1925, p. 11.

86 Nicola Nicolini nacque in Tollo, comune della provincia di Chieti in Abruzzo. La sua famiglia conta nomi cogniti nelle lettere e nella magistratura. Nel 1809 fu nominato Procurator Generale alla Corte Criminale di Terra di Lavoro. Nel settembre del 1810 passò ad occupare la carica di Presidente della Corte Criminale di Napoli e nel 1812 fu promosso al posto di Avvocato Generale presso la Corte Suprema di Giustizia. Nel 1821 tornò alla professione di avvocato. Ma nel 1831 fu richiamato alla carica giudiziaria col grado di giudice della Gran Corte Civile di Napoli, e con decreto del 17 novembre detto anno fu nominato Professore Ordinario di Diritto Penale nella Regia Università di Napoli. Nel 1832 fu reintegrato nel suo antico posto di Avvocato Generale presso la Corte Suprema di Giustizia e nell'agosto del $1841 \mathrm{fu}$ elevato al posto di Ministro Segretario di Stato senza portafoglio. Cfr. Giuseppe Madia, Le Quistioni di dritto di Nicola Nicolini, novella edizione, col confronto della legislazione vigente nel Regno e della odierna giurisprudenza preceduta dalle notizie su la vita e su le opere dell'Autore, I, XVIII, Napoli, 1870, p. I-II. 
dizione mentale in cui versano gli autori degli omicidi che il legislatore - all'art. 6 e all'art. 196 del codice penale del 20 maggio 1808 - definiva 'brutali', in quanto la crudeltà e la perfidia vi discoprono nel reo il libero uso di una volontà determinata:

Di tale monomania si parla ormai tanto e se ne ragiona e sragiona da' giornali e dagli autori di medicina legale, ch'ella è diventata nei giudizii penali l'eccezion di moda. Ma se questa specie di pazzi, che sanno quel che fanno, e lo fanno volendo, fossero da compassionarsi e da esserne piuttosto serrati in un ospizio d'infermi, che messi sotto la scure di Astrea, chi è fra i più odiosi scellerati che temer potrebbe la pena?

Il principio giuridico-filosofico, che sarebbe al fondamento della sovrapposizione dell' omicidio senza causa' alla 'monomania omicida', sembra essere quello per cui l'uomo finché è dotato di ragione non agisce mai senza un motivo e tale motivo per essere giusto deve risultare proporzionato all'azione. In altre parole, chi uccide il suo ingiusto aggressore negli stretti termini della necessità simultanea della legittima difesa opera secondo la retta ragione, essendo il motivo del delinquere proporzionato all'effetto. Diversamente, chi uccide per vendetta non ha un motivo legittimato né dalla retta ragione né dalla legge né proporzionato all'effetto. Se, dunque, questo principio viene accolto per questi due casi, come può non accogliersi nei confronti di chi fa il male solo per amore del male? Quanti «maledicono e calunniano senza essere stati offesi, senza interesse personale, senz'altro motivo che il piacere di veder soffrire e di nuocere? Date ad un di costoro un grado di perversità di più, più coraggio ed un pugnale, e voi avrete la matta bestialità di cui parla Dante».

Il Nicolini non nega l'esistenza di siffatte inclinazioni funeste ma ritiene che queste per giungere al grave stadio della monomania debbano essere ignorate, assecondate e accolte con superficialità, senza che sorga in chi ne è affetto alcuna esigenza di porvi rimedio. Questo non significa che chi favorisce la causa e non vi si oppone diventa 'sempre' reo dell'effetto ma, eccepisce il Nicolini, se è vero che la monomania sconvolge tanto la ragione da eliminare ogni conoscenza dell'atto perché sopprime interamente la coscienza, con- 
viene allora considerare l'autore del fatto come preso da «furore vero», da follia piena e non parziale.

Nel trattare le questioni di diritto relative alla terza classe dei reati di sangue, le quali segnano il passaggio dagli 'omicidi semplicemente volontari' agli 'omicidi premeditati', espone le proprie conclusioni nel processo che vedeva imputato di 'omicidio senza causa' Felice De Antonellis. Si tratta di un caso rientrante fra quelli di omicidio volontario nei quali non sia conosciuta alcuna esterna cagione eccitatrice della volontà disciplinato dall'art. 355 del codice penale del 1859. All'udienza della Corte Suprema del 19 giugno 1839, il Nicolini addusse le proprie memorie conclusive a motivazione del rigetto del ricorso dell'imputato contro l'accusa di omicidio aggravato dalla malvagità con abile maestria ${ }^{87}$.

Una giovane napoletana fu chiesta in sposa dall'imputato originario del Sannio Irpino, il quale, ottenuto il consenso paterno, la condusse all'altare la sera del 28 gennaio 1837. Più che una cerimonia nuziale, sembrò una cerimonia funerea, sostiene l'avvocato. Non vi fu alcuna festa, né doni e una fosca tristezza occupava lo sposo. Dal momento del matrimonio «alcuna luce di gioia lampeggiò mai dal suo oscuro sembiante», il De Antonellis veniva descritto come taciturno e irascibile. Colpito da infermità nervosa a scoppi improvvisi diventava «perpetua e funesta la sua divorante atrabile». Lo contraddistinguevano modi e tratti incivili o violenti non eccitati da alcuna esterna ragione. Smanioso trascorreva notti insonni, talvolta rigettava irritato le carezze della moglie e talaltra la minacciava di strapparle l'abito.

La mattina del 14 febbraio nella camera del fratello della moglie, il De Antonellis notò due pistole, le maneggiò e si accorse che erano cariche. Venne l'ora del pranzo e in quella circostanza, a detta dei testimoni, egli appariva tranquillo. Si alzò dal tavolo all'improvviso armato delle due pistole e rivolto verso la moglie «senza profferir parola, ne scarica una da sopra in giù sul di lei omero sinistro, e la fa cader morta fra le braccia del fratello» ${ }^{88}$. Si tratta di un omi-

87 Niccola Nicolini, Questioni di diritto trattate nelle conclusioni, ne' discorsi ed in altri scritti legali, IV, Napoli, 1839, p. 219.

88 Ivi, p. 221. 
cidio causale e volontario? Questa l'unica questione di fatto proposta alla Gran Corte. Non si dubita che il colpo omicida sia partito dalla pistola impugnata dal De Antonellis; non si dubita che al tempo dell'azione, né prima né dopo, non fosse mai sospesa neppure temporaneamente la facoltà di discernimento. La taciturnità propria della personalità dell'imputato proveniva da ben altro che da assenza d'ogni capacità intellettiva: scortese, contristato, scontroso ma non demente. Con forza argomentativa il Nicolini proseguiva affermando che l'imputato non poteva nemmeno considerarsi esaltato da furore o da mania:

nel significato di quella malattia deplorabile che rendendo l'uom macchina, lo spinge con impeto sì cieco ad azioni sanguinarie che toltagli la coscienza di quello che opera, fa ch'ei non ne provi soddisfazione interna, né rimorsi, perché non discernendo più il bene dal male, piange di quello, come ride di questo, indifferente all'uno ed all'altro ${ }^{89}$.

La Gran Corte respinse la dichiarazione di reità con ventiquattro motivi di annullamento. Ventitré riguardavano la giurisdizione, aspetti formali del processo, il metodo della discussione delle prove e della motivazione. Con l'ultimo, invece, la Corte sostenne che non essendo emersa nel processo una «cagione esterna determinatrice della volontà al reato» risultava violata la legge penale, anzi il senso comune, principio e fonte d'ogni legge: l'omicidio non poteva che essere dichiarato involontario. Il Nicolini non rivolse alcuna opposizione alla definizione data dalla Corte al reato rispetto alla 'mancanza di causale' ma aggiunse:

89 Ivi, pp. 221-222; Sul pensiero del Nicolini in merito alla demenza e al furore si vedano le sue conclusioni pronunciate all'udienza della camera criminale della corte suprema di giustizia nella causa di Francesco Saverio Mastrogiacomo, nel giorno 21 giugno 1833, che lo vedeva imputato dell'omicidio del figlioletto di venticinque mesi gettato in un pozzo. Cfr. Giuseppe Madia, Le Quistioni di dritto di Nicola Nicolini, I, XVIII, cit., p. 226: «Avrei desiderato, per onore dell'umanità, che l'uccisione del fanciulletto, per la quale il genitor di lui è stato condannato all'estremo supplizio, fosse veramente avvenuta per caso, o per atto involontario di un furioso o demente. [...] Ma poiché vi sono esseri sì malvagi, che funestando l'umanità con infrangerne tutte le leggi, meritano di essere cancellati dal numero degli uomini, conviene che vi sieno magistrati forti, i quali con atti di vigorosa giustizia garentiscano a tutti di queste leggi l'osservanza». 
Se per causa di un omicidio s'intenda un fatto esterno, che sentito dall'agente, sia ragion sufficiente dell'azione, e come di effetto moralmente o fisicamente necessario, tutte le prime mosse e la direzione e l'intensità ne spieghi, convien confessare ch' ella qui manchi assolutamente. Ma questa manca in ogni specie di omicidio imputabile ${ }^{90}$.

Nei soli omicidi 'leciti' per cause di giustificazione, l'azione esterna è proporzionata alla reazione ed è per tale ragione che la legge li dichiara esenti da pena. Ma la ragione motrice di tutti gli altri reati di sangue, i quali non possono pienamente giustificarsi, è sempre più o meno ingiusta, sempre mal proporzionata al misfatto. L'azione nell'omicida è più occasione che causa:

La causa vera è tutta nel suo animo o ferino, o intollerante e incomposto, spesso il più lieve disgusto senza altrui colpa, più spesso la sazietà, il capriccio, l'orgoglio della superchieria e della prepotenza, la tentazione di troncar con la spada un nodo molesto, è per lo scellerato ragion d'omicidio ${ }^{91}$.

Secondo il Nicolini quanti uccidono senza motivo - che la «tragedia antica fingeva agitati dalle Furie» e «ch'ora una nuova scuola ama chiamare monomani» - sono consapevoli dell'immoralità delle loro propensioni, hanno coscienza del male che desiderano, ma la loro libera determinazione non si traduce in atto se non quando giungono al punto estremo in cui le «brame irragionevoli ed atroci» diventano ingovernabili. Egli vede, nell'omicidio senza causa, un reato che «trascende ogni umano costume» ed in questo individua la ragione per cui fu definito 'brutale':

I nostri antichi lo chiamaron brutale, e non brutale a modo di leone o di toro, ma all'uso di tigre, il cui furor cieco, la cui bassa malvagità lo fa rivolgere, anche sazio di preda, senza provocazione né fame, non pure a divorare ogni altro animale, ma a fare in brani gli stessi figli suoi e la madre ${ }^{92}$.

\footnotetext{
90 Niccola Nicolini, Questioni di diritto, IV, Napoli, 1839, cit., p. 223.

91 Ivi, p. 224.

92 Ivi, p. 226.
} 
La bestialità del gesto non viene fatta risiedere nell'efferatezza dell'atto, nelle modalità con cui si uccide, bensì nella contrarietà alle regole etiche e morali che si solgono attribuire all'essere umano moralmente integro. L'azione di tale tipologia di omicida è involontaria tanto quanto quella di ogni altro assassino non provocato da alcuna circostanza ma che animi causa è malvagio. Quando in sede processuale viene provato che il colpo non poteva essere scaricato se non volontariamente; quando viene provato che, sebbene non consti alcuna causa, l'azione nel tumulto interno del momento è stata volontariamente compiuta, come in ogni altro reato ex impetu o deliberato ex improviso; quando si accerta che quella che in un primo momento sembrava «vaga scontentezza d'animo» ed «ostile inclinazione» era, invece, odio profondissimo e sete efferata di sangue, la causa dell'omicidio è finalmente individuata: la malvagità. Siamo nello stesso caso, riportato anch'esso dal Nicolini, dell'incendiario che senza aver ricevuto offesa, senza trarne vantaggio e senza avervi pensato mai anteriormente, «getta il fuoco distruttore nella ricolta del vicino». E se l'omicida discerne, al tempo del fatto, il bene dal male; se dell'azione conosce la natura, il fine e le conseguenze; se era padrone di dirigere o sospendere l'esercizio della sua volontà e quindi in pieno possesso della capacità di determinazione, è senz'altro imputabile di un fatto volontario: «è tanto più imputabile, quanto men se ne trova il motivo in ciò che suol muovere alle azioni criminose i malvagi ordinarii ${ }^{93}$.

Persino, il Filangieri, che il Nicolini definisce «modello di umanità e di dolcezza nella estimazione de' reati» ${ }^{94}$, colloca l'omicidio senza causa al massimo grado nella scala del dolo. E in linea di coe-

93 Ivi, pp. 227-228.

94 Il Filangieri nel trattare i problemi penali si faceva certamente interprete della fase più matura della corrente del riformismo illuminista europeo che vedeva nel sistema penale l'indicatore privilegiato di civiltà raggiunto da un popolo. Egli individuava, infatti, nel modello processuale accusatorio un modello assoluto, proprio di una società ideale formata da cittadini cui spettano uguali diritti e doveri, e condizionato, con il mezzo della legge, dalla protezione di tali diritti e dalla esaltazione di tali doveri. Sul punto si veda E. Dezza, Saggi di storia del diritto penale moderno, cit., p. 52. Sugli sviluppi dell'illuminismo giuspolitico nella seconda metà del Settecento europeo si veda in generale G. TARELlo, Storia della cultura giuridica moderna, I, Assolutismo e codificazione del diritto, Bologna, 1976, pp. 383-483. 
renza con il pensiero della dottrina prevalente si muoveva il legislatore del 1808 quando con l'art. 196 della legge del 20 maggio statuì:

rende qualificato l'omicidio [e per tale ragione meritevole di una pena aggravata] tanto l'ingiusta quanto la niuna causa [...]. L'omicidio è brutale quando è commesso per solo istinto di malvagità, senza l’impulso di alcuna altra causa ${ }^{95}$.

e lo sanzionò con la pena di morte esemplare.

La legislazione successiva, nella ricostruzione del Nicolini, benignamente collocò questi omicidi nella classe dei 'volontari ex impetu' o 'deliberati ex improviso' quando non sono premeditati. Egli fa riferimento ad una legge del 1819 che a differenza di quella del 1808 aprì a ben altri principi il proprio spirito. Non che il nuovo legislatore credesse impossibile o involontario l'omicidio senza impulso di causa esterna, ma nel novero dettagliato dei reati lasciò inosservati tali omicidi.

Perché, dunque, non considerare l'azione che proviene da una provocazione esterna quanto quella che erompe da cieco impeto di mal repressa disposizione interna dell'animo? Il legislatore del 1819 sembra aver accolto la tesi del Carmignani, secondo cui l'omicidio brutale non è omicidio più grave di quello commesso per causa più proporzionata. Esasperarne la pena, considerandone più grave il dolo appare agli occhi del giurista ingiustificato almeno quanto lo sarebbe scusarlo per difetto d'intelletto. Gli uomini «di retta mente e di retto cuore» non riescono ad immaginare fino in fondo i motivi che inducono al crimine qui emolumenta rerum fallacibus iudiciis vident. I motivi che conducono all'omicidio sono spesso così tenui e impercettibili, «che alcuni giudici sarebbero più pronti a negar tutto il fatto che a pronunziarvi l'assenza di un grande emolumento e di forti esterni motivi, quando ciò ne aggravi la pena ${ }^{96}$. Il Nicolini si pone consapevolmente nella prospettiva teoretica del Carmignani. Se l'ignoranza della causa del fatto potesse risolversi in una imputazione positiva degna della pena capitale, questa finirebbe per poggiare su fondamenta sin troppo deboli e incerte.

\footnotetext{
95 Legge 20 maggio 1808, art. 196.

96 Cicerone, De officiis, III, 8.
} 
Felice de Antonellis, per il suo omicidio, viene dai giudici condannato alla pena di morte e la decisione della Corte non allude ad alcuna occasione esterna che possa avere eccitato e condotto il colpevole al crimine. In realtà rileva il Nicolini, i giudici non credettero che la volontà dell'imputato fosse stata determinata senza alcun motivo, ma dalle argomentazioni emerge con chiarezza che si convinsero che l'insana mente del colpevole fu pervertitrice della sua volontà, come a dire che «l'iniquo motivo ne sia stato la soddisfazione che in un cuor barbaro produce l'esecuzione d'un misfatto inesplicabile e stranamente atroce». La Corte stessa, infatti, descrive la immoralità del colpevole, la sua cupa mestizia, i suoi furori malincolici. Allorché si trattò di decidere del destino dell'imputato, essa stabilì che non esterna bensì interna fosse la forza impulsiva che lo spinse ad uccidere.

Si poneva un evidente problema di certezza del diritto. Secondo il celebre giurista Carl Joseph Anton Mittermaier (1787-1867), uno dei criteri giuridici più sicuri per distinguere il crimine compiuto dal delinquente sano di mente dal crimine dell'insano consiste nel valutare se dall'azione criminosa ne torni qualche utile - palese od occulto - a chi la commette. Professore di diritto a Landshut, Bonn, Heidelberg, egli portò un contributo fondamentale alla contemporanea scienza giuridica, riflettendo sui principi dell'imputazione criminale negli alienati nel suo saggio De principio imputationis alienationum mentis in jure criminali recte constituendo. Secondo Mittermaier la mania parziale priverebbe del libero arbitrio il soggetto, sebbene sia colpita una sola facoltà dell'anima ${ }^{97}$.

Il giurista tedesco inquadra come melancholia i primi gradi delle monomanie, nelle quali il soggetto comincia ad essere travagliato dalla prepotente emersione di una idea, dalla tirannia di una forza irresistibile contro cui, invano, combatte ${ }^{98}$. Il momento in cui l'impulso a delinquere diventa irresistibile segna il superamento del confine con l'imputabilità. Occorre grande prudenza per discernerlo. Sapere che l'infermo abbia cercato di resistere a tale forza non è sufficien-

97 CARl Joseph Anton Mittermaier, De principio imputationis alienationum mentis in jure criminali recte constituendo, Heidelbergae, 1838, p. 9.

98 Ivi, pp. 46-47. 
te a congetturare la sua irresponsabilità. E nemmeno si può sempre presupporre l'irresistibilità della forza dell'impeto interno, se questo non si manifesta palesemente come cieco appetito che spinge al male senza causa esterna. Infatti, l'opinione di coloro che ritengono non esservi imputabilità in assenza di causa non può essere accolta per il fatto che considerano ignota alla natura umana la cupidità di fare del male unicamente per 'amore del male'99.

A suo dire, essi non considerano che spesso i misfatti celano cause occulte che nessuno oserebbe confessare e che risiedono nella malvagità dell'animo umano. Di tal natura dovrebbero considerarsi le cause che spesso sono state invocate dai pratici del diritto per spiegare crimini atroci, ovvero una tendenza irresistibile a quel particolare reato. L'intento della sua riflessione sul crimine senza causa apparente e sulla monomania non è quello di negare, senza eccezioni, l'esistenza di una mania parziale irresistibile, ma piuttosto quello di avvertire i cultori del diritto che tale interpretazione del fenomeno criminoso non può essere ammessa quando non appaia congiunta a nessuno dei fenomeni patologici che la scienza psichiatrica associa alla monomania e che denotano una mancanza della libertà di agire. Certamente chi è solito assecondare brutalmente ogni sua perversione, nel corso del tempo perviene ad una assuefazione di servitù morale al reato così profonda da rendergli quasi impossibile ogni forma di resistenza. In quest'ottica l'impeto di distruzione che vuole chiamarsi monomania omicida nasce da una condizione in cui il criminale si è posto volontariamente.

Il pensiero di Mittermaier sulla imputabilità penale delle azioni originate dalla alienazione mentale, viene a più riprese menzionato dal giurista torinese Luigi Giovanni Antonio Cibrario (1802$1870)^{100}$ che rivolgendosi ai giuristi e ai medici proclivi all'indul-

99 Mittermaier riprende il concetto di 'amore del male' già esposto da Pellegrino Rossi: «Ei fa il male per amor del male», cfr. Pellegrino Rossi, Trattato di diritto penale, II, cit., p. 24

100 Tra i suoi scritti di carattere storico-giuridico si ricorda il discorso Della pace pubblica tenuto in occasione dell'apertura dell'anno giudiziario della Camera dei conti nel 1839. In esso Cibrario esamina in chiave storica la funzione dello Stato e delle buone leggi nel mantenimento della pace e dell'ordine interno, così come quella delle pene, che devono avere un carattere di espiazione e di prevenzione, il tutto nella visuale del codice penale appena emanato e riecheggiando le teorie sette- 
genza con l'appellativo di «cortigiani dell'umanità» suggerisce loro di «guardare alla storia, alle memorie di quella istintiva crudeltà, di quel desiderio di distruzione che traspare talvolta negli animi infantili» ${ }^{101}$.

Mentre il problema della individuazione della natura dell' impulso cieco ad uccidere' - descritto ora come malvagità, ora come follia morale - vede coinvolti tanto il sapere medico-psichiatrico quanto quello giuridico; il tema della imputabilità delle azioni sanguinarie rappresenta invece un classico ambito giuridico. Le esperienze e le risultanze della scienza medica, che dimostrano come possa essere soltanto parziale l'obnubilamento della ragione e come possa la malattia in altri casi colpire soltanto la sfera volitiva, non appaiono specificamente accolte dal legislatore del tempo. Questi, infatti, annovera genericamente l'alienazione di mente fra le cause che escludono l'imputabilità. E questo apparente pressapochismo non è un male. Infatti, la vaghezza della formula legislativa, agli occhi del Cibrario ma anche del Mittermaier, appare una scelta ben ponderata nella misura in cui il diritto sul punto specifico ceda il passo alla competenza scientifica degli esperti in materia, e che quindi si debba risalire alle fonti della scienza medica per valutare - se e in che misura - la specifica condizione mentale del criminale sia tale da incidere sulla imputabilità.

Tirando le fila del discorso, il Cibrario riconosce un fondamento psicologico alla responsabilità penale. Pertanto, nessun crimine può essere imputato se non concorrono nel reo, al momento di commetterlo, la 'coscienza dell'azione' e la 'libertà di agire o non agire'. Inoltre bisogna tenere bene a mente che non tolgono o diminuiscono l'imputabilità solo le alienazioni 'evidenti', bensì anche le morbose perturbazioni della mente in grado di escludere o diminuire la libertà di agire. ${ }^{102}$ Sembra cioè necessario ammettere la possibilità non

centesche sulla proporzionalità delle pene e il pensiero di Romagnosi. Cfr. P. CASANA, Cibrario Luigi Giovanni Antonio, in Dizionario Biografico dei Giuristi Italiani (XII-XX secolo), I, cit., p. 533.

101 Cfr. Luigi Giovanni Antonio Cibrario, Dell'imputabilità delle azioni nelle alienazioni di mente, in Annali di giurisprudenza raccolta mensile pubblicata da una società di avvocati e di causidici, anno I, II, Torino, 1838, cit., p. 544.

102 Luigi Giovanni Antonio Cibrario, Dell'imputabilità delle azioni nelle alienazioni di mente, in Opuscoli, Torino, 1841, pp. 137-138. 
solo di una corruzione parziale dell'intelletto bensì anche la possibilità di una corruzione esclusiva della volontà.

\section{L'omicidio per follia morale: la Scuola positiva}

Il concetto di omicidio compiuto "per solo impulso di brutale malvagità' - insegna il giurista siciliano Giovanni Battista Impallomeni (1846-1907) ${ }^{103}$ - esclude ogni altra causa a delinquere, un qualsiasi altro movente e non si può spiegare altrimenti se non «come uno scoppio di ferocia istintiva» che denuncia nell'agente il difetto di sensibilità morale. Ciò rivelerebbe il 'mostro umano'104.

L'Impallomeni si pone esplicitamente il problema se si sia di fronte ad una mera 'anomalia psichica', ad una vera e propria malattia della mente, la quale esprimerebbe una sorta di regressione atavica all'animalità inferiore. Di fronte a questo interrogativo egli nega che il giurista debba fare ricorso a un concetto quale la regressione atavica, concetto metagiuridico e privo di un sufficiente e plausibile fondamento scientifico. L'animalità inferiore si caratterizza per una 'purezza' e una naturalità che la pongono in chiave etica ad un livello superiore rispetto al fenomeno della brutalità omicida. In tal caso l'uomo sarebbe ben peggiore della bestia che agisce sempre per soddisfare i suoi bisogni primari:

le belve feroci sono inoffensive quando non sono stimolate dalla fame, le tigri e le iene bevono il sangue della vittima, ma non la sbranano per pascersi della vista del sangue ${ }^{105}$.

L'obiettivo dell'Impallomeni è quello di contestare la spiegazione dell'omicidio brutale nei termini di regressione atavica. La con-

103 Nel 1888 un prestigioso incarico lo proiettò negli ambienti legislativi del Ministero di Grazia e giustizia. Apprezzato dal guardasigilli Zanardelli, fu da questi nominato vice-segretario della commissione interparlamentare incaricata di portare a termine le ultime modifiche al testo del primo codice penale del Regno d'Italia. Cfr. M.A. Cocchiara, Impallomeni, Giovanni Battista, in Dizionario Biografico dei Giuristi italiani (XII-XX secolo), II, cit., pp. 1106-1107.

104 Giovanni Battista Impallomeni, L'omicidio nel diritto penale, seconda edizione, Torino, 1900, p. 436.

105 Ibidem. 
dizione dell'omicida senza causa non ha la naturalità dell'animale. Non si muove nell'orbita delle leggi naturali. Si tratta, al contrario, di una patologia. La prima impressione in simili casi deve per il giurista essere il «sospetto di una causa morbosa» che affetti 'la sensibilità'. L'omicida brutale non è una bestia ma un uomo malato:

Molti fatti che sembrano inesplicabili si spiegano facilmente con una di quelle psicopatie, che per essere assai poco comuni sfuggono all'osservazione ordinaria; sfuggono principalmente perché non si manifestano con un disordine dell'intelligenza e sono perciò poco appariscenti, ma attaccano profondamente l'affettività o ammalano la volontà ${ }^{106}$.

Sarà quindi indispensabile per tali criminale un'approfondita perizia che dimostri trattarsi di folli morali, di persone affette da malattia alla volontà. È pur vero che l'omicidio può avere a suo coefficiente la brutale malvagità in concorso con un altro fattore scatenante. Così si spiegherebbero i fatti di chi uccide per pochi 'spiccioli' o del brigante che uccide per provare la polvere del fucile. Nelle cause insignificanti la malvagità umana si manifesta nella sua orrida brutalità, senza che perciò si tratti di omicidio commesso 'per solo impulso di brutale malvagità'.

Invece, la cosiddetta vendetta trasversale - annoverata dal Rainaldi -andrebbe espunta dal novero dei crimini bestiali senza causa. Si tratta senz'altro di un delitto sommamente malvagio, ma non compiuto per 'solo' impulso di brutale malvagità. Per comprenderne la distorta razionalità, è necessario mettersi nei panni del 'vendicatore', che uccide per procurare dolore ad un terzo e soddisfare così la propria sete di vendetta. Un più retto apprezzamento penale delle cause del delitto, una loro circostanziata valutazione consiglierebbe quindi di sostituire la qualifica «per solo impulso di brutale malvagità», circoscrivendola alle modalità oggettive di esecuzione tramite la denominazione di omicidio commesso «con brutale malvagità» ${ }^{107}$.

Negli stessi anni, uno dei celebri protagonisti della Scuola po-

106 Ivi, p. 437.

107 Ibidem. 
sitiva $^{108}$, Enrico Ferri (1856-1929) ${ }^{109}$, sosterrà che i casi di impulso momentaneo all'omicidio si identificano spesso con quelli di 'omicidio senza motivo'. L'omicidio diventa per sé stesso lo scopo unico dell'agente e rappresenta un sintomo di 'pazzia morale', corrispondente alla figura criminosa che i criminalisti classici - «troppo profani alle scienze naturali» - qualificavano nei termini di omicidio per sola brutale malvagità, sete di sangue, odio nei confronti dell'umanità $^{110}$.

Secondo il Ferri, talvolta l'invasione lenta e la cristallizzazione dell'idea omicida non escludono ma piuttosto eccitano nell'alienato la coscienza di essere pazzo o quantomeno di avere un desiderio ingiusto e disumano, meritevole di pene severe, senza per questo possa trattenersi dall'uccidere. Sarebbero questi nello specifico i casi che, secondo gli psichiatri dei primi anni dell'Ottocento, costituiscono la monomania omicida ${ }^{111}$. L'impulso omicida in assenza di uno stato emotivo o passionale, si presenta alla coscienza del malato e gli si impone contro la sua volontà. Esso impedisce e attraversa l'ordinaria concatenazione delle idee, e viene considerato dall'ammalato come anormale e straniero al suo io. Questo avviene - sostiene il Ferri - quando il proposito omicida giunge ad occupare i centri psichici che si organizzano e si polarizzano intorno all'idea fissa impul-

108 Nella sua Sociologia criminale - ampliata fino al 1929 - si propose di dar senso, precursore Romagnosi, ad una scienza dei delitti e delle pene rinnovata dal metodo sperimentale e basata sui dati dell'antropologia e della statistica criminale. Con conclusioni inalterate in quasi cinquant'anni elencò fattori antropologici, fisici e sociali del delitto, da cui desunse le varie categorie di delinquenti - pazzi, nati, abituali, occasionali, passionali - ancorate al concetto di pericolosità, da studiare nel reato e nel processo in quanto strumento di prognosi. Forte delle sue osservazioni scientifiche considerò i delinquenti «sempre anormali», nel non sapersi adattare all'ambiente sociale. Cfr. EnRICO Ferri, Sociologia criminale, Torino, 1900, p. 143. Si veda anche P. MARchetti, Le "sentinelle del male". L'invenzione ottocentesca del criminale nemico della società tra naturalismo giusnaturalismo e normativismo psichiatrico, in Quaderni Fiorentini, 38, 2009, pp. 1074-1080.

109 Sulla vita e sul pensiero dell'autore si veda in generale F. Colao, Ferri, Enrico, in Dizionario Biografio dei Giuristi Italiani (XII-XX secolo), I, cit., pp. 849852.

110 EnRICo FerRI, L'omicidio nell'antropologia criminale (omicida nato e omicida pazzo) con atlante antropologico-statistico, Torino, 1895, p. 573.

111 Ivi, p. 552. 
siva $^{112}$. Nella prospettiva del Ferri, il crimine, nelle sue forme ataviche o antiumane, (cioè contrarie alle condizioni immanenti e fondamentali dell'esistenza umana) e nelle sue manifestazioni evolutive antisociali (cioè contrarie all'assetto transitorio di una determinata società), non è mai il prodotto della libera volontà e malvagità individuale bensì piuttosto l'effetto e il sintomo di patologia individuale - nelle sue forme ataviche, e di patologia sociale - nelle sue forme evolutive. Il reato, quindi, risulterebbe sempre dall'incidenza criminogena dell'ambiente fisico e sociale combinata con le tendenze individuali, ereditarie o acquisite, e con gli impulsi occasionali ${ }^{113}$. In quest'ottica l'omicidio non può ammettersi come reato commesso per solo impulso di brutale malvagità. Infatti, l'impulso che scaturisce dalla sfera interiore del criminale deve combinarsi necessariamente con una forza criminogena esterna che favorisca la sua manifestazione.

Dietro la questione filosofico-giuridica del delirio della volontà, che ha cervelloticamente interessato cattedratici, giudici, legislatori e medici-legali, si nasconde il problema, più ampio e più antico, del rapporto fra libero arbitrio ed imputabilità. Infatti, se agevolmente si comprende che non si può attribuire libertà di arbitrio, né responsabilità penale quando esista lesione dell'intelletto ${ }^{114}$, deve altrettanto ammettersi che gli impulsi istintivi, quanto le morbose deviazioni della volontà, sono il sintomo di un'alterazione profonda della vita psichica, alterazione che denota sempre una lesione della sfera emozionale - 'sensifera' -, cui consegue il pervertimento funzionale della mente. Che l'uomo sia dotato di libero arbitrio o di libertà morale significa che di fronte alla continua e multiforme pressione dell'ambiente esterno e al vario dibattersi degli impulsi interni, spetti sempre alla sua volontà libera il decidere, in ultimo appello, fra due opposte possibilità. Pertanto se il soggetto sceglie il male, ne è sempre imputabile e deve esserne punito. La scuola criminale positiva non accetta questo unanime sillogismo dei giuristi perché ritiene che la fisio-psicologia po-

112 Ivi, p. 551.

113 Enrico Ferri, Sociologia criminale, cit., p. 463.

114 Antonio Michetti, Dell'Arbitrio e dell'imputabilità, Pesaro, 1886, p. 14, p. 175. 
sitiva abbia completamente annientata questa credenza del libero arbitrio o della libertà morale ${ }^{115}$. Non esiste, sostiene il Ferri, una volontà come entità monolitica per sé stante ma esistono singole e differenti volizioni ${ }^{116}$.

Vero è che nei processi criminali qualche fenomeno allucinativo, qualche concezione delirante del presunto criminale alienato, agevolano il compito medico-legale di accertamento della condizione mentale; ma altrettanto vero è che, indipendentemente da tali fenomeni, il pratico del diritto può trovarsi di fronte ad un imputato il quale, benché in apparenza ragioni ed intenda normalmente, è vittima di un vizio della volontà che rende incompleto, disordinato, inadeguato il processo fisio-psichico.

$\grave{E}$ in questo quadro che rientrarono le indagini scientifiche sulle monomanie. Esse offrirono talora un confuso scenario concettuale per chi volle invocarle al solo fine di esercitare una boria neologisti$\mathrm{ca}$, ma non si può negare che furono imprescindibile premessa per $\mathrm{i}$ posteriori progressi della scienza sull'inconscio ${ }^{117}$.

Le monomanie non sembrano essere un sistema nosologico fondato sulla retorica di medici materialisti, organologisti e fatalisti bensì espressione teorica di osservazioni scientifiche di specialisti che trovano eco nella scienza medico-legale dei secoli precedenti. Agli albori della medicina-legale, le manie parziali si riepilogavano nella melancolia o delirio esclusivo su un oggetto.

115 Enrico Ferri, Sociologia criminale, cit., p. 468.

116 Ivi, p. 479.

$117 \mathrm{Ci}$ si riferisce alle scoperte effettuate dalle neuroscienze, scoperte che sembrano mettere in discussione l'idea fatta propria dal diritto dell'uomo sostanzialmente libero di determinare il corso delle proprie azioni in assenza di conclamate patologie psichiatriche. Tali teorie vicine a quelle dei 'deliri della volontà' dei primi scorci dell'Ottocento, segnano un superamento netto degli orientamenti della Scuola lombrosiana volta a fondare l'alterità antropologica dell'uomo delinquente. Fenomeni come lo sdoppiamento della personalità o la trance ipnotica sembravano dimostrare come la volontà potesse giocare un ruolo meno decisivo sull'agire umano di quanto non si fosse sino a quel momento supposto. In generale su questo tema si veda P. Marchetti, L'inconscio in tribunale. Azioni incoscienti e diritto penale. Da Charcot alle neuroscienze, Milano, 2014. 


\section{L'imputabilità nell'incapace di volere}

Molte delle problematiche sollevate in relazione all'imputabilità hanno origine nel momento costitutivo del rapporto tra psichiatria e diritto penale, e nella elaborazione di un legame insoddisfacente tra contenuto scientifico e forma giuridica. Il rapporto fra il diritto penale e le scienze psichiatriche si consolida fra gli ultimi decenni del secolo XVIII e la prima metà del successivo, ed è questo l'arco temporale in cui si formano i fondamentali processi interni che riguardano entrambi i saperi ${ }^{118}$. È in questo scorcio di tempo che il sistema penale si costruisce come sistema di valutazione delle scelte: il criminale è colui che è in grado di operare una scelta razionale tra gli svantaggi e i benefici del crimine. In tale contesto emerge una forte specificità della scienza criminale che viene aprendosi alle novità della ricerca psichiatrica, impermeata di nuovi concetti medicolegali connessi al discorso della volontà nell'agire.

Il problema giuridico della imputabilità del reo affetto da una 'malattia della volontà', strettamente connesso al concetto di libero arbitrio ${ }^{119}$, si trova attanagliato nelle trame di quella rivoluzione concettuale caldeggiata dalla criminologia che segna il passaggio dalla centralità dell'individuo alla preminenza della società ${ }^{120}$. La Scuola classica - scrive il Ferri nella Sociologia criminale - sorgeva in nome dell'individualismo, per rivendicarne i diritti troppo soffocati dallo Stato nel medio evo ${ }^{121}$ e pertanto propugnava un concet-

118 In generale, sulla crescente mobilità dei confini concettuali e giuridici tra autori di reato imputabili e non, nel quadro - più ampio - della crisi degli istituti soggettivi nel diritto penale si veda R. Selminı, I confini della responsabilità, Napoli, 1998, p. 15.

119 Sul dibattito ottocentesco intorno al concetto di libero arbitrio in ambito giuspenalistico, con particolare riferimento ai diversi orientamenti dottrinali delle varie Scuole di pensiero si rinvia in generale a M. SBRICColi, Caratteri originari e tratti permanenti del sistema penale italiano (1860-1990), in ID., Storia del diritto penale e della giustizia: scritti editi e inediti (1972-2007), I, Milano, 2009, pp. 604-605. Per un recente inquadramento generale si veda F. ColAO, 'Le scuole penalistiche', in Enciclopedia Italiana di Scienze, Lettere ed Arti, ottava appendice, Roma, 2012, pp. 349-356.

120 Sull'ampio dibattito che orbita intorno al passaggio dal giuspersonalismo al giuspositivismo si veda ampiamente G. Chiodi, L. Garlati (a cura di), Dialogando con Beccaria. Le stagioni del processo penale italiano, Torino, 2015.

121 EnRICo Ferri, Sociologia criminale, cit., p. 23. 
to di responsabilità penale e di imputabilità totalmente imperniato sull'esistenza della libertà dell'uomo. Si tratta di tematiche affrontate dalla dottrina con quell'afflato chiarificatorio che nel silenzio della legge cercava di evitare che tali delicate problematiche fossero lasciate all'arbitrio dei giurati ${ }^{122}$.

Ritornando sulla specifica questione della responsabilità penale, il giurista Francesco Carrara (1805-1888) ${ }^{123}$ afferma che un fatto può essere imputato al suo autore se questi sia stato non soltanto la causa materiale di esso ma anche la causa morale ${ }^{124}$. L'uomo soggia-

122 Su tale ampio dibattito la letteratura è sterminata, si vedano almeno A. Gabelli, I giurati del nuovo regno italiano secondo la legge sull'ordinamento giudiziario e il codice di procedura penale, Milano, 1861; L. CASORATI, La nuova legge sul giurì, corredata dei lavori preparatori e delle discussioni parlamentari, Prato, 1874; P. Ellero, Il giurì in Italia, in ID., Opuscoli criminali, Bologna, 1874, pp. 245-275; E. CARdona, La nuova legge sui giurati studiata nei suoi rapporti con la scienza e con la storia, Napoli, 1875; D. CHIAVEs, Giudice mal giudicato: apologia del giurì nei giudizi penali letta all'adunanza della Società Filotecnica di Torino il 19 gennaio 1879, Torino, 1879; E. Ferri, Sociologia criminale, cit., pp. 790-795; R. Garofalo, 'Un giurì di persone colte', in Archivio di psichiatria, scienze penali ed antropologia criminale, 1881, [2-3], pp. 374-376; F. CARrara, Pensieri sulla giuria, in ID., Reminiscenze di cattedra e di foro, parte prima, Lucca, 1883, pp. 349375; P. LANZA, La giuria ed il giudizio penale davanti la Corte d'Assise. Studi e progetti di riforme, Pisa, 1886; R. De Novellis, Il giurì: note critico-storiche, Napoli, 1886; G. Crivellari, La Giuria in Italia, Napoli, 1897; F. Bonanno, Sul diritto penale e sul giurì. Scritti diversi, Catania, 1896; T. CANONICO, Urgenza di riformare la legge sui giurati: parole del senatore Canonico nella tornata del 18 gennaio 1899, Roma, 1899. Più recente invece si veda L. GARLATI, L'inconscio inquisitorio: l'eredità del Codice Rocco nella cultura processualpenalistica italiana, Milano, 2010.

123 Sulla vita e il pensiero del Carrara si vedano P. Grossi, Assolutismo giuridico e diritto penale (a proposito di recenti appuntamenti 'carrariani' e della ristampa della 'Parte generale' del 'Programma del corso di diritto criminale' di Francesco Carrara, in Quaderni Fiorentini per la storia del pensiero giuridico moderno, 1995, [24] pp. 469-475; P. CAPPELlini, Francesco Carrara e la codificazione del diritto, in Criminalia, 2007, [2] pp. 305-323; L. LACCHÈ, La penalistica costituzionale e il 'liberalismo giuridico'. Problemi e immagini della legalità nella riflessione di Francesco Carrara, in Quaderni fiorentini per la storia del pensiero giuridico moderno, I, 2007 [36], pp. 663-695; G. CAzzeTtA, Qui delinquit amat poenam. Il nemico e la coscienza dell'ordine in età moderna, Ivi, I, 2009 [38], pp. 478-489.

124 Francesco Carrara, Programma del corso di Diritto Criminale dettato nella R. Università di Pisa, parte generale, I, Lucca, 1877, p. 40. Sulla tematica del libero arbitrio si veda anche Francesco CARRARA, Libertà e spontaneità. Prolusione al corso di diritto e procedura penale (28 novembre 1882), in ID., Reminiscenze di cattedra e foro dell'avvocato Francesco Carrara, Lucca, 1883, pp. 508-509. Sul complesso concetto di libertà morale ed il suo rapporto con le malattie psichiche si veda U. Fornari, R. Rosso, Libertà morale, infermità di mente e forza irresistibile 
ce alla legge penale in quanto «ente dirigibile e questa sua subiezione ha causa oltre che nel suo intelletto, nella sua volontà». Egli collega la imputabilità giuridica alla partecipazione volitiva «libera ed intelligente» del reo e in questa prospettiva l'autore di un fatto di reato può essere chiamato a risponderne penalmente solo se al tempo della commissione del misfatto versava in una condizione psico-fisica da potersi valutare come 'moralmente libera'. Nell'azione delittuosa concorrono due forze, una fisica e l'altra morale. L'impulso morale, che è quello su cui si intende focalizzare l'attenzione, racchiude in sé la comprensione dell'illiceità della azione criminosa, la comprensione degli effetti giuridici che essa comporta, la libertà di elezione e la volontà di agire - definiti dal Carrara concorso dell'intelletto e concorso di volontà. Il Carrara ammette che in presenza di determinate condizioni psichiche la sfera volitiva dell'individuo possa subire delle alterazioni ma ritiene che debbano avere valore di scriminanti in senso stretto, sul piano penale, solo le circostanze che riducono $\mathrm{o}$ annullano il concorso dell'intelletto al reato ${ }^{125}$. Infatti, la libertà di elezione - ossia «il decidere a proprio talento il fare o il non fare, dietro i calcoli dell'intelletto» - non può mai mancare totalmente nell'uomo essendo una «potenza astratta dell'animo» ${ }^{126}$. Se si accolgono le considerazioni del Carrara sul libero arbitrio, la cosiddetta monomania - altrimenti detta - mania morale/mania della volontà, che per definizione non affligge l'intelletto del soggetto agente e che si risolve in una inclinazione alla malvagità immotivata, non annientando completamente il libero arbitrio non diminuisce la responsabilità penale del reo e anzi ne accresce la pericolosità sociale.

In una interessante prolusione del 1875, Enrico Pessina, con un approccio fortemente filosofico alle problematiche giuridiche e psichiatriche, evidenziava come negare totalmente il libero arbitrio nel reo significava giungere alla conclusione che la libertà della coscienza dell'individuo altro non è che un'illusione e che il criminale non è mai «libera cagione» del reato, minando alle fondamenta lo studio degli istituti di

nella psichiatria italiana dell'Ottocento, in Criminologia e responsabilità morale, Padova, 1990, p. 47.

125 Francesco Carrara, Programma del corso di Diritto Criminale, cit., p. 216.

126 Ibidem. 
diritto criminale di pluriennale tradizione ${ }^{127}$. Seguendo l'orientamento delle nuove teorie psichiatriche, afferma il Pessina, il delitto non sarebbe altro che una infelicitas fati, prodotto di innumerevoli coefficienti esterni che inducono al crimine ed in grado di intervenire nella sfera interiore del reo operando «come sovra un qualsivoglia istrumento opera l'artefice che trasforma i prodotti della Natura, e senza che l'uomo possa opporvi efficace resistenza ${ }^{128}$. «La scuola frenologica e fisiologica», a voler usare le parole del professore napoletano, avrebbe diffuso l'idea che sia possibile attraverso lo studio dell'organo cerebrale risalire alla più recondita sfera degli istinti e dei sentimenti, oltre che alle modalità di formazione dei processi cognitivi e volitivi, riducendo - in tal guisa - l'intelletto «ad una secrezione del cervello» ${ }^{129}$. Il dibattito sulla 'follia della volontà' si interseca con quello che ruota intorno all'istituto della giuria nell'ambito della Corte d'Assise ${ }^{130}$, immagine riflessa di un principio democratico oppure, al contrario, immagine deformata di una presunta opinione pubblica ${ }^{131}$.

127 Enrico Pessina, La libertà del volere - Prolusione al corso di diritto penale letta nella r. università di Napoli il dì 20 dicembre del 1875, in Discorsi varii, Napoli, 1915, p. 99.

128 Ivi, p. 100

129 Ivi, p. 104.

130 Sul problema dell'errore giudiziale si vedano M. Meccarelli, 'Due lati di una stessa figura'. Questione di fatto e di diritto fra Corte d'Assise e Cassazione nel dibattito dottrinale verso il codice di procedura penale del 1913, in F. Colao, L. Lacchè, C. Storti (a cura di), Processo penale e opinione pubblica in Italia tra Otto e Novecento, Bologna, 2008, pp. 163-194. Sulla Corte d'Assise più in generale si rinvia a A. Marongiu, 'Corte d'Assise (storia)', in Enciclopedia del diritto, X, Milano, 1964, pp. 774-783; S. Riccio, 'Corte d'Assise', in Novissimo Digesto Italiano, IV, Torino, 1959, pp. 915-928.

131 Sul rapporto tra giuria ed opinione pubblica si rimanda a L. LAcchè, Un luogo 'costituzionale' dell'identità giudiziaria nazionale dell'identità giudiziaria nazionale: la Corte d'Assise e l'opinione pubblica (1859-1913), in F. ColaO, L. LaCchÈ, C. Storti (a cura di), Processo penale e opinione pubblica in Italia tra Otto e Novecento, cit., pp. 77-120; ID., Una letteratura alla moda. Opinione pubblica, «processi infiniti» e pubblicità in Italia tra Otto e Novecento, in M.N. MiLETTI (a cura di), Riti, tecniche, interessi. Il processo penale tra Otto e Novecento, Milano, 2006, pp. 459513; ID., 'L'opinione pubblica saggiamente rappresentata'. Giurie e corti d'assise nei processi celebri tra Otto e Novecento, in P. MARCHETtI (a cura di), Inchiesta penale e pre-giudizio. Una riflessione interdisciplinare, Napoli, 2007, pp. 89-147. 


\section{Un maniaco in tribunale (1834)}

L'11 giugno 1834, di barbaro e bestiale parricidio ed uxoricidio fu accusato Giovanni Deci da Bassano, che dal Supremo Tribunale della Sacra Consulta fu condannato alla morte di esemplarità. Era originario di Bassano in Teverina, paesino in prossimità di Viterbo, marito di Maria De Paolis e padre di due figli, Bernardino e Caterina, rispettivamente di sei e undici anni. Nell'orazione dell'avvocato Oreste Raggi si legge che l'omicida, prima di mettere a morte la moglie a cui era unito da diciotto anni, sentì la voce del Signore sussurrargli: «Uccidi tua moglie che divenuta è un diavolo e bene uccidila perché se giunge ad afferrarti seco ti trascina nello inferno» ${ }^{132}$.

In ossequio al comando ricevuto, il Deci afferrò la zappa e colpì a morte la moglie stesa sul letto. Sentendo le grida della madre, la figlia Caterina accorse nella camera dove divenne anch'essa vittima della furia assassina del padre, mentre il fratello rimase ferito. Quando i vicini di casa suonarono alla sua porta per capire cosa fosse successo e quali fossero le ragioni di quelle urla di dolore, egli rispose: «Fuori i diavoli da casa mia, non voglio i diavoli in casa, io sono il Santo Padre che difendo il mio Dio» ${ }^{133}$.

Il Deci si macchiò di parricidio ed uxoricidio senza alcuna apparente ragione, senza che fosse intervenuta alcun movente passionale: né odio, né gelosia, né vendetta. Si trattava, secondo Raggi - avvocato dei poveri - di un tipico caso di monomania che, precisava, gli antichi chiamavano melancolia. Sulla base della memoria difensiva del Raggi, il Supremo Tribunale decise di rimettere la questione al Collegio medico-chirurgico di Roma, il quale nel giorno 11 dicembre 1837 emanò il seguente verdetto:

Dopo che ciascuno dei Membri del Collegio Medico-Chirurgico di Roma avea letto, ed esaminato il Processo compilato contro il Parricida, ed Uxoricida Giovanni Deci di Bassano si venne ad una ragionata discussione sul medesimo in generale

132 Oreste Raggi, Orazione per Giovanni Deci da Bassano reo di barbaro e bestiale parricidio ed uxoricidio condannato alla morte di esemplarità, Roma, 1837, p. 9.

133 Ivi, p. 10. 
adunanza, e si conchiuse che per meglio conoscere il vero stato di mente del detenuto Deci sarebbe stato opportuno che tre dei Colleghi lo avessero visitato più volte nella prigione, onde bene osservarlo, e riferirne quindi al Collegio il preciso stato relativo alla mente. Fu ciò eseguito per ben due volte con la esatta osservazione ed esame non solo del carcerato Deci, ma ben anche dei suoi custodi, e dei suoi compagni di segreta, e del tutto fu istruito il Collegio in una seconda adunanza generale. Aggiunte queste informazioni alla considerazione del complesso di tutti gli atti antecedenti, concomitanti e susseguenti di quel tristo avvenimento, il Collegio non dubitò, e non dubita di riconoscere lo stato 'monomaniaco' dell'infelice prigioniere Deci in quella orrenda uccisione.

Difatti il fisico del Deci non presenta le cose le più naturali, ed ordinarie, i suoi occhi sono sempre stralunati con vasi iniettati di sangue, i polsi eccessivamente lenti, piccoli, e bassi, la figura del suo capo non interamente regolare. Poco dorme, fa orazioni con frequenza, non proferisce mai parole sconce, invoca spesso il nome di Dio, e della Madonna, ed apparisce assai tranquillo, e taciturno. Ripete sempre di aver ucciso la moglie per comando di Gesù Cristo, poiché era indemoniata, e che la tenera figlia, che si mise di mezzo, restò uccisa anche essa, senza di lui volontà, sotto i colpi di un zappone, che egli scaricava contro sua moglie che era divenuta demonio, per rilevazione a lui fatta da Gesù Cristo. E realmente dopo molti anni di tranquillo matrimonio con figli ad eccezione di qualche rara contesa, inevitabile tra poveri contadini coniugati, conservandosi il Deci sempre religioso solitario, poco amante della fatica, e molto della Chiesa, pensieroso sino a passare generalmente per scemo, o pazzo una sera del giugno 1834 in mezzo alla maggior tranquillità, senza contesa, lungi da ogni causa manifesta, mangia secondo il solito colla infelice consorte, e poco beve, prega Iddio, si colca nel letto, passa tranquillo, ma sul far del giorno preso da estro terribile di mania afferra il manico di un zappone, e percotendone ciecamente la disgraziata moglie, giunge ad ucciderla in mezzo alle grida di 'viva Gesù', 'viva Maria' trionfando di avere ucciso il diavolo, che lo strascinava all'inferno. Una tenera figlia di circa dieci anni si scuote allo strepito, si mette di mezzo, e spera arrestare lo strazio di sua madre, ma rimane anche essa colpita ed offesa a tal segno, che ne muore il dì seguente. Un piccolo figlio di circa sette anni che non si muove atterrito, e tace in quello stesso letto 
già insanguinato rimane illeso. Intanto l'autore di sì orrendo eccidio non fugge né si nasconde, che ben lo poteva, resta tranquillo, torna alle solite faccende domestiche, si compiace di aver ucciso il diavolo, e di aver cosi obbedito a Gesù Cristo, e da quella epoca sino al momento attuale ha ripetuto sempre le stesse parole invariabilmente, senza mai mostrarsi né turbato, né avvilito, né pentito. Ora in seguito della ponderata considerazione di tutte queste cose, e di tutte le circostanze, i Membri Collegiali presenti nel numero di sedici [...] hanno per mezzo dello squittinio segreto, alla unanimità conchiuso che il carcerato Giovanni Deci era, allor quando commise questo eccidio, in istato di monomania, e che debba perciò considerarsi come infermo di mente, e non come colpevole, o reo [11 dicembre 1837] [Pendeva la causa nuovamente avanti il Sacro Tribunale quando l'infelice Giovanni Deci morì di consunzione nel carcere segreto il giorno 30 gennaio 1838$]^{134}$.

III. Le ragioni del legislatore

1. Per solo impulso di brutale malvagità

Le fondamenta della costruzione dell'omicidio si radicano dubbiamente nella dottrina di ius commune. Per quanto concerneva l'animus necandi, essa elaborò la figura della volontà deliberata, quale requisito indispensabile dell'omicidio. Se da una parte era necessario il dolo specifico di uccidere, dall'altra non importava la causa scatenante ${ }^{135}$. L'indagine su quest'ultima darebbe luogo ad un processo cognitivo che, a dirla con Antonio Buccellati, obbligherebbe a penetrare nella coscienza individuale del criminale ${ }^{136}$.

Tuttavia a livello legislativo in continuità con l'omicidio senza causa o bestiale d'antico regime, la valutazione dell'assenza di cau-

134 Ivi, pp. 49-51.

$135 \mathrm{Si}$ veda anche per quanto concerne l'età della giurisprudenza consulente M. Lucchesi, L'animus occidendi e l'animus deliberatus nei consilia di area lombarda, in Studi di storia del diritto, I, Milano, 1996, pp. 1-72.

136 Sul punto si veda A. Santangelo Cordani, Alla vigilia del Codice Zanardelli. Antonio Buccellati e la riforma penale nell'Italia postunitaria, cit., p. 322. 
sa continua a serpeggiare. Ad esempio, la legge sugli omicidi della Repubblica italiana del 25 febbraio 1804 stabilisce che l'«omicidio per causa brutale, compiuto senza alcun ragionevole motivo nell'uccisore per adirarsi contro la persona che poi ha uccisa» viene fatto rientrare nel novero degli omicidi aggravati e puniti con la pena di morte ${ }^{137}$.

Anche nel progetto di codice penale redatto per il Regno d'Italia nel $1808^{138}$, in particolare negli artt. 432-435, in cui ebbe grandissima parte il Romagnosi in linea con la scienza penalistica più aggiornata, si considera e si punisce l'omicidio «commesso per solo impulso di una brutale malvagità» con la pena di alto criminale o correzionale, alla stregua dell'omicidio premeditato.

Quanto alla legislazione penale dei vari Stati italiani che precedettero il codice penale unico per il Regno d'Italia, l'aggravante dell'omicidio commesso per solo impulso di brutale malvagità non trova riscontro nel codice delle Due Sicilie del $1819^{139}$, nel codice per gli Stati di Parma, Piacenza e Guastalla del $1820^{140}$ e nel Regolamento sui delitti e sulle pene emanato da Gregorio XVI nel $1832^{141}$.

137 L'omicidio «per causa brutale, senza ragionevole motivo» veniva punito con l'estremo supplizio al pari dell'omicidio premeditato, di quello in odio di legittima esecuzione o commesso per resistere alla forza comandata dalla pubblica Autorità e a quello commesso per abusare con violenza della vittima in quanto considerato omicidio qualificato da una piena e dolosa deliberazione. Cfr. Bollettino delle leggi della Repubblica italiana, I, Milano, 1804, art. 1. Cfr. anche P. VICO, Omicidio, in Digesto italiano. Enciclopedia del diritto metodica e alfabetica di legislazione, dottrina e giurisprudenza, XVII, Torino, 1904-1908, p. 226.

138 Cfr. Gian Domenico Romagnosi, Opere edite ed inedite sul diritto penale, vol. unico, parte II, Milano, 1842, pp. 1157-1194.

139 Sulle caratteristiche di tale codice e sul contesto in cui viene emanato si vedano i saggi raccolti in S. Vinciguerra, M. Da Passano (a cura di), Codice per lo Regno delle due Sicilie (1819). Parte seconda. Leggi penali, Padova, 1994, nonché F. SAluto, Diritto penale secondo l'ordine del codice per lo Regno delle due Sicilie, Palermo, 1858; D. Novarese, Istituzioni e processo di codificazione nel Regno delle Due Sicilie: le leggi penali del 1819, Milano, 2000; A.M. STILE, Il codice del 1819 per lo Regno delle Due Sicilie, in Diritto penale dell'Ottocento. I codici preunitari e il codice Zanardelli, studi raccolti da S. Vinciguerra, Padova, 1999, pp. 183-195.

140 Codice Penale per gli Stati di Parma, Piacenza e Guastalla, Parma, MDCCCXX. In ordine al codice penale parmense rinviamo al contributo di A. CADOPPI, Il codice penale parmense del 1820, in Diritto penale dell'Ottocento. I codici preunitari e il codice Zanardelli, cit., pp. 196-267.

141 Regolamento sui delitti e sulle pene del 20 settembre 1832, Roma. Per un'analisi contenutistica del Codice dello Stato Pontificio, rinviamo al contributo 
Tale fattispecie criminosa era invece contemplata, in particolare, aggettivata come 'bestiale' nel codice toscano del 1786 emanato da Pietro Leopoldo Granduca di Toscana che equiparava tale tipologia di omicidio a quello premeditato inserendoli nella medesima categoria criminale dei 'delitti atrocissimi' e pertanto irremissibilmente puniti con l'estremo supplizio della morte previa un'ora di gogna ${ }^{142}$. Nonostante fu un'impresa legislativa che accolse i più avanzati portati della scienza penale illuministica, sulla questione della bestialità nell'omicidio conservava un orientamento fortemente repressivo.

Sotto il profilo della pena nella Leopoldina veniva fatta anche una distinzione di genere: «la bestialità si punirà negli uomini con l'ultimo supplizio e nelle donne con l'ergastolo per venti anni» ${ }^{143}$, viene recepita anche da Leopoldo II nel codice penale toscano del $1853^{144}$, dal codice criminale per gli Stati Estensi del $1855^{145}$ e dal codice penale sardo-italiano del $1859^{146}$, sia pure con formule leggermente diverse.

di L. Fioravanti, Il regolamento penale gregoriano, in Diritto penale dell'Ottocento. I codici preunitari e il codice Zanardelli, cit., pp. 273-296. Ulteriori informazioni, sono reperibili in M. DA PASSANO, I tentativi di codificazione penale nello Stato Pontificio (1800-1832), in S. VInciguerra, I regolamenti penali di Papa Gregorio XVI per lo Stato Pontificio (1832), Padova, 2000, pp. CXLIII-CLXXXIII e in T. Padovani, Considerazioni sulla «parte generale» del Regolamento Gregoriano, ivi, pp. XLIII-LIV.

142 Sul punto si veda C. Paternitr, Note al codice criminale toscano del 1786, XLII, Padova, 1985, p. 31.

143 Ivi, p. 39.

144 Codice Penale pel Granducato di Toscana, Firenze, 1853, art. 309 §3. Sul codice si veda C. GHISALBERTI, Unità nazionale e unificazione giuridica in Italia. La codificazione del diritto nel Risorgimento, Roma-Bari, 1979, pp. 247-248; Si vedano anche i saggi raccolti in S. Vinciguerra, M. Da Passano (a cura di), Codice penale pel Granducato di Toscana (1853), Padova, 1995.

$145 \mathrm{Su}$ tale codice criminale si vedano C. CARCereri de Prati, Il codice criminale estense tra dispotismo illuminato di vecchio e nuovo tipo, in Codice criminale per gli Stati Estensi (1855), Padova, 2002, pp. XI-XIX; E.C. TAVILLA, Il diritto penale estense codificato. Aspetti sistematici e sostanziali, ivi, pp. XXI-XLVIII nonché A. Martini, Il codice criminale estense del 1855, in Diritto penale dell'Ottocento. I codici preunitari e il codice Zanardelli, cit., pp. 300-349.

146 Codice Penale per gli Stati di S. M. il Re di Sardegna, Torino, 1859, art. 533 n. 2. Sull'esperienza codificatoria del regno sardo-piemontese si vedano A. Aouarone, L'unificazione legislativa e $i$ codici del 1865, Milano, 1960, pp. 3-4 e 73-74; S. VinCIGUERRA, Breve profilo storico-giuridico del codice penale albertino, in S. Vinciguerra, M. Da Passano (a cura di), Codice penale per gli Stati di S. M. il Re di Sardegna (1839), Padova, 1993, pp. VII-XXVIIII; M. Da Passano, L'estensione del codice penale albertino alla Sardegna, ivi, pp. XXIX-L; S. VInciguerra., I codi- 
Il codice criminale toscano all'art. 309, $\$ 3$ dispone che «si punisce sempre come premeditato quell'omicidio che sia derivato da solo impulso di una brutale malvagità». Nel Granducato di Toscana, si credette quindi di risolvere il problema dell'omicidio senza causa equiparandolo all'omicidio premeditato sotto il profilo della pena. Nel suo commento al codice toscano, il giurista senese Giuseppe Puccioni (1788-1866) ${ }^{147}$, appartenente a quella cerchia di intellettuali che del diritto penale ne promosse una generale rifioritura di studi, tenne però distinte, nell'omicidio, la causa irragionevole e ingiusta dalla causa inesistente. Tali diverse cause conferiscono agli omicidi una natura giuridica altrettanto diversa. Infatti, in tale prospettiva, colui che uccide per causa ingiusta ed irragionevole rende manifesto l'impulso che lo ha spinto e determinato al delitto. Il Puccioni menziona, a titolo esemplificativo, il caso del subordinato che si rifiuta di denunziare il furto commesso dal proprio padre o dalla moglie ai danni del superiore e scoperto da questi viene ucciso; oppure il caso del marito che vuole porre la moglie fra le braccia di un altro uomo e che la uccide per essersi rifiutata. Questi sono alcuni dei casi di omicidi per causa ingiusta e irragionevole che, nella prospettiva del Puccioni, non dovranno considerarsi assimilabili agli omicidi premeditati bensì andranno qualificati come omicidi nati da improvviso moto d'animo la cui pena potrà essere aggravata eventualmente dal giudice sulla base di una sua valutazione arbitraria. Non è così per gli omicidi senza causa o ad lasciviam in cui è l'istinto cieco di versare il sangue che legittima la loro equiparazione per gravità agli omicidi premeditati. Quindi con la formula 'per solo impulso di brutale malvagità' dell'art. $309, \S 3$, il codice toscano ha vo-

ci penali sardo-piemontesi del 1839 e del 1859, in Diritto penale dell'Ottocento. I codici preunitari e il codice Zanardelli, cit., pp. 350-393.

147 Giuseppe Puccioni, Il codice penale toscano illustrato sulla scorta delle fonti del diritto e della giurisprudenza, IV, Pistoia, 1857, pp. 464-465. Sulla vita e l'opera di Puccioni cfr. Francesco Carrara, Giuseppe Puccioni ed il giure penale, in Opuscoli di diritto criminale, I, Firenze, 1898, pp. 5-96. Si tratta di un'opera in cui si colgono insieme i segni della grande Scuola storica toscana e quelli dell'esperienza maturata dall'autore nel suo lavoro di magistrato: una sintesi di perizia tecnica e respiro politico che rimanda allo stile giuridico della Firenze granducale. Sul punto cfr. M. Sbriccoli, Storia del diritto penale e della giustizia: scritti editi e inediti (1972-2007), I, cit., p. 506. 
luto far riferimento, secondo il Puccioni, ai soli omicidi senza causa e non anche a quelli per causa ingiusta, i quali restano annoverati fra gli omicidi per impeto improvviso. Mentre, invece, gli omicidi per libidine di sangue per l'allarme sociale che produce la loro atrocità, pongono il sistema penale in dovere di minacciarli, sempre, con grave punizione. L'omicidio brutale è considerato dal Puccioni reato persino più atroce dell'omicidio premeditato ${ }^{148}$. Egli riteneva altresì che la premeditazione propriamente detta, non si riscontri in questa tipologia di omicidio, perché solitamente viene eseguito appena viene deliberato nell'animo del criminale e l'assenza di una causa e la imprevedibilità che lo caratterizzano, lo identificano come maggiormente atroce rispetto al premeditato.

Tale fattispecie criminosa fu definita dal giurista Francesco Antonio Mori (1802-1860) $)^{149}$ - il quale prese parte larghissima nella ideazione e nella compilazione del codice penale toscano del $1853^{150}$ - delitto atrocissimo che spogliando l'agente d'ogni senso d'umanità, non può essere che severissimamente punito da ogni legislatore, che aspiri all'ambizione giuridica di proporzionare la pena alla quantità della colpa ${ }^{151}$. Sulla scia del Puccioni, anche il giurista Francesco Carrara (1805-1888) ${ }^{152}$, che trattò alla luce della formula codicistica toscana il «tema astruso dell'imputabilità della colpa», ritenne che l'ipotesi della premeditazione, quando è dissociata da par-

148 «Il genio malefico della distruzione che guida gli atti di questi scellerati è sempre pronto, sempre disposto alla strage. A differenza dell'omicida per premeditazione che risolve ad animo freddo e calmo la morte del suo nemico, e presceglie il luogo e il tempo opportuno per eseguirla, la iena a figura umana ogni volta che sente l'impulso di sua brutale malvagità si getta sulla sua vittima senza gli indugi della deliberazione e dei preparativi». GIUSEPPE Puccioni, Il codice penale toscano, cit., p. 464.

149 Sul Mori si veda almeno F. Colao, Mori, Francesco Antonio, in Dizionario biografico dei giuristi italiani, II, cit., pp. 1378-1379.

150 Per tali ragioni l'opera del Mori si considera come una sorta di interpretazione autentica del codice penale del 1853. Sul punto cfr. M. SBriccoli, Storia del diritto penale e della giustizia: scritti editi e inediti (1972-2007), I, cit., p. 506.

151 L'omicidio derivato da solo impulso di brutale malvagità che, precisa il Mori, nella giurisprudenza anteriore al codice si chiamava 'senza causa' o 'per causa brutale' è l'omicidio efferato della tigre e della iena quae parcit cognatis maculis. Francesco Antonio Mori, Teorica del codice penale toscano, Firenze, 1854, p. 250.

152 Sul Carrara si veda F. Colao, Carrara, Francesco, in Dizionario biografico dei giuristi italiani, I, Bologna, 2013, pp. 463-466. 
ticolare insidia e da altre aggravanti, presenta gravità minore dell'omicidio per libidine di sangue e questo tanto sotto il profilo morale quanto sotto il profilo politico. Sarebbe poi un errore, ritiene il giurista lucchese, supporre che il codice toscano avesse inteso riunire, nel designare tale 'specie omicidiaria', anche l'omicidio per 'causa ingiusta od irragionevole' sotto tale qualifica. L'omissione della aggravante della causa irragionevole non basterebbe come argomento per concluderne che il legislatore avesse voluto unificare questa qualifica alla mancanza assoluta di causa. Nel legislatore toscano vi era sufficiente ragione di omettere un provvedimento speciale contro l'omicidio per causa irragionevole, giacché l'antica giurisprudenza toscana conosceva questa aggravante e la invocava al solo fine di aumentare di un grado la pena ordinaria inflitta dalla legge del 1786. Riunire tutte queste figure in un solo reato, sia pure ai fini della pena, a detta del Carrara, presupporrebbe l'equiparazione della causa ingiusta alla premeditazione ed alla brutale libidine di sangue, presunzione che appare infondata alla luce dei principi ispiratori del codice, volti piuttosto a mitigare l'antica severità in materia di omicidio qualificato ${ }^{153}$.

L'omicidio bestiale già presente nella legislazione estense settecentesca si conserva nel codice estense, dove all'art. 360, §1 si menziona come ipotesi aggravante l'omicidio «commesso in totale mancanza di causa e per solo impulso d'una brutale malvagità». In tutte queste ipotesi, di omicidio qualificato dall'aggravamento dell'assenza di una causa ragionevole, viene dai vari codici comminata la pena di morte ${ }^{154}$.

Nel codice penale sardo del 1839 l'art. 580, n. 2 punisce con la morte l'omicidio anche «quando è commesso in totale mancanza di causa, e per solo impulso di una brutale malvagità». La norma si conserva nell'art 533, n. 2 del codice del 1859. L'art. 533 equipa-

153 Francesco Carrara, Programma del corso di diritto criminale, parte speciale ossia esposizione dei delitti in specie con aggiunta di note per uso della pratica forense, I, Lucca, 1872, pp. 288-289.

154 La pena di morte per tale tipologia di criminale viene prevista dall'art. 309 del codice toscano, dagli artt. 357-361 del codice estense e dagli artt. 531-533 del codice sardo-italiano. Cfr. P. VIco, Omicidio in Digesto italiano, XVII, cit., pp. 229-230. 
rava tale omicidio a quello commesso per altrui mandato e a quello preordinato allo scopo di commettere un altro reato. La Commissione per gli studi legislativi di Napoli stimò, però, troppo grave la pena di morte per gli omicidi 'semplicemente brutali' e propose per essi la pena dei lavori forzati a vita, ovvero la stessa pena prescritta per gli omicidi accompagnati da gravi sevizie. I lavori forzati a vita comminati come pena dall'art. 534 costituivano in ogni caso una pena aggravata rispetto alla pena di venti anni di lavori forzati prevista per l'omicidio volontario, ma non accompagnato da particolari circostanze e qualità. In altre parole, il legislatore del 1859 puniva con la morte l'omicidio bestiale, e non riconosceva che omicidi qualificati punibili di morte ed omicidi volontari punibili con i lavori forzati a vita. La Commissione napoletana era invece favorevole ad una doppia qualifica di omicidi: una prima classe di omicidi punibile di morte ed una seconda punibile con i lavori a vita, facendo scendere la pena dell'omicidio volontario semplice a soli venti anni di lavori forzati.

L'art. 534 fu poi modificato dal decreto legislativo del 17 febbraio del 1861 che sostituì la pena di morte con la pena dei lavori forzati a vita in tutta una serie di casi fra cui rientrava anche l'omicidio brutale:

1. L'omicidio commesso con prodizione od aguato che non costituiscano premeditazione (perché in caso di premeditazione era prevista la morte);

2. L'omicidio brutale senza causa;

3. L'omicidio accompagnato da gravi sevizie;

4. Il parricidio in linea discendentale.

Il Cosentino annotava che «si dice brutale l'omicidio volontario che non ha un fatto esterno per causale, ma prende unicamente origine dall'animo ferino ed incomposto dell'uccisore». I confini da lui delineati per l'omicidio brutale, sulla scorta della giurisprudenza contemporanea erano netti. Non era commesso in totale mancanza di causa l'omicidio al quale diede impulso un'antica e continua inimicizia fra l'uccisore e l'ucciso; o quando sia stato mosso da sdegno di vedere oltraggiato un terzo, specialmente se incapace a difendersi; 
né quando fosse commesso in rissa, anche se ingiustamente provocata dall'uccisore. La preesistenza di una causa qualunque esclude nell'omicidio la brutale malvagità ${ }^{155}$.

Nella legislazione europea la fattispecie appare quasi assente. Più semplicemente l'omicidio è punito soltanto se è volontario in senso stretto cioè nel caso in cui emerga una qualsiasi causa per aberrante che sia. Generalmente, infatti, i principali codici penali europei - sulla base di una indagine non esaustiva - tacciono della brutale malvagità. Tale omicidio non compare nel codice francese del 1810 e nelle sue successive modificazioni. Non compare nemmeno nel codice austriaco del 1852, in quello belga del 1867, nel codice di Zurigo del 1871, dell'Impero germanico del 1871, dell'Ungheria del 1878 e dell'Olanda del 1881. Si ritrova invece nel codice del Canton Ticino del 1873 che all'art. 291 lett. c afferma che «sarà punito col quarto grado di reclusione l'omicidio volontario quando sia commesso senza altra causa che l'impulso di brutale malvagità ${ }^{156}$, escludendo così la pena di morte.

\section{Il codice penale Zanardelli}

Il primo codice penale per il Regno d'Italia del 1889 si conferma sul tema della follia un testo innovatore e progressista rappresentando una svolta di grande portata per la cultura giuridica moderna. Con esso la dimensione umana della coscienza faceva irruzione nei tribunali nella sua veste di personalità psichica dell'imputato. Per la ricostruzione degli fatti criminosi emergevano tre sfere di interesse per il giurista: la dimensione del fatto nel suo regime di materialità, la dimensione della coscienza delle proprie azioni, la dimensione della libertà nelle volizioni.

Se da una parte il codice forniva parametri di valutazione per

155 Vincenzo Cosentino, Codice penale italiano annotato terza edizione contenente inoltre le modificazioni ad esso apportate dal dec. 17 feb. 1861 per le provincie napoletane; il richiamo degli articoli fra loro; il confronto con le disposizioni del Codice pen. francese [...], II, Napoli, 1863, p. 381.

156 Cfr. P. Vico, Omicidio, in Digesto italiano, cit., p. 232. 
un'analisi psicologica del criminale, dall'altra offriva parametri di valutazione per un'analisi di tipo morale. Nel codice Zanardelli, infatti, persiste «l'impulso di brutale malvagità» nella sua qualità di aggravante dell'omicidio volontario all'art 366, n. 3. Al pari delle bolle papali di antico regime, il codice della sinistra storica conservava la categoria giuridico-morale della malvagità come parametro valutativo nell'omicidio. La graduazione del crimine veniva incentrata sulla causa e in assenza di una causa che emergesse con chiarezza, il crimine veniva spiegato con la malvagità.

Per comprendere il peso morale di tale fattispecie giuridica appare illuminante ripercorrere il lungo itinerario che condusse alla previsione di tale circostanza aggravante. Il progetto del $1868^{157}$ prevedeva all'art. 284 lett. e la pena della reclusione di venticinque anni per l'omicidio «commesso senz'altra causa che l'impulso di brutale malvagità» ${ }^{158}$. L'omicidio volontario semplice veniva punito con la reclusione da venti a ventiquattro anni in forza dell'art. 285. Appare evidente la volontà di eliminare ogni pratica specificità all'ipotesi di omicidio brutale.

Occupandosi del riordinamento del titolo XII sui «reati contro la vita e l'integrità personale», il progetto del 1870 agli artt. $281 \mathrm{e}$ 282 poneva l'omicidio brutale fra quelli puniti con la reclusione a vita «sembrandole che presenti i caratteri da meritare tale pena [...] per la qualità delle persone [...] o per la loro indole speciale»e formulava la relativa disposizione nell'art. 334 , lett. e:

157 Senza parlare dei più lontani tentativi, preme ricordare che il primo progetto del Codice penale venne redatto nel 1868 da quella Commissione che risultò composta dalla fusione delle due Commissioni nominate l'una con decreto del 15 novembre 1865 per «studiare e proporre la riforma del sistema delle pene da servire di base alla formazione del nuovo Codice penale»; l'altra con decreto del 12 gennaio 1866 per «compilare il progetto del nuovo codice», valendosi anche dei risultati e delle conclusioni alle quali sarebbe giunta la prima. Cfr. Progetto del codice penale del Regno d'Italia (libro primo) presentato dal Ministro di grazia e giustizia e dei culti (Taiani), seduta del 23 novembre 1886, in Raccolta degli atti stampati per ordine della Camera dei deputati, legislatura XVI, sessione prima 1886-1887, dal 10 giugno 1886 al 4 settembre 1887 (V. Regio Decreto n. 4899, pubblicato il 7 settembre 1887, III, n. 74, Roma, 1887, pp. 1-2.

158 Verbali, nn. 84-85, pp. 522-529. 
L'omicidio volontario è punito con la reclusione a vita quando è commesso per solo impulso di brutale malvagità ${ }^{159}$.

Nel progetto del ministro Paolo Onorato Vigliani (1814-1900), invece, la fattispecie veniva omessa senza che se ne esplicitassero i motivi: nessuna osservazione da parte della Commissione senatoria e del Senato ${ }^{160}$.

$\mathrm{Fu}$ invece in seno alla Commissione del 1876 che il senatore De Falco propose di aggiungere l'aggravante della brutale malvagità. Ma il penalista Raffaele Conforti (1804-1880) ${ }^{161}$ osservava $^{162}$ che tale circostanza può talvolta essere anche semplicemente indizio di crassa e stupida ignoranza, e pertanto non le si dovrebbe riconoscere l'efficacia di una vera e propria aggravante. Se pure essa fosse il prodotto criminoso di un'indole feroce e perversa, può essere sufficientemente calcolata dal giudice nella latitudine della pena che è rimessa alla sua prudente estimazione ${ }^{163}$. Ma il primo progetto Zanardelli all'art. 322, n. 3 prevedeva la pena dell'ergastolo nell'ipotesi di reato commesso per solo impulso di brutale malvagità. Nella Relazione viene evidenziato che la somma gravità di questo reato si intende agevolmente se si consideri l'allarme sociale che esso può suscitare, ingenerando nei consociati la sensazione di essere in balia di criminali imprevedibili proprio perché privi di qualsiasi movente ${ }^{164}$.

159 Il progetto del codice penale pel Regno d'Italia, II, verbale n. 49, Firenze, 1870, pp. 335-336.

160 Progetto di legge per l'approvazione del codice penale del Regno d'Italia presentato al Senato dal ministro di grazia e giustizia Vigliani nella tornata 24 febbraio 1874, Roma, 1874, artt. 363-370.

161 Per un inquadramento biografico e ideologico si veda G. Monsagrati, Conforti, Raffaele, in Dizionario biografico degli Italiani, Roma, 1982, pp. 806810.

162 Il Conforti presentò le sue osservazioni in qualità di vicepresidente del Senato dal 20 novembre 1876 al ministero di Grazia e Giustizia nel primo governo Cairoli (24 marzo 1878), cfr. G. Monsagrati, Conforti, Raffaele, cit., p. 809.

163 Verbali, n. 12, p. 129.

164 Relazione e progetto lasciato in corso di studio dal Ministro Zanardelli con le modificazioni proposte dal Ministro Savelli, in Allegati al progetto del codice penale del Regno d'Italia (Savelli), tornata del 26 novembre 1883, Roma, 1883, p. 126. 
Le stesse considerazioni si ritrovano nei progetti Savelli ${ }^{165}$ e Pessina $^{166}$ e confluiscono nel secondo ed ultimo progetto Zanardelli all'art. 346, n. 3 che, definiva l'omicidio «qualificato e soggetto alla pena dell'ergastolo per ragione dell'intrinseca malvagità del fatto quando è commesso per solo impulso di brutale malvagità».

Mentre la Commissione della Camera dei deputati non sollevava obiezioni, quella senatoria nella tornata del 14 giugno 1888 osservava che l'"omicidio per brutale malvagità', che il progetto Zanardelli annovera fra gli omicidi qualificati, si vorrebbe classificato fra quelli aggravati per i quali all'art. 346 si prevedeva la pena della reclusione da ventidue a ventiquattro anni, accostando così tale tipologia a quella dell'omicidio premeditato. La Commissione senatoria sottolineava che in fondo si trattava di una figura assai rara di omicidio, a cui il giudice poteva fare agevolmente ricorso nelle ipotesi di omicidi senza causa apparente.

Carsicamente l'omicidio per malvagità era colto nella sua pratica valenza di consentire al giudice il superamento dell'impasse nell'incapacità di individuare la causa.

Dal punto di vista della Commissione senatoria, non si nega che il cinismo di chi uccida per voluttà manifesti nel colpevole una profonda perversione ma si sostiene che esso trova maggiore analogia con l'omicidio accompagnato da sevizie, piuttosto che con l'omicidio premeditato. Se la nequizia è parimenti manifesta nelle due tipologie di omicidi, vi è un tratto caratteristico che li distingue, giacché il 'brutale' emana da un moto improvviso di un animo aperto alle violenze; il 'premeditato' costituisce invece il portato di una deliberazione maturamente presa da un animo perverso, nel quale la riflessione, anziché ravvivare il sentimento del dovere, reca nuovi incitamenti al delitto. Chi uccide per sola brutalità dovrebbe incorrere

165 Progetto del codice penale del Regno d'Italia presentato alla Camera dei deputati nella tornata del 26 novembre 1883 dal Ministro di Grazia e Giustizia e dei Culti (Savelli) con la relazione ministeriale, Roma, 1883, art. 327, n. 3: «Si applica la pena dell'ergastolo, se il delitto è commesso [...] per solo impulso di brutale malvagità».

166 Progetto di codice penale pel Regno d'Italia presentato dall'onorevole Savelli alla Camera dei deputati nella tornata del 26 novembre 1883 confrontato con le modificazioni proposte dal Ministro di Grazia e Giustizia (Pessina), Roma, 1885, art. 344, n. 3. 
nel massimo rigore del sistema penale, al fine di difendere la società dal pericolo permanente che emana dalla ferocia di chi corre al più efferato dei delitti con una leggerezza che è superata soltanto dalla sua profonda malvagità ${ }^{167}$. Nella Commissione di revisione, il senatore Calcedonio Inghilleri (1836-1926), contesta la possibilità stessa di un omicidio per solo impulso di brutale malvagità, in quanto ove esistesse, significherebbe avere agito in stato di pazzia e quindi dovrebbe essere assegnato alle strutture sanitarie. La qualifica che informa il cosiddetto omicidio sine causa sarebbe priva di fondamento giuridico e di materiale esistenza, poiché - a detta dell'Inghilleri - coloro che uccidono senza motivo sono soltanto poveri dementi. L'omicidio, in quanto reato, non può esistere se non in presenza di una causa ${ }^{168}$.

\section{Casi esemplari in Cassazione}

La qualifica in questione consta di due estremi, il primo dei quali è che l'omicidio sia commesso per un impulso di malvagità, non umana ma brutale, e cioè senza una causa esterna eccitatrice; tale essendo il costume, non degli uomini, ma dei bruti.

In una decisione del 12 giugno 1849 con cui la Cassazione di Torino sentenziava sul ricorso dell'imputato Zanda contro la sentenza emessa in secondo grado, la Corte mette in rilievo la distinzione nell'omicidio fra l'ipotesi di una causa ignota e l'ipotesi di una causa inesistente, essendo soltanto quest'ultima a giustificare un aggravio della pena ${ }^{169}$. Infatti, se la causa è ignota, ciò non prova la sua inesistenza, e quindi non dimostra il concorso della qua-

167 Relazione della Commissione speciale composta dai senatori Vigliani (presidente), Ghiglieri (vicepresidente), Puccioni (segretario), Auriti, Bargoni, Calenda, Canonico, Costa, Deodati, Errante, Eula, Majorana-Calatabiano, Manfredi, Paoli, Pessina sul disegno di legge che autorizza il Governo del Re a pubblicare il Codice penale per il Regno d'Italia già approvato dalla Camera dei Deputati e presentato al Senato dal Ministro di Grazia e Giustizia (Zanardelli), tornata del 14 giugno 1888, Roma, 1888, p. 226.

168 Ibidem.

169 Cassazione Torino, 12 giugno 1849, (Zanda), in Gazzetta dei Tribunali, Genova, 1849, p. 140. 
lifica; la quale, tanto più perché circostanza di aggravamento, non può mai presumersi, ma va chiaramente accertata, provando cioè la mancanza di una qualunque causa esterna impulsiva. Nella giurisprudenza si è ritenuto che la sentenza non può «pretermettere di accennare i fatti e addurre i motivi da cui dedusse l'essenziale elemento della brutale malvagità». Dunque non può essere motivata la sentenza sulla qualifica della brutale malvagità ove si pretenda dedurla dal non potersi spiegare altrimenti il fatto. La Cassazione il 5 dicembre del 1901 decidendo del ricorso presentato dall'imputato Antonio Brezzo contro la condanna del giudice d'appello per lesioni personali volontarie 'per solo impulso di brutale malvagità' contro Veneziano considera non sufficientemente motivata la qualifica aggravante del reato accogliendo in tal guisa il primo motivo di merito del ricorso. La Suprema Corte, infatti afferma che la difficoltà a trovare il motivo del reato non esclude che un motivo vi sia stato, e, sino a quando 1'“occulto movente' sia possibile nella casistica empirica, il giudice non può discendere alla ipotesi della somma gravità del delitto commesso per impulso di brutale malvagità ${ }^{170}$. L'essere stati i due avversari, il Brezzo e la sua vittima, per un buon tratto della sera del misfatto a bere insieme nell'osteria e apparentemente in buoni rapporti non può far presumere che non vi fosse «egreferenza» - sia pure occulta - fra loro; può, invece, farc ragionevolmente presumere che, probabilmente con l'apporto dei fumi del vino, sia nata anche istantaneamente della «malevoglienza». Aggiunge la Corte con tono sferzante:

Sarebbe stato più logico quasi il tribunale che, non sapendo escogitare il motivo di cui andava in cerca, fosse venuto piuttosto all'ipotesi dell'infermità o seminfermità di mente; ma supporre che due che stavano amichevolmente a bere nell'osteria, che non aveano avuto motivo di bisticciarsi fra loro e che, come suppone il tribunale, non avevano motivo alcuno per offendersi vicendevolmente, uno di questi, che poi non risulta di essere stato altra volta processato e tanto meno condannato per reati di sangue, si fosse spinto a inveire contro il compagno ad lasciviam, cioè mosso dallo spirito di

170 Cassazione, 5 dicembre 1901 (Brezzo), in Rivista penale di dottrina, legislazione e giurisprudenza, LV, Torino, 1902, p. 220. 
brutale malvagità, è una supposizione troppo arrischiata, da meritare, per lo meno, che venga sottoposta alla critica di un altro tribunale ${ }^{171}$.

La Cassazione ritenne che il convincimento del giudice di merito non fosse fondato su 'seri motivi' bensì su motivi erronei, sicuramente diversi da quelli sui quali la legge si era determinata ad ammettere l'aggravante di cui all'art. 366, n. 3 (codice Zanardelli) per i reati di sangue, «fortemente e virilmente contrastata nella dottrina» e pertanto non poteva servire di sostegno ad una condanna grave, per un reato che dal primo giudice era stato persino ritenuto non sufficientemente provato ${ }^{172}$.

La Cassazione toscana il 14 maggio 1847 decideva su un ricorso presentato dall'imputato V. contro la decisione della Corte Regia del 24 marzo 1847 con cui veniva dichiarato reo d'omicidio commesso per moto improvviso d'animo, per causa irragionevole, ingiusta e brutale nella persona della giovane R. trovata esamine nelle ore pomeridiane del 5 luglio 1846 con dieci ferite nella testa infertele con corpo contundente e lacerante. Dalla posizione dei fatti in premessa, la Corte Regia ritenne che $\mathrm{V}$. si fosse determinato ad uccidere la R. nell'incontro fortuito con lei avuto in strada, al seguito della resistenza dalla vittima opposta alle sue ingiuste e lascive richieste. E considerando che nel concorso di una causa irragionevole e brutale la giurisprudenza pratica era solita procedere ad esasperare d'un grado la pena determinata dalla legge per gli omicidi derivanti da causa improvvisa all'art. 14 della legge del 30 agosto 1795, condannò l'imputato alla pena di 15 anni di servizio ai pubblici lavori e all'esilio dal Granducato di Toscana. Il ricorrente dava debito alla sentenza pronunciata dalla Corte su più punti. Uno di questi concerneva l'aver confusamente ed inesattamente ignorata la questione sollevata dalla difesa dell'imputato che sosteneva non potersi parla-

171 Ibidem.

172 Il giudice di primo grado aveva emesso sentenza di assoluzione del Brezzo per insufficienza di prove. Sentenza contro cui fu presentato ricorso dal procuratore del re, il quale si «dolse che male era stato assoluto, perché si fece dal pretore un erroneo apprezzamento delle risultanze processuali» dalle quali emergeva con evidenza la colpabilità del Brezzo. Cfr. Cassazione, 5 dicembre 1901 (Brezzo), in Rivista penale, LV, Torino, 1902, p. 221. 
re di omicidio 'per causa brutale', senza ammettere l'esistenza di siffatta causa nel concorso di un carattere feroce e sanguinario dell'omicida e questo elemento 'essenziale' della causa brutale era escluso dai risultati del dibattimento in cui emergeva, al contrario, accertata la dolcezza del carattere e la precedente vita immune dell'imputato da ogni rimprovero.

La Cassazione su tale questione ritenne opportuno precisare che il carattere dell'omicidio per moto improvviso dell'animo eccitato da 'causa irragionevole e brutale' debba desumersi dalle circostanze e dalla causa del fatto, senza che sempre sia necessario desumerlo dalla vita antecedente dell'omicida ${ }^{173}$.

Va poi precisato che il gravame dell' impulso per brutale malvagità' deve essere desunto dal «complessivo dei fatti e dalle circostanze incensurabilmente apprezzate dal giudice di merito negli stretti confini delle sue attribuzioni» e che pertanto alla Corte suprema alla quale sono riservate soltanto le violazioni del diritto e delle forme processuali - risulta insindacabile l'apprezzamento sulla esistenza o mancanza dell'impulso di brutale malvagità ${ }^{174}$.

Nel processo che vedeva imputato di omicidio qualificato, ai sensi dell'art 533, n. 2 del codice penale, Ionata Francesco, la Cassazione di Roma nella udienza del 13 giugno 1881 decise sulla questione della unicità o pluralità della causa, ovvero del movente che spinse l'accusato ad uccidere. La Corte censura la questione perché il giudice del merito non si chiese se l'omicidio si fosse commesso per 'solo' impulso di brutale malvagità, oppure altresì per altro movente. L'art. 533 del codice sardo col dire che l'omicidio volontario è punito di morte quando è commesso 'senz'altra causa che per impulso di brutale malvagità' presuppone evidentemente che con la 'brutale malvagità' possa concorrere - in rapporto eziologico un'altra causa; d'onde la conseguenza che non altrimenti può dirsi verificata in concreto questa specie di omicidio se non sia provato

173 Cassazione toscana, 14 maggio 1847, in Annali di giurisprudenza. Raccolta di decisioni della Corte Suprema di Cassazione, della Corte regia e dei Tribunali di prima istanza, Firenze, 1847, p. 365.

174 Costituisce 'apprezzamento di fatto' il ritenere sussistente o meno tale aggravante. Cfr. Cassazione, 21 febbraio 1901 (Rovano), in Rivista penale, LIII, Torino, 1901, p. 555. 
che fu commesso per tale tipologia di impulso e che non vi si aggiunse alcuna altra causa. Dunque, nel caso concreto sottoposto al giudizio della Corte Suprema:

essendo risultato dell'impulso brutale, ma non essendo risultato altresì che vi fosse qualche altra causa (perché su quest'ultima circostanza non si interrogarono i giurati) non poteva il ricorrente venir condannato alla pena comminata per chi uccide volontariamente per 'solo' impulso brutale ${ }^{175}$.

Non potrebbe obiettarsi in contrario essere superflua l'interrogazione sul concorso o meno di un'altra causa, come se il concorso di altra causa escludesse necessariamente l'impulso brutale dato che non è lecito trascurare alcuno degli elementi del reato riconosciuti essenziali dalla legge positiva. È meno esatto, dice la Corte sostenere che con l'impulso brutale non possa coesistere un'altra causa la quale col suo concorso valga a diminuire la imputabilità dell'agente e consigli quindi una diminuzione di grado nella pena che all'omicidio commesso per 'solo' impulso brutale sarebbe dovuta. Tale possibile concorso, continua la Corte, si avrebbe nella ipotesi di 'parziale infermità', dalla difesa infatti invocata a favore del ricorrente, poiché:

la malvagità brutale che addita quale unica cagione dell'omicidio un odio snaturato ed inesplicabile contro il genere umano può benissimo accoppiarsi alla semi-imbecillità, la quale, obliterando le facoltà intellettive e volitive dell'uomo gli impedisce di delinquere con calcolo, con logica e per un motivo se non giustificabile comprensibile ${ }^{176}$.

Secondo la Corte, nel caso Ionata non essendo così forte «la forza morale del reato», né così «grave il danno sociale» neppure la pena deve raggiungere tale grado di gravezza come sarebbe se all'impulso brutale non si aggiungesse la semi-infermità. Si è in più occasioni, dice la Corte, disputato se chi agisce per 'solo' impulso brutale debba sottoporsi a vera pena o se sia piuttosto da rinchiudersi in un

175 Cassazione Roma, 13 giugno 1881 (Ionata), in Rivista penale, XV, Firenze, 1881, p. 77.

176 Ibidem. 
manicomio criminale, al pari di colui che agisce per forza irresistibile e che per l'art. 94 del codice penale non è soggetto a pena.

Oltretutto rilevò la Corte, l'espressione 'brutale malvagità', come causale del delitto, non è di quelle espressioni giuridiche che non possono usarsi nelle questioni ai giurati, «non contenendo alcun vocabolo che accenni a concetti lontani dal comune linguaggio» ${ }^{177}$.

Un'altra precisazione scriminante va fatta fra causa inesistente e causa ingiusta dell'omicidio. La qualifica 'per impulso di brutale malvagità' si fonda infatti non già sulla maggiore o minore giustizia o ragionevolezza della causa esterna eccitatrice bensì sull'assenza di questa. È evidente come sia cambiato lo stesso concetto di sine cau$s a$, che in passato come si è rilevato in precedenza, voleva significare anche la irragionevolezza del movente. Così, nella giurisprudenza si è statuito che se 'causa impulsiva del reato' fu la vendetta non poteva invocarsi tale ipotesi omicidiaria costituita unicamente dalla mancanza di ogni causa, e che, proprio dal sine causa deriva il 'brutale' nell'accezione del 'non umano'178.

Nella decisione con cui la Cassazione il 10 maggio 1897 decideva sul ricorso dell'imputato Foglia, la suprema corte ritenne che «ammessa l'esistenza di una causa a delinquere, nel caso di specie, il fatto di avere la moglie impedito al marito di percuotere una loro figlia; ammessa questa causa, benché ingiusta, non si può senza contraddizione parlare di impulso di brutale malvagità ${ }^{179}$ anche perché già nel 1849 la Corte stabilì che non può qualificarsi tale l'omicidio commesso in seguito a maltrattamenti usati dall'ucciso contro una terza persona «perché un oltraggio fatto ad altri può in certi casi eccitare nello spettatore uno sdegno ben ragionevole, massime quando vede soperchiato ed oppresso un misero incapace di difesa, essendo questo un sentimento che move da istinto umano e talvolta generoso, anziché da ferocia brutale ${ }^{180}$. L'esistenza della provocazione esclude l'esistenza della qualifica in esame e pertanto «la questione

177 Ivi, p. 77.

178 Cassazione, 21 novembre 1898 (Pezzimento), in Rivista penale, XLIX, n. 470, Torino, 1899, p. 190.

179 Cassazione, 10 maggio 1897 (Foglia), in Corte Suprema, 1897, 144.

180 Cassazione Torino, 12 giugno 1849 (Zanda), in Gazzetta dei Tribunali, Genova, 1849, 140. 
ai giurati sulla provocazione è sempre subordinata alla negativa di quella sull'impulso di brutale malvagità» ${ }^{181}$.

Ove manchi una causa esterna impulsiva e verificandosi in tal guisa la ragione della qualifica, sembra che non abbia influenza alcuna il fatto che l'azione del colpevole sia stata rivolta contro una persona determinata. Il Carrara insegna diversamente sostenendo che «quando l'attacco fu diretto contro un individuo determinato, al quale soltanto, e a nessun altro uomo, si voleva togliere la vita, la tesi della qualifica rimarrà sempre insostenibile. Poiché non agisce per il solo barbaro piacere di spargere sangue umano colui che particolarmente ed esclusivamente anela il sangue di un individuo ${ }^{182}$. L'omicida, in tale ipotesi, odia quello specifico uomo - sia pure irragionevolmente - ma non odia l'umanità ${ }^{183}$.

$\mathrm{Al}$ contrario, nella giurisprudenza si è deciso che «il fine di uccidere una determinata persona non è incompatibile con l'aggravante della brutale malvagità» dato che l'aggravante in questione non può verificarsi che in un caso concreto, ovvero contro una o più determinate persone e non consiste nella sete di sangue in genere, ma nel commettere un reato di sangue senza una causa apparente ${ }^{184}$.

L'altro estremo della qualifica è che la brutale malvagità sia stata il solo impulso a commettere l'omicidio; poiché, ove con questo coesistesse un'altra causa, non si verificherebbe più quell'accrescimento di danno mediato che costituisce la ragione giustificatrice della qualifica. Nella giurisprudenza anteriore all'emanazione del codice Zanardelli si considerò contraddittoria e quindi incompatibile la scusa del vizio parziale di mente con l'affermata esistenza della brutale malvagità nell'omicidio senz'altra causa, poiché, se a costituire la qualifica si richiede la volontà determinata ad operare il male per la sola libidine dello stesso ed in conseguenza di una spontanea determinazione dell'intelletto, è impossibile amalgamare tale concet-

181 Cassazione, 23 marzo 1898 (Picone), in Rivista penale, XLVII, n. 1151, Torino, 1898, p. 596.

182 Francesco Carrara, Programma del corso di diritto criminale parte speciale ossia esposizione dei delitti in specie, I, cit., §. 1201, p. 287.

183 Ivi, §. 1203, pp. 289-290.

184 Cassazione, 1 maggio 1899 (Di Paolo), in Rivista penale, n. 1729, L, Torino, 1899 , p. 88. 
to di profonda malvagità con quel debilitamento delle facoltà intellettuali presupposto dal vizio parziale di mente; sono termini che si escludono a vicenda ${ }^{185}$. In questa prospettiva la brutale malvagità sembra presupporre nell'agente l'assenza di ogni ragionevole motivo che valga a scemare la imputabilità dei suoi atti, presuppone un pienissimo dolo, uno stato d'animo della più consumata depravazione.

Non mancarono però statuizioni difformi. Infatti, nell'applicazione del codice, la Cassazione unica dapprima ritenne che chi 'uccide senza causa', o come dice l'art. 366, n. 3, 'per impulso di brutale malvagità', non può pretendere di avere agito 'per difetto parziale di forza morale’, perché ciò suppone una causa, la quale non può concorrere in un reato che si vuole commesso nell'assenza di ogni causa, e per solo impeto d'odio contro l'umanità ${ }^{186}$.

Ma il 4 aprile del 1900 nel processo che vedeva imputato di tale omicidio Pietro Mancini, la Cassazione mutò orientamento, dichiarando non incompatibile con la brutale malvagità il vizio parziale di mente di mente ${ }^{187}$.

Considerato in diritto che:

anche l'infermo di mente, non del tutto irresponsabile, possa determinarsi a un delitto per solo impulso di brutale malvagità, cioè senz'altra causale, si vede al lume della ragion

185 Cassazione Napoli, 14 agosto 1874 (Migliaccio), in Rivista penale, I, Padova, 1874, p. 356; Legge, 1874, 980.

186 Cassazione 5 febbraio 1896 (Russo), in Rivista penale, XLIII, n. 1025, Torino, 1896, p. 419; Cassazione 22 febbraio 1897 (De Cesare), in Rivista penale, XLV, n. 984, Torino, 1897, p. 489; Cassazione 31 gennaio 1898 (Puxeddu-Sanna), in Rivista penale, XLVII, n. 809, Torino, 1898, p. 413; Cassazione 16 gennaio 1899 (Giacobbe), in Rivista penale, XLIX, n. 696, Torino, 1899, p. 307.

187 Nel pubblico dibattito seguito dinanzi la Corte d'assise dell'Aquila, il giorno 7 febbraio a carico di Pietro Mancini, accusato di un omicidio consumato e di due mancati, tutti determinati da solo impulso di brutale malvagità, il presidente della Corte propose ai giurati, per ciascun delitto, la scusante del vizio parziale di mente ma tale proposta fu subordinata alla condizione che si fosse che si fosse deciso negativamente sulla questione della aggravante della brutale malvagità. Ciononostante, i giurati, affermata la completa responsabilità del Mancini secondo l'accusa, votarono affermativamente entrambe le questioni relative alle due circostanze: l'una aggravante, l'altra scusante. E la Corte su tale verdetto condannò il Mancini, quale colpevole dei tre delitti accompagnati da entrambe le circostanze alla pena complessiva della reclusione per venti anni, dieci mesi e quattro giorni, oltre gli accessori di legge. 
comune. Data la sua morale imputabilità, essa viene anche per lui a nascere e definirsi con relazione e proporzione ai suoi comuni elementi. Non possono coesistere date circostanze d'aggravamento con altre minoranti, quando sì le une che le altre abbiano identica sorgente, o sede; come quelle dipendenti da uno stato passionale dell'animo, il quale, naturalmente, non può trovarsi ad un tempo in condizioni diverse, opposte e contraddittorie tra loro ${ }^{188}$.

Altra sede infatti ha l'impulso delittuoso - che alberga nell'animo e muove dal sentimento - rispetto allo stato mentale del delinquente. Le due condizioni personali possono coesistere, in tal caso, al pari delle due circostanze del reato e di conseguenza può senz'altro scemarsi la imputabilità di tale criminale. Lo stato mentale pur indebolendo nell'agente la forza di resistere all'impulso menomandone la coscienza o la libertà dell'atto, non fa in modo che la medesima non possa essere e rimanere per lui la vera e sola causa determinante al delitto.

La non incompatibilità fra le due circostanze del reato fu dichiarata anche nel processo che vedeva imputato di omicidio "per solo impulso di brutale malvagità' Quercioli Cesare su cui pendevano altre due accuse ${ }^{189} \mathrm{e}$ in cui la Corte precisò che:

se nella mente che dà la percezione delle cose, si forma la convinzione del delitto e la coscienza relativa, soltanto però nell'animo, sede delle passioni, ne sorge e ne può sorgere la spinta, mossa dal sentimento solleticato e sedotto. Perciò

188 Cassazione 4 aprile 1900 (Mancini), in Rivista penale, LII, Torino, 1900, p. 602; Cassazione, 14 marzo 1901 (Federici), in Rivista penale, LIII, Torino, 1901, p. 641; Cassazione 14 luglio 1903 (Calabria), in Rivista penale, LVIII, Torino, 1903, p. 672; Cassazione 24 maggio 1904 (Quercioli) in Rivista penale, LXI, Torino, 1905, p. 49.

189 La seconda accusa era di aver, con minacce di gravi danni imminenti alla persona, costretto il mugnaio Domenico Cioni a dargli da mangiare e da bere; la terza di porto abusivo d'un pugnale. Per tali reati la Corte d'assise di Siena lo condannò all'ergastolo. Il Quercioli presentò ricorso in Cassazione deducendo come motivo di annullamento del giudizio, la violazione degli artt. 494 del codice di procedura penale, 366 e 47 del codice penale per aver il presidente posta la questione sulla seminfermità di mente subordinatamente a quella della brutale malvagità come solo impulso al delitto, ravvisando fra le due circostanze un'incompatibilità. Cfr. Cassazione 24 maggio 1904 (Quercioli) in Rivista penale, LXI, Torino, 1905, p. 49. 
quando si tratti, come nel caso concreto, di stabilire qual sia stato il movente di un delitto, non è alle condizioni mentali dell'agente che deve aversi riguardo, per quanto esse possano influire sulla sua morale imputabilità ${ }^{190}$.

La Corte evidenza la differenza «per essenza» fra 'stato della mente' e 'stato dell'animo' fra cui non può esserci vera incompatibilità risiedendo in luoghi diversi e lontani. L'impulso di brutale malvagità può essere tanto l'effetto d'un 'moto improvviso dell'animo', quanto l'effetto di una precedente matura deliberazione, la Cassazione così ha chiarito la questione sulla compatibilità fra l'omicidio 'per impulso brutale' e quello 'premeditato'. Non appare contraddittorio il verdetto dei giurati che ammetta entrambe le qualifiche «imperocché niente vale a escludere che il colpevole di tale omicidio per solo impulso di brutale malvagità abbia meditato il delitto, ne abbia studiati e preparati i mezzi di esecuzione e vi si sia risoluto con calma, con tanta calma quanta può esserne in chi non ha altra causa che lo spinga al malefizio» ${ }^{191}$.

\section{Aggravamento della pena o ricovero coatto in manicomio}

L'omicidio del monomaniaco - in quanto omicidio senza causa -, osservato attraverso la lente del giurista, sembra poter rientrare a pieno titolo nell'applicazione dell'art. 366 del codice Zanardelli disciplinante l'ipotesi di omicidio commesso per solo impulso di brutale malvagità. Tale circostanza, come abbiamo visto, rientra fra quelle in grado di concorrere ad aumentare la gravità dell'omicidio. Nel linguaggio comune, queste ultime si dividono in circostanze aggravanti e in circostanze qualificanti, da cui derivano due specie di omicidi, gli aggravati e i qualificati. Mentre le circostanze aggravanti, per quanto accrescano la criminosità del fatto non sono tali da modificarne sostanzialmente gli effetti, le circostanze qualificanti imprimono, inve-

190 Ibidem.

191 Cassazione Milano, 19 dicembre 1863, (Franchini) in Gazzetta dei Tribunali, 1863, p. 461; Cassazione toscana, 2 aprile 1849 in Annali, 1849, 175. 
ce, all'omicidio una gravità speciale. La terza qualifica dell'omicidio prevista dall'art. 366 del codice si rileva da sé nella sua importanza, come sosteneva Francesco Carrara, «per l'efferatezza d'animo del colpevole e per il timore che giustamente tale categoria di uomini ingenera nella società» ${ }^{192}$ e come ebbe a dire più tardi anche Giulio Cesare Crivellari (1834-1895) ${ }^{193}$ «per la perfidia o brutalità del reo» ${ }^{194}$.

All'omicidio del monomaniaco poteva applicarsi altresì l'art. 46 che si fonda su principi antitetici rispetto all'art. 366, disciplinando le cause di esclusione della imputabilità. Infatti, l'art. 46 del codice penale fornisce una definizione della imputabilità in senso negativo, guardandola sotto il profilo dello stato psichico del reo in relazione alla capacità di avere la coscienza o la libertà dei propri atti. Il problema che il legislatore ha affrontato e risolto con tale disposizione riguarda la dirimenza della imputabilità per causa di difetto di volontà dell'azione nell'autore. L'articolo così recita:

Non è punibile colui che, nel momento in cui ha commesso il fatto, era in tale stato di infermità di mente da togliergli la coscienza o la libertà dei propri atti.

Il giudice, nondimeno, ove stimi pericolosa la liberazione dell'imputato prosciolto, ne ordina la consegna all'Autorità competente per i provvedimenti di legge.

In questa formula legislativa viene cristallizzato il concetto giuridico di imputabilità, prevedendo le cause che la escludono, e di sanità mentale come tradizionale presupposto della colpevolezza ${ }^{195}$. Si è pertanto considerati sani di mente per il diritto penale se si è in possesso della capacità di comprendere il valore giuridico - quanto

192 Francesco Carrara, Commento al Codice penale, Roma, 1889, p. 225.

193 Per le note biografiche sul Crivellari si veda F. Rossi, Crivellari, Giulio Cesare, in Dizionario biografico dei giuristi italiani (XII-XX secolo), I, cit., pp. 613614.

194 GiUlo Crivellari, Il codice penale per il Regno d'Italia corredato di brevi Avvertenze e Note ad ogni Libro e ad ogni Titolo, delle referenze agli articoli del Codice stesso, nonché dei Codici Sardo, Toscano, delle Due Sicilie, Parmense, Estense, Pontificio, Francese, Austriaco, delle Leggi speciali punitive vigenti e di un indice alfabetico-analitico, Torino, 1889, p. 134.

195 Cfr. P. Nuvolone, Giuseppe Zanardelli e il codice penale del 1889, in F. ChIARINI (a cura di) Giuseppe Zanardelli, Milano, 1985, pp. 163-182, in particolare pp. 171-173. 
agli effetti - delle proprie azioni e se si è in possesso di una volontà di determinazione libera, ove manchi l'una o l'altra capacità si è considerati infermi di mente. Di norma, il soggetto che agisce sa e vuole quello che fa. Ma questa regola può subire eccezioni ed è proprio alla ricerca di queste eccezioni, nelle quali l'elemento morale scompare o si affievolisce, che la scienza del tempo rivolse la sua attenzione.

Con la formula inequivocabile dell'art. 46 escludente l'imputabilità allo stato di infermità di mente, il legislatore ha con chiarezza incluso nell'universo giuridico il concetto di alterazione parziale della psiche. In tal modo, abbandonando la formula del Codice toscano (art. $34)^{196}$ e quella del Codice sardo (art. 94) ${ }^{197}$ ha risolto la questione ardua dell'accoglimento giuridico della follia parziale. I concetti di coscienza dei propri atti e libertà di elezione menzionati nel codice toscano sembrano evocare alcune pagine del Carmignani dedicate alla volontà colpevole come volontà libera e alla imputabilità come capacità di valutare il valore etico e sociale dell'azione e di determinarsi a essa scegliendo fra opposte motivazioni ${ }^{198}$. Si spera che in tal modo, scrive il Crivellari, il legislatore abbia «cacciata dalle aule della giustizia quella forza irresistibile che, cervelloticamente discussa ed applicata, aveva terminato col gittare il ridicolo talvolta, il discredito sempre sulla giuria» ${ }^{199}$.

Le cause che escludono l'imputabilità di cui all'art. 46 vengono dal codice penale tenute ben distinte dalle cause scusanti disciplinate dall'art. 51. Fra le cause scusanti rientrava l'impeto dell'ira in seguito ad ingiusta provocazione e l'impeto di ingiusto ed intenso dolore $^{200}$. L'articolo 51, nella sua prima parte, così recitava:

Colui che ha commesso il fatto nell'impeto d'ira o d'intenso dolore, determinato da ingiusta provocazione, è punito con la

196 Codice Penale pel Granducato di Toscana, Firenze, 1853, art. 34: «Le violazioni della legge penale non sono imputabili, quando chi le commise non ebbe coscienza dei suoi atti e libertà d'elezione».

197 Codice Penale per gli Stati di S. M. il Re di Sardegna, Torino, 1859, art. 94: «Non vi è reato se l'imputato trovavasi in istato di assoluta imbecillità, di pazzia, o di morboso furore quando commise l'azione, ovvero se vi fu tratto da una forza alla quale non poté resistere».

198 Cfr. Giovanni Carmignani, Teoria delle leggi della sicurezza sociale, cit., p. 230 ss.

199 Giulio Crivellari, Il codice penale per il Regno d'Italia, cit., p. 28.

200 Ivi, p. 29. 
reclusione non inferiore ai venti anni, se la pena stabilita per il reato commesso sia l'ergastolo, e negli altri casi con la pena stabilita per il reato commesso diminuita di un terzo.

L'omicidio del monomaniaco che agisce senza motivo apparente non rientra, a nostro avviso, nell'applicazione dell'articolo disciplinante il reato d'impeto, dove esiste una provocazione oppure uno stato passionale che spinge il criminale ad agire.

L'articolo 46 fornì, come ebbe a dire la parte più entusiasta della dottrina giuridica, la risoluzione ai più gravi problemi della scienza del diritto, della psichiatria, della psicopatologia, della psicologia penale e della medicina legale ${ }^{201}$.

Il codice segna un momento decisivo nel dibattito sulla natura interna o esterna della forza irresistibile ${ }^{202}$. Se la forza irresistibile la si considera esterna si pone l'ipotesi di una violazione fisica, estranea alla teorica dell'imputabilità, in quanto il soggetto che è reso strumento in mano altrui non può considerarsi soggetto agente. Se invece per forza irresistibile si intende una forza interna, in essa potevano essere comprese sia uno stato patologico sia le diverse specie di coazione morale, si pensi alla legittima difesa, all'ordine della legge, alla minaccia grave, allo stato di necessità. Tale concetto merita qualche altro chiarimento. Bisogna distinguere, infatti, la forza irresistibile che è l'emanazione di uno stato psichico morboso, da quella che è rappresentata da uno stato di necessità psicologica.

Su iniziativa di Zanardelli, nell'art. 46 si giunse all'eliminazione dei riferimenti a quanto non rientra nella sfera dell'infermità di mente e quindi, in primo luogo, all'eliminazione della forza irresistibile da stati passionali. Nei codici preunitari la nozione comprendeva il costringimento fisico e la coazione morale. In seguito, invece, il va-

201 F. Manduca, Il nuovo codice penale italiano e i suoi criteri organici, in Completo trattato teorico e pratico di diritto penale secondo il codice unico del Regno d'Italia, I, pubblicato da P. Cogliolo, cit., p. 525.

202 Sul concetto di forza irresistibile, si veda in generale, D. Santamaria, Forza irresistibile, in Enciclopedia del diritto, XVIII, Milano, 1969, pp. 5-15; R. CRESPOLANI, Forza irresistibile, in Enciclopedia giuridica italiana, VI, parte III, Milano, 1916, p. 350-356; G. Belli, Forza irresistibile, in Nuovo Digesto Italiano, VI, Torino, 1938, p. 113. In particolare sulla forza insuperabile che spinge al crimine nell'età della codificazione E. Musumecr, Emozioni, crimine, giustizia. Un'indagine storico-giuridica tra Otto e Novecento, cit., p. 39. 
lore attribuito nella prassi all'espressione «forza irresistibile», intesa nel senso di coazione morale, si era via via ampliato, fino a riguardare gli stati d'ira e gli stati passionali; in altre parole, la forza irresistibile tendeva in concreto ad assumere il significato di necessità psicologica. Ed è proprio per evitare interpretazioni distorte di tal fatta - e i conseguenti abusi - che l'art. 46 elimina il concetto di forza irresistibile, e comunque disciplina l'esclusione della imputabilità per tendenze irresistibili, solo nel caso in cui queste siano riferibili a individui infermi di mente ${ }^{203}$.

Pertanto, con il concetto di libertà dei propri atti che ha sostituito quello più ambiguo di forza irresistibile, il Codice del 1889 ha inteso indicare la possibilità di operare altrimenti, facendo riferimento agli effetti immediati di un'infermità di mente tale da privare l'individuo della capacità di volere. Questo appare da tutte le relazioni preparatorie delle Commissioni ministeriali per la realizzazione del codice penale per il Regno d'Italia ${ }^{204}$.

Negli articoli 46 e 47 confluirono tutte quelle tendenze irresistibili, tutte quelle impulsioni psicopatologiche che afferiscono alla follia parziale, quali ad esempio mania sistematica omicida, mania sistematica suicida, cleptomania, piromania, dipsomania, aidiomania, allotriofagia, scatolagia, coprolalia, antropofagia e molte altre ossessioni speciali che sono alterazioni del processo volitivo tali da escludere nell'agente ogni possibilità di reazione e ogni attitudine a determinarsi secondo gli ordinari motivi giuridici $^{205}$.

Per i delitti e per le pene rimarrà sempre vero che le cause influenti sulle volizioni possono essere di due tipi: quelle che eliminano qualsiasi attività volitiva interna dell'individuo; e quelle che invece la sforzano ma non la distruggono. Nel primo caso il criminale sarà lasciato senza castigo o ricoverato in un manico-

203 Sul punto si veda E. DezzA, Saggi di storia del diritto penale, cit., p. 315. Per un quadro più esaustivo dell'intera questione si veda A. SeTti, Dell'imputabilità (dall'art. 44 Codice penale all'art. 48), in Completo trattato teorico e pratico di diritto penale, cit., pp. 579-749, in particolare pp. 642-687 e più succintamente, LuIGI Majno, Commento al codice penale, I, Torino, 1915, pp. 106-109.

204 Si veda A. SetTi, Dell'imputabilità (dall'art. 44 Codice penale all'art. 48), cit., p. 672.

205 Ivi, p. 673. 
mio, a seconda che la forza impellente derivi dall'altrui violenza o da uno stato psichico morboso; nel secondo caso sarà punito per non essersi opposto con la sua forza psichica all'impulso criminogeno.

In questo quadro, il solo impulso di brutale malvagità, inteso come deliberato proposito di fare del male per il solo fine di fare del male, sembra non essere più ammissibile di fronte agli studi e ai progressi della scienza del tempo che aveva indagato sotto nuova luce le cause a delinquere, individuando quelle che prepotentemente tolgono all'individuo la forza di reagire e di opporre all'impulso criminogeno le norme etiche, morali e giuridiche acquisite.

La previsione di due distinti articoli, l'uno il 46 in combinato disposto con il 47, e l'altro il 51 sembra diretta a tenere ben distinte le cause psicopatologiche che conducono alla inimputabilità dalle cause di tipo passionale che hanno solo forza mitigatoria della pena. Secondo il codice del 1889 non può subire eccezioni il principio per cui le perturbazioni di mente procedenti da stati passionali (e non da infermità totale o parziale) non hanno forza escludente la imputabilità. Sebbene possa cogliersi una certa somiglianza tra lo stato passionale - si pensi all'impeto d'ira, allo sconvolgimento della mente derivante dallo stato di dolore - e l'alienazione mentale, annoverare gli stati passionali fra le dirimenti equivarrebbe quasi a proclamare il fallimento del sistema repressivo. Tale scelta normativa, netta e chiara, mira a risolvere tutte quelle intricate problematiche che nascevano dal considerare gli stati passionali come stati irresistibili - in forza dei quali l'agente doveva essere curato e non punito - e che conducevano al parossismo di considerare tutti i delinquenti come affetti da speciali neurosi.

Si pensi all'orientamento del Ferri che vede il delitto come il risultato, e non altro, di una serie di cause sociali e di processi complessi dello spirito individuale che si manifestano nelle disposizioni morfologiche del cervello. Come regola generale, in ossequio alle esigenze di certezza del diritto, si dovrebbe ritenere - a detta di Giuseppe Ziino - che in certi stati passionali ricorra un'alterazione della potenza «eccito-motrice» della volontà ma se questi non sono tali da degenerare in frenosi possono essere gestiti dalle funzionalità della 
mente e della coscienza etico-morale. In tali casi l'uomo agisce sotto il predominio di un sentimento di cui come spesso accade ha volontariamente accettato il «tirannico imperio» ${ }^{206}$.

Il codice del 1889 ha inteso prevedere con l'art. 46 una formula in cui potessero riconoscersi tutti quegli stati psicopatologici fino ad allora sconfessati, sul pretesto di non riuscire con esattezza scientifica a darsene ragione o di non essere dalla psichiatria determinati con precisione sul piano anatomico: e ci si riferisce proprio alle monomanie ${ }^{207}$. Per esorcizzare i pericoli di ingiuste condanne o ingiuste assoluzioni, fu scelto di separare in due distinte dimensioni - la passionale e la psicopatologica - quella che nel codice sardo era un'unica e misteriosa forza irresistibile. Nell'infermità di mente dell'art. 46 si è inclusa tale forza ma solo ove derivi da alterazione morbosa, da mania sistematica, da pazzia impulsiva.

Occorre però chiarire taluni lineamenti dei concetti di coscienza e libertà dei propri atti. L'infermità di mente per poter produrre l'effetto della inimputabilità deve essere tale da privare l'agente della coscienza dei propri atti oppure anche solo della libertà di essi. Il che equivale a dire che l'art. 46 racchiude in sé due diverse ipotesi, ciascuna sufficiente ad escludere la imputabilità.

La locuzione 'coscienza degli atti' non deve intendersi, sostiene Luigi Majno (1852-1915), nel senso di completa mancanza di capacità di discernimento. Moltissimi pazzi hanno coscienza degli atti da essi meditati e compiuti, ma in tutti costoro manca la cosiddetta coscienza morale intesa nel senso di sano giudizio etico dei propri atti. Ne consegue l'auspicio che la giurisprudenza pratica interpreti la formula 'coscienza dei propri atti' nel senso più alto e più complesso, e non la confonda con la semplice alterazione della percezione come il termine coscienza suggerirebbe ad una prima superficiale approssimazione. In tal caso un gran numero di alienati, continua il Majno, specialmente quelli affetti da follie lucide andrebbero «a popolare i luoghi di espiazione» ${ }^{208}$. L'infermità di mente dirime la responsabilità penale anche quando priva il soggetto agente del-

206 Giuseppe Zirno, La fisiopatologia del delitto, Napoli, 1881, pp. 254 ss.

207 Cfr. A. SEтtr, Dell'imputabilità (dall'art. 44 Codice penale all'art. 48), cit., p. 680.

208 Luigi Majno, Commento al codice penale italiano, I, cit., p. 111. 
la libertà degli atti. Intorno agli effetti che l'infermità di mente deve produrre per poter escludere la punibilità, si può affermare - con Impallomeni - che la mancanza di coscienza si risolve nella pazzia o malattia intellettuale e la mancanza di libertà degli atti nella pazzia impulsiva o malattia della volontà ${ }^{209}$.

Già aveva scritto acutamente Francesco Carrara che nell'articolo 46 è ricompresa tanto la deficienza di mente, creata da mancato sviluppo o da sviluppo imperfetto delle relative facoltà, quanto la alterazione morbosa comprensiva di tutte le forme ed alterazioni patologiche permanenti o accidentali, totali o parziali ${ }^{210}$. Egli aveva precisato che per 'mente' dovesse intendersi un concetto ampio, comprensivo di tutte le facoltà psichiche dell'uomo, dalla memoria alla coscienza, dalla intelligenza alla volontà, dal raziocinio al senso morale ${ }^{211}$.

Il professore di diritto e procedura penale all'Università di Napoli, Michele Longo, nel commentare l'art 366 del codice Zanardelli - disciplinante l'omicidio per solo impulso di brutale malvagità - accosta tale reato ai casi di infermità in grado di privare l'agente della libertà dei propri atti di cui all'art. $46^{212}$. La follia omicida può assumere forme differenti, in modo da sfuggire talvolta all'osservazione del magistrato o del perito. In altre parole, essa può apparire occultata sotto le parvenze di una brutale malvagità, che invece sono il prodotto di stati di squilibrio psichico non adeguatamente accertati ma che costituiscono la causa del delitto. I seguaci della scuola classica, tra cui come abbiamo visto l'Impallomeni, convenivano sul punto che l'omicidio per brutale malvagità fosse l'effetto di anomalie psichiche. Da qui la necessità che gli imputati venissero sottoposti ad una perizia psichiatrica con cui dimostrare la presenza di

209 Giovanni Battista Impallomeni, Il codice penale italiano illustrato, I, Firenze, 1890 , p. 166.

210 Si veda sul punto Francesco Carrara, Commento al Codice penale, Roma, 1889, p. 35.

211 Ibidem.

212 Riferendosi ai giudici, Michele Longo scrive: «Meglio se ei si fosse affidato ad abile perito, poiché allora, molto facilmente, si sarebbe persuaso di trovarsi di fronte, non ad un malvagio delinquente, ma ad un folle da rinchiudersi in manicomio, né permettersi, per la sua pericolosità, che ritorni in seno al consorzio sociale». Cfr. Michele Longo, Commento al codice penale italiano, II, Torino, 1911, p. 328. 
una patologia della volontà. L'ossessione omicida, che scaturisce da un processo progressivo di degenerazione delle volizioni nel criminale, può sfociare tanto in un impulso improvviso, istantaneo e impetuoso, quanto in un impulso preordinato e calcolato. La inverosimiglianza del racconto del fatto da parte del criminale, la constatazione dell'innocenza della vittima, costringono il giudice a perdersi nel labirinto dell'incertezza. Da tale impasse secondo questa logica non poteva che uscirne, ricorrendo «all'estremo baluardo di salvezza della giustizia», cioè alla formula di imputazione di omicidio per brutale malvagità ${ }^{213}$. Al contrario, l'azione criminosa sprovvista di causa apparente doveva essere spiegata con una delle tante specie di follie impulsive, la prova delle quali dipendeva, più che dalla indagine oggettiva del fatto, dall'esame peritale fondato sui principi della psicopatologia forense.

Come appare chiaro, la materia è ben ricca per discussioni di vasta risonanza e lo diventa ancora più se si pone mente alle relazioni e interconnessioni che inevitabilmente intercorrono tra diritto e psicopatologia forense $\mathrm{e}^{214}$.

Nel 1874 Pietro Ellero (1833-1933) ${ }^{215}$, giurista noto soprattutto per la sua strenua campagna per l'abolizione della pena di morte, interrogandosi sulla scarsa efficacia deterrente della sanzione penale osserva, in linea generale, come ciò sia particolarmente evidente

213 Ibidem.

214 Per uno studio, più strettamente novecentesco, sul rapporto fra la scienza psicoanalitica e il diritto si veda F. Miglorino, Edoardo Weiss e la «giustizia penale». Zone di contagio tra psicoanalisi e diritto, Roma, 2016.

215 Nell'intento di far nascere la nuova Italia sotto l'egida umanitaria del rispetto e della consapevolezza del valore della vita, egli riesce a coinvolgere nel Giornale per l'abolizione della pena di morte numerosi penalisti e pensatori italiani e stranieri di alto livello, come Carrara, Pessina, Karl Joseph Anton Mittermaier e Arnould Bonneville de Marsangy. Nel 1861 è invitato a Milano a insegnare Filosofia del diritto presso l'Accademia scientifico-letteraria. Dopo pochi mesi è chiamato dall'Università di Bologna sulla cattedra di Diritto e procedura penale, dapprima come professore straordinario e poi, dal novembre 1862, come ordinario. A Bologna rimane per diciannove anni, e tra i suoi allievi si segnalano Enrico Ferri, Leonida Bissolati, Giacomo Matteotti, Filippo Turati e Giuseppe Brini. Cfr. E. D’Aмісо, Ellero, Pietro, in Dizionario biografico dei giuristi italiani (secoli XII-XX), I, cit., pp. 792-794; Sul punto si veda E.C. TavilLa, Ordine biologico e ordine morale. Appunti sulla riflessione criminologica italiana in tema di pena di morte (sec XIX), in Historia et ius. Rivista di Storia giuridica dell'età medievale e moderna, 10, 2016. 
«ne' massimi misfatti» e tra questi fa rientrare gli omicidi commessi «per causa gratuita o brutale», «i quali vogliono un pervertimento e sovvertimento d'idee, di voglie, di istinti, di sentimenti e fin di sensi tale, che lo spirito umano doventa un uragano e un subbisso» ${ }^{216}$. Certamente nelle parole di Ellero si avverte l'afflato riformatore di chi ambisce a riformare il diritto penale in senso umanitario ma al contempo si avverte un segno di resa, di fronte a fenomeni criminosi che appaiono incomprensibili agli occhi del giurista, essendo quel sovvertimento d'idee e di istinti così pericolosamente prossimo alla follia da dover essere relegato a materia di studio degli alienisti. 

CAPITOLO III

\section{OSPEDALIZZARE I CRIMINALI MALINCONICI UNA RIMEDITAZIONE IN NOME DEI DIRITTI}

\section{L'ospedale psichiatrico}

L'Ottocento è certamente il laboratorio all'interno del quale contestualizzare, attraverso un approccio di ricerca storico-epistemologico, il progetto di gestione della malattia mentale. Il grande internamento manicomiale dei criminali inizia nei primi anni del secolo negli ospedali psichiatrici civili e solo più tardi - a cavallo con il Novecento - nei manicomi giudiziari ${ }^{1}$. In questi universi asilari si incontravano follia e pericolosità sociale, declinate insieme all'incrocio fra discorso psichiatrico e discorso giuridico. Si trattava di soggettività ibride, criminali e folli, la cui storia criminale si ritrovava trasferita nei testi peritali. La cartella clinica, fonte ancora poco utilizzata, che rimane sepolta, malconcia, quando non distrutta nei fondi d'archivio, preserva non solo lo sguardo della psichiatria ma soprattutto lo sguardo del diritto che decide in tali casi di destinare il criminale ad una pena diversa. In un certo senso, la cartel-

1 Sull'evoluzione storica dell'internamento manicomiale si veda V.P. BABINI, Alcune osservazioni su una terapia ottocentesca: $i$ manicomi criminali, in L. DeL Pistoia, F. Bellato (a cura di), Curare e ideologia del curare in psichiatria, Lucca, 1981; V.P. Babini, M. Cotti, F. Minuz, A. Tagliavini, Tra sapere e potere, La psichiatria italiana nella seconda metà dell'Ottocento, cit.; A. BorZAcchiello, Alle origini del manicomio criminale, in G. Pugliese, G. Giorgini (a cura di), Mi firmo per tutti. Dai manicomi criminali agli ospedali psichiatrici giudiziari. Un'inchiesta e una proposta, Roma, 1997. 
la clinica ha la capacità di formare la nuova identità del criminale. Nel rapporto che lega il crimine alla follia ad entrare in gioco ci sono elementi del reato che finiscono per costituire indizi di una certa personalità deviata ${ }^{2}$. Nel caso specifico del reato senza causa, dove l'elemento oggettivo del reato è l'assenza di un movente e l'elemento soggettivo psicologico è la deviazione dalla morale, la fattispecie criminosa può essere essa stessa indiziaria di follia malinconica - di follia morale ${ }^{3}$. Si tratta di elementi del reato che rispondono a criteri di osservazione clinica che svolgono una funzione ancillare per la scienza psichiatrica.

Il dibattito fra psichiatri e giuristi dei primi decenni del secolo ottocentesco sulla necessità di stabilire confini precisi tra follia e pieno esercizio della libertà, sulla 'zona intermedia'4, sulla malinconia o monomania o pazzia ragionante-morale condussero a riforme sul piano legislativo che videro la luce soltanto alla fine del secolo e nei primissimi anni di quello successivo. Il folle morale, avvicinato sempre più al pazzo criminale fino a farli coincidere - si pensi alla proposta lombrosiana di una identità del folle morale, del delinquente nato - metteva in crisi il manicomio come luogo di cura e la logica stessa dell'internamento manicomiale. Imbecillità morale, pazzia morale acquisita, pazzia morale paranoica, pazzia morale epilettica, fra tutte le alterazioni degli affetti e dei sentimenti, erano le forme morbose che più facilmente scatenavano gli istinti criminali. Erano anzi le più diffuse anomalie che si riscontravano nei criminali pazzi, fra quei condannati che transitavano dal carcere al manicomio. La percezione di una psicopatia pervertitrice della sfera affettiva e morale dell'individuo rendeva possibile una mirabile manovra: nono-

2 Sul punto si veda G. Grassi, C. Bombardieri, Il policlinico della delinquenza. Storia degli ospedali psichiatrici giudiziari italiani, Milano, 2016, pp. 125-127. Più ampiamente si veda, M. Galzigna, La malattia morale. Alle origini della psichiatria moderna, Venezia, 1992.

3 Ibidem.

4 I casi dubbi fra reità e pazzia, gli stati intermedi fra queste due condizioni, così lontane fra loro nell'apprezzamento che se ne fa, e pur realmente così affini in tanti lati della loro natura intima, sarebbero interpretate e giudicate nel modo più conforme all'umanità e alla giustizia, che dimandano soprattutto che non sia condannato chi non si può a giusto rigore considerar colpevole. Cfr. A. TAMBurini, Dei manicomi criminali e d'una lacuna nell'odierna legislazione, in Rivista sperimentale di Freniatria, 2, 1876, p. 453. 
stante la frammentazione dei quadri nosologici, essa non restringeva il dominio della follia ma lo allargava a dismisura fino a comprendere, in tutte le sue gradazioni e manifestazioni, l'insensato, l'anomalo, il mostruoso, il perverso ${ }^{5}$. Soltanto verso la fine dell'Ottocento si assiste ad un vero e proprio processo di estensione della funzione del manicomio, in alcuni casi con apposite sezioni criminali, a questa categoria di soggetti, che non erano né rei folli, né folli rei, ma piuttosto una specie particolare di folli la cui follia consisteva nel compimento del reato senza una causa razionale. Le sezioni criminali degli ospedali psichiatrici e i successivi manicomi criminali servivano, come affermò Lombroso nel 1872, proprio per quella specie intermedia tra il delitto e la pazzia ${ }^{6}$.

Nella prima metà dell'Ottocento i criminali finivano internati fra i pazzi semplici, fra quelli che non avevano commesso alcun reato. E, pertanto, prima dell'istituzione dei manicomi per criminali, nei vari ospedali psichiatrici provinciali distribuiti su tutto il territorio nazionale finivano internate le cosiddette 'belve umane', coloro che si erano macchiati di delitti senza una causa impulsiva se non per il loro senso morale pervertito, fonte di una infinita serie di comportamenti violenti e antisociali, pur in presenza di un intelletto perfettamente lucido. In questa maniera si cercava di risolvere la vexata quaestio della follia lucida, di una lesione della volontà in assenza di delirio.

\section{Il caso di Bologna. L'ospedale psichiatrico 'Francesco Roncati'}

I malati mentali di Bologna e provincia inizialmente ricoverati presso l'ospedale del fisico S. Orsola assieme ai pazienti interessati da altre patologie, a partire dal XVIII secolo cominciarono ad essere concentrati in un unico reparto appositamente costruito. Nel 1860 il

5 F. Migliorino, Il corpo come testo. Storie del diritto, Torino, 2008, pp. 139140.

6 C. Lombroso, Osservazioni critiche del s.c. prof. Cesare Lombroso intorno alle memorie del dott. Serafino Biffi 'Sui provvedimenti per i delinquenti pazzi in Italia', in Rendiconti del R. Istituto Lombardo Scienze, Lettere e Arti, 5, 1872, p. 863. 
governatore delle provincie dell'Emilia, Farini, nello statuto allegato al decreto riguardante la riforma degli ospedali bolognesi, stabilì che per la cura dei pazzi si dovesse provvedere tramite un manicomio generale per le provincie dell'Emilia o con uno speciale per la provincia di Bologna. Con questo decreto - che mirava a risolvere sia il problema gestionale che quello organizzativo della spedalità bolognese tramite l'istituzione del corpo amministrativo degli Spedali, quale unico centro amministrativo e di sorveglianza per gli ospedali della città - si modificava concretamente la situazione dell'assistenza dei malati mentali, rimasta fino ad allora relegata all'interno di una gestione sanitaria generale e la provincia cominciò ad esserne direttamente coinvolta. Il definitivo passaggio gestionale dal corpo amministrativo degli Spedali alla provincia, che fin dal 1865 aveva visto sancite le proprie competenze in merito al mantenimento dei mentecatti avvenne nel 1868, con deliberazione del 19 settembre. Solo a partire dal 1 gennaio del 1869 la deputazione provinciale iniziò a gestire l'istituto psichiatrico, che venne separato dal corpo amministrativo degli Spedali e denominato, da quel momento, manicomio provinciale.

\subsection{I criminali malinconici}

Nella prima metà dell'Ottocento, presso l'ospedale psichiatrico provinciale Francesco Roncati ${ }^{7}$ di Bologna si ritrovano internati - poiché considerati affetti da una grave forma di malinconia - diversi autori di reati sprovvisti di moventi. Tra le diverse centinaia di cartelle cliniche che costituiscono il fondo archivistico del manicomio, se ne ritrovano alcune concernenti criminali provenienti dalle carceri che

\footnotetext{
7 Sulla storia del manicomio bolognese si vedano A. Alvisi, L'antico ospedale dei pazzi in Bologna, Bologna, 1881; F. RoncATI, Ragioni e modi di costruzione ed ordinamento del manicomio provinciale di Bologna, Bologna, 1891; A. FioritTI, L. Lo Russo, Il dire e il fare: Governo regionale ed evoluzione dei servizi psichiatrici in Emilia Romagna, Bologna, 1994; A. CASAgrande, L'Ospedale Psichiatrico Provinciale 'Francesco Roncati' in Bologna, in L. Contegiacomo, E. Toniolo (a cura di), 'Chisà che me tira fuori un calcheduni da stomanicomio'. L'alienazione mentale nella memoria storica e nelle politiche sociali, Rovigo, 1994, pp. 77-94; E. MonTANARI, Sant'Isaia 90. Cent'anni di follia a Bologna, Bologna, 2015.
} 
essendo considerati affetti da malinconia vennero trasferiti nel manicomio bolognese, esentati per infermità dalla pena giudiziaria ma parimenti isolati ed internati. Uno degli obiettivi era quello di ampliare e specializzare il controllo alienistico su uno spettro di comportamenti considerati devianti e pericolosi, portando all'espiazione della pena non solo coloro che per effetto di quella particolare forma di follia dei sentimenti morali aveva consumato il reato bensì anche chi in virtù di tali sintomi indiziari avrebbe potuto in potenza diventare capace di compierlo. Nei registri nosografici dei primi cinquant'anni dell'Ottocento, i medici-legali del 'Roncati' utilizzavano ancora l'antica categoria della melanconia, che non verrà mai totalmente sostituita, ma che in alcuni casi lasciava il passo alla monomania - incipiente formula nosologica di matrice francese. Ne è testimone il tableau ${ }^{8}$ dei casi criminali rinvenuti nell'Archivio del manicomio bolognese concernenti talora soggetti malinconici considerati socialmente pericolosi che non avevano consumato alcun delitto fermandosi al tentativo e talaltra criminali che furono trasferiti dalle carceri in manicomio per aver consumato omicidi senza altra causa che per melanconia.

\subsection{L'internamento di Giuseppe Fabbri (1821)}

Tra le diverse decine di cartelle cliniche contenenti la diagnosi della malinconia si è scelto di dedicare una particolare attenzione ad un caso giudiziario in particolare, quello che vide come protagonista il criminale Giuseppe Fabbri ${ }^{9}$. Le ragioni di questa scelta risiedono nella chiarezza espositiva che fu utilizzata dai medici alienisti, che lo ebbero sotto osservazione, nel redigere la perizia psichiatrica da cui si coglie la stretta correlazione tra la sua particolare malattia e la, altrettanto particolare, tipologia di crimini di cui si macchiò. Nel giudizio peritale, infatti, si ritrovano sviluppate in maniera dettagliata, tutte le questioni giuridiche sulla imputabilità dei fatti che furono sollevate dal giudice nel corso del processo penale.

8 I singoli casi criminali rinvenuti presso l'Archivio dell'ospedale psichiatrico provinciale Francesco Roncati si ritrovano in appendice.

9 Archivio ospedale psichiatrico provinciale Francesco Roncati, F.G., uomini usciti, n. 116 [1822]; n. 172 [1825]. 
Giuseppe Fabbri, originario di Castel dei Britti, di anni 36, fu autore di più furti ed omicidi e per questi reati fu arrestato e tenuto in custodia presso le carceri di S. Michele in Bosco. Nel corso del processo penale che lo vedeva imputato di omicidio senza causa e di furto aggravato dalla qualità dell'assenza di una causa fu richiesto dai giudici il parere dei medici alienisti sulla sua condizione mentale sussistendo il sospetto di simulata melanconia ${ }^{10}$.

A seguito del giudizio peritale sulla sua condizione mentale, redatto il 21 luglio 1820 dai medici alienisti Carlo Dal Re e Pietro Benfenati, fu riconosciuto affetto da malinconia e per tale ragione il giorno 18 marzo 1821 venne dalle carceri di S. Michele in Bosco trasportato all'ospedale psichiatrico provinciale Francesco Roncati. Dalla perizia emerse che il Fabbri «per un mese e mezzo circa dopo il suo ingresso diede sintomi di malinconia misti a somma avvedutezza e a decisa malizia e malvagità e mostrava una evidente alterazione delle facoltà morali».

Il caso Fabbri è senz'altro uno di quei casi criminali in cui l'imputazione del reato di omicidio senza causa trova la sua stretta connessione con la malattia della malinconia nella sua peculiare specificità di malattia della volontà. La malvagità nell'agire criminale che il sistema penale presume in forza dell'assenza del movente ad uccidere in tal caso non viene considerata come circostanza aggravante bensì come circostanza attenuante, come riflesso di una malattia dell'animo e della mente che altera le volizioni e le inclinazioni morali e che pertanto determina una mitigazione della pena e la necessità del ricovero in una struttura manicomiale.

Si riporta per esteso il contenuto della perizia psichiatrica che segnò il destino giudiziario del Fabbri. Egli per i suoi reati scontò la pena mitigata in cinque anni di reclusione in manicomio.

Parere intorno al detenuto Giuseppe Fabbri dei dottori Carlo Dal Re e Pietro Benfenati:

Egli è certo che dagli scrittori di medicina legale viene reputato perfettamente sano di mente e di godere il libero esercizio delle intellettuali facoltà, quell'uomo che si forma

10 Ibidem. 
idea delle cose come tutti gli altri uomini, che esprime gli stessi giudizi e che ragiona, che discerne il bene dal male, l'utile dal nocevole, che conosce il valore delle cose più care a ciascuno e quindi apprezzi la vita, la salute, l'amore dei genitori, dei figli, della patria, del proprio onore, la religione che professa. Quell'uomo adunque che in parte o in tutto manca degli annunciati attributi è quello stesso che la medicina legale ritiene malato nelle facoltà sue intellettuali è il vero uomo deviato dal retto pensare e ragionare, è quello cui contempla la legge e dà materia di dissuasione nel Foro.

Prestabilite queste massime che servir devono di norma al nostro parere, ci faremo ora ad esporre le questioni proposteci dal Giudice Processante Sig. Dott. Bonega, che noi abbiamo ristretto alle seguenti:

Se il detenuto Fabbri sia realmente o simulatamente affetto da pazzia; se ammessa la realtà della pazzia o alcune sue specie, lo era antecedentemente al commesso delitto o nell'atto di eseguirlo; Se in qualunque stato di alterazione di mente si trovava il Fabbri nel commettere il delitto, possa dirsi e giudicarsi che abbia agito con avvertenza e con discernimento e quindi con dolo.

Dalle informazioni prese sul conto del detenuto Fabbri dall'inizio dei processi in diverse epoche contro il medesimo istituiti, e dalle nostre proprie osservazioni ed indagini sullo stesso praticate abbiamo rilevato quanto segue;

Nel 1816 mentre il Fabbri trovavasi girovago nel Comune di S. Lazzaro per affezione del Sig. Giuseppe Bongiochi Chirurgo di quel Comune, persona degna di fede, veniamo accertati che il Fabbri mai a proposito quasi sempre rideva o faceva fatti, che accusava di aver sempre fame, che per la sua stravaganza e pazzia veniva da tutti soprannominato il 'mattaccino' infine che un giorno essendo stato dai carabinieri arrestato, il vide in mezzo alla forza fare dei fatti e rideva di tutto piacere.

Nel 1819 il Fabbri venne processato a Castel S. Pietro. Troviamo nel processo che certo Alberto Raggi fornaio nel suo costituto dice che il Fabbri soleva fare delle pazzie e dei segni colle mani a guisa dei pagliacci, spesso saltellando (sue precise parole).

Dall'ultimo processo istituito contro il Fabbri in causa dell'omicidio commesso nelle carceri, rilevasi che il testimonio Orfi nel suo costituto espose che il Fabbri era un soggetto di naturale taciturno, che parlava a sproposito, che quasi sempre rideva senza motivo e faceva fatti così che sembravagli persino di poco giudizio (precise parole del testimonio). 
In tutti li processi confessava egli ingenuamente tutti li furti commessi, alcuni dei quali per le circostanze d cui erano accompagnati potevasi occultarsi, e rendeva così vani gli sforzi del Fisco per comprovarli.

Col riso, con fatti e con tutti quei segni che aprivano il giudizio, venne dal Fabbri ricevuta la sentenza d'Appello, che lo condannava a cinque anni di galera. Durante il servizio che il Fabbri prestò nelle carceri criminali in qualità di 'scoppatore', a detta dei custodi e degli scoppatori suoi colleghi. Ora era taciturno, ora senza ragione rideva, ora faceva dei fatti alla maniera dei pazzi.

Appena commesso l'omicidio, il sottoscritto Benfenati, uno dei medici fiscali, lo vide ritornare ridendo. Fatto tradurre il Fabbri all'ospedale per assicurarsi dello stato della sua salute in rapporto al suo morale e al suo fisico e portate su di esso le nostre osservazioni nel modo che ci è sembrato più opportuno, abbiamo riscontrato:

Un uomo di aspetto pallido, aveva un'insolita mobilità d'occhi, come se fosse affetto da strabismo che qualche volta fissa vibranti al suolo come di un uomo assorto in profondi pensieri; che parlando spesse volte e fuor di proposito cade in smodate risa, muovendosi in strani modi e senza avvertirlo o le mani o i piedi, condotto ad un confronto di idee, ad un qualche raziocinio egli si perde, tace e ride, oppure esprime un incongruo e falso giudizio; che all'idea del suo delitto che ridendo confessa, di un carcere, di una galera perpetua espressagli con i più tetri colori, che a quella di un patibolo, di pena eterna all'altro mondo egli ne rimane in vero indifferente e ride o con atteggiamento indifferente dice 'tutto è nulla si mangi'; che quando il custode dell'ospedale nella sera gli inceppa con la catena i piedi, egli ride e si mette a fare dei fatti dando tutti li segni del giubilo; che richiestogli se amasse suo padre, rispose che non gli importava nulla. Queste o simili altre interrogazioni reiteratamente fatte hanno ottenuto un risultato uguale all'antecedente. $\mathrm{Ci}$ siamo infine assicurati che aveva esso la lingua costantemente sporca ed appare affetto da bulimia, la quale costantemente viene comprovata dalla fame insaziabile, dai fatti o dalle grida di giubilo che fa al suono delle campane. Quanto ai fatti di reato il fabbri nel commettere i delitti non ha usato quei necessari riguardi onde ne rimanesse occulto l'autore, se con ingenuità li ha confessati, poteva infatti rendere dubbio il Fisco che egli ne fosse l'autore o forse lo avrebbe ritenuto innocente; se all'annuncio dei 
cinque anni di galera egli gioisca; se commesso l'omicidio per niente si atterrisca anzi conserva il solito suo contegno, se ritorna dall'esame ridendo; se all'idea di un carcere perpetuo, di un patibolo si mostra indifferente. Se all'applicazione dei ceppi alli suoi piedi salta e giubila, bisogna convenire che il medesimo non si fornì idea della cosa come gli altri uomini se la formano, che non conosce il valore delle cose stesse che per conseguenza non emette che imperfetti ed erronei giudizi, non fornì che imperfetti e falsi raziocini e che quindi sia affetto da delirio melanconico. Le alterazioni del corpo corrispondono a quelle della morale, forniscono perciò la piena prova dell'esistenza del delirio e rimuovono ogni sospetto di simulazione. Il Fabbri risulta affetto da melancolia, la quale dagli autori di medicina legale viene definita un delirio ovvero un falso giudizio che si aggira sopra un solo oggetto.

La storia delle sue azioni e li delitti stessi da lui commessi e la sua esuberanza comprovano la esistenza della melancolia. La melancolia lo trascinò, a parer nostro, a commettere l'omicidio, che lo liberava di chi gli rubava il pane e che quindi gli diminuiva il piacere, la delizia di mangiare. Il delirio melanconico che appunto verte sull'oggetto, formò la causa impulsiva all'omicidio pertanto il Fabbri nel commettere l'omicidio agì senza avvertenza e senza discernimento e quindi senza dolo ${ }^{11}$.

Bologna, 21 luglio 1820

I medici fiscali Carlo Dal Re e Pietro Benfenati

Secondo il parere psichiatrico degli alienisti che furono interpellati dal giudice nel corso del processo penale e che tennero sotto osservazione clinica l'imputato, Giuseppe Fabbri risultava affetto da melancolia. Nel testo della perizia si ritrova non solo la definizione del morbo melancolico che aveva attraversato secoli di storia medico-legale e giuridica e che già dai criminalisti di età moderna venne descritto come malattia della morale e della volontà ma, altresì, la piena sussistenza del nesso di causalità tra la malattia e i reati imputati al reo. Si trattava dei reati di furto e di omicidio che non trovarono altra causa se non la condizione di malattia mentale in cui ver-

11 A.O.P.P., Francesco Roncati, Registro nosografico, F.G., uomini usciti, n. 116 [1822]; n. 172 [1825]. 
sava il Fabbri, la quale ne costituiva causa impulsiva. In forza della perizia psichiatrica redatta dai medici legali Dal Re e Benfenati, allegata alle carte processuali, fu emessa sentenza di condanna mitigata a cinque anni di reclusione da scontare in manicomio. Decorsi i cinque anni Giuseppe Fabbri fu rimesso in libertà ${ }^{12}$.

\section{Il caso di Roma. L'ospedale psichiatrico Santa Maria della Pietà}

Soltanto verso la fine del secolo il principio della difesa sociale, cardine dei progetti della Scuola positiva di diritto penale fondata sull'antropologia criminale lombrosiana, si profilò come il fulcro attorno a cui costruire le argomentazioni a favore delle sezioni criminali dei manicomi ${ }^{13}$ e dei manicomi criminali. In tali istituti sarebbero stati accolti tutti coloro che si erano macchiati di reato in condizione di mente riconosciuta aberrante che prima venivano ricoverati fra i pazzi semplici. Si dovrà infatti aspettare la fine del secolo ottocentesco perché in Italia sorgano i primi tre manicomi criminali distaccati dagli ospedali psichiatrici ordinari ${ }^{14}$. L'ospedale psichiatrico S. Maria della Pietà ${ }^{15}$, invece, era fra quelli che aveva un intero padiglione dedicato ai criminali. Durante la Restaura-

12 A.O.P.P., Francesco Roncati, Atti amministrativi, Polizia Provinciale, n. 828, in F.G., uomini usciti, n. 116 [1822]; n. 172 [1825].

13 Solo nel 1877 nel progetto di legge sui manicomi fu inserito un riferimento a speciali sezioni penali negli ospedali psichiatrici provinciali ordinari, presentato dal ministro dell'Interno Giovanni Nicotera, progetto che però non ebbe corso. Una successiva interrogazione del 14 aprile 1877 dell'onorevole Augusto Righi al Guardasigilli riproponeva la questione. Sul punto si veda G. Grassi, C. BombardieRI, Il policlinico della delinquenza. Storia degli ospedali psichiatrici giudiziari italiani, cit., p. 32.

14 Prevalse a lungo un sostanziale disinteresse politico sul tema dei manicomi criminali, emersero molte cautele e resistenze e le proposte di legge e le interpellanze per la istituzione dei manicomi criminali furono in sostanza lasciate cadere nel vuoto. Il 14 dicembre del 1875 il deputato Francesco De Renzis presentò una prima risoluzione alla Camera per impegnare il governo a valutare la possibilità di istituire degli ospedali atti a raccogliere i criminali che presentavano tratti di follia. Cfr. R. CAnosa, Storia del manicomio in Italia dall'Unità a oggi, Milano, 1979, p. 139.

15 Sulla storia dell'ospedale S. Maria della Pietà si vedano F. Fedeli BernardiNI, A. Iaria, A. Bonfigli, L'ospedale dei pazzi di Roma dai papi al '900. Fonti per la storia della follia: Santa Maria della Pietà e il suo archivio storico, secc. XVI-XX, I, 
zione e per tutta la prima metà dell'Ottocento, l'ospedale subì una continua alternanza di amministrazioni in autonomia o in unione all'ospedale di Santo Spirito. In questo periodo continuò ad aggravarsi la grave situazione ambientale ed assistenziale dovuta innanzitutto al grande affollamento (dai 119 censiti nel 1812 si assiste ad una progressiva moltiplicazione dei ricoverati che arriveranno ai 503 nel 1861), all'inadeguatezza strutturale della sede di via della Lungara ed all'urgenza di una riorganizzazione dei servizi medici ed assistenziali del manicomio, denominazione questa ormai entrata stabilmente in uso. Nel 1850, con il motu proprio di Pio IX, tutti gli ospedali di Roma vennero riuniti sotto un'unica Commissione amministratrice. Con la presidenza del Cardinale Morichini si cominciò a prevedere anche per il manicomio una struttura di tipo ospedaliero: venne chiamato alla direzione sanitaria Giovanni Gualandi, medico alienista che già aveva lavorato presso il manicomio di Bologna, con il compito di riformare i ruoli medico ed infermieristico. Si deve in particolare a lui l'impianto dell'archivio sanitario dell'ospedale e quindi della modulistica delle cartelle cliniche, dei registri medico statistico nosologico, del movimento giornaliero dei ricoverati, delle registrazioni delle diete. Negli ultimi anni del governo pontificio, nonostante le dimissioni del Gualandi si assiste ad un consolidamento della situazione dell'ospedale che arriverà ad ospitare, all'arrivo dei piemontesi nel settembre del 1870, oltre le 600 unità. Con il passaggio allo Stato unitario, il manicomio assunse lo status di opera pia, in base alla legge del 3 agosto 1862 e continuò ad essere amministrata dalla rinnovata Commissione amministrativa degli ospedali fino al 1891. In questi anni il Santa Maria della Pietà divenne il manicomio di riferimento per l'intera provincia di Roma, allora quasi corrispondente all'attuale territorio laziale. Nel 1891 si avviarono le trattative per la cessione del manicomio all'Amministrazione provinciale di Roma, cessione che si concretizzò pienamente, dopo alterne vicende, solo nel 1919.

Bari, 1994; ID., L'ospedale dei pazzi di Roma dai papi al '900. Lineamenti di assistenza e cura a poveri e dementi, II, Bari, 1994. 


\subsection{I criminali malinconici}

$\mathrm{Al}$ di là di qualche cenno che concerne la storia dell'istituto manicomiale, ciò che rileva ai fini del nostro discorso è la storia criminale di quei colpevoli malinconici destinati all'internamento. A partire dagli ultimi decenni dell'Ottocento in Italia, anche nella prassi giudiziaria, si assiste al pieno accoglimento delle categorie diagnostiche della medicina-legale. Le diagnosi psichiatriche proposte dagli alienisti interpellati nel corso dei processi penali, veicolavano la decisione del giudice di trasferire i condannati dal carcere al manicomio, luogo considerato più idoneo a scontare la pena. Le cartelle cliniche rinvenute nell'ospedale psichiatrico $\mathrm{S}$. Maria della Pietà raccontano la storia giudiziaria di imputati di omicidio e di altri delitti sprovvisti di una causa apparente descritti dagli alienisti come affetti da malinconia, da una forma di follia lucida e morale.

Nei casi criminali il ricovero veniva disposto con decreto dal tribunale del luogo dove aveva sede il manicomio, sopra istanza del procuratore del Re, provvedendo in Camera di consiglio, sentito un perito alienista. Venivano internati soltanto i soggetti ritenuti pericolosi per sé e per gli altri e che recavano pubblico scandalo perché per gli alienati cronici tranquilli e - tra questi erano ebeti, cretini e idioti - il tribunale emetteva ugualmente ordinanza di ricovero definitivo con cui ne disponeva la segnalazione al prefetto della provincia perché si potesse provvedere altrimenti alla loro assistenza in uno degli istituti pubblici o privati destinati ad accogliere soltanto gli alienati non pericolosi ${ }^{16}$.

Nelle perizie spesso tali criminali venivano descritti come individui attanagliati da un carattere insocievole, che sceglievano di preferenza i luoghi appartati e solitari, e che sembravano sovente immersi nei vapori di una oscura melanconia ${ }^{17}$. I giudici riconobbero sulla base del consulto medico una forma di follia parziale, d'altronde negarla avrebbe significato ammettere l'esistenza di tendenze depravate ignominiose e comprovanti la dismisura della turpitudine nell'eccesso della crudeltà.

16 Si veda l'art. 50 del R.D. 5 marzo 1905, n. 158 in G.U. 17 maggio 1905, n. 116 .

17 I casi criminali rinvenuti presso l'Archivio dell'Ospedale psichiatrico provinciale di Roma si ritrovano in appendice. 
Nei casi archivistici rinvenuti presso l'archivio del manicomio romano il ricovero manicomiale dei criminali veniva disposto in applicazione della legge n. 36 del 1904 recante disposizioni sull'organizzazione interna dei manicomi e sulla custodia e cura degli alienati e sulla base del Regio decreto 5 marzo 1905, n. 158 con cui fu approvato il regolamento di attuazione ${ }^{18}$. Tale legge nasceva dalla esigenza di uniformazione nella regolamentazione del problema giuridico della follia. Prima del 1904 gli adempimenti amministrativi necessari per disporre un ricovero coattivo e le relative procedure non garantivano omogeneità di trattamento sul territorio del Regno d'Italia. Ogni amministrazione locale seguiva leggi locali in totale autonomia ${ }^{19}$.

Il dettato normativo era espressione delle concezioni psichiatriche positivistiche dominanti in quegli anni ${ }^{20}$ e i principi informatori che la reggevano in quanto legge di ordine pubblico, rispondevano all'esigenza di arginare il problema della malattia mentale attraverso la custodia degli alienati in luoghi ben separati dalla società. L'esigenza avvertita come precipua e necessaria era quella di salvaguardare la comunità sociale dalla pericolosità dei malati psichiatrici ricorrendo alla pratica della 'incapacitazione' ${ }^{21}$ volta a tenerli in cu-

18 R.D. 5 marzo 1905, n. 158 in G.U. 17 maggio 1905, n. 116.

19 L. 14 febbraio 1904, n. 36, in G.U. 22 febbraio 1904, n. 43. Sul punto si veda M. Morello, I malati di mente dalla legislazione preunitaria alla legge Basaglia, Fano, 2012, p. 95. Per un approfondimento si vedano G. SANTANiello, L'organizzazione sanitaria sul piano provinciale, in R. AlEssi (a cura di), L'amministrazione sanitaria, Vicenza, 1967, pp. 46-47; A. LonNI, Pubblica sicurezza, sicurezza pubblica e malato di mente. La legge del 1904, in A. De Bernardi (a cura di), Follia, psichiatria e società. Istituzioni manicomiali, scienza psichiatrica e classi sociali nell'Italia moderna e contemporanea, Milano, 1982, p. 264; G. Lo Russo, L. ONNIS, Manicomio e legislazione psichiatrica in Italia (1904-1978). Profilo storico e note critiche, in Giornale storico di psicologia dinamica, IV, f. 7, Napoli, 1980, p. 43.

20 La legislazione del 1904 era espressione della cultura positivista che diede alla malattia mentale un'interpretazione in termini rigidamente biologici, che attribuiva scarsa rilevanza ai fattori sociologici, psicologici e culturali ma costituiva pur sempre un superamento delle paure irrazionali e dei pregiudizi che portarono a reazioni esclusivamente espulsive, sulla base della ritenuta pericolosità e della non curabilità del malato di mente. In generale si veda A. VeNTRE, Intervento alla tavola rotonda sul tema: 'Evoluzione del concetto di malattia mentale e suoi risvolti in riferimento alla legge 180', in Atti e memorie dell'Accademia di Storia dell'arte sanitaria, III, a. I, n. 2, 1982.

21 La custodia presso un manicomio assicurava la neutralizzazione dell'alienato. La potenziale pericolosità del malato di mente, valutata dalla duplice 
stodia al fine di renderli incapaci di recare nocumento a sé stessi e agli altri.

\subsection{L'internamento di Luigi Galeotti (1906)}

Tra le diverse decine di cartelle cliniche rinvenute presso il manicomio di Roma, concernenti criminali affetti da malinconia si è scelto di porre luce su un caso criminale in particolare, quello che vide come protagonista il malinconico Galeotti Luigi ${ }^{22}$. Nato a Valmontone nel 1873, di anni trentadue al momento dell'arresto e meccanico di professione. Nel 1906 venne internato nel manicomio giudiziario di Aversa per essere stato riconosciuto, dai periti psichiatrici, affetto da una forma grave di malinconia. Sulla base di tale diagnosi nosologica nel primo processo a suo carico fu dichiarato esente da penali responsabilità per i reati di furto aggravato e tentato omicidio. Si trattava di reati commessi senza un chiaro movente per cui i giudici sospettarono che si trattasse di un caso di infermità mentale. Per tali ragioni in sede processuale fu richiesta la perizia di un alienista che potesse decretare sulla condizione psichica del criminale al tempo dei delitti commessi. Il consulto clinico dello psichiatra aprì al Galeotti le porte del manicomio. Il ricovero fu allora disposto dal delegato di pubblica sicurezza di Aversa, sulla base della sentenza emessa nel 1907 dalla Sezione Penale della Corte d'Appello degli Abruzzi. Nel primo processo penale a suo carico, Luigi Galeotti fu imputato di sette furti in danno dell'Amministrazione Postale di Giulianova, di Castellammare, dell'Ufficio postale di Casoria e di tentato omicidio plurimo nelle persone di Ferrini Venanzio, Domenico Pelliccione, Mariani Giuseppe, Ponfilo De Gregorio, Mastelli Giovanni. Tale processo si svolse, in primo grado, dinanzi al Tribunale penale di Sulmona che ebbe inizio nel giorno 29

prospettiva di pericolosità verso gli altri ma anche di pericolosità verso sé stessi, veniva sopita attraverso il ricorso a pratiche di contenimento. Sul punto si veda A. Lonni, Pubblica sicurezza, sicurezza pubblica e malato di mente, cit., p. 278.

22 ASMP, Cartelle cliniche, t. IX, f. 2720, [1909-1915]. 
gennaio 1906 e, in secondo grado, dinanzi alla Corte d'Appello degli Abruzzi nel 1907 che ne dispose il ricovero nel manicomio giudiziario di Aversa.

Si riporta la sentenza della sezione penale della Corte d'Appello degli Abruzzi che ne dispose l'internamento ${ }^{23}$ :

Il Presidente della Corte di Appello degli Abbruzzi [sezione penale]

Nella causa a carico di Galeotti Luigi fu Antonio di anni 32 detenuto nel manicomio di Aversa ed attualmente nel manicomio di Roma

Imputato di 7 furti qualificati in danno dell'Amministrazione Postale di Giulianova e di Castellammare, e dell'Ufficio postale di Casoria, nonché di tentato omicidio di Ferrini Venanzio, Domenico Pelliccione, di Mariani Giuseppe, di Ponfilo De Gregorio, di Mastelli Giovanni

Art. 404 nn. 4-5 c. p.

Veduta la Sentenza del Tribunale Penale di Sulmona proferita nel giorno 29 gennaio 1906;

Veduto l'appello prodotto avverso la medesima dal suddetto imputato condannato alla reclusione per anni tredici, mesi nove e giorni quindici, a lire settantadue di pena pecuniaria e tre anni di vigilanza;

Veduta la istanza del Pubblico Ministero, con la quale chiede si proceda alla discussione del suddetto appello;

Veduti gli articoli 409 e 410 del codice di procedura penale;

\section{Ordina}

Citarsi il suddetto imputato a comparire nel locale di questa Corte e propriamente nella Sala destinata per le Udienze Penali, pel giorno di lunedì otto del mese di febbraio 1909 alle ore 9 a.m. con la continuazione, onde assistere alla discussione dell'appello sopraindicato con l'avvertenza che gli è lecito nominarsi un difensore nella persona di un Avvocato ammesso ad esercitare avanti la Corte, quando non intenda avvalersi del difensore d'ufficio

23 ASMP, Sentenza Corte d'Appello degli Abruzzi [sezione penale], n. 166, [1907], in Atti giudiziari, t. IX, f. 2720, [1909-1915]. 
che viene all'uopo nominato nella persona dell'Avv. De Paolo Giuseppe ${ }^{24}$.

Aquila, 14 gennaio 1909

Il Presidente D’Errico

Galeotti Luigi a seguito della sentenza emessa dalla Corte d'Appello degli Abruzzi, fu ricoverato nel manicomio giudiziario di Aversa il 27 aprile 1906. Sottoposto a perizia psichiatrica risultò affetto da malinconia ereditaria. Idea madre del delirio era quella di «ritenersi inventore del moto perpetuo ed ostacolato nella esplicazione e nell'applicazione sociale delle sue invenzioni da nemici a volte occulti e a volte palesi, i quali, sotto la veste di streghe ed avvalendosi di mezzi misteriosi - fluidi, sostanze chimiche - mirano a colpirlo in ogni manifestazione della sua vita organica e psichica $»^{25}$. Nel corso del procedimento fu dimostrato, sul piano probatorio, che i reati commessi presentavano un'origine morbosa, per cui in grado di appello fu prosciolto dall'accusa ed assegnato definitivamente al manicomio.

Per il Galeotti fu scelto il manicomio giudiziario di Aversa, sulla base dei criteri di assegnazione previsti dalle disposizioni di legge sull'amministrazione dei manicomi. Dopo circa due anni di internamento ad Aversa, il 15 gennaio 1909 fu trasferito nel manicomio di S. Maria della pietà di Roma ${ }^{26}$ sulla base dell'ordinanza del delegato di Pubblica Sicurezza di Aversa ${ }^{27}$ del 14 gennaio 1909 in seguito ad autorizzazione avuta dalla Prefettura di Caserta in ottemperanza alla sentenza di proscioglimento del Tribunale di S. Maria Capua Vetere del 29 dicembre.

Il 21 gennaio del 1909 il Procuratore Generale del Re presso la Corte d'Appello di Roma inviò una missiva al Direttore del Manicomio di Roma ${ }^{28}$ Mingizzini con cui chiedeva l'autorizzazione all'am-

24 ASMP, Corte d'Appello degli Abruzzi (sezione penale), n. 166, [1907].

25 ASMP, Atti della Direzione del Manicomio giudiziario di Aversa, in cartelle cliniche, t. IX, f. 2720, [1909-1915].

26 ASMP, Verbale di ammissione provvisoria, 1. b, t. IX, f. 2720, n. 1734, [1909-1915].

27 ASMP, Ordinanza del delegato di Pubblica Sicurezza di Aversa, n. 14, [1909].

28 ASMP, Atti della Procura Generale del Re presso la Corte d'Appello di Ro$m a$, n. 137, [1909]. 
missione del Galeotti in manicomio ${ }^{29}$, in risposta alla richiesta del Procuratore Generale di L'Aquila di spedire il certificato, in carta libera per uso amministrativo, comprovante il ricovero definitivo di Galeotti Luigi presso il manicomio di Roma.

Si riporta la missiva che il Direttore del manicomio romano, Mingizzini, sentito il parere del Professore alienista Montesano sulla condizione psichica del Galeotti, inviò al Procuratore del Re di Roma:

Per ottemperare al disposto dell'art. 2, comma 2 della Legge 14 febbraio 1902 n. 36 sui manicomi e sugli alienati, partecipo alla S. V. Ill.ma che la persona indicata in margine ricoverata in via provvisoria in questo manicomio fino dal 16 gennaio per ordine del Delegato di Pubblica Sicurezza di Aversa è stata dal Primario della Sala di Osservazione Sign. Prof. Montesano riconosciuta affetta da malinconia originaria malattia per la quale ne ritengo necessario l'internamento e per conseguenza l'ammissione definitiva. Prego dunque la S. V. Ill.ma a compiacersi di far pervenire a questa Direzione il Decreto Presidenziale di cui è menzione nel suindicato articolo di legge ed a provocare dal Presidente del Tribunale la nomina del curatore provvisorio del quale la prego farmi conoscere il nome ${ }^{30}$.

\section{All'Ill.mo Procuratore del Re di Roma Salvio Il Direttore Mingizzini}

Riconosciuto affetto da malinconia e inimputabile per i reati commessi, il Galeotti dopo qualche mese di ricovero nel manicomio di Roma venne dimesso il 18 luglio 1909 perché ritenuto non pericoloso per sé e per gli altri e, pertanto, il Regio Tribunale civile e penale di Roma ne dispose l'affidamento ai familiari:

Procuratore del Re di Roma Salvio

Ordinanza

Oggetto: licenziamento dal manicomio di Galeotti Luigi

29 ASMP, Atti della Direzione del manicomio S.M. della Pietà di Roma, t. IX, f. 2720, n. 17624, [1909].

30 ASMP, Atti della Direzione del manicomio S.M. della Pietà di Roma, t. IX, f. 2720, n. 17847, [1909]. 
Il R. Tribunale civile e penale di Roma sez. terza composto degli Ill.mi Sig.ri Magistrati

Avv. Cav. Squarcetti Agostino [Presidente]

Avv. Marciano Fortunato

Avv. Ciolella Settimio [Giudici]

Riunito in Camera di Consiglio ha emesso il seguente decreto Letta la domanda di Parente Genesio tendente ad ottenere la liberazione di Galeotti Luigi dal manicomio.

Poiché dall'ultimo rapporto sanitario del direttore del manicomio in data 26 giugno 1909 risulta che il Galeotti è sempre tranquillissimo e non presenta reazioni pericolose entro le allucinazioni alle quali va tuttora soggetto, che può essere senza pericolo custodito in famiglia. Poiché risulta che il Parente sia in grado di attendere a tale custodia date le migliorate condizioni di salute dell'ammalato.

In applicazione dell'art. 3 della Legge 14 febbraio 1904 n. 36 e n. 68 del relativo regolamento.

Lette le richieste del P.M.

Autorizza il Direttore del Manicomio di S. Maria della Pietà di Roma a licenziare il ricoverato Galeotti Luigi per essere consegnato al cognato Parente Genesio ${ }^{31}$.

Roma lì 12 luglio 1909 Il Presidente Squarcetti

Copia conforme per uso d'ufficio Roma 12 luglio 1909

Il 18 luglio del 1909 il Galeotti venne rimesso in libertà ma la sua storia giudiziaria e manicomiale non terminò in quella data. $\mathrm{La}$ sera dell'11 ottobre 1909 camminando per le strade della città di Roma, Luigi Galeotti esplose un colpo di rivoltella contro Bartolucci Domenico al fine di ucciderlo, cagionandogli lesioni al labbro inferiore, alla lingua e alla volta del palato e la perdita di due denti. Tra i due non vi era stato alcun alterco, i due neppure si conoscevano. Per tali reati il Galeotti fu imputato di tentato omicidio e porto abusivo di armi aggravato dall'assenza di una causa. Ma anche in questo nuovo processo penale a suo carico, la Sezione di accusa della Corte d'Appello di Roma lo dichiarò esente da penale responsabilità in ordine all'imputazione di mancato omicidio aggravato essendogli riconosciuta la piena infermità mentale. La Corte ritenendone peri-

31 ASMP, Ordinanza del Regio Tribunale civile e penale di Roma (sezione terza) del 12 luglio 1909, n. 590, in Atti giudiziari, t. IX, f. 2720, [1909]. 
colosa la liberazione ne ordinò la consegna all'autorità competente di pubblica sicurezza e il ricovero in manicomio. Luigi Galeotti fu riammesso nel manicomio $\mathrm{S}$. Maria della Pietà di Roma il giorno 16 aprile 1911 per ordine della locale Corte d'Appello.

In nome di sua Maestà Vittorio Emanuele III per Grazia di Dio e per volontà della Nazione, Re d'Italia

La Sezione di accusa della Corte d'Appello di Roma composta degli Ill.mi sigg.

De Notaristefani Cav. Ferdinando Presidente

Marini Cav. Donato Consigliere

Pujia Cav. Francesco Consigliere

Con l'intervento del Pubblico Ministero rappresentato dal Sign. Calabrese Cav. Raffaele Sostituto Procuratore Generale con l'assistenza del Vice Cancelliere infrascritto;

udito il rapporto fatto dal Pubblico Ministero che svolse le sue requisitorie scritte il dì 16 marzo 1911;

Udita la lettura degli atti del processo fatta dal suddetto Vice Cancelliere in presenza dello stesso Pubblico Ministero;

Procedendo nei modi prescritti dagli artt. 427 e seguenti del Codice di Procedura Penale;

Ha pronunciata la seguente sentenza a carico di:

Galeotti Luigi fu Antonio di anni 38 da Valmontone meccanico,

detenuto, imputato di mancato omicidio in persona di Bartolucci Domenico e porto di rivoltella senza licenza In Roma, lì 11 ottobre 1909

Ritenute, che con ordinanza della Camera di Consiglio in data 11 gennaio 1910, venivano rinviati per il corso ulteriore al Procuratore Generale gli atti a carico di Galeotti Luigi imputato di mancato omicidio per avere la sera dell'11 ottobre 1909 in Roma esploso un colpo di rivoltella contro Bartolucci Domenico a fine di ucciderlo, cagionandogli lesioni al labbro inferiore, alla lingua e alla volta del palato e la perdita di due denti con l'indebolimento di altri da cui derivò malattia ed incapacità di attendere alle ordinarie occupazioni per giorni trenta e debilitamento permanente dell'organo della masticazione; nonché di porto abusivo di rivoltella.

Ritenuto che il Galeotti, latitante, fu tratto in arresto a Valmontone per un furto qualificato commesso la notte dal 18 al 19 ottobre.

Siccome risultava essere egli stato più volte ricoverato nel 
manicomio, da cui fu dimesso il 18 luglio 1909 a richiesta della famiglia, sebbene presentasse ancora dei disturbi mentali la sezione d'accusa con sentenza 9 marzo 1916 disponeva la perizia psichiatrica che la Camera di Consiglio riteneva superflua.

Dalla perizia, eseguita dal Professore De Pedris, risultò che il Galeotti è affetto da malinconia originaria ambiziosa, su di un fondo di imbecillità morale, a base degenerativa ereditaria; risultò quindi essere egli in tale stato di infermità mentale che non ha la libertà dei propri atti e che tali sue condizioni lo rendono inadatto e pericoloso nella vita sociale. Sebbene il procuratore Generale chiedesse dichiararsi non luogo a procedere contro il Galeotti, ordinandosene nel contempo a consegna all'autorità competente, la Sezione d'Accusa su analoga richiesta dello stesso Procuratore Generale, ordinò una revisione di perizia che fu affidata al Professore Montesano con sentenza 11 novembre 1910.

Attesoché la perizia del Professor Montesano conclude: che il Galeotti è affetto da malinconia cronica e per tale infermità dovrebbe il medesimo secondo la maggioranza degli autori essere considerato irresponsabile di ogni azione criminosa, quanto mai la sua responsabilità non potrebbe essere mai nello speciale delitto superiore a quelle consentite dell'art. 47 del nostro codice penale.

Attesoché dato il carattere della malattia da cui è affetto il Galeotti, si trovi più consono a giustizia ritenere la conclusione principale del perito per l'applicazione cioè dell'art. 46 c.p. e non per quella subordinata dell'art. 47 c.p., perché tale l'esistenza di quella malattia ogni manifestazione delittuosa del Galeotti non può considerarsi indipendentemente da essa, non essendo in alcun modo possibile stabilire quanto di volontario e quanto di morboso vi sia nell'azione di un individuo certamente affetto da tare organiche;

Attesochè ai fini della istruttoria non sia più necessario tener allegato al processo precedente l'altro per furto qualificato già deferito contro il Galeotti;

P.Q.M.

La Sezione d'Accusa visti artt. 46 c.p., 429-431 c.p.p.

In conformità delle conclusioni del P.M.

Dichiara Galeotti Luigi esente da penale responsabilità in ordine al mancato omicidio imputatogli per essere egli affetto da piena malinconia ed essendone pericolosa la liberazione, 
ne ordina la consegna all'autorità competente di Pubblica Sicurezza.

Ordina infine che il processo per furto contro il Galeotti, allegato ai presenti atti, venga per l'ulteriore corso restituito al Procuratore del Re di Velletri.

\section{Roma 3 aprile $1911^{32}$}

Il 18 settembre 1913 Luigi Galeotti riuscì ad evadere dal manicomio, fu ritrovato e nuovamente internato. Nel mese di dicembre dello stesso anno riuscì ancora una volta a valicare le mura perimetrali del manicomio e a riprendersi la libertà da latitante. Per comprendere le ragioni di fatto e di diritto che condussero i giudici, in due diversi processi penali, a dichiarare l'infermità mentale del Galeotti si riporta il testo integrale della perizia psichiatrica redatta dal Dottor Montesano, medico primario e psichiatra del S. Maria della Pietà di Roma.

Appena arrivato in manicomio immediatamente invocò a sua difesa il vizio di mente e l'irresponsabilità a base dell'art. 46 c.p. (articolo da lui testualmente citato) ricordando essere stato più volte al manicomio. Sottoposto a perizia si trovarono sempre spiccata la sua malinconia e le idee morbose rilevate nei precedenti diari, senza alcun mutamento. Il soggetto sostenne e sostiene che i suoi atti delinquenziali non sono voluti ma imposti dai suoi nemici visibili e invisibili, sia mettendo in condizione di non poter vivere onestamente, sia suggestionandogli e facendogli necessariamente compiere atti che alla sua coscienza morale ripugnano. Quanto vi sia di vero in queste affermazioni è discutibile; certo però che se resta al paziente la capacità di sfruttare la sua condizione morbosa a scopo delinquenziale e se perciò il delirio non ha completamente asservito a sé tutta la vita psichica, e può in qualche caso esser messo a tacere, rimanesi in campo speculativo più che altro, di solito le idee morbose portano a semplici manifestazioni oppressive verbali e più specialmente grafiche, se la condotta può in un certo modo rimanere

32 ASMP, Corte d'Appello di Roma, Sentenza n. 85, n. 48 del Regolamento generale dell'accusa, $n .17$ del Registro della Procura generale, procedimento a carico di Galeotti Luigi detenuto e imputato di mancato omicidio e porto d'armi, in Atti giudiziari, t. IX, f. 2720, [1911]. 
indipendente dalle idee deliranti, non è men vero che si è stabilita ora una condizione per cui il soggetto compie con facilità atti pericolosi per effetto se non diretto, per lo meno indiretto delle sue idee morbose. Tutto ciò rende al parer del sottoscritto indispensabile l'internamento permanente (l'infermo ha commesso finora fra tentati omicidi, furti, minacce, lesioni, contravvenzioni circa trenta reati).

18 settembre 1913. Ieri notte il Galeotti d'accordo con altro criminale (Sperati) riusciva ad evadere dal reparto dopo aver segato con adatto istrumento una sbarra di un finestrone del dormitorio ed essersi calato con lenzuola annodate.

6 ottobre 1913. Il ricoverato evaso è stato ritrovato e ricoverato al manicomio dall'Ispettore Venanzoni.

Il Galeotti appare alquanto sciupato, pallido, con lineamenti contraffatti per essersi completamente raso barba e baffi forse per rendere più difficile il suo riconoscimento. Egli racconta come è avvenuta la fuga; però evidentemente egli tende a dissimulare e a far ricadere la colpa principale del fatto sul compagno Sperati, sicché i particolari che il paziente fornisce non riescono troppo attendibili. Il Galeotti si trova un po' avvilito per la sua rientrata nell'Istituto, trova giusto quanto ha fatto, anzi dice e ripete che il modo stesso con cui ha compiuta la evasione dimostra che egli non è malato ma sano di mente ed intelligente. Non si persuade né del suo stato di malato, né della regolarità del suo internamento nel manicomio, anzi parla già di iniziare pratiche legali presso l'autorità giudiziaria per ottenere la liberazione.

12 novembre 1913. L'autorità giudiziaria manda in seguito al ricorso del Galeotti copia di sentenza di proscioglimento con ordinanza di ricovero in manicomio. Il documento fu comunicato all'interessato, il quale naturalmente non ne è rimasto affatto convinto, vera irriducibilità vesanica.

14 dicembre 1913. Ieri sera nonostante il paziente fosse dato in consegna speciale per la fuga e le sue tendenze spiccate all'evasione fossero note lippis et tonsaribus, il Galeotti riusciva nuovamente a lasciare le mura ospitali di questo Istituto.

Nella perizia del medico Montesano Luigi Galeotti viene descritto come un criminale lucido che conosce la normativa penale in forza della quale in sede processuale ne fu dichiarata l'infermità mentale e la esenzione da responsabilità per i reati compiuti. Diverse 
furono le lettere da lui scritte in manicomio in cui dichiarava di non essere pazzo, di comprendere pienamente il peso delle sue azioni criminose, di non avvertire alcun senso di colpa per i reati compiuti. Nel suo paese di origine, Valmontone, era noto per i comportamenti bislacchi che spesso assumeva, come la volta in cui, ancora ricercato per essere evaso dal manicomio, indossò una toga rubata ed entrò in un'aula di giustizia. In pieno possesso delle facoltà intellettive ma con una forza volitiva indebolita dalla malattia, per ammissione e convinzione dell'infermo i reati compiuti non erano da lui voluti ma imposti da entità nemiche, visibili e invisibili. Le dichiarazioni, la condotta e l'assenza di moventi nei reati compiuti condussero gli psichiatri, che ebbero il Galeotti sotto osservazione clinica, ad individuare i signa prodromici della malinconia: delirio circoscritto, volizioni alterate, coscienza morale corrotta.

Dopo l'evasione messa a punto nel mese di dicembre del 1913 il Galeotti in manicomio non vi entrò più. L'evaso commise un ultimo reato prima di morire, questa volta l'omicidio riuscì a consumarlo per poi morire a sua volta. Il 17 novembre 1915 uccise il brigadiere Epifanio Porello e a seguito di un malore l'assassino morì quella stessa notte. 

APPENDICE

1. I malinconici socialmente pericolosi internati nell'ospedale psichiatrico Francesco Roncati di Bologna (1813-1847)

1. Piccinini Domenico, nato nel 1769, affetto da malinconia entra in manicomio dopo un breve periodo in carcere nel $1813^{1}$.

2. Gabrieli Giuseppe, nato nel 1753, affetto da malinconia entra in manicomio dopo un breve periodo in carcere nel $1813^{2}$.

3. Notari Antonio, nato nel 1802, affetto da malinconia entra in manicomio dopo un breve periodo in carcere nel $1818^{3}$.

4. Balugani Pellegrino, nato nel 1768, affetto da malinconia entra in manicomio dopo un breve periodo in carcere nel $1820^{4}$.

5. Candelari Andrea, la cui data di nascita rimane ignota, affetto da malinconia entra in manicomio dopo un breve periodo in carcere nel $1821^{5}$.

6. Lodi Domenico, nato nel 1794 , affetto da malinconia entra in manicomio dopo un breve periodo in carcere nel $1821^{6}$.

7. Vecchi Antonio, la cui data di nascita rimane ignota, affetto da

\footnotetext{
1 A.O.P.P., Francesco Roncati, P.D., uomini usciti, n. 4 [1813].

A.O.P.P., Francesco Roncati, G.G., uomini morti, n. 4 [1813].

3 A.O.P.P., Francesco Roncati, N.A., uomini usciti, n. 51 [1819].

4 A.O.P.P., Francesco Roncati, B.P., uomini usciti, n. 73 [1820].

5 A.O.P.P., Francesco Roncati, C.A., uomini morti, n. 34 [1821].

6 A.O.P.P., Francesco Roncati, L.D., uomini morti, n. 35 [1821].
} 
malinconia entra in manicomio dopo un breve periodo in carcere nel $1821^{7}$.

8. Beltrami Luigi, nato nel 1783, affetto da malinconia entra in manicomio dopo un breve periodo in carcere nel $1823^{8}$.

9. Torci Giuseppe, nato nel 1792, affetto da malinconia entra in manicomio dopo un breve periodo in carcere nel $1823^{9}$.

10. Brancacci Paolo, la cui data di nascita rimane ignota, affetto da malinconia entra in manicomio dopo un breve periodo in carcere nel $1824^{10}$.

11. Reali Giuseppe, nato nel 1776, affetto da malinconia entra in manicomio dopo un breve periodo in carcere nel $1824^{11}$.

12. Traldi Edoardo, nato nel 1764, affetto da malinconia entra in manicomio dopo un breve periodo in carcere nel $1824^{12}$.

13. Detta Di Gesù Teodora, nata nel 1775, affetta da malinconia entra in manicomio dopo un breve periodo in carcere nel $1825^{13}$.

14. Iobbi Domenico, nato nel 1784, affetto da malinconia entra in manicomio dopo un breve periodo in carcere nel $1825^{14}$.

15. Carpi Angiola, la cui data di nascita rimane ignota, affetta da malinconia entra in manicomio dopo un breve periodo in carcere nel $1827^{15}$. 16. Canè Pietro, nato nel 1787, affetto da malinconia entra in manicomio dopo un breve periodo in carcere nel $1827^{16}$.

17. Veronesi Francesco, nato nel 1766, affetto da malinconia entra in manicomio dopo un breve periodo in carcere nel $1827^{17}$.

18. Santi Camillo, nato nel 1788, affetto da malinconia entra in manicomio dopo un breve periodo in carcere nel $1828^{18}$.

\footnotetext{
7 A.O.P.P., Francesco Roncati, V.A., uomini usciti, n. 94 [1821].

A.O.P.P., Francesco Roncati, B.L., uomini usciti, n. 140 [1823], n. 363 [1832].

A.O.P.P., Francesco Roncati, T.G., uomini morti, n. 56 [1823].

A.O.P.P., Francesco Roncati, B.P., uomini morti, n. 73 [1824].

A.O.P.P., Francesco Roncati, R.G., uomini morti, n. 68 [1824].

2 A.O.P.P., Francesco Roncati, T.E., uomini usciti, n. 152 [1824]; n. 192 [1825].

3 A.O.P.P., Francesco Roncati, D.T., donne morte, n. 103 [1825].

14 A.O.P.P., Francesco Roncati, I.D., uomini usciti, n. 190 [1825]; n. 295 [1829].

15 A.O.P.P., Francesco Roncati, C.A., donna morta, n. 138 [1827].

16 A.O.P.P., Francesco Roncati, C.P., uomini morti, n. 122 [1827].

17 A.O.P.P., Francesco Roncati, V.F., uomini usciti, n. 238 [1827].

18 A.O.P.P., Francesco Roncati, S.C., uomini usciti, n. 253 [1828], n. 287 [1829].
} 
19. Vignoli Annunziata, nata nel 1778, affetta da malinconia entra in manicomio dopo un breve periodo in carcere nel $1828^{19}$.

20. Barilli Giovanni, nato nel 1778, affetto da malinconia entra in manicomio dopo un breve periodo in carcere nel $1828^{20}$.

21. Martelli Rosalia, nata nel 1777, affetta da malinconia entra in manicomio dopo un breve periodo in carcere nel $1829^{21}$.

22. Romagnoli Luigi, nato nel 1782, affetto da malinconia entra in manicomio dopo un breve periodo in carcere nel $1829^{22}$.

23. Guizzardi Giovanni, nato nel 1790, affetto da malinconia entra in manicomio dopo un breve periodo in carcere nel $1830^{23}$.

24. Hercolani Giovanni, nato nel 1800, affetto da malinconia entra in manicomio dopo un breve periodo in carcere nel $1830^{24}$.

25. Landi Agostina, nata nel 1797, affetta da malinconia entra in manicomio dopo un breve periodo in carcere nel $1830^{25}$.

26. Pesci Leandro, nato nel 1793, affetto da malinconia entra in manicomio dopo un breve periodo in carcere nel $1830^{26}$.

27. Spioni Domenica, nata nel 1767 , affetta da malinconia entra in manicomio dopo un breve periodo in carcere nel $1830^{27}$.

28. Marzocchi Pietro, nato nel 1814, affetto da malinconia entra in manicomio dopo un breve periodo in carcere nel $1831^{28}$.

29. Mascagni Angelo, nato nel 1808, affetto da malinconia entra in manicomio dopo un breve periodo in carcere nel $1831^{29}$.

30. Ugolini Giacomo, nato nel 1803, affetto da malinconia entra in manicomio dopo un breve periodo in carcere nel $1831^{30}$.

19 A.O.P.P., Francesco Roncati, V.A., donne morte, n. 160 [1828].

A.O.P.P., Francesco Roncati, B.G., uomini morti, n. 147 [1829].

A.O.P.P., Francesco Roncati, M.R., donne morte, n. 165 [1829].

A.O.P.P., Francesco Roncati, R.L., uomini morti, n. 144 [1829].

A.O.P.P., Francesco Roncati, G.G., uomini usciti, n. 329 [1830], n. 348 [1831], n. 439 [1833].

24 A.O.P.P., Francesco Roncati, H.G., uomini usciti, n. 319 [1830].

25 A.O.P.P., Francesco Roncati, L.A., donne morte, n. 175 [1830].

26 A.O.P.P., Francesco Roncati, P.L., uomini morti, n. 156 [1830].

27 A.O.P.P., Francesco Roncati, S.D., donne morte, n. 174 [1830].

28 A.O.P.P., Francesco Roncati, M.P., uomini usciti, n. 349 [1831], n. 413 [1833], n. 473 [1834], n. 563 [1836], n. 771 [1839];

29 A.O.P.P., Francesco Roncati, M.A., uomini usciti, n. 340 [1831

30 A.O.P.P., Francesco Roncati, U.G., uomini usciti, n. 353 [1831]. 
31. Gamberini Giuseppe, nato nel 1790, affetto da malinconia entra in manicomio dopo un breve periodo in carcere nel $1832^{31}$.

32. Bianconi Giovanni, nato nel 1778 , affetto da malinconia entra in manicomio dopo un breve periodo in carcere nel $1834^{32}$.

33. Casali Luigi, la cui data di nascita rimane ignota, affetto da malinconia entra in manicomio dopo un breve periodo in carcere nel $1834^{33}$. 34. Mariotti Maria Francesca, nata nel 1762, affetta da malinconia entra in manicomio dopo un breve periodo in carcere nel $1834^{34}$.

35. Milianti Domenico, nato nel 1788, affetto da malinconia entra in manicomio dopo un breve periodo in carcere nel $1834^{35}$.

36. Ricci Carlo, nato nel 1782, affetto da malinconia entra in manicomio dopo un breve periodo in carcere nel $1834^{36}$.

37. Castellari Francesco, nato nel 1812, affetto da malinconia entra in manicomio dopo un breve periodo in carcere nel $1835^{37}$.

38. Fiorini Giovanni Battista, nato nel 1795, affetto da malinconia entra in manicomio dopo un breve periodo in carcere nel $1835^{38}$.

39. Oppi Nicola, nato nel 1813, nato nel 1795, affetto da malinconia entra in manicomio dopo un breve periodo in carcere nel $1835^{39}$. 40. Morandi Caterina, nata nel 1769, affetta da malinconia entra in manicomio dopo un breve periodo in carcere nel $1837^{40}$.

41. Tosarelli Evangelista, nata nel 1756, affetta da malinconia entra in manicomio dopo un breve periodo in carcere nel $1837^{41}$.

42. Tartari Lucio, nato nel 1811, affetto da malinconia entra in manicomio dopo un breve periodo in carcere nel $1839^{42}$.

31 A.O.P.P., Francesco Roncati, G.G., uomini morti, n. 372 [1832], n. 494 [1835].

32 A.O.P.P., Francesco Roncati, B.G., uomini usciti, n. 441 [1834]; n. 627 [1837].

33 A.O.P.P., Francesco Roncati, C.L., uomini morti, n. 211 [1834].

34 A.O.P.P., Francesco Roncati, M.M., donne morte, n. 410 [1834].

35 A.O.P.P., Francesco Roncati, M.D., uomini morti, n. 215 [1834].

36 A.O.P.P., Francesco Roncati, R.C., uomini usciti, n. 482 [1834].

37 A.O.P.P., Francesco Roncati, C.F., uomini usciti, n. 517 [1835].

38 A.O.P.P., Francesco Roncati, F.G., uomini usciti, n. 493 [1835].

39 A.O.P.P., Francesco Roncati, O.N., uomini morti, n. 519 [1835], n. 284 [1838].

40 A.O.P.P., Francesco Roncati, M.C., donne morte, n. 307 [1837].

41 A.O.P.P., Francesco Roncati, T.E., donne uscite, n. 647 [1838].

42 A.O.P.P., Francesco Roncati, T.L., uomini morti, n. 299 [1839]. 
43. Marzocchi Domenico Antonio, nato nel 1790, affetto da malinconia entra in manicomio dopo un breve periodo in carcere nel $1839^{43}$.

44. Canè Giulio, nato nel 1819, affetto da malinconia entra in manicomio dopo un breve periodo in carcere nel $1841^{44}$.

45. Garelli Angelo, nato nel 1781, affetto da malinconia entra in manicomio dopo un breve periodo in carcere nel $1841^{45}$.

46. Gualandi Caterina, nata nel 1796, affetta da malinconia entra in manicomio dopo un breve periodo in carcere nel $1841^{46}$.

47. Marchioni Giovanni, nato nel 1820, affetto da malinconia entra in manicomio dopo un breve periodo in carcere nel $1841^{47}$.

48. Romagnoli Agostino, nato nel 1798, affetto da malinconia entra in manicomio dopo un breve periodo in carcere nel $1841^{48}$.

49. Mezzetti Maria, nata nel 1806 , affetta da malinconia entra in manicomio dopo un breve periodo in carcere nel $1843^{49}$.

50. Franchi Pietro, nato nel 1812, affetto da malinconia entra in manicomio dopo un breve periodo in carcere nel $1844^{50}$.

51. Grandi Angelo, nato nel 1813, affetto da malinconia entra in manicomio dopo un breve periodo in carcere nel $1845^{51}$.

52. Gottardi Luigi, nato nel 1802, affetto da malinconia entra in manicomio dopo un breve periodo in carcere nel $1847^{52}$.

53. Rossi Geltrude, nata nel 1793, affetta da malinconia entra in manicomio dopo un breve periodo in carcere nel $1847^{53}$.

43 A.O.P.P., Francesco Roncati, M.D., uomini usciti, n. 782 [1840], n. 918 [1842], n. 962 [1843], n. 325 [1848].

44 A.O.P.P., Francesco Roncati, C.G., uomini usciti, n. 847 [1841].

45 A.O.P.P., Francesco Roncati, G.A., uomini usciti, n. 820 [1841].

46 A.O.P.P., Francesco Roncati, G.C., donne morte, n. 750 [1841].

47 A.O.P.P., Francesco Roncati, M.G., uomini usciti, n. 815 [1841].

48 A.O.P.P., Francesco Roncati, R.A., uomini usciti, n. 822 [1841].

49 A.O.P.P., Francesco Roncati, M.M., donne morte, n. 830 [1843].

50 A.O.P.P., Francesco Roncati, F.P., uomini usciti, n. 1083 [1844].

51 A.O.P.P., Francesco Roncati, G.A., uomini usciti, n. 1100 [1845].

52 A.O.P.P., Francesco Roncati, G.L., uomini usciti, n. 1303 [1847].

53 A.O.P.P., Francesco Roncati, R.G., donne morte, n. 519 [1848]. 
2. I malinconici autori di reato internati nell'ospedale psichiatrico Francesco Roncati di Bologna (1823-1836)

1. Atti Pietro, originario di Cento. Entra in manicomio il 18 aprile del $1823^{54}$.

La perizia del medico del carcere di S. Giovanni in Monte con cui si chiede il trasferimento dell'imputato di tentata aggressione e tentato omicidio in manicomio perché affetto da malinconia:

Pietro Atti a mio parere si può giudicare assolutamente pazzo, affetto da melanconia con quella stravaganza che io sin dal principio esposi. Poiché per caratterizzarsi un pazzo non è necessario che abbia tutti quanti i caratteri della pazzia e anzi nel delirio malinconico un oggetto solo può stravolgere talmente le facoltà intellettuali che si può dire di essere quel tale pazzo. Il nostro Atti è persuaso di essere un gran letterato, un gran scrittore, un uomo capace di dare una costituzione ad uno Stato: non è questa pazzia? Il suo aspetto non è naturale mentre ha l'occhio torbido, buio, e spesso immobile e minaccioso. Egli è facilissimo di adirarsi ed io l'ho veduto fuggire davanti al giudice che lo esaminava, tutto furibondo ed andarsene per tornare al suo carcere. L'altro giorno perché una guardia voleva chiudere una finestra, si accese di furore ed il vice custode delle carceri prudentemente impedì che si chiudesse. Io medesimo che volevo farlo uscire di carcere conobbi che ciò lo urtava a segno di farlo montare in collera e desistetti. Il medesimo come attestano i compagni di carcere e le Guardie di S. Giovanni in Monte e delle carceri criminali, soffre una veglia quasi continua e quante volte fanno la visita nella notte lo trovano sempre desto e di più ad ogni legger rumore si scuote, come uno spaventato. Tutti questi segni furono giudicati fra gli altri segni caratteristici di una mente sconcertata e non mai in istato naturale. A questi segni si aggiungano le stravaganze sue particolari che ho notato negli altri miei rapporti che si conserva una certa uniformità nelle sue pazzie che in diverse circostanze se fosse malizioso non dovrebbe tenere, per mio avviso si vede chia-

54 A.O.P.P., Francesco Roncati, A.P., uomini usciti, n. 149 [1824], n. 166 [1824], n. 554 [1836]. 
ro che costui è realmente pazzo. Del resto altri segni fisici caratteristici della pazzia di codesto uomo non ne abbiamo: ma per un delirio melanconico bastano pochi per caratterizzarlo.

Bologna, lì 25 febbraio 1823

Il medico fiscale dell'ist. carcerario

Carlo Dott. Dal Re

2. Beltrami Luigi, 40 anni, di Bologna, di professione muratore. Entra in manicomio il giorno 7 agosto $1823^{55}$.

La perizia del medico fiscale del carcere con cui viene richiesto il trasferimento dell'imputato di tentato omicidio dal carcere al manicomio perchè considerato affetto da monomania omicida:

Quest'uomo preso da un forte accesso maniaco omicida entrò improvvisamente in una Chiesa nel tempo della messa con in mano un istrumento di ferro col quale cominciò a percuotere tutte le persone che gli si presentavano davanti. Fu curato nel corso di due mesi e con delle deplezioni sanguigne recuperò perfettamente la sanità.

Bologna, 7 agosto 1823

Medico alienista N. Paolini

3. Antonelli Teresa, bolognese, di professione servente. Entra in manicomio il 14 luglio $1826^{56}$.

La perizia del medico fiscale del carcere con cui viene richiesto il trasferimento dell'imputata di tentata aggressione dal carcere al manicomio perché considerata affetta da monomania:

Illustrissimo Signore

Ieri sera fu qui tradotta certa Antonelli Teresa invasa da monomania andava in modo da rompere tutto ciò che le si presenta, ed offendere chiunque. Le altre infermi degenti nell'ospedale carcerario sono restate spaventate e la povera Carlotta Sandri dal timore è stata assalita da convulsioni. Qui non vi è letto di forza, qui non vi

55 A.O.P.P., Francesco Roncati, B.L., uomini usciti, n. 140, [1823]; n. 363, [1832].

6 A.O.P.P., Francesco Roncati, A.T., donne morte, n. 150, [1828]. 
è che il modo di legarne uno solo, che non resta mai sicuro perché il letto è movibile. Qui manca tutto e siamo realmente tutti disturbati vedendo il disturbo che hanno li infermi e l'impossibilità nello stesso tempo di rimediarvi. Mi raccomando al zelo e carità di Vostra Signoria Illustrissima acciò ci aiuti in questo frangente, procurando che al più presto passi nell'ospedale apposito di $\mathrm{S}$. Orsola e ridoni alla nostra infermieria la quiete e la sicurezza. Avrei potuto farla collocale in altra sala ma non trovo chi voglia servire questa maniaca.

Dall'ospedale carcerario, lì 13 luglio

Il medico fiscale Carlo Dott. Dal Re

4. Bergonzoni Luigi, di Bologna, 19 anni, studente di filosofia. Entra in manicomio il 7 luglio del 1836 perché considerato affetto da monotristimania religiosa ${ }^{57}$.

La perizia del medico alienista che lo ebbe sotto osservazione clinica e che descrisse il caso nel registro nosografico:

Le notizie avute intorno alla malattia di questo giovane sono che da due mesi a questa parte egli soffre di certa debolezza al sistema nervoso che non gli permette di molto applicarsi. Se per qualche ora avesse egli letto o scritto ed in altro modo studiato era preso da senso di vuoto al capo, da confusione di idee che non gli lasciavano bene intendere ciò che studiasse ed era costretto a cessare di fare quella qualunque operazione che aveva incominciato. $\mathrm{Fu}$ ritrovato una notte a Casalecchio vicino al canale ove pare volesse gettarsi. Fu così trasportato all'ospedale carcerario.

Medico alienista M. Marchesini

57 A.O.P.P., Francesco Roncati, uomini usciti, n. 570, [1836]. 
3. I malinconici autori di reato internati nell'ospedale psichiatrico Santa Maria della Pietà di Roma (1906-1916)

1.

\begin{tabular}{|l|l|}
\hline Galeotti Luigi $^{58}$ & \\
\hline Data e luogo di nascita & 1873 Valmontone \\
\hline $\begin{array}{l}\text { Data del ricovero in } \\
\text { manicomio }\end{array}$ & 1906 \\
\hline Tipologia di reato & $\begin{array}{l}\text { Mancato omicidio, plurimo omicidio, furti } \\
\text { qualificati, porto d'armi (in totale trenta reati } \\
\text { senza moventi) }\end{array}$ \\
\hline Ricovero disposto da & $\begin{array}{l}\text { Sezione Penale della Corte d'Appello degli } \\
\text { Abruzzi }\end{array}$ \\
\hline Provenienza & Manicomio giudiziario di Aversa \\
\hline Diagnosi psichiatrica & Grave forma di malinconia \\
\hline
\end{tabular}

Il Messaggero, 17 novembre 1915, p. 3

Cronaca di Roma

\section{Le gesta del Galeotti a Valmontone}

\section{La morte dell'assassino del brigadiere Purello}

Grande impressione ha prodotto nella città la notizia del feroce delitto commesso da uno sciagurato. Il brigadiere Purello era troppo conosciuto, e le sue doti erano troppo apprezzate perché funzionari e agenti non sentissero vivo cordoglio per la morte dell'ottimo graduato. Intanto la salma della vittima del dovere è vegliata per turno dagli agenti della squadra investigativa. Al cav. Rostagno e ai delegati Cadolino e D'Alena si sono recati molti cittadini, i quali hanno chiesto se potevano mandare delle corone dei fiori. L'autopsia sarà fatta oggi, mercoledì nel pomeriggio. Il giudice Ravioli vi assisterà e quindi, permetterà che la salma sia trasportata nella chiesetta attigua all'ospedale. Domani mattina, poi, alle 10, avranno luogo i funerali, i quali avranno, senza dubbio una grande solennità. Vi parteciperanno numerosi funzionari, le rappresentanze dei vari corpi armati e molti cittadini. Come già annunziammo i funerali saranno fatti a spese dello Stato. Abbiamo potuto

58 ASMP, Cartelle cliniche, t. IX, f. 2720, [1909-1915]. 
parlare con il bravo agente scelto Vincenzo Rizzo, il quale fu presente alla tragedia, e vide cadere il Purello ai suoi piedi. Il Rizzo è come sotto l'oppressione di un incubo; e ricorda con frasi commosse la morte del suo superiore ed amico. Egli ha confermato in tutti i particolari la precisa narrazione da noi fatta, aggiungendo che né egli né il Purello avevano pensato che il Galeotti fosse armato.

\section{La morte dell'assassino}

Le condizioni di Luigi Galeotti si sono andate aggravando nel pomeriggio. Verso sera l'uccisore del brigadiere Purello ha perduto conoscenza; e all'una della notte cessava di vivere.

\section{Le gesta del Galeotti a Valmontone}

Il nostro corrispondente ci scrive:

L'assassinio del brigadiere Epifanio Purello ha prodotto nella nostra cittadinanza viva l'impressione suscitando sentimenti di compianto per la povera vittima del dovere. L'assassino Galeotti Luigi, è nato a Valmontone addì 20 luglio 1872 da distinta ed agiata famiglia, ed allontanatosi fin da bambino dal paese non vi ebbe più stabile dimora. Fin da giovane incominciò la sua 'brillante' carriera di delinquente e più volte fu qui rimpatriato dalle varie questure del regno.

Qui però rimaneva per pochi giorni e si dava subito alla latitanza, ricercato sempre dalla pubblica sicurezza o per contravvenzione alla vigilanza o per aver commessi altri reati. Tutti lo conoscevano col soprannome di 'trappolino' ed era il vero tipo dell'uomo astuto ed audace. Una volta ad un suo zio che per sentimento umanitario volle ospitarlo pochi giorni scassinò il negozio rubandogli una rivoltella e poco denaro. Anni sono mentre era rinchiuso in questo carcere mandamentale, eludendo con grande furberia la vigilanza del guardiano, evase e portò con sé un altro detenuto. Arrestato ad Avezzano, ove sembra avesse compiuto altri reati, fu inviato ad un manicomio criminale. Si ricordano di lui astuzie e audacie inverosimili. Una volta mentre era ricercato, indossata la toga di avvocato si presentò in una Corte di assise.

Da qualche anno qui non si sentiva parlare più di 'trappolino', e si riteneva per certo che egli fosse ormai per molti anni assicura- 
to alla giustizia. Ma nello scorso mese di agosto egli fece la sua improvvisa apparizione in paese e si recò a pranzare nella trattoria di Sarandrea Augusto il 'ciociaro'. Sembra però che le locali autorità di pubblica sicurezza non fossero a conoscenza dell'ultima evasione del temuto delinquente che indisturbato poté allontanarsi. Si ritiene però che la sua visita a Valmontone non fosse stata del tutto inutile.

Un mese fa, come il 'messaggero' ha pubblicato, di notte tempo venne commesso un furto di più di cento paia di scarpe nella calzoleria di Maiorani Giacinto, e dopo pochi giorni i ladri penetrarono nella trattoria dello Stesso Sarandrea rubandovi 96 lire in denaro e 30 mazzi di carte da giuoco. Usciti dal Sarandrea gli stessi ladri si accingevano a scassinare la tabaccheria di Leoni Ercole, a cui furono disturbati da un fratello del proprietario che affacciatosi dalla finestra grida 'a ladro'. I ladri fuggirono ma lasciarono sul posto le carte rubate al Sarandrea, un paletto ed una copia del Giornale d'Italia della stessa sera che commisero i furti.

Ora se si tiene conto dell'audacia dei furti e del fatto che il Giornale d'Italia doveva essere stato necessariamente portato da Roma col treno della mezzanotte (i furti avvenivano alle 2), dobbiamo avere il sospetto, molti anzi hanno la persuasione, che i ladri o qualcuno di essi fosse venuto appositamente da Roma, e quest'uno potrebbe essere senz'altro il Galeotti. Si è venuto pure a conoscenza che 'Trappolino' è stato visto a Valmontone 20 giorni fa. Avrebbe parlato con qualche amico allontanandosi subito dal paese.

2.

\begin{tabular}{|l|l|}
\hline Alessandrini Alfredo ${ }^{59}$ & \\
\hline Data e luogo di nascita & 1872 Ischia di Castro (VT) \\
\hline Data del ricovero in manicomio & 1909 \\
\hline Tipologia di reato & Tentato omicidio (senza causa) \\
\hline Ricovero disposto da & Procuratore del Re \\
\hline Provenienza & $\begin{array}{l}\text { Carcere giudiziario di Regina Coeli } \\
\text { di Roma }\end{array}$ \\
\hline Diagnosi psichiatrica & mania sistematica (omicida) \\
\hline
\end{tabular}

59 ASMP, Cartelle cliniche, t. IX, f. 3226, [1909-1910]. 
L'annomilenovecentonove il giorno 16 ottobre la Camera di Consiglio presso il Tribunale Civile e penale di Roma composta dai Signori:

Prelloni Cesare [Presidente]

Doria Vincenzo

Menardelli Giovanni [Giudici]

Il primo dei quali è addetto all'ufficio d'Istruzione

Sentita la relazione del Giudice Istruttore e anche gli atti del procedimento penale istruito a carico di Alessandrini Alfredo di Pietro di anni 37 da Ischia di Castro (Roma) residente in Fuscaldo (Cosenza) detenuto

\section{Imputato}

di mancato omicidio per avere in Roma il 28 luglio 1909, a fine di uccidere, esploso cinque colpi di rivoltella compiendo così tutto quanto era necessario a consumare l'eccidio, che non avendo per circostanze indipendenti dalla sua volontà, essendo rimasto illeso Monzocchi Giuseppe contro cui furono da lui esplosi due colpi di rivoltella e feriti con altri quattro colpi Pagliatenza Carlo, Ghisali Luigi e Pertiana Malena.

Ordinanza del Tribunale civile e penale di Roma

Ritenuto che Alessandrini Alfredo, di Pietro, con ordinanza della Camera di Consiglio Penale in data 16 ottobre 1909 è stato dichiarato irresponsabile e quindi non punibile per i reati a lui ascritti

la Corte ha dichiarato non luogo a procedimento penale contro il prof. Alessandrini Alfredo in applicazione dell'art. 46 c.p. ${ }^{60}$.

60 ASMP, Ordinanza Tribunale civile e penale di Roma 22 ottobre 1909, n. 2901/01, [1909], in Atti giudiziari, t. IX, f. 3226, [1909-1910]. 
3.

\begin{tabular}{|l|l|}
\hline Baldacci Giuseppe $^{61}$ n. matr. 9973 & \\
\hline Data e luogo di nascita & 1863 Montemaggio (prov. Pesaro) \\
\hline Data del ricovero in manicomio & 1913 \\
\hline Tipologia di reato & Reati di sangue \\
\hline Ricovero disposto da & Pretore di Tivoli \\
\hline Provenienza & \\
\hline Diagnosi psichiatrica & mania sistematica (omicida) \\
\hline
\end{tabular}

Registro nosografico

Ammesso il giorno 16 luglio 1913 per ordine del pretore di Tivoli con certificato del Dottor Montesano Sterlich Eugenio in data 15 luglio 1913.

Nella perizia del medico primario Dottor Montesano si legge:

Prima dello sviluppo della attuale malattia il Baldacci era di carattere cupo con tendenze misantrope. In più occasioni lo si è visto manifestare palesemente ed ossessivamente il suo desiderio di uccidere. La volontà di uccidere non risulta basata su alcuna motivazione razionale. Le vittime di tali minacce non hanno mai concorso in alcun modo a far sorgere l'impulso omicida. Questo risiede nell'animo del Baldacci che presenta un intelletto integro e appare pienamente in possesso delle facoltà cognitive. Il Baldacci è stato incarcerato per reati di sangue. Pertanto riconoscendolo affetto da mania sistemica omicida si ritiene necessario l'internamento.

Decreto del Regio Tribunale Civile e Penale di Roma ${ }^{62}$

Composto degli ill.mi Sigg. Magistrati

Del Giudice Cav. Mauro [Presidente]

Guarini Luigi

Splendore Saverio

Riunito in Camera di Consiglio ha emesso il seguente decreto

61 ASMP, Cartelle cliniche, t. IX, f. 948, [1913-1914].

62 ASMP, Decreto del Regio Tribunale Civile e Penale di Roma 13 agosto 1914, n. 792, in Atti giudiziari, t. IX, f. 948, [1913-1914]. 
Letta la relazione del Direttore del manicomio, da cui risulta che il detto Baldacci è stato riconosciuto affetto da mania sistemica omicida. Poiché sono state osservate le forme prescritte dall'art. 2 cap. 1 della legge 14 febbraio 1904, n. 36.

Sulla relazione del giudice delegato autorizza in linea definitiva la immissione nel manicomio di S. Maria della Pietà di Roma di Giuseppe Baldacci reo di omicidio senza causa. Così deciso in Camera di Consiglio il 13 agosto 1913.

Roma 14 agosto 1913

Il cancelliere Pisani

4.

\begin{tabular}{|l|l|}
\hline Filonzi Giovanni ${ }^{\mathbf{6 3}} \mathrm{n}$. matr. 10347 & \\
\hline Data e luogo di nascita & 1859 Prov. Ancona \\
\hline Data del ricovero in manicomio & 1914 \\
\hline Tipologia di reato & $\begin{array}{l}\text { Imputato di omicidio e tentato } \\
\text { omicidio (senza causa) }\end{array}$ \\
\hline Ricovero disposto da & Giudice istruttore di Roma \\
\hline Provenienza & Carcere di Regina Coeli di Roma \\
\hline Diagnosi psichiatrica & Sospetta mania sistematica \\
\hline
\end{tabular}

Registro nosografico

Filonzi Giovanni del fu Domenico e della fu Monesi Vittoria ammesso il giorno 18 maggio 1914 per ordine del giudice istruttore di Roma con lettera in data 12 maggio 1914, nato a Belvedere Ostiense e proveniente dalle Carceri di Regina Coeli, di anni 55.

Atti del Tribunale penale di Roma. Ordinanza Giudice Istruttore ${ }^{64}$

L’anno 1914 il giorno 11 del mese di maggio in Roma il giudice Istruttore presso il Tribunale Maffei Ruggero

Poiché nel processo a carico di Filonzi Giovanni fu Domenico

63 ASMP, Cartelle cliniche, t. IX, f. 1876, [1914-1915].

64 ASMP, Atti del Tribunale penale di Roma. Ordinanza Giudice Istruttore 12 maggio 1914, n. 20393, in Atti giudiziari, t. IX, f. 1876, [1914-1915]. 
imputato di omicidio in persona di Latini Giovanni e mancato omicidio in danno di Gentili Felice devesi procedere a perizia psichiatrica dello stesso imputato

Poiché occorrendo tenere a disposizione dei periti Proff. Bianconi Giovanni e Montesano Giuseppe l'imputato Filonzi Giovanni rendesi necessario il ricovero del medesimo al manicomio di S. Maria della Pietà in Roma per le necessarie osservazioni dei periti

P.Q.M.

Ordiniamo il ricovero dell'imputato Filonzi Giovanni attualmente detenuto a Regina Coeli al manicomio di S. Maria della Pietà in Roma

Roma 12 maggio 1914

Il Giudice Istruttore Maffei

Il cancelliere Ragnazzi

Perizia psichiatrica del medico Dottor Montesano

Filonzi Giovanni la sera del 17 gennaio 1914 venne a lite con un tale Latini Giovanni contro il quale esplose tre colpi di rivoltella colpendolo all'addome e ferendolo alla coscia destra, un tale Gentili Felice alla coscia sinistra che riportò la frattura del femore. Il Filonzi rinviato a giudizio fu sottoposto a perizia psichiatrica. Durante gli esami eseguiti in questo manicomio furono constatati una lieve debolezza mentale e degenerazione del carattere in parte congenita e in parte aggravata dagli abusi alcolici, dall'aterosclerosi diffusa. La degenerazione del carattere ricorda molto da vicino la mania sistemica omicida per la limitazione dei sentimenti etico morali per la grande suscettibilità ad attacco di collera grave e a manifestazioni impudiche e per l'esagerazione a compiere pratiche di culto religioso.

I periti conclusero che il Filonzi in condizioni abituali di calma sia pienamente responsabile per qualsiasi specie di delitto poiché la debolezza mentale è così lieve da non togliergli la coscienza del fine e del valore dei propri atti e perché avendosi in lui non poche irregolarità di sviluppo di tendenze in modo da dare alla condotta un carattere di necessità. Avendo egli però commesso il delitto in un attacco di collera durante la quale non poté inibire i propri impul- 
si per una perdita transitoria più o meno grave della libertà dei suoi atti e per ciò gli accordarono il beneficio della diminuzione di imputabilità.

5.

\begin{tabular}{|l|l|}
\hline Alfonsi Domenico & \\
\hline Data e luogo di nascita & 1882 Castignano prov. Ascoli Piceno \\
\hline Data del ricovero in manicomio & 1915 \\
\hline Tipologia di reato & Imputato di omicidio (senza causa) \\
\hline Ricovero disposto da & $\begin{array}{l}\text { Presidente della Corte di Assise di } \\
\text { Roma }\end{array}$ \\
\hline Provenienza & $\begin{array}{l}\text { Carcere giudiziario di Regina Coeli di } \\
\text { Roma }\end{array}$ \\
\hline Diagnosi psichiatrica & mania sistematica omicida \\
\hline
\end{tabular}

Il Presidente della Corte di Assise di Roma (Circolo ordinario)

Vista la sopra estesa richiesta del Sign. Procuratore Generale

Visto il certificato medico attestante che il detenuto Alfonsi Domenico, deferito al giudizio di questa corte d'Assise dà segni di alienazione mentale e urge ricoverarlo in un manicomio

Visto l'articolo 19 del R.D. 5/10/1913 n. 1177 per l'attuazione del c.p.p.

\section{Ordina}

Il ricovero di urgenza nel manicomio provinciale di Roma dell'imputato Alfonsi Domenico con la osservanza delle opportune cautele determinate dal suo stato di detenzione.

Roma 9 maggio 1915

Mortara

${ }^{65}$ ASMP, Cartelle cliniche, t. IX, f. 2791, [1915]. 
6.

\begin{tabular}{|l|l|}
\hline Sebastiani Agapito ${ }^{66}$ & \\
\hline Data e luogo di nascita & 1857 Riofreddo (Prov. Roma) \\
\hline Data del ricovero in manicomio & 27 febbraio 1915 \\
\hline Tipologia di reato & $\begin{array}{l}\text { Imputato di tentato omicidio (senza } \\
\text { causa) }\end{array}$ \\
\hline Ricovero disposto da & $\begin{array}{l}\text { Giudice istruttore del Tribunale di } \\
\text { Roma }\end{array}$ \\
\hline Provenienza & $\begin{array}{l}\text { Carcere giudiziario di Regina Coeli di } \\
\text { Roma }\end{array}$ \\
\hline Diagnosi psichiatrica & Sospetta mania sistematica omicida \\
\hline
\end{tabular}

Registro nosografico

Sebastiani Agapito del fu Matteo ammesso il giorno 27 febbraio 1915 per ordine del giudice Istruttore del Tribunale di Roma III sezione con lettera in data 23 febbraio 1915. Nato a Riofreddo e proveniente dalle carceri di Regina Coeli, di anni 58.

In nome di Sua Maestà Vittorio Emanuele III

Per grazia di Dio e volontà della Nazione Re d'Italia

L'anno 1915 il giorno 23 febbraio il Giudice Istruttore presso il Tribunale Penale di Roma III sezione ha pronunziato la seguente ordinanza nel procedimento penale contro Sebastiani Agapito fu Matteo di anni 58 da Riofreddo detenuto nelle Carceri Giudiziarie di Roma.

Imputato di mancato omicidio. Vista la domanda avanzata dai periti psichiatrici Sigg. Montesano e Biancone allo scopo di ottenere che il detenuto Sebastiani sia dal Carcere trasferito nel Manicomio di S. Maria della Pietà in Roma, dove lo stesso Sebastiani può essere assoggettato ad un esame accurato e continuo, indispensabile per assolvere il compito affidato ai periti stessi.

Attesochè tale domanda si appalesa fondata ed è perciò che va accolta.

P.Q.M.

Visti gli articoli 209 e 217 c.p.p.

${ }^{66}$ ASMP, Cartelle cliniche, t. IX, f. 2606, [1915]. 
Ordina

che l'imputato Sebastiani Agapito detenuto nelle Carceri Giudiziarie di Roma, sia trasferito nel Manicomio di S. Maria della Pietà di questa città, rimanendo quivi, sempre in istato di detenzione, e sotto la responsabilità dell'autorità dirigente tale istituto, per essere assoggettato alle opportune osservazioni da parte dei periti psichiatrici, e senza l'assistenza dell'Ufficio del Pubblico ministero e dei difensori

Il Giudice Istruttore F. Masci

Perizia psichiatrica del medico primario Dottor Montesano

È un periziando. Si trasferisce al reparto infermeria per restare a disposizione di uno dei periti, Professor Bianconi.

Il contegno del Sebastiani è tale da rendersi incompatibile la sua presenza ulteriore nel reparto, egli ha minacciato ripetutamente un altro ricoverato.

Poiché il periziando è un delinquente pericolosissimo così si trasferisce alle Carceri.

Atti della direzione del manicomio ${ }^{67}$

In data 21 maggio 1915 il direttore del manicomio dispone le dimissioni del ricoverato e la consegna agli agenti di Pubblica Sicurezza del Commissariato di Trastevere per tradurlo alle carceri di Regina Coeli dalle quali proveniva.

Roma 20 maggio 1915

Commissariato di P.S. di Trastevere n. 1034-19-Q.

D'ordine dell'Ill.mo Signor Giudice Istruttore Masci prego V. S. Ill.ma consegnare agli agenti latori della presente il detenuto Sebastiani Agapito fu Matteo che deve essere associato nuovamente nelle carceri di Regina Coeli.

Il Commissario Gramentieri

67 ASMP, Cartelle cliniche, t. IX, f. 2606, n. 2226. 
7.

\begin{tabular}{|l|l|}
\hline Fedeli Elena in Merlino $\mathbf{6}^{68}$ & \\
\hline Data e luogo di nascita & 1874 Prov. Teramo \\
\hline Data del ricovero in manicomio & 17 marzo 1915 \\
\hline Tipologia di reato & Parricidio (senza causa) \\
\hline Ricovero disposto da & $\begin{array}{l}\text { Commissario di Pubblica Sicurezza di } \\
\text { Trastevere }\end{array}$ \\
\hline Provenienza & Carceri giudiziarie delle Mantellate \\
\hline Diagnosi psichiatrica & Monomania omicida \\
\hline
\end{tabular}

Osservazione peritale psichiatrica del medico primario Dottor Alfredo Mochi

dell'8 giugno 1916 .

Fedeli vedova Merlino Elena fu Angelo, e della fu Di Donato Susanna nata a Pietrocannello (Teramo). Entrata nel manicomio il 31 marzo 1916. Fu già ricoverata in manicomio dal 14 gennaio 1915 al 17 marzo in osservazione giudiziaria perché imputata di parricidio senza causa.

La diagnosi fatta fu di monomania omicida. Dall'anamnesi risulta che in tale condizione mentale affogò suo figlio di due anni.

È di carattere querulo, superstizioso, irritabile. Mantiene le idee persecutorie contro il marito che lo crede causa di tutta la sua sventura.

Ordinanza del Giudice Istruttore presso il Tribunale penale di Roma ${ }^{69}$

L'anno 1915 il giorno 8 gennaio in Roma il giudice istruttore presso il Tribunale penale di Roma ha pronunziato la seguente ordinanza nel procedimento penale contro Fedeli Elena in Merlini di Angelo e di Susanna Di Donato nata a Pietrocannello ritenuta attualmente nelle Carceri delle Mantellate

Imputata di parricidio commesso in Roma il 28 ottobre 1915 in

68 ASMP, t. IX, f. 2460, [1915-1917].

69 ASMP, Ordinanza del giudice istruttore del Tribunale penale di Roma 15 gennaio 1915, t. IX, f. 2460, n. 176. 
persona del proprio figlio Salvatore detta la istanza con la quale i periti psichiatrici chiedono che la imputata sia ricoverata in un pubblico manicomio per le necessarie osservazioni sulla base dell'art. 209 c.p.p.

Ordina

che la suddetta Fedeli Elena in Merlini sia tradotta nel manicomio di Santa Maria della Pietà in Roma ed ivi lasciata a disposizione dell'autorità giudiziaria nello stato di detenzione in cui si trova sotto la responsabilità dell'autorità dirigente il manicomio.

Roma 8 gennaio $1915 \quad$ Il giudice Istruttore Avv. Mosca

Decreto del Regio Tribunale civile e penale di Roma, (sez. IV civile) $)^{70}$

Composto degli ill.mi sigg. magistrati:

Sasso Cav. Gaetano

Cochetti Enrico

Arnaldi Ernesto

Riunito in Camera di Consiglio ha emesso il seguente

Decreto

Letta la istanza del Pubblico Ministero con cui si chiede che venga autorizzato il ricovero definitivo nel manicomio di Fedeli Elena [ved. Merlino]

Letta la relazione del Direttore del Manicomio da cui risulta che ricoverata la Fedeli invia di urgenza nel manicomio di S. Maria della Pietà per ordine del delegato alla pubblica sicurezza del carcere Regina Coelio sin dal 31 marzo 1916 la medesima è stata dal primario della sala di osservazione Prof. Giannuli riconosciuta affetta da stato equivalente epilettico.

Poiché sono state osservate le forme prescritte dall'art. 2, cap. I della legge 14 febbraio 1904, n. 36 poiché non può provvedersi allo stato alla condizione economica della demente P.Q.M.

70 ASMP, Decreto del Regio Tribunale civile e penale di Roma (sez. IV civile) 15 giugno 1916, t. IX, f. 2460, n. 2825. 
Sulla relazione del giudice delegato autorizza in linea definitiva la immissione nel manicomio di S. Maria della Pietà di Roma di Fedeli Elena e riserva ogni provvedimento sulla nomina del curatore.

Così deciso in Camera di Consiglio il 14 aprile 1916.

Copia conforme per uso ufficio,

Roma 15 aprile, 1916.

8.

\begin{tabular}{|l|l|}
\hline Alessandri Cherubina $^{71}$ & \\
\hline Data e luogo di nascita & 1890 Fiuggi \\
\hline Data del ricovero in manicomio & 4 luglio 1916 \\
\hline Tipologia di reato & $\begin{array}{l}\text { Imputata di incendio e procurato } \\
\text { aborto }\end{array}$ \\
\hline Ricovero disposto da & $\begin{array}{l}\text { Giudice istruttore del Tribunale di } \\
\text { Roma }\end{array}$ \\
\hline Provenienza & Carceri giudiziarie delle Mantellate \\
\hline Diagnosi psichiatrica & Monomania \\
\hline
\end{tabular}

Ordinanza del giudice istruttore del Tribunale civile e penale di Roma

In nome di Sua Maestà Vittorio Emanuele III

Per grazia di Dio e per volontà della Nazione

Re D'Italia

Il giudice istruttore del Tribunale civile e penale di Roma Favari Silvio ha pronunciato la seguente

Ordinanza n. prot. 554/9, 1916.

Nel processo in corso d'istruzione a carico di Alessandri Cherubina, di Antonio, di anni 26, da Fiuggi - detenuta nelle Carceri delle Mantellate

imputata di incendio e di procurato aborto, commesso in Fiuggi rispettivamente il 15 gennaio 1915 e nel marzo dello stesso anno.

Poiché in seguito alla richiesta del Giudice Istruttore di Frosinone è

71 ASMP, Cartelle cliniche, t. IX, f. 3815, [1916]. 
stata disposta la perizia psichiatrica in persona dell'imputata detenuta Alessandri Cherubina, ed i periti, nominati con le formalità di legge, hanno fatto esplicita domanda di ricovero della perizianda nel Manicomio S. Maria della Pietà per le necessarie osservazioni come risulta dal verbale di incarico peritale del 30 giugno ultimo scorso in assenza di una causa nei reati commessi sospettandosi una forma monomaniacale di infermità psichiatrica. Poiché pertanto deve provvedersi per il ricovero della detenuta Alessandri nel manicomio suindicato

Visti gli artt: 209 cod. proc. pen ${ }^{72}$ e 43 delle norme di attuazione.

\section{Ordina}

Il ricovero della perizianda Alessandri Cherubina nel manicomio di S. Maria della Pietà dove dovrà rimanervi nello stato di detenzione in cui si trova sotto la personale responsabilità del Direttore dell'istituto manicomiale, per il tempo strettamente necessario alle osservazioni, e richiede, per la traduzione della detenuta dal Carcere delle Mantellate al suddetto Manicomio di S. Maria della Pietà, in esecuzione del presente provvedimento, il Commissario di pubblica sicurezza di Trastevere, cui sarà fatta pervenire, oltreché al p.m. ed al Direttore del manicomio, copia della presente ordinanza a cura della Cancelleria dell'ufficio d'Istruzione ${ }^{73}$.

Roma 1 luglio 1916

Il giudice Istruttore Favari Il Cancelliere Cianchi

72 Codice Procedura Penale approvato con Regio Decreto del 27 febbraio 1913, n. 127 in Raccolta Ufficiale delle Leggi e dei Decreti del Regno d'Italia, I, 1913, art. 209.

73 ASMP, Ordinanza del Giudice Istruttore del Tribunale civile e penale di Roma, n. 554/9, in Atti giudiziari, t. IX, f. 3815, [1916]. 
INDICE DEI NOMI

Adam Charles, 45 n. 87

Ala Raffaele, 71, 71 n. 155, 72

Alberti Michael, 22 n. 24, 23, 23

nn. 27-28, 56, 56 n. 119

Alessandri Cherubina, 205, 206

Alessandrini Alfredo, 195, 196

Alessi Renato, 173 n. 19

Alfonsi Domenico, 200

Alighieri Dante, 7, 7 n. 1, 8

Allacci Leone, 20 n. 20

Alvazzi del Frate Paolo, 11 n. 10

Alvisi Alfredo, 164 n. 7

Amati Girolamo, 20 n. 20

Ambrosoli Filippo, 67 n. 146

Antonelli Teresa, 191

Aquarone Alberto, 132 n. 146

Areteo di Cappadocia, 19, 19 n. 17

Aristotele, 8, 8 n. 4, 9, 10 n. 9, 22 n. 24

Arnaldi Ernesto, 204

Ascheri Mario, 51 n. 103

Atti Pietro, 190

Aubert de Poitiers, 33, 33 n. 54

Audegean Philippe, 63 n. 136

Auriti Francesco, 141 n. 167

Babini Valeria Paola, 83 n. 15, 161

Baldacci Giuseppe, 197, 198
Balduin Friedrich, 34, 34 n. 58, 34 n. 60

Balugani Pellegrino, 185

Bargoni Angelo, 141 n. 167

Barilli Giovanni, 187

Bartoli Roberto, 60 n. 125

Bartolucci Domenico, 178

Barzellotti Giacomo, 87, 87 n. 28, 88,89

Bayle Laurent Antoine, 20 n. 20

Bayle Pierre, 45, 45 n. 88

Beccaria Cesare, 63, 63 n. 136, 64 n. 137

Bellato Franco, 161 n. 1

Bellomo Manlio, 40 n. 72

Beltrami Luigi, 186, 191

Benfenati Pietro, 166, 168, 169, 170

Bergonzoni Luigi, 192

Berlinguer Luigi, 67 n. 146

Bertazzoli Bartolomeo, 16 n. 5

Bertazzoli Claudio, 16, 16 n. 5

Bettiol Giuseppe, 60 n. 127

Bianconi Giovanni, 188, 199

Birocchi Italo, 63 n. 136

Bissolati Leonida, 158 n. 215

Blottin Jean-François, 98 
Boari Marco, 15 n. 1, 20 n. 20, 51 n. 103

Boccaccio Giovanni, 7, 7 n. 1

Bodin Jean, 33, 33 n. 53

Bombardieri Chiara, 162 n. 2, 170 n. 13

Bonacini Pierpaolo, 63 n. 134

Bonanno Francesco, 125 n. 122

Bonfigli Alessandra, 170 n. 15

Bongiochi Giuseppe, 167

Bonneville de Marsangy Arnould, 158 n. 215

Bonomo Giuseppe, 31 n. 47

Borzacchiello Assunta, 161 n. 1

Bossi Egidio, 41 n. 74

Brancacci Paolo, 186

Briganti Tommaso, 60, 60 n. 130, 61 n. 131,62 n. 133

Brini Giuseppe, 158 n. 215

Brundage James, 39 n. 70

Buccellati Antonio, 82, 82 n. 12, 130, 130 n. 136

Burton Robert, 23, 23 n. 25

Cabras Pier Luigi, 22 n. 24

Cadoppi Alberto, 131 n. 140

Calabrese Raffaele, 179

Calabria Arianna, 60 n. 125

Calabritto Monica, 19 n. 14

Calenda Corrado, 8 n. 3

Calenda Di Tavani Vincenzo, 141 n. 167

Candelari Andrea, 185

Canè Giulio, 189

Canè Pietro, 186

Canonico Tancredi, 125 n. 122, 141 n. 167

Canosa Romano, 170 n. 14

Cantoni Remo, 45 n. 86

Capparoni Pietro, 20 n. 20

Cappellini Paolo, 125 n. 123

Carcereri de Prati, 132 n. 145

Cardone Andrea, 109 n. 85
Carmignani Giovanni, 67, $67 \mathrm{n}$. $147,68,69,69$ n. $149,73,73$ n. $159,115,152,152$ n. 198

Carnazza Rametta Giuseppe, 86, 86 n. 25

Carpi Angiola, 186

Carpzov Benedikt, 25, 25 n. 32, 26, 26 nn. 33-34, 30 n. 44, 37, 37 n. $69,50,50$ n. $100,51,51 \mathrm{n}$. 104, 52, 53 n. 107, 55, 55 n. 118, 57 n. 121

Carrara Francesco, 83 n. 16, 125, 125 nn. $122-123,125$ n. 124 , 126, 126 n. 125,133 n. 147 , 134, 134 n. 152, 135, 135 n. 153, 147, 147 n. 182, 151, 151 n. $192,157,157$ n. 210,158 n. 215

Casagrande Aurelia, 164 n. 7

Casali Luigi, 188

Casorati Luigi, 125 n. 122

Castellari Francesco, 188

Castle Frederik Albert, 97 n. 58

Catalano Elena Maria, 60 n. 127

Catelan Nicolas, 63 n. 136

Catena Bartolomeo, 32 n. 49

Cattabeni Caio Mario, 20 n. 20

Capogrossi Giuseppe, 71 n. 154

Cavalca Desiderio, 62 n. 133

Cavanna Adriano, 66 n. 143

Cavina Marco, 11 n. 10, 39 n. 70, 63 n. 134

Cazzaniga Antonio, 20 n. 20

Cazzetta Giovanni, 125 n. 123

Celio Aureliano, 19, 20 n. 19

Celso Aulo Cornelio, 19 n. 18

Chiarini Francesca, 151 n. 195

Chiaves Desiderato, 125 n. 122

Chiffoleau Jacques, 62 n. 133

Chiodi Giovanni, 19 n. 15, 27 n. 36, 53 n. 108,124 n. 120

Cibrario Luigi Giovanni Antonio, 
117, 117 n. 100, 118, 118 nn. 101-102

Cicerone Marco Tullio, 15, 115 n. 96

Ciolella Settimio, 178

Cioni Domenico, 149 n. 189

Clark Michael, 51 n. 103

Clark Stuart, 31 n. 47

Claro Giulio, 17, 17 nn. 7-8

Cardona Enrico, 125 n. 122

Cocchiara Maria Antonella, 119 n. 103

Cochetti Enrico, 204

Cogliolo Pietro, 85, 85 n. 24, 153 n. 201

Colao Floriana, 67 n. 146, 108 n. 83, 121 n. 109, 124 n. 119, 127 n. 130,134 n. 149

Colombero Chiara, 20 n. 20, 21 n. 21

Comanducci Paolo, 67 n. 146

Condorelli Orazio, 40 n. 72

Conforti Raffaele, 139, 139 nn. 161-162

Contegiacomo Luigi, 164 n. 7

Contigiani Ninfa, 71 n. 154, 74 n. 162

Contoli Carlo, 71 n. 154

Cordero Franco, 58 n. 123

Cortese Ennio, 27 n. 38

Cosentino Vincenzo, 136, 137 n. 155

Costa Andrea Antonio Baldassarre, 141 n. 167

Cotti Maurizia, 83 n. 15, 161 n. 1

Crawford Catherine, 51 n. 103

Crespolani Riccardo, 153 n. 202

Crivellari Giulio Cesare, 125 n. 122, 151, 151 nn. 193-194, 152, 152 n. 199

Cuche Paul, 109 n. 85

D’Afflitto Eustachio, 60 n. 130
D’Amico Elisabetta, 158 n. 215

D’Aquino Tommaso, 10 n. 8, 10 n. 9

Da Passano Mario, 131 n. 139, 132 n. 141,132 n. 144,132 n. 146

Dahm George, 47 n. 91

Dal Re Carlo, 166, 169, 170, 191

Dalbrenta Daniele Velo, 82 n. 13

Davide [Re d'Israele], 32

De Antonellis Felice, 111, 112, 116

De Bernardi Alberto, 20 n. 20, 173 n. 19

De Gregorio Ponfilo, 174, 175

De Martigny Collard, 103, 104, 104 n. 74

De Novellis Raffaele, 125 n. 122

De Renzi Salvatore, 20 n. 20

De Renzi Silvia, 21 n. 20, 21 n. 21, 51 n. 103

De Renzis Francesco, 170 n. 14

Deci da Bassano Giovanni, 128, 128 n. 132, 130

Degli Ubaldi Baldo, 16, 16 n. 3

De Notaristefani Ferdinando, 179

Del Giudice Mauro, 197

Del Pistoia Luciano, 161

Delcorno Carlo, 8 n. 2

Delitala Giacomo, 60 n. 126

Dell'Osso Giuseppe, 60 n. 125

Demuro Gian Paolo, 47 n. 91, 60 n. 126

Deodati Edoardo, 141 n. 167

Dérobert Léon, 20 n. 20

Descamps Olivier, 58 n. 123

Descartes René, 45 n. 87

Detta Di Gesù Teodora, 186

Dezza Ettore, 105 n. 76, 108 n. 83, 114 n. 94, 154 n. 203

Di Renzo Villata Maria Gigliola, 39 n. 70,41 n. 74

Di Simone Maria Rosa, 11 n. 10

Dilcher Gerhard, 39 n. 70 
Dingli Caruana Edward, 67 n. 146 Dini Alessandro, 20 n. 20

Dioni Gianluca, 28 n. 39

Diurni Giovanni, 58 n. 123

Doffai Claudio, 33

Donahue Charles [Jr.], 39 n. 70

Doria Vincenzo, 196

Droetto Antonio, 45 n. 86

Dubuisson Paul Émile, 79 n. 5, 94 nn. 48-49, 101, 102 n. 72

Ellenberger Henri Frédéric, 44, 44 n. 84

Ellero Pietro, 125 n. 122, 158, 158 n. $215,159,159$ n. 216

Engelmann Woldemar, 47 n. 91

Errante Vincenzo, 141 n. 167

Esquirol Jean-Étienne-Dominique, 78,78 n. 2, 87, 87 n. $27,95,97$

Eula Lorenzo, 141 n. 167

Fabbri Giuseppe, 165, 166, 167, $168,169,170$

Falaride, 9

Farinacci Prospero, 16, 16 n. 4, 18, $18 \mathrm{nn} .11-12$

Favari Silvio, 205, 206

Fedeli Bernardini Franca, 170 n. 15

Fedeli Elena, 203, 204, 205

Feldtman Enrico, 103, 104

Feola Tommaso, 21 n. 20

Ferraria Iacobina, 18

Ferri Enrico, 121, 121 n. 108, 121 n. $110,122,122$ n. 113,123 , 123 n. $115,124,124$ n. 121 , 125 n. $122,155,158$ n. 215

Ferracuti Franco, 60 n. 125

Ferrini Venanzio, 174, 175

Ferro Filippo Maria, 20 n. 20

Filangieri Gaetano, 64, 65 n. 140, 74 n. $163,114,114$ n. 94

Filonzi Giovanni, 198

Fioravanti Laura, 132 n. 141

Fioravanti Maurizio, 27 n. 36
Fiorelli Pietro, 40 n. 71, 54 n. 114

Fiorini Giovanni Battista, 188

Fioritti Angelo, 164 n. 7

Flashar Hellmut, 22 n. 24

Fornari Ugo, 125 n. 124

Foucault Michel, 77 n. 1

Franchi Pietro, 189

Froldi Rino, 20 n. 20

Frova Carla, 11 n. 10

Fulci Ludovico, 83, 83 n. 17

Gabelli Aristide, 125 n. 122

Gabrieli Giuseppe, 185

Gaito Alfredo, 60 n. 127

Galeotti Luigi, 174, 175, 176, 177, $178,179,180,181,181$ n. 32, 182, 183, 193, 194

Galzigna Mario, 162 n. 2

Gamberini Giuseppe, 188

Gambiglioni Angelo [L'Aretino], 17, 17 n. 6

Gandolfi Giovanni Battista Giacomo, 80,80 n. 6

Garelli Angelo, 189

Garlati Giugni Loredana, 40 n. 72, 125 n. 122

Garofalo Raffaele, 125 n. 122

Gatti Tancredi, 58 n. 123

Gaudemet Jean, 47 n. 92

Gauthier René-Antoine, 8 n. 4

Gauvard Claud, 62 n. 133

Gentili Felice, 198

Georget Étienne-Jean, 78, 79, $79 \mathrm{n}$. 3, 92, 93 n. 39, 94, 95, 102 n. 73

Geri Marco Paolo, 67 n. 146

Gerin Cesare, 20 n. 20

Ghiglieri Francesco, 141 n. 167

Ghisalberti Carlo, 62 n. 133, 132 n. 144

Ghisali Luigi, 196

Ginzburg Carlo, 31 n. 47

Giorgini Giovanna, 161 n. 1 
Giuliani Alessandro, 46 n. 89, 51 n. 102, 60 n. 129, 105 n. 75

Giuliani Giuseppe, 74, 74 nn. 162163

Giustiniani Lorenzo, 60 n. 130

Gottardi Luigi, 189

Graebner Gottfried Lebrecht, $22 \mathrm{n}$. 24, 23 n. 28, 56 n. 119

Grandi Angelo, 189

Grassi Gaddomaria, 162 n. 2, 170 n. 13

Gregorio XVI, 71 n. 154, 74 n. 162, 131

Griesinger Wilhelm, 94 n. 46

Grosseteste Roberto, 8 n. 4

Grossi Paolo, 125 n. 123

Grosso Carlo Federico, 108 n. 83

Grozio Ugo, 25 n. 33

Gualandi Caterina, 189

Gualandi Giovanni, 171

Guarini Luigi, 197

Guizzardi Giovanni, 187

Haller Albrecht Von, 20 n. 20

Harpprecht George Friedrich, 40, 40 n. 73,41 n. 75,43

Heige Peter, 25, 25 n. 30, 31, 31 n. $46,35,35$ n. $62,57,57$ n. 122

Henningsen Gustav, 31 n. 47

Hercolani Giovanni, 187

Herviller Giovanna, 33

Hobbes Thomas, 25, 25 n. 31

Hoxha Damigela, 39 n. 70

Iaria Antonio, 170 n. 15

Impallomeni Giovanni Battista, 119, 119 nn. 103-104, 157, 157 n. 209

Inghilleri Calcedonio, 141

Iobbi Domenico, 186

Ionata Francesco, 144

Leone XII, 71 n. 154

Jöcher Christian Gottlieb, 20 n. 20

Kaiser Wolfram, 23 n. 27
Kéry Lotte, 58 n. 123

Kestner Christian Wilhelm, $20 \mathrm{n}$. 20

Kleinheyer Gerd, 26 n. 33

Klibansky Raymond, 18 n. 9, 22 n. 24

Kohlrausch Friedrich Wilhelm Georg, 109 n. 85

Kuttner Stephan, 47 n. 92, 51 n. 103, 59 n. 124

Labriola Antonio, 84 n. 22

Lacché Luigi, 72 n. 157, 108 n. 83, 125 n. 123,127 n. 130,127 n. 131

Landi Agostina, 187

Lanza Pietro, 125 n. 122

Lanzillo Maria Laura, 63 n. 136

Latini Giovanni, 199

Léauté Jacques, 47 n. 92

Leibbrand Werner, 19 n. 16

Leoni Ercole, 195

Leucci Eugenio, 61 n. 130

Leuret François, 94, 94 nn. 42-43, 95, 95 n. 51, 95 n. 53, 96 n. 55

Levack Brian Paul, 31 n. 47

Lévy Jean-Pierre, 54 n. 114

Lippi Donatella, 22 n. 24

Livi Carlo, 81, 81 n. 10, 82

Lo Russo Giuditta, 173 n. 19

Lo Russo Leo, 164 n. 7

Locke John, 27, 27 n. 37

Lodi Domenico, 185

Löffler Alexander, 46 n. 91

Lombardi Baldassarre, 7 n. 1

Lombroso Cesare, 82, 82 n. 13, 83 n. $14,163,163$ n. 6

Longo Michele, 157, 157 n. 212

Lonni Ada, 173 n. 19, 174 n. 21

Lovari Francesca, 22 n. 24

Lucchesi Marzia, 58 n. 123, 130 n. 135

Lutero Martin, 32 n. 50, 44, 44 n. 85 
Luvoni Ranieri, 20 n. 20

Luzzatto Giuseppe Ignazio, 50 n. 98

Madia Giuseppe, 109 n. 86, 112 n. 89

Maffei Ruggero, 198

Mahier Pierre Émile, 20 n. 20

Maiorani Giacinto, 195

Maire Vigueur Jean Claude, $41 \mathrm{n}$. 74

Majno Luigi, 154 n. 203, 156, 156 n. 208

Majorana Calatabiano Salvatore, 141 n. 167

Mancini Pietro, 148, 148 n. 187

Manduca Filippo, 153 n. 201

Mannori Luca, 66 n. 143

Marc Charles Chretien Henri, 92, 92 n. 36, 94 n. 44

Marchetti Paolo, 77 n. 1, $121 \mathrm{n}$. 108, 123 n. 117,127 n. 131

Marchetti Valerio, 20 n. 20

Marchioni Giovanni, 189

Marciano Fortunato, 178

Mariani Giuseppe, 174, 175

Marini Donato, 179

Mariotti Maria Francesca, 188

Marongiu Antonio, 58 n. 123, 127 n. 130

Martelli Rosalia, 187

Martini Adriano, 132 n. 145

Martyn Georges, 27 n. 36

Marzocchi Domenico Antonio, 189

Marzocchi Pietro, 187

Mascagni Angelo, 187

Massetto Gian Paolo, 17 n. 7

Massironi Andrea, 39 n. 70

Mastelli Giovanni, 174, 175

Mastrogiacomo Francesco Saverio, 112 n. 89

Matteotti Giacomo, 158 n. 215

Maudsley Henry, 94 n. 47, 99, 109 n. 85
Maxwell Joseph, 109 n. 85

Mayer Michael, 109 n. 85

Mazolli Gerardo, 36, 36 n. 65, 37

Mazzacane Aldo, 18 n. 11, 108 n. 83

Mazzuchelli Gian Maria, 60 n. 130

Meccarelli Massimo, 27 n. 36, 127 n. 130

Meersseman Gilles Gérard, 8 n. 2

Menardelli Giovanni, 196

Mereu Italo, 58 n. 123

Mezzetti Maria, 189

Michetti Antonio, 122 n. 114

Migliorino Francesco, 158 n. 214, 163 n. 5

Milani Giuliano, 62 n. 133

Miletti Marco Nicola, 127 n. 131

Milianti Domenico, 188

Minnucci Giovanni, 39 n. 70

Minuz Fernanda, 83 n. 15, 161 n. 1

Miraglia Biagio Gioacchino, 81, 81 n. $8,97,97$ n. 56

Mittermaier Carl Joseph Anton, 116, 116 n. 97, 117, 118, 158 n. 215

Moccia Sergio, 25 n. 33

Monesi Vittoria, 198

Monsagrati Giuseppe, 139 nn. 161162

Montanari Elisa, 164 n. 7

Montesano Giuseppe, 199, 202

Montesano Sterlich Eugenio, 197

Monzocchi Giuseppe, 196

Morandi Caterina, 188

Morello Maria, 173 n. 19

Mori Francesco Antonio, 134, 134 nn. 149-150-151

Musson Anthony, 27 n. 36

Musumeci Emilia, 81 n. 10, 83 n. 14, 153 n. 202

Nardi Bruno, 8 n. 2

Nardi Enzo, 15 n. 1 
Neppi Modona Guido, 108 n. 83

Niccolò Del Re, 18 n. 11

Nicola Filippo, 17

Nicolini Nicola, 109, 109 n. 86, 111 n. $87,112,112$ n. $89,113,113$

n. $90,114,115,116$

Nicomaco, 9

Nicotera Giovanni, 170 n. 13

Notari Antonio, 185

Novarese Daniela, 131 n. 139

Nuvolone Pietro, 151 n. 195

Nypels Jean Servais Guillaume, 98 n. 62

Onnis Luigi, 173 n. 19

Opocher Tommaso, 28 n. 39

Oppi Nicola, 188

Orfila Mathieu Joseph Bonaventure, 93, 93 n. 40

Padoa Schioppa Antonio, 66 n. 143, 67 n. 148

Padovani Tullio, 60 n. 125

Pagano Mario, 105 n. 76

Pagliatenza Carlo, 196

Palazzo Francesco, 11 n. 11, 48 n. 93

Panofsky Erwin, 18 n. 9, 22 n. 24

Papa Emilio Raffaele, 108 n. 83

Paravicini Bagliani Agostino, $41 \mathrm{n}$. 74

Parente Genesio, 178

Pastore Alessandro, 15 n. 2, $21 \mathrm{n}$. 20, 21 n. 21, 40 n. 71, 51 n. 103

Paterniti Carlo, 132 n. 142

Pelissero Marco, 60 n. 125

Pelliccione Domenico, 174, 175

Pennington Kenneth, 51 n. 103

Pereira Auguste, 94 n. 45, 94 n. 50, 97,97 n. 57, 98, 98 n. 60, 99 n. 63, 100, 100 n. 66

Perkins William, 34, 34 n. 56

Pertiana Malena, 196
Pesci Leandro, 187

Pessina Enrico, 126, 127, $127 \mathrm{n}$. 127, 140, 140 n. $166,141 \mathrm{n}$. 167, 158 n. 215

Petrocelli Biagio, 60 n. 125

Piccinini Domenico, 185

Pierini Giovanni, 21 n. 20

Pietro Leopoldo [Granduca di Toscana], 132

Pifferi Michele, 58 n. 123

Pihlajamäki Heikki, 27 n. 36

Pinel Philippe, 78, 87 n. 26, 106 n. 77

Pintacuda De Michelis Fiorella, 32 n. 50

Pogliano Claudio, 20 n. 20

Porello Epifanio, 183

Porter Roy, 20 n. 20

Pozzolini Alfredo, 109 n. 85

Prelloni Cesare, 196

Procaccino Angela, 60 n. 125

Prodi Paolo, 47 n. 92

Puccinotti Francesco, 89, 90, 90 n. 32, 91

Puccioni Giuseppe, 133, 133 n. 147, 134, 134 n. 148,141 n. 167

Pugliese Giovanna, 161 n. 1

Pujia Francesco, 179

Quaglioni Diego, 39 n. 70

Quercioli Cesare, 149, 149 nn. 188189

Rabbé Alphonse, 67 n. 146

Raggi Alberto, 167

Raggi Oreste, 128 n. 132

Rainaldi Giovanni Domenico, 62, 62 n. 134, 63 n. 135

Reali Giuseppe, 186

Regnault Elias, 94, 94 n. 42, 95, 95

n. 51,96 n. 55

Remer Christoph Andreas, $53 \mathrm{n}$. 109, 53 n. 111, 54 n. 116 
Renazzi Filippo Maria, 11 n. 10

Ribémont Bernard, 39 n. 70

Riccardi Paolo, 85 n. 24

Ricci Carlo, 188

Rice Charles, 97 n. 58

Righi Augusto, 170 n. 13

Rizzo Vincenzo, 194

Romagnoli Agostino, 189

Romagnoli Luigi, 187

Romagnosi Gian Domenico, 65, 65 nn. 142-143, 66 n. 144, 67, 69, 69 n. $150,70,71$ n. 153,72 , 106,106 n. 78, 131 n. 138

Roncati Francesco, 163, 164, 164 n. $7,165,165$ nn. 8-9, 166, 169 n. 11,170 n. $12,185,190$

Rosoni Isabella, 60 n. 128

Rossi Filippo, 151 n. 193

Rossi Geltrude, 189

Rossi Giovanni, 15 n. 2, 21 n. 20, 40 n. 71,41 n. 74

Rossi Pellegrino, 72, 72 nn. 157158, 106, 106 n. 79, 107, 107 n. 82,117 n. 99

Rosso Rossana, 125 n. 124

Saluto Francesco, 131 n. 139

Salvini Anton Maria, 7 n. 1

Santangelo Cordani Angela, $82 \mathrm{n}$. 12, 130 n. 136

Santaniello Giuseppe, 173 n. 19

Santi Camillo, 186

Santoro Teresa, 81 n. 8

Sarandrea Augusto, 195

Sarti Nicoletta, 63 n. 134

Sasso Gaetano, 204

Saul [re d'Israele], 32

Savelli Giannuzzi Bernardino, 139 n. $164,140,140$ nn. $165-166$

Saxl Fritz, 18 n. 9, 22 n. 24

Sbriccoli Mario, 27 n. 36, 41 n. 74, 74 n. 162,108 n. 83,124 n. 119, 133 n. 147,134 n. 150
Scalvanti Oscar, 67 n. 146

Scarano Luigi, 108 n. 84

Schaffstein Friedrich, 47 n. 91

Schröder Jan, 26 n. 33

Sebastiani Agapito, 201, 202

Seidel Menchi Silvana, 39 n. 70

Selmini Rossella, 124 n. 118

Sennert Daniel, 19

Setti Augusto, 154 nn. 203-204, 156 n. 207

Siefener Michael, 31 n. 47

Sorice Rosalba, 47 n. 91, 50 n. 98, 58 n. 123,62 n. 133,65 n. 141

Spinoza Baruch, 44, 45, 45 n. 86

Spioni Domenica, 187

Spitzer Alan Barrie, 21 n. 20

Splendore Saverio, 197

Sprengel Curzio, 20 n. 20

Squarcetti Agostino, 178

Starobinski Jean, 23 n. 25

Stile Alfonso Maria, 131 n. 139

Stok Fabio, 15 n. 2

Storti Claudia, 127 nn. 130-131

Stroppiana Luigi, 19 n. 17

Stryk Samuel, 34, 34 n. 59, 35, 35 n. 61,35 n. $63,52,52$ n. 105 , 53, 53 n. 110, 54, 54 n. 113 , 54 nn. 115-116, 55, 55 n. 117

Tagliarini Francesco, 60 n. 125

Tagliavini Annamaria, 83 n. 15, $161 \mathrm{n} .1$

Tamassia Arrigo, 84, 84 nn. 20-21

Tamburini Augusto, 162 n. 4

Tannery Paul, 45 n. 87

Tanzi Aristide, 27 n. 36

Tarello Giovanni, 114 n. 94

Tartari Lucio, 188

Tavilla Elio Carmelo, 132 n. 145, 158 n. 215

Thillaye Auguste, 20 n. 20

Toniolo Emanuele, 164 n. 7

Torci Giuseppe, 186 
Tosarelli Evangelista, 188

Traldi Edoardo, 186

Trampus Antonio, 65 n. 139

Traunfellner Zdzislaw, 20 n. 20

Trescale du Mayne, 33

Turati Filippo, 158 n. 215

Ugolini Giacomo, 187

Ulpiano, 15

Vallone Giancarlo, 61 n. 130

Vassalli Giuliano, 48 n. 93

Vecchi Antonio, 185

Veronesi Francesco, 186

Vico Pietro, 131 n. 137, 135 n. 154, 137 n. 156

Vigliani Paolo Onorato, 139, 139 n. 160, 141 n. 167

Vignoli Annunziata, 187

Vigouroux Auguste, 94 n. 49, 102 n. 71

Vinciguerra Sergio, 74 n. 162, 131 n. 139,132 n. 141,132 n. 141 , 132 n. 144,132 n. 146

Virgilio, 8
Vismara Giulio, 41 n. 74

Vladoff Dimitri, 102 n. 72

Völker Arina, 23 n. 27

Wettley Annemarie, 19 n. 16

Wolff Christian, 28, $28 \mathrm{nn}$. 39-40, 29, 30, 30 n. 43, 49, 49 n. 97 , 50 n. 99

Wolfgang Schild, 25 n. 32

Wood Horatio Curtis, 97, 97 n. 59, 101, 101 n. 70

Zacchia Paolo, 15 n. 2, 20, 20 n. 20, 21, 21 n. 22, 22, 22 n. 24, 23, 23 n. 26, 24, 28, 28 n. 42, 30, 30 n. $45,31,33,33$ n. 52, 36, 40 n. $71,44,48,48$ n. 94,49 , 54, 54 n. 112

Zanardelli Giuseppe, 138, 139, 139 n. $164,140,141$ n. 167,143 , 150, 151 n. 195, 153

Zendri Christian, 62 n. 133

Ziino Giuseppe, 155, 156 n. 206

Zordan Giorgio, 17 n. 6

Zorzi Andrea, 62 n. 133 



\section{SOMMARIO}

Note introduttive

\section{CAPITOLO I \\ MALINCONIA CRIMINALE}

I. Follia morale: un itinerario medico-legale (secc. XVII-XIX)

1. La melancholia fra le tipologie giuridiche del furor

2. «Furiosus satis suo furore punitur»

3. La melancholia come mania circoscritta e il furor come mania generalizzata

4. L'ingresso della malinconia nell'universo giuridico 24

5. Le false credenze dei malinconici 29

6. Caput melancholicum balneum esse diaboli: la 'bestialis Melancholia' 31

7. Tracce di processi a melancholici (secc. XVII-XVIII) 36

8. Indeterminismo e assenza di libero arbitrio nei reati dei malinconici 44

9. La imputabilità dei criminali malinconici 46

10. Follia morale o immoralità nella dottrina 59

\section{CAPITOLO II \\ MONOMANIA OMICIDA \\ LE METAMORFOSI DELLA MALINCONIA (SEC. XIX)}

I. Le ragioni della scienza medica

1. Deviazioni dalla morale $\quad 77$

$\begin{array}{ll}\text { 2. Influssi medico-legali } & 78\end{array}$

3. Tentativi definitori $\quad 80$

4. Il problema probatorio 86

5. L'omicidio come mezzo 93

6. Monomania id est Melanconia 96

$\begin{array}{lr}\text { 7. Un fantôme? } & 103\end{array}$ 
1. Il male per amore del male: la Scuola classica 105

$\begin{array}{lr}2 . & \text { L'omicidio per follia morale: la Scuola positiva } \\ & 119\end{array}$

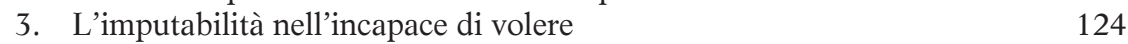

$\begin{array}{ll}\text { 4. Un maniaco in tribunale (1834) } & 128\end{array}$

$\begin{array}{lr}\text { III. Le ragioni del legislatore } & 130\end{array}$

1. Per solo impulso di brutale malvagità 130

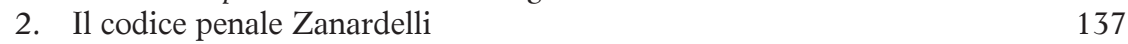

3. Casi esemplari in Cassazione 141

4. Aggravamento della pena o ricovero coatto in manicomio 150

\section{CAPITOLO III \\ OSPEDALIZZARE I CRIMINALI MALINCONICI \\ UNA RIMEDITAZIONE IN NOME DEI DIRITTI}

$\begin{array}{ll}\text { 1. L'ospedale psichiatrico } & 161\end{array}$

2. Il caso di Bologna. L'ospedale psichiatrico ‘Francesco Roncati’ 163

2.1. I criminali malinconici 164

2.2. L'internamento di Giuseppe Fabbri (1821) 165

3. Il caso di Roma. L'ospedale psichiatrico Santa Maria della Pietà 170

$\begin{array}{ll}\text { 3.1. I criminali malinconici } & 172\end{array}$

3.2. L'internamento di Luigi Galeotti (1906) 174

APPENDICE

1. I malinconici socialmente pericolosi internati nell'ospedale psichiatrico Francesco Roncati di Bologna (1813-1847)

2. I malinconici autori di reato internati nell'ospedale psichiatrico Francesco Roncati di Bologna (1823-1836)

3. I malinconici autori di reato internati nell'ospedale psichiatrico Santa Maria della Pietà di Roma (1906-1916) 
1. Coli U., Collegia et sodalitates, 1913.

2. Donatelli I., La "consortia" di Avesa, 1914.

3. VAlenza P., Il diritto di usufrutto nelle leggi sulle tasse del registro, 1915.

4. Zingali G., La statistica della criminalità, 1916.

5. Tumedei C., La separazione dei beni ereditari, 1917.

6. Albertoni A., L"Apokeryxis", 1923.

7. SALVI F., La cessione dei beni ai creditori, 1947.

8. Milani F., Distinzioni delle servitù prediali, 1948.

9. FAssò G., I "quattro autori" del Vico, 1949.

10. FerRi L., La trascrizione degli acquisti "mortis causa" e problemi connessi, 1951.

11. Rossi G., La "Summa arboris actionum" di Ponzio da Ylerda, 1951.

12. Poggeschi R., Le associazioni e gli altri gruppi con autonomia patrimoniale nel processo, 1951.

13. Matteucci N., Antonio Gramsci e la filosofia della prassi, 1951.

14. Forchielli P., I contratti reali, 1952.

15. SALVI F., Il possesso di stato familiare, 1952.

16. FAssò G., La storia come esperienza giuridica, 1953.

17. Palazzini Finetti L., Storia della ricerca delle interpolazioni nel Corpus iuris giustinianeo, 1953.

18. Rossi G., Consilium sapientis iudiciale, 1958.

19. Mancini G.F., La responsabilità contrattuale del prestatore di lavoro, 1957.

20. Ferri L., L'autonomia privata, 1959.

21. Torelli P., Scritti di storia del diritto italiano, 1959.

22. Santini G., I Comuni di Valle del medioevo. La Costituzione federale del "Frignano", 1960.

23. Gianniti F., I reati della stessa indole, 1959.

24. GHEZZI G., La prestazione di lavoro nella comunità familiare, 1960.

25. NARDI E., Case "infestate da spiriti" e diritto romano e moderno, 1960.

26. FERRI L., Rinunzia e rifiuto nel diritto privato, 1960.

27. GHEZzi G., La responsabilità contrattuale delle associazioni sindacali, 1963.

28. Bonsignori A., Espropriazione della quota di società a responsabilità limitata, 1961.

29. Redenti E., Scritti e discorsi giuridici di un mezzo secolo, vol. I, Intorno al diritto processuale, 1962.

30. Redenti E., Scritti e discorsi giuridici di un mezzo secolo, vol. II, Intorno al diritto sostanziale, 1962.

31. Gualandi A., Spese e danni nel processo civile, 1962.

32. Bonsignori A., Assegnazione forzata e distribuzione del ricavato, 1960.

33. Mancini G.F., Il recesso unilaterale e $i$ rapporti di lavoro, vol. I, Individuazione della fattispecie. Il recesso ordinario, 1962.

34. NARDI E., Rabelais e il diritto romano, 1962.

35. Romagnoli U., Il contratto collettivo di impresa, 1963.

36. Santini G., I "comuni di pieve" nel medioevo italiano, 1964.

37. RUdAN M., Il contratto di tirocinio, 1966.

38. Bonini R., I "libri de cognitionibus" di Callistrato. Ricerche sull'elaborazione giurisprudenziale della "cognitio extra ordinem", 1964.

39. Colliva P., Ricerche sul principio di legalità nell'amministrazione del Regno di Sicilia al tempo di Federico II, 1964.

40. Mengozzi P., L’agenzia di approvvigionamento dell'Euratom, 1964.

41. Scritti minori di Antonio Cicu, tomi I e II, Scritti di teoria generale del diritto - Diritto di famiglia, 1965.

42. Scritti minori di Antonio Cicu, Successioni e donazioni. Studi vari, 1965.

43. Sacchi Morsiani G., Il potere amministrativo delle Comunità europee e le posizioni giuridiche dei privati, I, 1965.

44. Ghezzi G., La mora del creditore nel rapporto di lavoro, 1965.

45. Roversi Monaco F.A., Enti di gestione. Struttura, funzioni, limiti, 1967.

46. Gianniti F., L'oggetto materiale del reato, 1966. 
47. Mengozzi P., L'efficacia in Italia di atti stranieri di potestà pubblica su beni privati, 1967.

48. Romagnoli U., La prestazione di lavoro nel contratto di società, 1967.

49. Montuschi L., I limiti legali nella conclusione del contratto di lavoro, 1967.

50. Ranieri S., Scritti e discorsi vari, vol. I, Scritti di diritto penale, 1968.

51. Ranieri S., Scritti e discorsi vari, vol. II, Scritti di procedura penale, 1968.

52. Bonini R., Ricerche di diritto giustinianeo, 1968.

53. SANTINI G., Ricerche sulle "Exceptiones legum romanorum", 1969.

54. Lo Castro G., La qualificazione giuridica delle deliberazioni conciliari delle fonti del diritto canonico, 1970.

55. SaCchi Morsiani G., Il potere amministrativo delle Comunità europee e le posizioni giuridiche dei privati, II, 1970.

56. Roversi Monaco F.A., La delegazione amministrativa nel quadro dell'ordinamento regionale, 1970.

57. Gianniti F., Studi sulla corruzione del pubblico ufficiale, 1970.

58. De Vergottini G., Indirizzo politico della difesa e sistema costituzionale, 1971.

59. Mengozz P., Il regime giuridico internazionale del fondo marino, 1971.

60. CARINCI F., Il conflitto collettivo nella giurisprudenza costituzionale, 1971.

61. Osti G., Scritti giuridici, voll. I e II, 1973.

62. Zueldi F., Servizi pubblici e attività imprenditoriale, 1973.

63. Pergolesi F., Sistema delle fonti normative, 1973.

64. Montuschi L., Potere disciplinare e rapporto di lavoro, 1973.

65. Pattaro E., Il pensiero giuridico di L.A. Muratori tra metodologia e politica, 1974.

66. PINI G., Arbitrato e lavori pubblici, 1974.

67. CARPI F., L'efficacia "ultra partes" della sentenza civile, 1974.

68. De Vergottini G., Lo "Shadow cabinet", 1973.

69. PaOlucci L.F., La mutualità nelle cooperative, 1974.

70. De Gennaro A., Crocianesimo e cultura giuridica italiana, 1974.

71. Stortoni L., L'abuso di potere nel diritto penale, 1978.

72. Gianniti F., Prospettive criminologiche e processo penale, 1977.

73. Bonvicini D., Le "joint ventures": tecnica giuridica e prassi societaria, 1977.

74. De Vergottini G., Scritti di storia del diritto italiano, voll. I, II, III, 1977.

75. Lambertini R., I caratteri della Novella 118 di Giustiniano, 1977.

76. Dalla D., L'incapacità sessuale in diritto romano, 1978.

77. Di Pietro A., Lineamenti di una teoria giuridica dell'imposta sull'incremento di valore degli immobili, 1978.

78. MazZACuva N., La tutela penale del segreto industriale, 1979.

79. Romanelli G., Profilo del noleggio, 1979.

80. Borghesi D., Il contenzioso in materia di eleggibilità, 1979.

81. Dalla Torre G., L'attività assistenziale della Chiesa nell'ordinamento italiano, 1979.

82. CARPI F., La provvisoria esecutorietà della sentenza, 1979.

83. Alleva P., Il campo di applicazione dello statuto dei lavoratori, 1980.

84. Puliatti S., Ricerche sulla legislazione "regionale" di Giustiniano, 1980

85. Fassò G., Scritti di filosofia del diritto, voll. I, II, III, 1982.

86. SGubBi F., Uno studio sulla tutela penale del patrimonio, 1980.

87. Lambertini R., Plagium, 1980.

88. Dalla D., Senatus consultum Silanianum, 1980.

89. VANDELLI L., L'ordinamento regionale spagnolo, 1980.

90. NARDI E., L'otre dei parricidi e le bestie incluse, 1980.

91. Pellicanò A., Causa del contratto e circolazione dei beni, 1981.

92. Giardini D., Politica e amministrazione nello Stato fondato sul decentramento, 1981.

93. Bortolotti D., Potere pubblico e ambiente, 1981.

94. Roffi R., Contributo per una teoria delle presunzioni nel diritto amministrativo, 1982.

95. Alessi R., Scritti minori, 1981.

96. Bassanelli Sommariva G., L'imperatore unico creatore ed interprete delle leggi e l'autonomia del giudice nel diritto giustinianeo, 1983.

97. ZanotTi A., Cultura giuridica del Seicento e jus publicum ecclesiasticum nell'opera del cardinal Giovanni Battista De Luca, 1983.

98. Illuminati G., La disciplina processuale delle intercettazioni, 1983.

99. Toniatti R., Costituzione e direzione della politica estera negli Stati Uniti d'America, 1983.

100. NARDI E., Squilibrio e deficienza mentale in diritto romano, 1983. 
101. Dalla D., Praemium emancipationis, 1983.

102. Mazzacuva N., Il disvalore di evento nell'illecito penale - L'illecito commissivo doloso e colposo, 1983.

103. Studi in onore di Tito Carnacini. I. Studi di diritto costituzionale, civile, del lavoro, commerciale, 1983.

104. CAIA G., Stato e autonomie locali nella gestione dell'energia, 1984.

105. Baratti G., Contributo allo studio della sanzione amministrativa, 1984

106. Вовтоцотті D., Attività preparatoria e funzione amministrativa, 1984.

107. Puliatti S., Ricerche sulle novelle di Giustino II. La legislazione imperiale da Giustiniano I a Giustino II, 1984.

108. Lambertini R., La problematica della commorienza nell'elaborazione giuridica romana, 1984.

109. ZueLLI F., Le collegialità amministrative, 1985.

110. Pedrazzoli M., Democrazia industriale e subordinazione, 1985.

111. Zаnотті M., Profili dogmatici dell'illecito plurisoggettivo, 1985.

112. Ruffolo U., Interessi collettivi o diffusi e tutela del consumatore, I, 1985.

113. Biagi M., Sindacato democrazia e diritto, 1986.

114. Insolera G., Problemi di struttura del concorso di persone nel reato, 1986.

115. Malagù L., Esecuzione forzata e diritto di famiglia, 1986.

116. Ricci G.F., La connessione nel processo esecutivo, 1986.

117. ZaNotTi A., Il concordato austriaco del 1855, 1986.

118. Selmini R., Profili di uno studio storico sull'infanticidio, 1987.

119. Dalla D., "Ubi venus mutatur", 1987.

120. Zunarelli S., La nozione di vettore, 1987.

121. Zoli C., La tutela delle posizioni "strumentali" del lavoratore, 1988.

122. Cavina M., Dottrine giuridiche e strutture sociali padane nella prima età moderna, 1988.

123. Califano L., Innovazione e conformità nel sistema regionale spagnolo, 1988.

124. SARTi N., Gli statuti della società dei notai di Bologna dell'anno 1336 (contributo allo studio di una corporazione cittadina), 1988.

125. SCARPONi S., Riduzione e gestione flessibile del tempo di lavoro, 1988

126. Bernardini M., Contenuto della proprietà edilizia, 1988.

127. La Torre M., La "lotta contro il diritto soggettivo". Karl Larenz - la dottrina giuridica nazionalsocialista, 1988.

128. Garcia De ENTERria J., Le obbligazioni convertibili in azioni, 1989.

129. Biagi Guerini R., Famiglia e Costituzione, 1989.

130. CaIA G., Arbitrati e modelli arbitrali nel diritto amministrativo, 1989.

131. Magagni M., La prestazione caratteristica nella Convenzione di Roma del 19 giugno 1980, 1989.

132. Petroni L., La disciplina pubblicistica dell'innovazione tecnologica in Francia, 1990.

133. ZanotTi A., Le manipolazioni genetiche e il diritto della Chiesa, 1990.

134. SARTOR G., Le applicazioni giuridiche dell'intelligenza artificiale, 1990.

135. Rossi L.S., Il "buon funzionamento del mercato comune". Delimitazione dei poteri fra CEE e Stati membri, 1990.

136. Lucheтti G., La legittimazione dei figli naturali nelle fonti tardo imperiali e giustinianee, 1990.

137. SarTi N., Un giurista tra Azzone e Accursio, 1990.

138. Gustapane A., La tutela globale dell'ambiente, 1991.

139. Bottari C., Principi costituzionali e assistenza sanitaria, 1991.

140. Donini M., Illecito e colpevolezza nell'imputazione del reato, 1991.

141. Perulli A., Il potere direttivo dell'imprenditore, 1992.

142. VANDELLI L. (a cura di), Le forme associative tra enti territoriali, 1992.

143. GASPARRI P., Institutiones iuris publici, 1992.

144. CaPuZzo E., Dal nesso asburgico alla sovranità italiana, 1992.

145. Biavati P., Accertamento dei fatti e tecniche probatorie nel processo comunitario, 1992.

146. Ferrari F., Atipicità dell'illecito civile. Una comparazione, 1992.

147. Gustapane A., Sartor G., Verardi C.M., Valutazione di impatto ambientale. Profili normativi e metodologie informatiche, 1992.

148. Orlandi R., Atti e informazioni della autorità amministrativa nel processo penale. Contributo allo studio delle prove extracostituite, 1992.

149. Carpani G., Le aziende degli enti locali. Vigilanza e controlli, 1992. 
150. Musso A., Concorrenza ed integrazione nei contratti di subfornitura industriale, 1993.

151. Donini M., Il delitto contravvenzionale. "Culpa iuris" e oggetto del dolo nei reati a condotta neutra, 1993.

152. Califano Placci L., Le commissioni parlamentari bicamerali nella crisi del bicameralismo italiano, 1993.

153. Fornasari G., Il concetto di economia pubblica nel diritto penale. Spunti esegetici e prospettive di riforma, 1994.

154. Manzini P., L'esclusione della concorrenza nel diritto antitrust italiano, 1994.

155. Tэмотео M., Le successioni nel diritto cinese. Evoluzione storica ed assetto attuale, 1994.

156. Sesta M. (a cura di), Per i cinquant'anni del codice civile, 1994.

157. Tullini P., Contributo alla teoria del licenziamento per giusta causa, 1994.

158. Rescigno F., Disfunzioni e prospettive di riforma del bicameralismo italiano: la camera delle regioni, 1995.

159. Lugaresi N., Le acque pubbliche. Profili dominicali, di tutela, di gestione, 1995.

160. SARTI N., Maximum dirimendarum causarum remedium. Il giuramento di calunnia nella dottrina civilistica dei secoli XI-XIII, 1995.

161. Colliva P., Scritti minori, 1996.

162. Dugato M., Atipicità e funzionalizzazione nell'attività amministrativa per contratti, 1996.

163. Gardini G., La comunicazione degli atti amministrativi. Uno studio alla luce della legge 7 agosto 1990, n. 241, 1996.

164. MANZINI P., I costi ambientali nel diritto internazionale, 1996.

165. Miтtica M.P., Il divenire dell'ordine. L'interazione normativa nella società omerica, 1996.

166. Luchetti G., La legislazione imperiale nelle Istituzioni di Giustiniano, 1996.

167. La Torre M., Disavventure del diritto soggettivo. Una vicenda teorica, 1996.

168. CAMON A., Le intercettazioni nel processo penale, 1996.

169. Mancini S., Minoranze autoctone e Stato. Tra composizione dei conflitti e secessione, 1996.

170. Zanobetti Pagnetti A., La non comparizione davanti alla Corte internazionale di giustizia, 1996.

171. Bricola F., Scritti di diritto penale. Vol. I, Dottrine generali, Teoria del reato e sistema sanzionatorio. Vol. II, Parte speciale e legislazione complementare, Diritto penale dell'economia, 1997.

172. Graziosi A., La sentenza di divorzio, 1997.

173. Mantovani M., Il principio di affidamento nella teoria del reato colposo, 1997.

174. Biavati P., Giurisdizione civile, territorio e ordinamento aperto, 1997.

175. Rossi G. (1916-1986), Studi e testi di storia giuridica medievale, a cura di Giovanni Gualandi e Nicoletta Sarti, 1997.

176. Pellegrini S., La litigiosità in Italia. Un'analisi sociologico-giuridica, 1997.

177. Boni G., La rilevanza del diritto dello Stato nell'ordinamento canonico. In particolare la canonizatio legum civilium, 1998.

178. Scritti in onore di Giuseppe Federico Mancini. Vol. I, Diritto del lavoro, 1998.

179. Scritti in onore di Giuseppe Federico Mancini. Vol. II, Diritto dell'Unione europea, 1998

180. Rossi A., Il GEIE nell'ordinamento italiano. Criteri di integrazione della disciplina, 1998.

181. Bongiovanni G., Reine Rechtslehre e dottrina giuridica dello Stato. H. Kelsen e la Costituzione austriaca del 1920, 1998.

182. Caputo G., Scritti minori, 1998.

183. Garrido J.M., Preferenza e proporzionalità nella tutela del credito, 1998.

184. Bellodi Ansaloni A., Ricerche sulla contumacia nelle cognitiones extra ordinem, I, 1998.

185. Franciosi E., Riforme istituzionali e funzioni giurisdizionali nelle Novelle di Giustiniano. Studi su nov. 13 e nov. 80, 1998.

186. Cattabriga C., La Corte di giustizia e il processo decisionale politico comunitario, 1998.

187. Mancini L., Immigrazione musulmana e cultura giuridica. Osservazioni empiriche su due comunità di egiziani, 1998.

188. Gustapane A., L'autonomia e l'indipendenza della magistratura ordinaria nel sistema costituzionale italiano. dagli albori dello Statuto Albertino al crepuscolo della bicamerale, premessa di Giuseppe De Vergottini, 1999.

189. RICCI G.F., Le prove atipiche, 1999.

190. Canestrari S., Dolo eventuale e colpa cosciente. Ai confini tra dolo e colpa nella struttura delle tipologie delittuose, 1999.

191. FAssò G., La legge della ragione. Ristampa, a cura di Carla Faralli, Enrico Pattaro, Giampaolo Zucchini, 1999. 
192. Fassò G., La democrazia in Grecia. Ristampa, a cura di Carla Faralli, Enrico Pattaro, Giampaolo Zucchini, 1999.

193. Scarciglia R., La motivazione dell'atto amministrativo. Profili ricostruttivi e analisi comparatistica, 1999.

194. Briguglio F., "Fideiussoribus succurri solet", 1999.

195. Maltoni A., Tutela dei consumatori e libera circolazione delle merci nella giurisprudenza della Corte di giustizia, profili costituzionali, prefazione di Augusto Barbera, 1999.

196. Fondaroli D., Illecito penale e riparazione del danno, 1999.

197. Rossi L.S., Le convenzioni fra gli Stati membri dell'Unione europea, 2000.

198. Gragnoli E., Profili dell'interpretazione dei contratti collettivi, 2000.

199. Boni G., La rilevanza del diritto secolare nella disciplina del matrimonio canonico, 2000.

200. Lugaresi N., Internet, privacy e pubblici poteri negli Stati Uniti, 2000.

201. Lalatta Costerbosa M., Ragione e tradizione. Il pensiero giuridico ed etico-politico di Wilehlmvon Humboldt, 2000.

202. Semeraro P., I delitti di millantato credito e traffico di influenza, 2000.

203. VERZa A., La neutralità impossibile. Uno studio sulle teorie liberali contemporanee, 2000.

204. LoLli A., L'atto amministrativo nell'ordinamento democratico. Studio sulla qualificazione giuridica, 2000.

205. Busetto M.L., Giudice penale e sentenza dichiarativa di fallimento, 2000.

206. Campanella P., Rappresentatività sindacale: fattispecie ed effetti, 2000.

207. Bricola F., Scritti di diritto penale. Opere monografiche, 2000.

208. LASSANDARI A., Il contratto collettivo aziendale e decentrato, 2001.

209. Bianco A., Il finanziamento della politica in Italia, 2001.

210. Raffi A., Sciopero nei servizi pubblici essenziali. Orientamenti della Commissione di garanzia, 2001.

211. Piergigli V., Lingue minoritarie e identità culturali, 2001.

212. Cafaro S., Unione monetaria e coordinamento delle politiche economiche. Il difficile equilibrio tra modelli antagonisti di integrazione europea, 2001.

213. Morrone A., Il custode della ragionevolezza, 2001.

214. Masutti A., La liberalizzazione dei trasporti in Europa. Il caso del trasporto postale, 2002.

215. Zanotti A., Orlando F., L'itinerario canonistico di Giuseppe Caputo, 2002.

216. Lupor M.A., Conflitti transnazionali di giurisdizioni. Vol. I, Policies, metodi, criteri di collegamento. Vol. II, Parallel proceedings, 2002.

217. LolLi A., I limiti soggettivi del giudicato amministrativo. Stabilità del giudicato e difesa del terzo nel processo amministrativo, 2002.

218. Curi F., Tertium datur. Dal Common Law al Civil Law per una scomposizione tripartita dell'elemento soggettivo del reato, 2003.

219. Cottignola G., Studi sul pilotaggio marittimo, 2003.

220. GARDINI G., L'imparzialità amministrativa tra indirizzo e gestione. Organizzazione e ruolo della dirigenza pubblica nell'amministrazione contemporanea, 2003.

221. Cevenini C., Virtual enterprises. Legal issues of the on-line collaboration between undertakings, 2003.

222. Monducci J., Diritto della persona e trattamento dei dati particolari, 2003.

223. Villecco Bettelli A., L'efficacia delle prove informatiche, 2004.

224. Zucconi Galli Fonseca E., La convenzione arbitrale rituale rispetto ai terzi, 2004.

225. BRighi R., Norme e conoscenza: dal testo giuridico al metadato, 2004.

226. Luchetti G., Nuove ricerche sulle istituzioni di Giustiniano, 2004.

227. Studi in memoria di Angelo Bonsignori, voll. I, II, 2004.

228. Piperata G., Tipicità e autonomia nei servizi pubblici locali, 2005.

229. Canestrari S., Foffani L. (a cura di), Il diritto penale nella prospettiva europea. Quali politiche criminali per l'Europa? Atti del Convegno organizzato dall'Associazione Franco Bricola (Bologna, 28 febbraio-2 marzo 2002), 2005.

230. Memmo D., Miconi S. (a cura di), Broadcasting regulation: market entry and licensing. Regolamentazione dell'attività radiotelevisiva: accesso al mercato e sistema di licenze. Global Classroom Seminar, 2006.

230. bis Briguglio F., Studi sul procurator, 2007.

231. Querzola L., La tutela anticipatoria fra procedimento cautelare e giudizio di merito, 2006.

232. TARozzi S., Ricerche in tema di registrazione e certificazione del documento nel periodo postclassico, 2006.

233. Bотті F., L'eutanasia in Svizzera, 2007. 
234. Fondaroli D., Le ipotesi speciali di confisca nel sistema penale, 2007.

235. Alagna R., Tipicità e riformulazione del reato, 2007.

236. Giovannini M., Amministrazioni pubbliche e risoluzione alternativa delle controversie, 2007.

237. Montalti M., Orientamento sessuale e costituzione decostruita. Storia comparata di un diritto fondamentale, 2007.

238. Tordini Cagli S., Principio di autodeterminazione e consenso dell'avente diritto, 2008.

239. Legnani Annichini A., La mercanzia di Bologna. Gli statuti del 1436 e le riformagioni quattrocentesche, 2008.

240. LoLli A., L'amministrazione attraverso strumenti economici, 2008.

241. VACCARELla M., Titolarità e funzione nel regime dei beni civici, 2008.

242. Tubertini C., Pubblica amministrazione e garanzia dei livelli essenziali delle prestazioni, 2008.

243. Fioriglio G., Il diritto alla privacy. Nuove frontiere nell'era di Internet, 2008.

244. Bотті F., Manipolazioni del corpo e mutilazioni genitali femminili, 2009.

245. Nisco A., Controlli sul mercato finanziario e responsabilità penale. Posizioni di garanzia e tutela del risparmio, 2009.

246. Zanobetti Pagnetti A., Il rapporto internazionale di lavoro marittimo, 2008

247. Маттіо $\mathrm{F}$., Ricerche sulla formazione della categoria dei cosiddetti quasi delitti, 2010.

248. Bertaccini D., La politica di polizia, 2009.

249. Astrologo A., Le cause di non punibilità. Un percorso tra nuovi orientamenti interpretativi e perenni incertezze dogmatiche, 2009.

250. Di MARIA S., La cancelleria imperiale e $i$ giuristi classici: "Reverentia antiquitatis" e nuove prospettive nella legislazione giustinianea del codice, 2010.

251. VALENTINI E., La domanda cautelare nel sistema delle cautele personali, 2010.

252. Querzola L., Il processo minorile in dimensione europea, 2010.

253. Bologna C., Stato federale e "national interest". Le istanze unitarie nell'esperienza statunitense, 2010.

254. Rasia C., Tutela giudiziale europea e arbitrato, 2010.

255. Zucconi Galli Fonseca E., Pregiudizialità e rinvio (Contributo allo studio dei limiti soggettivi dell'accertamento), 2011.

256. Bellodi Ansaloni A., Ad eruendam veritatem. Profili metodologici e processuali della quaestio per tormenta, 2011.

257. Pontoriero I., Il prestito marittimo in diritto romano, 2011.

258. Giustizia senza confini. Studi offerti a Federico Carpi, 2012.

259. Gustapane A., Il ruolo del pubblico ministero nella Costituzione italiana, 2012.

260. Cainniello M., Premesse per una teoria del pregiudizio effettivo nelle invalidità processuali penali, 2012.

261. Briguglio F., Il Codice Veronese in trasparenza. Genesi e formazione del testo delle Istituzioni di Gaio, 2012.

262. Valentini E., La domanda cautelare nel sistema delle cautele personali, Nuova edizione, 2012.

263. Tassinari D., Nemo tenetur se detegere. La libertà dalle autoincriminazioni nella struttura del reato, 2012.

264. Martelloni F., Lavoro coordinato e subordinazione. L'interferenza delle collaborazioni a progetto, 2012.

265. Roversi-Monaco F. (a cura di), Università e riforme. L'organizzazione delle Università degli Studi ed il personale accademico nella legge 30 dicembre 2010, n. 240, 2013.

266. Torre V., La privatizazione delle fonti di diritto penale, 2013.

267. Raffiotтa E.C., Il governo multilivello dell'economia. Studio sulle trasformazioni dello Stato costituzionale in Europa, 2013.

268. Caruso C., La libertà di espressione in azione. Contributo a una teoria costituzionale del discorso pubblico, 2013.

269. Pedrini F., Le “clausole generali". Profili teorici e aspetti costituzionali, 2013.

270. Curi F., Profili penali dello stress lavoro-correlato. L'homo faber nelle organizzazioni complesse, 2013.

271. Casale D., L'idoneità psicofisica del lavoratore pubblico, 2013.

272. Nicodemo S., Le istituzioni della conoscenza nel sistema scolastico, 2013.

273. Legnani Annichini A., "Proxeneta est in tractando». La professione ingrata del mediatore di commercio (secc. XII-XVI), 2013.

274. Monducci J., Il dato genetico tra autodeterminazione informativa e discriminazione genotipica, 2013.

275. Mantovani M., Contributo ad uno studio sul disvalore di azione nel sistema penale vigente, 2014

276. De Donno M., Consensualità e interesse pubblico nel governo del territorio, 2015. 
277. Pacilli M., L'abuso dell'appello, 2015.

278. PIŠTAN Č., Tra democrazia e autoritarismo. Esperienze di giustizia costituzionale nell'Europa centro-orientale e nell'area post-sovietica, 2015.

279. Bellodi Ansaloni A., L'arte dell'avvocato, actor veritatis. Studi di retorica e deontologia forense, 2016.

280. Нохна D., La giustizia criminale napoleonica. A Bologna fra prassi e insegnamento universitario, 2016.

281. Querzola L., L'efficacia dell'attività processuale in un diverso giudizio, 2016.

282. Pieri B., Usurai, ebrei e poteri della Chiesa nei consilia di Paolo da Castro, 2016.

283. Rasia C., La crisi della motivazione nel processo civile, 2016.

284. Drigo C., Le Corti costituzionali tra politica e giurisdizione, 2016.

285. Polacchini F., Doveri costituzionali e principio di solidarietà, 2016.

286. CalCaGNILE M., Inconferibilità amministrativa e conflitti di interesse nella disciplina dell'accesso alle cariche pubbliche, 2017.

287. VILLA E., La responsabilità solidale come tecnica di tutela del lavoratore, 2017.

288. VINCIERI M., L'integrazione dell'obbligo di sicurezza, 2017.

289. Casale D., L'automaticità delle prestazioni previdenziali. Tutele, responsabilità e limiti, 2017.

290. GANARIN M., L'interpretazione autentica nelle attuali dinamiche evolutive del diritto canonico, 2018.

291. Laus F., Il rapporto collaborativo tra pubblico e privato nella contrattazione pubblica. Unione Europea e ordinamenti nazionali: analisi comparata di modelli e riforme, 2018.

292. Bonacini P., Multa scripsit, nihil tamen reperitur. Niccolò Mattarelli giurista a Modena e Padova (1204 ca.-1314 ca.), 2018.

293. Gabellini E., L'azione arbitrale. Contributo allo studio dell'arbitrabilità dei diritti, 2018.

294. LupoI M.A., Tra flessibilità e semplificazione. Un embrione di case management all'italiana?, 2018.

295. Dallari F., Vincoli espropriativi e perequazione urbanistica. La questione della discrezionalità, 2018.

296. Donini A., Il lavoro attraverso le piattaforme digitali, 2019.

297. Novaro P., Profili giuridici dei residui delle attività antropiche urbane. Gli incerti confini della gestione dei rifiuti urbani, 2019.

298. Mаттіо . F., Giustiniano, gli argentarii e le loro attività negoziali. La specialità di un diritto e le vicende della sua formazione, 2019.

299. RafFiotta E.C., Norme d'ordinanza. Contributo a una teoria delle ordinanze emergenziali come fonti normative, 2019.

300. Medina M.H., Servio Sulpicio Rufo: un retrato final desde la perspectiva de Cicerón, 2020.

301. Centamore G., Contrattazione collettiva e pluralità di categorie, 2020.

302. Caruso C., La garanzia dell'unità della Repubblica. Studio sul giudizio di legittimità in via principale, 2020.

303. MatTheudakis M.L., L'imputazione colpevole differenziata. Interferenze tra dolo e colpa alla luce dei principi fondamentali in materia penale, 2020

304. Tega D., La Corte nel contesto. Percorsi di ri-accentramento della giustizia costituzionale in Italia, 2020.

305. Bologna C., La libertà di espressione dei «funzionari», 2020.

306. AвIs S., Capace di intendere, incapace di volere. Malinconia, monomania e diritto penale in Italia nel XIX secolo, 2020. 


Finito di stampare nel mese di novembre 2020 per i tipi di Bononia University Press 